\title{
Improving resource capacity planning in hospitals with
}

business approaches

Wineke AM van Lent

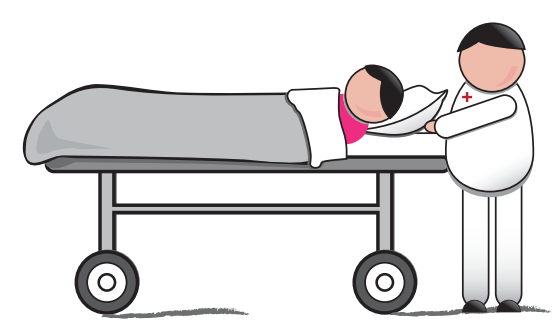




\section{IMPROVING RESOURCE CAPACITY PLANNING IN HOSPITALS WITH BUSINESS APPROACHES}

Wineke Agnes Marieke van Lent 
Address of correspondence:

Wineke AM van Lent

Overschiestraat 22

1062 XE Amsterdam

W.v.lent@nki.nl

Cover design: Cindy Bauhuis

Layout: Wineke AM van Lent

Printed by: $\quad$ Gildeprint Drukkerijen

ISSN: $\quad$ 1878-4968

HSS-11-005: Health Technology and Services Research, University of Twente

Publication and distribution of this dissertation was financially supported by the University of Twente and the Netherlands Cancer Institute - Antoni van Leeuwenhoek Hospital (NKI-AVL). 


\author{
PROEFSCHRIFT \\ ter verkrijging van \\ de graad van doctor aan de Universiteit Twente, \\ op gezag van de Rector Magnificus, \\ Prof. Dr. H Brinksma \\ volgens besluit van het College van Promoties \\ in het openbaar te verdedigen \\ op donderdag 1 december 2011 om 16.45 uur \\ door \\ Wineke Agnes Marieke van Lent \\ geboren op 13 augustus 1982 \\ te Winterswijk
}


Dit proefschrift is goedgekeurd door:

Prof. Dr. W.H. van Harten (Universiteit Twente)

(C) Copyright 2011: Wineke AM van Lent, Amsterdam, the Netherlands

All rights reserved. No part of this dissertation may be reproduced or transmitted in any form or by any means, electronic or mechanical, including photocopying, recording or any information storage or retrieval system, without permission in writing from the author, or, when appropriate, from the publishers of the publications.

ISBN : 978-90-365-3279-2

DOI nummer : $10.3990 / 1.9789036532792$ 


\section{Beoordelingscommissie}

Prof. Dr. R.A. Wessel (voorzitter \& secretaris van de promotie commissie)

Prof. Dr. MJ IJzerman (Universiteit Twente)

Prof. Dr. A.P.W.P. van Montfort (Universiteit Twente)

Prof. Dr. J.J. van de Klundert (Erasmus Universiteit Rotterdam)

Prof. Dr. O.A.M. Fisscher (Universiteit Twente)

Prof. Dr. J. Wijngaard (Rijksuniversiteit Groningen)

Prof. Dr. H.J.J.M. Berden (Tias / Nimbas Business School)

Dr. Ir. E.W. Hans (Universiteit Twente) 



\section{Contents}

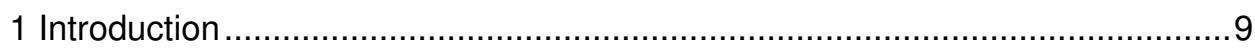

2 Exploring Improvements in Patient Logistics in Dutch hospitals ....................27

3 Exploring Types of Focused Factories in Hospital Care: A Multiple Case Study

4 International Benchmarking of Specialty Hospitals. A Series of Case Studies on Comprehensive Cancer Centres

5 Improving the Efficiency of a Chemotherapy Day Unit: Applying a Business Approach to Oncology ............................................................................103

6 A Review on the Relation between Simulation and Improvement ................119

7 Reducing the Throughput Time of the Diagnostic Track involving CT Scanning

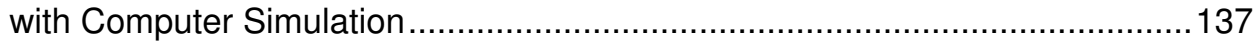

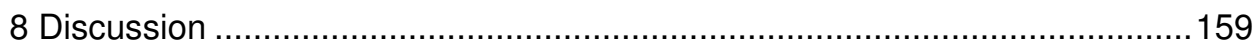

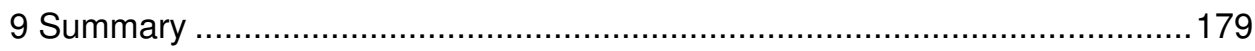

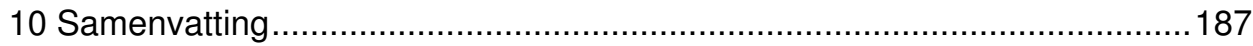

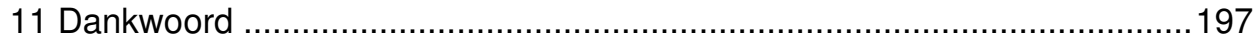

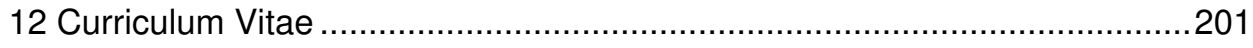

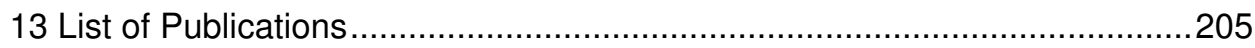

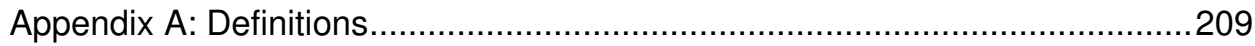

Appendix B: Measurement Instrument for Focused Factories in Hospital Care215

Appendix C: Selecting Indicators for International Benchmarking of Radiotherapy

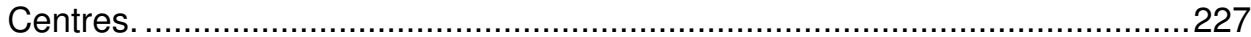


1 Introduction 
The aim of this dissertation is to contribute to the knowledge on the adoption of business approaches used to improve operations management in hospitals. This introduction explains why hospitals might consider using approaches originating from business and services for this purpose. Furthermore, this chapter describes the research scope, the research questions, the research methods used, and the outline of the dissertation.

\section{The challenge of hospital management}

The median spending on healthcare in the Organisation for Economic Co-operation and development (OECD) countries was $8.8 \%$ of Gross Domestic Product (GDP) in 2008 , with the USA as the biggest spender (16\%) (1). The introduction of new technologies and drugs, and an ageing population that demands more care contribute to the increased healthcare costs. At the same time, the workforce available to deliver care is becoming scarce due to the ageing population $(2,3)$. As a result, governments struggle to maintain and allocate costs. Governments can limit healthcare costs with the following scenarios (4-7): 1. Increasing the patients' contribution to healthcare costs, or; 2 . Decreasing the number of medical services delivered to patients, or; 3 . By introducing expenditure caps on specific costs such as wages, or; 4 . By slowing the diffusion rate of cost intensive technologies through effective technology assessment programs, or; 5 . Stimulating hospitals to work more efficiently, for example by encouraging price competition. The latter option seems attractive as this may lead to the least resistance of patients and professionals.

The combination of an increased demand, staffing problems and limited budgets may result in waiting lists if the level of resources needed to deliver care stagnates. This can have negative consequences on patient satisfaction and patient outcomes $(8,9)$. As patients also expect safe and effective care the Institute of Medicine defined six aspects of quality of care: patient-centeredness, effectiveness, efficiency, safety, timeliness and accessibility (10). To satisfy all aspects hospitals have to reorganize their processes. However, hospitals might be confronted with conflicts between the different aspects. For example, it is desirable to have a high utilization and short access times at the same time, but an increased capacity reduces access times and may be less efficient if this results in a lower utilization.

The challenges that hospitals are struggling with, have been present in business for years. Business organizations have to organize their processes in such a way that objectives regarding quality, speed, dependability, flexibility and costs are met 
(11). Operations management $(\mathrm{OM})$ is concerned with the delivery process of products and services (11). The challenge of OM is "to satisfy your customers by providing error-free goods and services which are 'fit for their purpose' "(11). In delivering error-free products, $\mathrm{OM}$ is related to quality management. With quality management, organizations try to deliver high quality products or services, to develop processes that guarantee the quality, and to improve this quality continuously. Lately $\mathrm{OM}$ approaches tend to overlap with quality management and vice versa. For example, lean management supports the development of efficient processes that produce error free products as this increases customer satisfaction and saves money for correcting mistakes. Although hospitals differ from most businesses, research showed that promising approaches such as benchmarking, operations research, lean management and six sigma, can be adopted in healthcare (12-16). This dissertation discusses business approaches from both the operations management and the quality management fields and tends to focus on the operations management part.

Throughout this dissertation, abbreviations and terminology are used. Appendix A describes the most relevant ones such as the business approaches.

\section{Research scope}

Operations Management improvements in hospitals can be identified on many aspects. The scope is further refined with a framework that classifies planning and control in healthcare organizations (17). Table 1 presents the framework.

The columns of Table 1 show four managerial areas on which planning and control takes place. The first one is medical planning, in which a medical professional decides about the diagnosis and treatment. The second column, resource capacity planning, addresses "the dimensioning, planning, scheduling, monitoring, and control of renewable resources" (17). This area is also referred to as patient logistics (18). Material coordination deals with supplying each process with sufficient consumable material to proceed with the delivery of their service. Finally, financial planning covers the management of the costs and revenues of the organization.

The rows in Table 1 represent the hierarchical levels of control. The strategic level concerns structural decisions that are characterized by a long-term planning 
horizon and are often based on highly aggregated information. The operational offline level concerns the day-to-day planning that takes place before the execution of these activities. An example is scheduling patients into a roster for a consult in an outpatient clinic. The decision making freedom at this level is limited by the other hierarchical levels. On the operational online level monitoring and control takes place. The organization reacts on unexpected changes on the day the planning is executed such as illness of staffs and emergency patients. In between the operational levels and the strategic level is the tactical level, here line managers translate the strategic policy to their departments. Compared to the operational planning it has a longer planning horizon (usually months to weeks) and more decision freedom.

Table 1 Framework to classify planning and control in healthcare organizations (17)

\begin{tabular}{|c|c|c|c|c|c|}
\hline & & & Manager & areas & \\
\hline & & $\begin{array}{l}\text { Medical } \\
\text { planning }\end{array}$ & $\begin{array}{l}\text { Resource } \\
\text { capacity } \\
\text { planning }\end{array}$ & $\begin{array}{l}\text { Material } \\
\text { coordination }\end{array}$ & $\begin{array}{l}\text { Financial } \\
\text { planning }\end{array}$ \\
\hline$\underset{\text { d }}{\bar{\Phi}}$ & Strategic & $\begin{array}{l}\text { Research and } \\
\text { treatment } \\
\text { methods }\end{array}$ & $\begin{array}{l}\text { Case mix } \\
\text { planning, layout } \\
\text { planning, } \\
\text { capacity } \\
\text { dimensioning }\end{array}$ & $\begin{array}{l}\text { Supply chain } \\
\text { and } \\
\text { warehouse } \\
\text { design }\end{array}$ & $\begin{array}{l}\text { Contracting } \\
\text { insurance } \\
\text { companies, } \\
\text { investment } \\
\text { plans }\end{array}$ \\
\hline 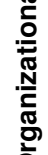 & Tactical & $\begin{array}{l}\text { Defining medical } \\
\text { protocols }\end{array}$ & $\begin{array}{l}\text { Allocating time } \\
\text { and resources } \\
\text { to specialties, } \\
\text { rostering }\end{array}$ & $\begin{array}{l}\text { Supplier } \\
\text { selection, } \\
\text { tendering }\end{array}$ & $\begin{array}{l}\text { Determining } \\
\text { and allocating } \\
\text { budgets, } \\
\text { annual plans }\end{array}$ \\
\hline & Operational offline & $\begin{array}{l}\text { Diagnosis and } \\
\text { planning of } \\
\text { individual } \\
\text { treatment }\end{array}$ & $\begin{array}{l}\text { Patient } \\
\text { scheduling, } \\
\text { workforce } \\
\text { planning }\end{array}$ & $\begin{array}{l}\text { Purchasing, } \\
\text { determining } \\
\text { order sizes }\end{array}$ & RNG billing \\
\hline & Operational online & $\begin{array}{l}\text { Handling } \\
\text { emergencies } \\
\text { and } \\
\text { complications }\end{array}$ & $\begin{array}{l}\text { Monitoring, } \\
\text { emergency } \\
\text { coordination }\end{array}$ & Rush ordering & $\begin{array}{l}\text { Billing } \\
\text { complication }\end{array}$ \\
\hline
\end{tabular}

This research focuses on resource capacity planning as we zoom in on utilization and acceptable access times. Resource capacity planning is closely related to the other managerial areas; e.g. medical planning affects when patients should be scheduled, this affects the materials needed on a specific date and time and this results in a financial action to send a bill. Distinguishing between the hierarchical levels is harder because these levels interact with each other and activities are not always separated. For example, the person who schedules the surgery is also responsible for the reallocation of unused surgery time. In this research, the case 
mix on the strategic level was considered as stable and was therefore rarely touched apart from a study on the relation between focus and operational performance. Thus, the research scope is mainly limited to the tactical and operational level in hospitals; see the grey area in Table 1.

\section{Approaches to improve resource capacity planning}

This section describes the approaches that are examined in this dissertation as there are many business approaches available to improve resource capacity planning in hospitals.

Focused factories are proposed as a way to increase the efficiency of hospital care (19-23). By focusing on specific products or services, the trade-offs that hinder the fulfilment of product requirements and deteriorate the competitiveness of the organization are reduced (24-27). Herzlinger (19) describes focus factories as (multidisciplinary) organizations based on common objectives (e.g. the treatment of specific patient groups). Porter (28), Herzlinger (19) and Christensen (29) suggest that increasing focus results in processes that are better organized around patients, higher patient volumes, more cost-effective care, and improved medical outcomes. In other words, the strategic decisions for focus enable a better organization of processes on the tactical and operational levels as presented in Table 1.

The second approach examined in this dissertation is benchmarking which focuses on learning from others and setting realistic performance targets. Benchmarking is defined as "the search for- and implementation of best practices" (30). For healthcare Mosel and Gift provided the following definition: "... benchmarking is the continual and collaborative discipline of measuring and comparing the results of key work processes with those of the best performers. It is learning how to adapt these best practices to achieve breakthrough process improvements and build healthier communities" (12). As best practices can be identified on all hierarchical levels, benchmarking can be applied on the strategic, tactical and operational level.

Business approaches such as business process re-engineering (BPR), lean management and six sigma describe in more detail how processes should be changed. We decided to limit the scope to lean management because the results seem promising and many lean principles seem to correspond with healthcare (31- 
41), where patients need to receive the right treatment at the right time in the most effective way. Lean management focuses on value for the customer (in healthcare the patient), the value stream (each activity must add value for the patient), flow (service delivery without stoppages or backflows), pull (deliver it when it is needed) and perfection (32). Lean management seems most suitable for resource capacity planning on the operational levels as it prescribes organizations to become more flexible and to produce multiple products on the same line with minimal set-up times. It also seems possible for strategic and tactical levels.

Another approach is operations research, which is able to support decision making processes by quantifying the consequences of improvement suggestions and designing optimized interventions (42). The strength of these techniques is their ability to quantify the effects of proposed interventions. However, they do not prescribe organizations how to organize processes. Many different mathematical modelling techniques have been used in healthcare. This research was limited to simulation since this is one of the most frequently applied modelling techniques in healthcare (14). Simulation for resource capacity planning can be applied on the strategic, tactical and operational levels of the framework in Table 1.

\section{Research questions and methods}

This dissertation examines whether business approaches can improve resource capacity planning in hospitals. This section presents the research questions, their relevancy and the methods.

\section{Research question 1: Exploring business approaches in Dutch hospitals}

Reviews report improvements or provide recommendations for improvements on resource capacity planning with operations research models (14), simulation (43), six sigma and lean management $(15,44)$ and business process re-engineering $(45)$. These reviews conclude that the study designs used to evaluate the effect of the interventions are not always rigorous; most evaluation consists of a pre-post analysis within a single organization $(15,44)$, and controls are often lacking. Not only do these reviews feature hardly any papers with negative results, they provide no insight into the selection and combination of approaches used in hospitals. 
To our knowledge, the use, combination and effects of approaches to improving resource capacity planning in hospitals are hardly reported upon in the literature. An exception is Yasin et al. (46) who surveyed 108 Tennessee (USA) hospitals in 2002. Using self-reported surveys, they found a $100 \%$ implementation rate for continuous improvement $(\mathrm{Cl})$. Total quality management and benchmarking scored above $60 \%$. Business process re-engineering, just-in-time techniques, job reengineering and organizational restructuring were rated between $29.8 \%$ and $60 \%$. Related research in the Netherlands that examined the activities undertaken as part of quality management systems during that same period (47) reported a lower uptake than Yasin et al. (46).

Based on the above, we concluded that additional information on this subject was needed. Therefore, the following research question was defined:

What approaches and tools to improve patient logistics use Dutch hospitals, what is their effect on performance and how are they evaluated?

In 94 hospitals, we surveyed business approaches and tools, and analysed the results the hospitals claimed to have achieved.

Research question 2: Using focused factories to change the operations strategy

Literature describes focus as a diffuse mix of treatment characteristics, patient characteristics, specialty characteristics, and organizational aspects (19-23). Examples of focused factories consider different types of organizations, such as cancer clinics (19), trauma centres (22), specialty hospitals $(20,21,48)$, and ambulatory surgery centres $(23,49)$. Due to this diversity in examples, the definition of 'focus' in hospital care seems to lack clarity. This makes evaluating the efficiency of focused factories difficult and may explain the mixed outcomes on operational performance of focused factories. For positive effects see $(23,49)$, for negative examples see $(50,51)$. Therefore, the following research question was defined:

How do hospitals apply focused factories with regard to their degree of focus, their organizational context and the operational performance?

With this study, we expect to contribute to the understanding of characteristics of the care delivery system and operations strategy for different types of focus. Regarding the hospital planning and control framework, this study gains insight into the effects of the strategic level (the decision to focus the organization) on the tactical and operational levels. 
The study consisted of a cross-case comparison of four, separately performed, multiple-case studies in different specialty fields. These fields were selected to correspond with and reflect the variety of focus examples in the literature (19$22,48,49)$. Each multiple-case study consisted of three to four cases in which the degree of focus was investigated with an instrument developed for the industry (52) that we adapted for our study. The operational performance was investigated with qualitative and quantitative process indicators that varied per specialty field. Furthermore, for the organizational context we examined the operations strategy (related to focusing), the use of standardized procedures, the use of dedicated (physical) layouts, planning routines, and team composition.

Research question 3: Benchmarking to learn from others and to set realistic performance targets.

To our knowledge there are hardly papers discussing international benchmarking on operations management and more specifically resource capacity planning in hospitals. Improvement opportunities might thus be missed, as there are clear indications that healthcare performance between countries (and regions) show large differences (53). Furthermore, the available papers on benchmarking on operations management in hospitals seldom present the benchmarking method, the identified best practices, and the accomplished improvements in a structured way. Most papers directly zoom in on the indicators and the comparison of results. It seems that international benchmarking, as a tool to improve resource capacity planning in hospitals, is not well described and possibly not well developed.

To become more efficient, healthcare shows a trend towards specialization of hospitals (or their units) $(48,54,55)$. Schneider et al. describe specialty hospitals as hospitals "that treat patients with specific medical conditions or those in need of specific medical or surgical procedures" (48). Most research involving general and specialty hospitals concentrates on the differences (48) whereas identification of more optimal practices (benchmarking), especially regarding operations management, is seldom the topic of research.

International benchmarking in specialty hospitals seems to require further research. We defined the following research questions:

1. What is the feasibility of international (comprehensive) bench-marking in specialty hospitals to identify achievable performance levels and to improve operations management?

2. What is the most suitable process for benchmarking operations management in international specialty hospitals? 
3. What are the success factors for international benchmarking in specialty hospitals?

The selected research setting consisted of comprehensive cancer centres (consisting of 3 to 4 organizations), as representative of a type of specialty hospital operating in an internationally competitive environment. The number of cases per case study was limited to four. The benchmark of the hospitals concerned mainly strategic level (patient case mix, dimensioning of the hospital) and tactical aspects of resource capacity planning such as policies and information availability regarding access times and utilization. The benchmark of the radiotherapy departments included also aspects related to patient satisfaction and patient safety, as many hospitals consider all these aspects when redesigning processes. The benchmark of the chemotherapy day unit included resource capacity planning on all levels.

For each case study a separate research protocol that consisted of the selection criteria for the involved hospitals, the benchmarking process, and the definitions of the indicators was developed. Both qualitative and quantitative methods were used to collect data for each case study; this included semi-structured interviews during the site visits. The research team compared the organizations on individual score per indicator and total score. After each case, the research team reflected on the feasibility, the benchmarking process and success factors for international benchmarking on comprehensive cancer centres.

\section{Research question 4: Improving with benchmarking and lean management}

In 2005, the Institute for Healthcare Improvement (IHI), amongst other claimed that lean management could improve healthcare processes (31). By that time examples of lean thinking were mainly provided by national healthcare quality agencies, such as IHI (31), the National Health Service (34), and by proponents of lean management such as the Lean Management Institute (33). Peer-reviewed publications were scarce; we found examples in surgery (35), an entire hospital $(36,38)$, laboratories $(39,40)$, a pharmacy $(37)$ and an endoscopy unit $(41)$. They all showed promising results but most publications tended to have a descriptive character, lacked pre- and post-measurements and did not use controlled studies. Thus, although lean management proponents claim to improve efficiency, the scientific evidence in healthcare supporting this claim seems limited and the literature mainly seems to report on lean management in low complex high-volume processes. The complexity of cancer care and the continuous changes caused by scientific progress make oncology an interesting area to study the application of 
lean management in hospitals: if it works in oncology, it might work in other hospital processes as well.

This resulted in the following research question:

How to apply a combination of benchmarking and lean management to enable a considerable patient growth in a chemotherapy day unit (CDU) without proportionally adding staff, while sustaining current quality and patient satisfaction levels?

The study had a before-and-after design. As the CDU was facing a patientscheduling problem, this research mainly focused on the operational level on the framework for hospital planning and control (17). Like many healthcare improvement projects, this project was structured according to the Plan-Do-CheckAct cycle (56). The benchmark was used to identify attainable performance levels for efficiency, and causes for differences. With an in-depth analysis using lean management, improvement opportunities from the benchmark were confirmed and completed. The in-depth analysis also made the CDU less dependent of their benchmarking partners for improvement opportunities.

Research question 5: simulation models and their contribution to hospital improvements.

To our knowledge, four papers researched the prevalence of implementing recommendations derived from operations research models in healthcare $(14,57-$ 59). They all concluded that actual implementation in practice is hardly reported in the literature.

Although these four reviews provide insight into the actual implementation of recommendations based on simulation models, it remains unclear whether the results are valid in the present context. Wilson (58) completed his comprehensive study in 1981, which leads to the question whether the conclusions are still valid, given the advances in simulation software and techniques. The review of Lagergren (59) was not focused solely on simulation and was, by the author's own account, "incomplete". The review of Fone et al. (57) concerned simulation studies on population health and healthcare delivery instead of operations management in individual hospitals. Although the work of Brailsford et al. (14) appears complete, the results were not limited to simulation and did not examine the realized impact of the changes recommended by the models. 
Understanding the relation between simulation models and improvements requires insight into the conditions that increase the implementation rate. To our knowledge, four papers (60-63) have strived to identify these conditions. As this research also included manufacturing companies, it remains unclear whether their result can be applied to the healthcare sector.

Thus, actual implementation in practice is hardly reported upon in the literature, just as research into the conditions that increase the implementation rate and the realized impact of the changes recommended by the modeller. Therefore, the following research objectives were defined:

1. To determine the frequency that simulation recommendations are executed to improve operations management in individual hospitals.

2. To determine what factors contribute to the implementation of simulation study recommendations.

3. To determine the research methods used to evaluate implemented simulation recommendations.

4. To examine the difference between literature and reality with regard to the implementation of simulation recommendations.

Question 1, 2 and 3, were answered with a literature review. The differences regarding implementation between literature and reality were examined with a survey among the authors of the identified papers of the review.

Research question 6: using computer simulation to reduce the diagnostic track involving CT scanning

One of the presumed causes of inefficiency in healthcare is a lack of collaboration between departments (64). Jun et al. (43) and Fletcher and Worthington (65), already concluded that few simulation models in hospitals encompass multiple units or departments. In 2010, VanBerkel et al. reported on 88 hospital models that encompass multiple departments (64). They found one paper that included the relation between radiology and the operations theatre (66). This paper modelled the number of technologist and the effects on technologist utilization and operating room utilization. It is remarkable that the relation between radiology and other departments has hardly been examined as so as many patient flow processes depend on radiology.

The combination of the lack of a systems view in modelling radiology departments and the suggestion that the effects of interventions based on simulation models are hardly published (14,57-59), led to the following research question: 
How can computer simulation be used to reduce the throughput time of the diagnostic track involving CT scanning by changing the capacity allocated to each patient group while maintaining an acceptable overtime and idle time of the CT?

The diagnostic track starts with the outpatient consultation where the radiology request is written, followed by the radiology procedure(s) and the track finishes with the consultation in which the radiology report is discussed. This systems view on the diagnostic track is relevant because a short throughput time is desirable for patients and their referring physicians who need the scan to discuss a treatment plan.

After a pre intervention analysis of our case study hospital, four interventions were prospectively evaluated by computer simulation on access time, overtime and idle time of the CT. One intervention was implemented and evaluated on with a post intervention analysis.

\section{Dissertation outline}

Table 2 summarizes the research questions, the research methods, the chapter that provides the answer to the research question and the organizational levels that were examined within the field of resource capacity planning as described in Table 1. In chapter 2, we surveyed approaches and tools that aim to improve patient logistics and analysed the results the Dutch hospitals claimed to have achieved. Chapter 3 explores the application of the focused factory concept in hospital care, by investigating the degrees of focus, the organizational context and the operational performance in four multiple case studies. Chapter 4 examines the feasibility, the process and the success factors of international (comprehensive) benchmarking in specialty hospitals. Chapter 5 presents a single case study with a before-and-after design in which the applicability of benchmarking and lean management to improve the efficiency of a highly specialized chemotherapy day unit is examined. Chapter 6 discusses the relation between simulation and implementation with a literature review and a survey among authors of the identified papers. Chapter 7 examines how computer simulation can be used to reduce the throughput time of diagnostic track involving CT scanning by changing the capacity allocated to each patient group while maintaining an acceptable overtime and idle time of the CT. The conclusions and discussion are presented in chapter 8 . Finally, chapter 9 contains the summary. 
Table 2 Outline of the dissertation

\begin{tabular}{|c|c|c|c|}
\hline Research question & Research method & Chapter & $\begin{array}{l}\text { Organizational } \\
\text { level }\end{array}$ \\
\hline $\begin{array}{l}\text { What approaches and tools to improve } \\
\text { patient logistics use Dutch hospitals, what } \\
\text { is their effect on performance and how are } \\
\text { they evaluated? }\end{array}$ & Survey & 2 & All \\
\hline $\begin{array}{l}\text { How do hospitals apply focused factories } \\
\text { with regard to their degree of focus, the } \\
\text { organizational context and the operational } \\
\text { performance? }\end{array}$ & 4 multiple case studies. & 3 & $\begin{array}{l}\text { Effects of focus } \\
\text { on strategic } \\
\text { level on the } \\
\text { tactical and } \\
\text { operational } \\
\text { levels }\end{array}$ \\
\hline $\begin{array}{l}\text { What is the feasibility, the most suitable } \\
\text { benchmarking process and what are the } \\
\text { success factors of international } \\
\text { (comprehensive) benchmarking in } \\
\text { specialty hospitals to identify achievable } \\
\text { performance levels and to improve } \\
\text { operations management? }\end{array}$ & 3 multiple case studies & 4 & $\begin{array}{l}\text { Case 1: } \\
\text { strategic and } \\
\text { tactical } \\
\text { Case 2: all } \\
\text { levels } \\
\text { Case 3: mainly } \\
\text { strategic and } \\
\text { tactical }\end{array}$ \\
\hline $\begin{array}{l}\text { How to apply a combination of } \\
\text { benchmarking and lean management to } \\
\text { enable a considerable patient growth in a } \\
\text { chemotherapy day unit (CDU) without } \\
\text { proportionally adding staff, while } \\
\text { sustaining current quality and patient } \\
\text { satisfaction levels? }\end{array}$ & $\begin{array}{l}\text { Single case study with a } \\
\text { before-and-after design }\end{array}$ & 5 & $\begin{array}{l}\text { Mainly } \\
\text { operational and } \\
\text { tactical level. }\end{array}$ \\
\hline $\begin{array}{l}\text { 1) What is the frequency rate that } \\
\text { simulation recommendations are executed } \\
\text { to improve operations management in } \\
\text { individual hospitals, 2) what are the factors } \\
\text { that contribute to implementation, 3) what } \\
\text { research methods are used to evaluate } \\
\text { implemented simulation recommendations } \\
\text { 4) what are differences between literature } \\
\text { and reality? }\end{array}$ & $\begin{array}{l}\text { Literature review + } \\
\text { survey }\end{array}$ & 6 & All levels \\
\hline $\begin{array}{l}\text { How can computer simulation be used to } \\
\text { reduce the throughput time of diagnostic } \\
\text { track involving CT scanning by changing } \\
\text { the capacity allocated to each patient } \\
\text { group while maintaining an acceptable } \\
\text { overtime and idle time of the CT? }\end{array}$ & $\begin{array}{l}\text { Before-and-after design } \\
\text { in which the intervention } \\
\text { was based on a } \\
\text { simulation model }\end{array}$ & 7 & Mainly tactical \\
\hline
\end{tabular}




\section{Reference List}

1. OECD. Health Data: Key Indicators. 2011.

[http://www.oecd.org/dataoecd/52/42/48304068.xls] Last accessed 11-8-2011.

2. OECD. ALFS Summary Tables: Population. Population 15-64. 2011. [http://stats.oecd.org/index.aspx?queryid=254] Last accessed: 11-8-2011

3. Cooper RA, Getzen TE, McKee HJ, Laud P: Economic and demographic trends signal an impending physician shortage. Health Affairs 2002, 21:140.

4. Bodenheimer T: High and rising health care costs. Part 1: seeking an explanation. Annals of Internal medicine 2005, 142:847.

5. Bodenheimer T: High and rising health care costs. Part 2: technologic innovation. Annals of Internal medicine 2005, 142:932.

6. Bodenheimer T: High and rising health care costs. Part 3: the role of health care providers. Annals of Internal medicine 2005, 142:996.

7. Bodenheimer T, Fernandez A: High and rising health care costs. Part 4: can costs be controlled while preserving quality? Annals of Internal medicine 2005, 143:26.

8. Foote JL, Houston DJ, North NH: Betwixt and between: ritual and the management of an ultrasound waiting list. Health Care Analysis 2002, 10:357-377.

9. Rachlis M: Public solutions to health care wait lists. Canadian Centre for Policy Alternatives $=$ Centre canadien de politiques alternatives; 2005.

10. Committee on Quality of Health Care in America: Crossing the Quality Chasm: A New Health System for the 21st Century. Washington DC: Institute of Medicine; 2001.

11. Slack N, Chambers S, Johnston R: Operations Management. Financial Times / Prentice Hall; 2007.

12. Mosel D, Gift B: Collaborative benchmarking in health care. Joint Commission Journal on Quality Improvement 1994, 20:239.

13. de Koning $H$, Verver JPS, van den Heuvel J, Bisgaard S, Does R: Lean six sigma in healthcare. Journal for Healthcare Quality 2006, 28:4.

14. Brailsford SC, Harper PR, Patel B, Pitt M: An analysis of the academic literature on simulation and modelling in health care. Journal of Simulation 2009, 3:130-140.

15. Langabeer JR, DelliFraine JL, Heineke J, Abbass I: Implementation of Lean and Six Sigma quality initiatives in hospitals: A goal theoretic perspective. Operations Management Research 2009, 2:13-27.

16. van Lent WAM, de Beer R, van Harten W: International benchmarking of specialty hospitals. A series of case studies on comprehensive cancer centres. BMC Health Services Research 2010, 10:253.

17. Hans EW, Van Houdenhoven M, Hulshof PJH. A framework for health care planning and control. In: Handbook of Health Care Systems Scheduling. Hall, Randolp (Ed.) Springer International Series in Operations Research \& Management Science, 2011, 168: chapter 12.

18. Elkhuizen SG: Patient oriented logistics: studies on organizational improvement in an academic hospital. 2008.

19. Herzlinger RE: Market Drive Healthcare, Who wins, who loses in the transformation of Americas largest service industry. Addisson-Wesley; 1997.

20. Meyer $\mathrm{H}$ : Focused factories. Are you ready for the competition? Hospitals \& health networks/AHA 1998, 72:24.

21. Casalino LP, Devers KJ, Brewster LR: Focused factories? Physician-owned specialty facilities. Health Affairs 2003, 22:56.

22. Hyer NL, Wemmerlőv U, Morris Jr JA: Performance analysis of a focused hospital unit: The case of an integrated trauma center. Journal of Operations Management 2009, 27:203-219. 
23. Yang S, McLaughlin CP, Vaughan RW, Aluise JJ: Factory focus in hospital-owned ambulatory surgery. International Journal of Service Industry Management 1992, 3:6375 .

24. Skinner W: The focused factory. Harvard Business Review 1974.

25. Hayes R: Operations, strategy, and technology: pursuing the competitive edge. Strategic Direction 2006, 22.

26. Ruwe DM, Skinner W: Reviving a rust belt factory. Harvard Business Review 1987, 65:70-76.

27. Mukherjee A, Mitchell W, Talbot FB: The impact of new manufacturing requirements on production line productivity and quality at a focused factory. Journal of Operations Management 2000, 18:139-168.

28. Porter ME, Teisberg EO: Redefining health care: creating value-based competition on results. Harvard Business Press; 2006.

29. Christensen $\mathrm{CM}$, Grossman JH, Hwang J: The innovator's prescription: a disruptive solution for health care. McGraw-Hill Professional; 2009.

30. Camp RC: Benchmarking: The Search for Industry Best Practices that Lead to Superior Performance. Milwaukee,(USA) 1989.

31. Womack JP, Miller D, Institute for Healthcare Improvement: Going lean in health care. Institute for Healthcare Improvement; 2005.

32. Womack JP, Jones DT: Lean thinking: banish waste and create wealth in your corporation. Simon and Schuster; 2003.

33. Lean Enterprise Institute. Lean Enterprise Institute: Knowledge Center. Healthcare. 2011.

34. Locock L: Healthcare redesign: meaning, origins and application. British Medical Journal 2003, 12:53.

35. Raue W, Haase O, Junghans T, Scharfenberg M, Müller JM, Schwenk W: 'Fast-track' multimodal rehabilitation program improves outcome after laparoscopic sigmoidectomy: a controlled prospective evaluation. Surgical endoscopy 2004, 18:1463-1468.

36. Jimmerson C, Weber D, Sobek DK: Reducing waste and errors: piloting lean principles at Intermountain Healthcare. Joint Commission Journal on Quality and Patient Safety 2005, 31:249-257.

37. Sobek DK, Jimmerson C: C: Applying the Toyota Production System to a Hospital Pharmacy. In: Proceedings of the Industrial Engineering Research Conference, 2003.

38. Lindgaard Laursen M, Gertsen F, Johansen J: Applying lean thinking in hospitals exploring implementation difficulties. In: 3rd International Conference on the Management of Healthcare and Medical Technology, 2003, 7-9.

39. Sunyog M: Lean Management and Six-Sigma yield big gains in hospital's immediate response laboratory. Quality improvement techniques save more than $\$ 400,000$. Clinical leadership \& management review: the journal of CLMA 2004, 18:255.

40. Condel JL, Sharbaugh DT, Raab SS: Error-free pathology: applying lean production methods to anatomic pathology. Clinics in laboratory medicine 2004, 24.

41. Laing K, Baumgartner K: Implementing" Lean" Principles to Improve the Efficiency of the Endoscopy Department of a Community Hospital: A Case Study. Gastroenterology Nursing 2005, 28:210.

42. Buhaug $\mathrm{H}$. Long waiting lists in hospitals Operational research needs to be used more often and may provide answers. British Medical Journal 2002, 324(7332), 252-253.

43. Jun JB, Jacobson SH, Swisher JR: Application of discrete-event simulation in health care clinics: A survey. Journal of the Operational Research Society 1999,109-123.

44. DelliFraine JL, Langabeer JR, Nembhard IM: Assessing the evidence of Six Sigma and Lean in the health care industry. Quality Management in Healthcare 2010, 19:211.

45. Elkhuizen SG, Limburg M, Bakker PJM, Klazinga NS: Evidence-based re-engineering: re-engineering the evidence: A systematic review of the literature on business process 
redesign (BPR) in hospital care. International Journal of Health Care Quality Assurance 2006, 19:477-499.

46. Yasin MM, Zimmerer LW, Miller P, Zimmerer TW: An empirical investigation of the effectiveness of contemporary managerial philosophies in a hospital operational setting. International Journal of Health Care Quality Assurance 2002, 15:268-276.

47. Sluijs EM, Wagner C: Progress in the implementation of Quality Management in Dutch health care: 1995-2000. International Journal for Quality in Health Care 2003, 15:223.

48. Schneider JE, Miller TR, Ohsfeldt RL, Morrisey MA, Zelner BA: The economics of specialty hospitals. Medical Care Research and Review 2008, 65:531.

49. McLaughlin CP, Yang S, van Dierdonck R: Professional service organizations and focus. Management Science 1995,1185-1193.

50. Greenwald L, Cromwell J, Adamache W, Bernard S, Drozd E, Root E, Devers K: Specialty versus community hospitals: referrals, quality, and community benefits. Health Affairs 2006, 25:106.

51. Zigmond J: CMS probe sought. Death sparks specialty hospital queries. Modern Healthcare 2006, 36:7.

52. Pesch MJ, Schroeder RG: Measuring factory focus: an empirical study. Production and Operations Management 1996, 5:234-254.

53. World Health Organization: The World Health Report 2000. Health Systems: Improving Performance. 2000.

54. United States Government Accountability Office [GAO]: Specialty Hospitals: Geographic Location, Services Provided, and Financial Performance. Washington, DC; 2003. [http://www.gao.gov/new.items/d05647r.pdf] Last accessed: 11-8-2011

55. United States Government Accountability Office [GAO]: Specialty Hospitals: Information on Potential Facilities. Washington, DC: 2005.[ http://www.gao.gov/new.items/d04167.pdf] Last accessed: 11-8-2011

56. Deming WE: Out of the Crisis. The MIT Press; 2000.

57. Fone D, Hollinghurst S, Temple M, Round A, Lester N, Weightman A, Roberts K, Coyle E, Bevan G, Palmer S: Systematic review of the use and value of computer simulation modelling in population health and health care delivery. Journal of Public Health Medicine 2003, 25:325-335.

58. Wilson JCT: Implementation of Computer Simulation Projects in Health Care. Journal of the Operational Research Society 1981, 32:825-832.

59. Lagergren $\mathrm{M}$ : What is the role and contribution of models to management and research in the health services? A view from Europe. European Journal of Operational Research 1998, 105:257-266.

60. McHaney R, Cronan TP: Toward an empirical understanding of computer simulation implementation success. Information \& management 2000, 37:135-151.

61. McHaney R, White D, Heilman GE: Simulation project success and failure: Survey findings. Simulation \& Gaming 2002, 33:49.

62. Robinson S: Measuring Service Quality in the Process of Delivering a Simulation Study: The Customer's Perspective. International Transactions in Operational Research 1998, 5:357-374.

63. Robinson S, Pidd M: Provider and customer expectations of successful simulation projects. The Journal of the Operational Research Society 1998, 49:200-209.

64. Vanberkel PT, Boucherie RJ, Hans EW, Hurink JL, Litvak N, Van Lent WAM, Van Harten WH: A Survey of Health Care Models that Encompass Multiple Departments. International Journal of Health Management and Information 2010, 1:37-69.

65. Fletcher A, Worthington DJ: What is a "generic" hospital model? A comparison of generic and specific hospital models of emergency patient flows, Health Care Management Science, 2009, 12(4): 374-391.

66. Centeno MA, Albacete C, Terzano DO, Carrillo M, Ogazon T: A simulation study of the radiology department at JMH. Winter Simulation Conference, 2000, 2:1978-1984. 


\section{Exploring Improvements in Patient Logistics in Dutch hospitals}

W.A.M. van Lent

E.M. Sanders

W.H. van Harten

Submitted 


\section{Abstract}

\section{Objective}

To examine the approaches and tools used to improve patient logistics in Dutch hospitals, the reported effect of these approaches on performance and the methods used to evaluate them.

\section{Material and Methods}

Self-reported survey among patient-logistics advisors in 94 Dutch hospitals.

\section{Results}

Forty-eight percent of all hospitals participated. Ninety-eight percent took multiple approaches, $39 \%$ of them taking five approaches or even more. Care pathways were the approach preferred by $43 \%$, followed by business-process re-engineering and lean six sigma (both 13\%). Flowcharts were the commonest tool, and were used on a regular basis by $94 \%$ hospitals. Less than $10 \%$ of the hospitals used DEA analysis and critical path analysis on a regular basis. Approximately $50 \%$ of hospitals that evaluated the effects of approaches on efficiency, throughput times and financial results reported that they had accomplished their goals. Goal accomplishment in general hospitals ranged from $63 \%$ to $67 \%$, in academic teaching hospitals from $0 \%$ to $50 \%$, and in teaching hospitals from $25 \%$ to $44 \%$. More than $86 \%$ performed an evaluation, $53 \%$ performed a post-intervention measurement.

\section{Conclusions}

Hospitals used a combination of approaches and tools. No approach seemed to outperform the others. To understand which approach works best under specific circumstances, research should be conducted into the selection and application of approaches, their contingency factors, and goal-setting procedures. 


\section{Introduction}

In the Netherlands, as in many other Western countries, healthcare costs are rising (1). To tackle this, the government recently introduced market-based approaches intended to limit expenditure and to improve the quality of healthcare (2). Hospitals are now being forced to improve the efficiency of their processes - all at a time when demand is increasing and the recruitment of sufficient staff is difficult. Simultaneously, the focus of quality management in healthcare is gradually shifting away from clinical effectiveness (3) to greater emphasis on process improvement and organizational focus (4). The Institute of Medicine (IoM) has also declared timeliness and efficiency to be important aspects of quality in healthcare (5).

At least two studies have investigated the relationship in many hospitals between activities intended to improve the quality of healthcare and hospital performance on different aspects such as financial results, length of stay and other factors $(6,7)$. Both found that these activities positively affected performance. But because these publications examined quality-improvement activities according to the broad loM definition of quality (including safety and effectiveness), they provide no insight into activities undertaken to improve patient logistics.

The challenges now faced by hospitals with regard to patient logistics are similar to those faced by manufacturing organizations with regard to operations management (OM). OM research covers "the activity of managing the resources which are devoted to the production and delivery of products and services." (8) Historically speaking, OM approaches in businesses gradually started to overlap with quality management, for example in lean management and six sigma (for definitions, see Table 1 on page 33). Research showed that promising approaches such as benchmarking, operations research, lean management and six sigma, can be adopted in healthcare (9-13). In view of the differences between manufacturing and healthcare Naveh and Stern doubt whether approaches developed for business can be applied in hospitals (14).

Despite such differences, reviews on business approaches such as operations research models, (11), simulation (15), six sigma and lean management (12), and business-process re-engineering (16) report improved patient logistics in hospitals or recommendations for these improvements. These reviews conclude that the study designs followed to evaluate the effect of the interventions are not always rigorous; most evaluation consists of a pre-post analysis within a single organization (12), and controls are often lacking. Not only do these reviews feature 
hardly any papers with negative results, they provide no insight into the selection and combination of approaches used in the hospital sector.

To our knowledge, little research is conducted on the use, combination and effects of approaches to improving patient logistics in hospitals. One exception is Yasin et al., (17) who surveyed the extent to which the following approaches were implemented in 108 Tennessee (USA) hospitals in 2002: continuous improvement $(\mathrm{Cl})$, total quality management (TQM), business-process re-engineering (BPR), just-in-time techniques (JIT), organizational restructuring, job re-engineering (JR) and benchmarking (BM). Self-reported surveys found a 100\% implementation rate for $\mathrm{Cl}$ in for-profit hospitals and $98.7 \%$ in non-profit hospitals. TQM and BM scored above $60 \%$ in both hospitals types. BPR, JIT, JR and organizational restructuring were rated between $29.8 \%$ and $60 \%$. Self-reported success was rated from very ineffective to very effective. The lowest success rate was reported for BPR in nonprofit hospitals $(68.2 \%)$, the highest for $\mathrm{Cl}$ in for-profit hospitals $(100 \%)$. In the same period, Sluijs et al. (18) examined the activities undertaken as part of quality management systems in Dutch medical institutions. The uptake seemed lower than the implementation rate reported by Yasin et al. (17). Either the methodologies were incomparable or the implementation rate was higher in the US hospitals.

On the basis of the above, we concluded that additional information was needed on approaches to patient logistics and on how they affect performance. In 94 hospitals we therefore surveyed such approaches and the tools used to support them, analysed the results reported with these approaches and the methods used to evaluate them.

\section{Materials and Methods}

We used a self-reported survey whose content validity had been verified by three independent researchers and two consultants active in the field of patient logistics. All provided feedback on the research design and the survey. After minor modifications, the survey was piloted by four respondents at four different Dutch hospitals. This led to textual modifications. 
The survey consisted of five sections:

1. Hospital type. There were three hospital types: general hospital, nonacademic teaching hospitals (not affiliated to universities), and academic teaching hospitals (affiliated to universities).

2. Approaches used to improve patient logistics. This section consisted of two questions, one focusing on approaches that had been used during the previous two years, and one focusing on the approach that had been used most intensively during the same period. We selected 11 approaches on the basis of 1.) literature on the application of approaches to improving patient logistics healthcare and, 2.) the authors' expertise and the validation of five independent experts. Table 1 (page 33) presents these approaches and the literature upon which their selection was based.

3. The frequency with which hospitals use tools or activities related to a specific approach to improve patient logistics (in the rest of this chapter this will be called tools). We added this section after consulting the independent experts. As hospitals might use different definitions for the same approaches, our intention was to provide greater insight into the tools that hospitals actually use. We asked respondents to rate the intensity at which their hospital used specific tools on a five-point Likert scale (from rarely used to almost always used). We excluded tools that were intended primarily to bring about cultural change or safety improvements. Our selection of tools was based upon the literature presented in Table 1. The experts' input and the pilot study were used to refine the list of tools. Altogether, 25 tools and groups of tools were selected. The tools are described in Table 2 on page 34.

4. Goal accomplishment. We examined three aspects of this: efficiency, throughput times and financial results. The use of multiple performance aspects in hospitals was suggested by Yasin et al. (17), and Alexander et al. (19). Respondents scored the performance achieved on each aspect on a qualitative scale with four answers: goals had been accomplished, results had exceeded the goals, goals had not been achieved, not evaluated.

5. Evaluation methods. To examine the strength of evidence of the results, respondents were asked to describe the type of evaluation (quantitative, qualitative) and the method of data gathering (sample, pre-post measurement). Lastly, we asked whether the hospital had published on their improvement efforts. 
Sample

Staff advisors or managers responsible for patient logistics in Dutch general, academic, and non-academic teaching hospitals were asked to participate. In the Netherlands, such staffs are employed in various departments. We approached them through logistic networks for healthcare, personal contacts and hospital information. They were sent an invitation and reminder by e-mail, and, if necessary, a final reminder by telephone. Altogether, we approached staff in all 94 Dutch hospitals: eight academic teaching hospitals, 58 general hospitals, and 27 nonacademic teaching hospitals (52).

\section{Data analysis}

If, at a minimum, the questions on the hospital type and the approaches had been answered, surveys were included for analysis. As the maximum sample size was 94 and as the questions provided options for answers, we anticipated that we would use mainly non-parametric data and descriptive statistics in the form of cross tables. In the cross tables we included only those hospitals that had provided answers on all questions relevant for that cross table. The number of hospitals included per item is shown in the results section. 
Table 1 Approaches to patient logistics, with abbreviations and descriptions

\begin{tabular}{|c|c|c|}
\hline $\begin{array}{l}\text { Approaches to } \\
\text { patient logistics } \\
\text { (with } \\
\text { abbreviation) }\end{array}$ & $\begin{array}{l}\text { Applications } \\
\text { in healthcare } \\
\text { literature }\end{array}$ & Definition \\
\hline $\begin{array}{l}\text { Total Quality } \\
\text { Management } \\
\text { (TQM) }\end{array}$ & $(20)$ & $\begin{array}{l}\text { "TQM is a method for ridding people's lives of wasted effort by } \\
\text { involving everyone in the processes of improvement; improving } \\
\text { the effectiveness of work so that the results are achieved in less } \\
\text { time. The methods and techniques used in TQM can be applied } \\
\text { throughout the organization. They are equally useful to finance, } \\
\text { sales, marketing, distribution, development, manufacturing, } \\
\text { public relations, personnel, to every one of a company's } \\
\text { activities." (21) }\end{array}$ \\
\hline $\begin{array}{l}\text { Business Process } \\
\text { Re-engineering } \\
\text { (BPR) }\end{array}$ & $(16)$ & $\begin{array}{l}\text { "The fundamental rethinking and radical redesign of business } \\
\text { processes to achieve dramatic improvements in critical, } \\
\text { contemporary measures of performance, such as cost, quality, } \\
\text { service, and speed." (22) }\end{array}$ \\
\hline $\begin{array}{l}\text { Operations } \\
\text { Research (OR) }\end{array}$ & $(11,23,24)$ & $\begin{array}{l}\text { "Operations research is a scientific approach of providing } \\
\text { executive departments with a quantitative basis for decisions } \\
\text { regarding the operations under their control." (25) }\end{array}$ \\
\hline $\begin{array}{l}\text { Lean Management } \\
\text { (LM) }\end{array}$ & $(12,26,27)$ & $\begin{array}{l}\text { "An integrated socio-technical system whose main objective is to } \\
\text { eliminate waste by concurrently reducing or minimizing supplier, } \\
\text { customer and internal variability." (28) }\end{array}$ \\
\hline Six Sigma (SS) & $(29,30)$ & $\begin{array}{l}\text { "Six sigma methodology provides the techniques and tools to } \\
\text { improve the capability and reduce the defects in any process. It } \\
\text { improves any existing business process by constantly reviewing } \\
\text { and re-tuning the process." (10) }\end{array}$ \\
\hline $\begin{array}{l}\text { Lean six Sigma } \\
\text { (LSS) }\end{array}$ & $(10,31,32)$ & $\begin{array}{l}\text { "A combination of lean management and six sigma. It is a } \\
\text { methodology that maximizes shareholder value by achieving the } \\
\text { fastest rate of improvement in customer satisfaction, cost, } \\
\text { quality, process speed, and invested capital." (32) }\end{array}$ \\
\hline $\begin{array}{l}\text { Theory of } \\
\text { Constraints (TOC) }\end{array}$ & $(33-36)$ & $\begin{array}{l}\text { "A management approach that emphasizes the importance of } \\
\text { managing constraints. A constraint or bottleneck is any thing that } \\
\text { prevents you from getting more of what you want." (37) }\end{array}$ \\
\hline $\begin{array}{l}\text { Care Pathways } \\
(\mathrm{CP})\end{array}$ & $(38-40)$ & $\begin{array}{l}\text { "This are structured multidisciplinary care plans which detail } \\
\text { essential steps in the care of patients with a specific clinical } \\
\text { problem." (38) }\end{array}$ \\
\hline $\begin{array}{l}\text { Benchmarking } \\
\text { (BM) }\end{array}$ & $(9,13,41,42)$ & "The search for- and implementation of best practices." (41) \\
\hline $\begin{array}{l}\text { Collaborative } \\
\text { Improvement }(\mathrm{Cl})\end{array}$ & $(43-45)$ & $\begin{array}{l}\text { "A collaborative brings together groups of practitioners from } \\
\text { different healthcare organizations to work in a structured way to } \\
\text { improve one aspect of the quality of their service." (46) }\end{array}$ \\
\hline $\begin{array}{l}\text { Focused Factories } \\
\text { (FF) }\end{array}$ & $(47-50)$ & $\begin{array}{l}\text { "Its entire apparatus is focused on accomplishing the particular } \\
\text { manufacturing task demanded by the company's overall strategy } \\
\text { and marketing perspective." (51) }\end{array}$ \\
\hline
\end{tabular}




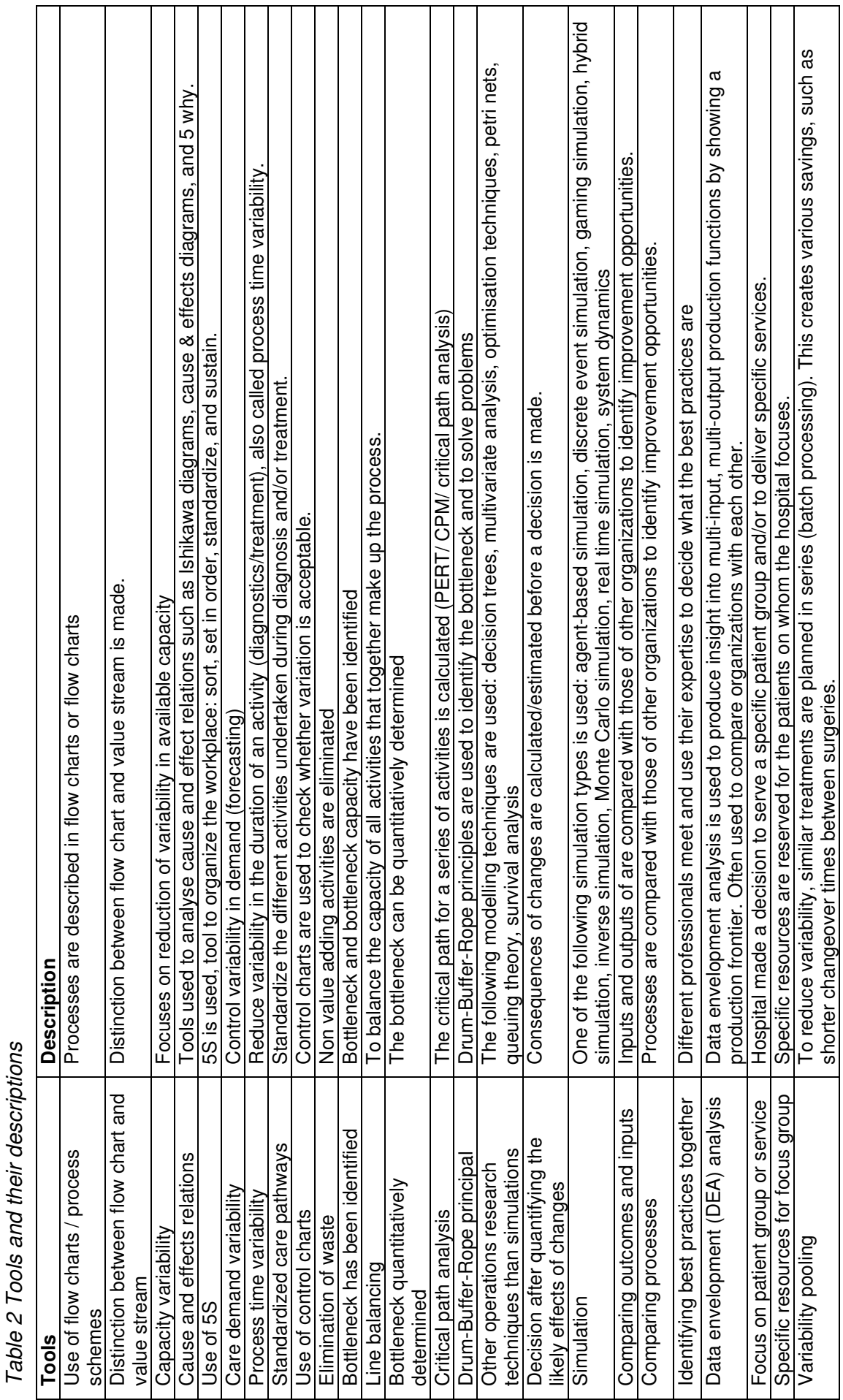




\section{Results}

Although 52 hospitals returned the survey, six were excluded due to missing data, thus representing a response rate of $48 \%(n=46)$. Table 3 presents the response rate per hospital type and the total number of hospitals of that type in the Netherlands.

Table 3 Type of hospital in survey relative to the total number of such hospitals in the Netherlands

\begin{tabular}{|l|c|c|c|c|}
\hline Hospital type & Excluded & $\begin{array}{l}\text { Included in } \\
\text { analysis }\end{array}$ & $\begin{array}{l}\text { Total number of } \\
\text { hospitals in the } \\
\text { Netherlands }\end{array}$ & $\begin{array}{l}\text { Fraction of hospitals } \\
\text { included in our sample }\end{array}$ \\
\hline $\begin{array}{l}\text { Academic } \\
\text { teaching } \\
\text { hospital }\end{array}$ & 0 & 6 & 8 & 75 \\
\hline General hospital & 4 & 27 & 59 & 48 \\
\hline $\begin{array}{l}\text { Non-academic } \\
\text { teaching } \\
\text { hospital }\end{array}$ & 2 & 13 & 27 & 48 \\
\hline Total & 6 & 46 & 94 & \\
\hline
\end{tabular}

Table 4 shows that the 46 hospitals used care pathways most $(91 \%)$, followed by benchmarking (78\%). Focused factories (22\%), lean six sigma (17\%) and six sigma $(13 \%)$ were used much less. Table 4 also shows the total numbers and combinations of approaches used by hospitals. For example, 32 of the 42 hospitals that used care pathways (91\%) also used benchmarking, 20 of the 42 used business-process re-engineering and 20 used lean management. During the past two years, $98 \%$ had used multiple approaches, and $39 \%$ had used five or even more. 
Table 4 Frequency of approaches used, and frequency with which they were combined (percentages, $n=46$ )

\begin{tabular}{|l|c|c|c|c|c|c|c|c|c|c|c|c|}
\hline Approaches & \multirow{2}{*}{$\begin{array}{l}\text { Total } \\
(\%)\end{array}$} & \multicolumn{6}{|l|}{$\begin{array}{l}\text { Other approaches used by hospitals that used the approach } \\
\text { indicated in the left-hand column. }\end{array}$} \\
\cline { 2 - 16 } & & $C P$ & $B M$ & $B P R$ & $L M$ & $T O C$ & $C l$ & $T Q M$ & OR & $F F$ & LSS & $S S$ \\
\hline $\begin{array}{l}\text { Clinical pathways } \\
\text { (CP) }\end{array}$ & 91 & & 32 & 20 & 20 & 18 & 15 & 10 & 12 & 10 & 8 & 6 \\
\hline Benchmarking (BM) & 78 & 32 & & 20 & 18 & 18 & 13 & 11 & 11 & 7 & 6 & 4 \\
\hline $\begin{array}{l}\text { Business Process re- } \\
\text { engineering (BPR) }\end{array}$ & 48 & 20 & 20 & & 14 & 10 & 6 & 6 & 10 & 6 & 5 & 4 \\
\hline $\begin{array}{l}\text { Lean management } \\
\text { (LM) }\end{array}$ & 48 & 20 & 18 & 14 & & 13 & 7 & 4 & 8 & 7 & 2 & 5 \\
\hline $\begin{array}{l}\text { Theory of constraints } \\
\text { (ToC) }\end{array}$ & 43 & 18 & 18 & 10 & 13 & & 8 & 6 & 7 & 6 & 2 & 4 \\
\hline $\begin{array}{l}\text { Continuous } \\
\text { improvement (CI) }\end{array}$ & 33 & 15 & 13 & 6 & 7 & 8 & & 4 & 1 & 5 & 2 & 1 \\
\hline $\begin{array}{l}\text { Total Quality } \\
\text { Management (TQM) }\end{array}$ & 28 & 10 & 11 & 6 & 4 & 6 & 4 & & 5 & 2 & 2 & 1 \\
\hline $\begin{array}{l}\text { Operations research } \\
\text { (OR) }\end{array}$ & 28 & 12 & 11 & 10 & 8 & 7 & 1 & 5 & & 4 & 3 & 3 \\
\hline $\begin{array}{l}\text { Focused factories } \\
\text { (FF) }\end{array}$ & 22 & 10 & 7 & 6 & 7 & 6 & 5 & 2 & 4 & & 1 & 1 \\
\hline Lean six sigma (LSS) & 17 & 8 & 6 & 5 & 2 & 2 & 2 & 2 & 3 & 1 & & 3 \\
\hline Six sigma (SS) & 13 & 6 & 4 & 4 & 5 & 4 & 1 & 1 & 3 & 1 & 3 & \\
\hline
\end{tabular}

Regarding the approach that had been used most intensively over the previous two years, $26 \%$ of the hospitals $(n=46)$ reported multiple preferred approaches, and $13 \%$ did not prioritize a specific approach. Table 5 presents the prioritized approaches per hospital type. Again, care pathways were used by far the most $(35 \%)$, but business process re-engineering and lean six sigma (both 11\%) received more mentions than benchmarking (9\%). Lean management and total quality management were used in $9 \%$ of the hospitals. 
Table 5 Most intensively used approaches per hospital type (percentages, $n=46$ )

\begin{tabular}{|l|l|c|c|c|}
\hline Approaches for patient logistics & $\begin{array}{l}\text { Academic } \\
\text { teaching } \\
\text { hospitals } \\
\text { (number) }\end{array}$ & $\begin{array}{l}\text { General } \\
\text { hospitals } \\
\text { (number) }\end{array}$ & $\begin{array}{l}\text { Non- } \\
\text { academic } \\
\text { teaching } \\
\text { hospitals } \\
\text { (number) }\end{array}$ & Total (\%) \\
\hline Care pathways & 4 & 9 & 7 & $35 \%$ \\
\hline Business-process re-engineering & 1 & 2 & 2 & $11 \%$ \\
\hline Lean six sigma & 1 & 4 & 1 & $11 \%$ \\
\hline Benchmarking & 0 & 5 & 0 & $9 \%$ \\
\hline Lean Management & 0 & 4 & 0 & $9 \%$ \\
\hline Total Quality management & 1 & 1 & 1 & $9 \%$ \\
\hline Theory of constraints & 0 & 5 & 0 & $7 \%$ \\
\hline Collaborative improvements & 0 & 1 & 0 & $5 \%$ \\
\hline Operations research & 1 & 0 & 0 & $2 \%$ \\
\hline Focused factories & 1 & 3 & 2 & $2 \%$ \\
\hline Six sigma & 0 & 0 & 1 & $2 \%$ \\
\hline
\end{tabular}

NB Multiple answers per hospitals were possible

Table 6 shows which tools the hospitals used to improve patient logistics. Flowcharts were the commonest tool, of the 38 hospitals that answered this question: 16 used them consistently, 19 used them regularly, and three used them sometimes. Standardized care pathways, elimination of waste, line balancing and identifying the capacity of the bottleneck were used always or regularly by at least $50 \%$ of the hospitals. The tools used least frequently scored less than $30 \%$ on the combination of 'always' and 'regularly'. They included quantitative tools such as DEA analysis, drum-buffer-rope principals, critical path analysis, and operations research techniques. Among these least frequently used tools were also tools such as process and outcome comparison that required collaboration with other organizations. Another not frequently used tool was $5 \mathrm{~S}$, which concerns storage and maintenance of equipment and materials. 
Table 6 The frequency with which tools/activities to improve patient logistics are used

\begin{tabular}{|c|c|c|c|c|c|c|c|}
\hline \multirow{2}{*}{\multicolumn{2}{|c|}{ Tools }} & \multirow{3}{*}{$\begin{array}{l}\begin{array}{l}\text { Total } \\
\mathbf{N}\end{array} \\
38 \\
\end{array}$} & \multicolumn{5}{|c|}{ Intensity of tools used (number of responses) } \\
\hline & & & \multirow{2}{*}{$\begin{array}{c}\text { Always } \\
16\end{array}$} & \multirow{2}{*}{$\frac{\text { Regularly }}{19}$} & \multirow{2}{*}{$\frac{\text { Sometimes }}{3}$} & \multirow{2}{*}{$\frac{\text { Rarely }}{0}$} & \multirow{2}{*}{$\begin{array}{c}\text { Never } \\
0\end{array}$} \\
\hline 1 & Use of flow charts & & & & & & \\
\hline 2 & Standardized care pathways & 36 & 5 & 22 & 6 & 3 & 0 \\
\hline 3 & Elimination of waste & 37 & 5 & 12 & 10 & 7 & 3 \\
\hline 4 & $\begin{array}{l}\text { Distinction between flow charts } \\
\text { and value stream }\end{array}$ & 34 & 5 & 5 & 12 & 4 & 8 \\
\hline 5 & Line balancing & 35 & 4 & 20 & 7 & 3 & 1 \\
\hline 6 & Bottleneck has been identified & 36 & 4 & 13 & 14 & 4 & 1 \\
\hline 7 & Cause-and-effect relations & 38 & 4 & 8 & 12 & 10 & 4 \\
\hline 8 & Process time variability & 35 & 2 & 19 & 11 & 3 & 0 \\
\hline 9 & $\begin{array}{lll}\text { Bottleneck } & \text { has } & \text { been } \\
\text { quantitatively determined } & \end{array}$ & 34 & 2 & 14 & 11 & 6 & 1 \\
\hline 10 & Decide after quantifying effects & 36 & 2 & 8 & 14 & 10 & 2 \\
\hline 11 & Reduce care demand variability & 35 & 1 & 20 & 5 & 7 & 2 \\
\hline 12 & Reduce variability in capacity & 35 & 1 & 18 & 11 & 5 & 0 \\
\hline 13 & Focus on patient group or service & 34 & 1 & 11 & 11 & 5 & 6 \\
\hline 14 & $\begin{array}{l}\text { Specific resources for focus } \\
\text { groups }\end{array}$ & 35 & 1 & 9 & 14 & 8 & 3 \\
\hline 15 & Variability pooling & 32 & 1 & 7 & 5 & 10 & 9 \\
\hline 16 & Identifying best practices together & 35 & 1 & 4 & 11 & 13 & 6 \\
\hline 17 & Use of control charts & 30 & 1 & 3 & 4 & 11 & 11 \\
\hline 18 & Simulation & 32 & 1 & 2 & 3 & 12 & 14 \\
\hline 19 & Comparison of processes & 34 & 0 & 5 & 13 & 12 & 4 \\
\hline 20 & $\begin{array}{l}\text { Comparison of outcomes and } \\
\text { inputs }\end{array}$ & 33 & 0 & 4 & 13 & 11 & 5 \\
\hline 21 & $\begin{array}{l}\text { Other operations research } \\
\text { techniques than simulations }\end{array}$ & 32 & 0 & 4 & 5 & 8 & 15 \\
\hline 22 & Use of $5 S$ & 33 & 0 & 3 & 7 & 10 & 13 \\
\hline 23 & Critical path analysis & 32 & 0 & 3 & 3 & 7 & 19 \\
\hline 24 & Drum-buffer rope principals & 29 & 0 & 3 & 1 & 3 & 22 \\
\hline 25 & DEA analysis & 27 & 0 & 2 & 1 & 4 & 20 \\
\hline
\end{tabular}

Table 7 shows per hospital type whether the goals of the business approach had been achieved with regard to their different performance aspects $(n=35)$. Efficiency was evaluated in $89 \%$ of the hospitals, throughput times in $83 \%$, and financial results in $74 \%$. Forty-nine percent of the hospitals reported having accomplished efficiency goals, $40 \%$ having achieved throughput times, and $40 \%$ having achieved the desired financial results. With regard to performance, general hospitals reported more accomplishments than failures: 12 having achieved efficiency goals against six efficiency failures (a success rate of $67 \%$ ), ten having achieved desired throughput times against six failures (63\% success rate), ten successes regarding financial results against five failures regarding financial results (success rate: $67 \%$ ). Academic hospitals scored more successes than failures only with regard to financial results, while non-academic teaching hospitals scored more failures than successes on all aspects. 
Table 7 Results per performance aspect per type of hospital

\begin{tabular}{|l|l|c|c|c|c|}
\hline $\begin{array}{l}\text { Performance } \\
\text { aspect }\end{array}$ & $\begin{array}{l}\text { Score on } \\
\text { performance } \\
\text { aspect }\end{array}$ & $\begin{array}{l}\text { Academic } \\
\text { teaching } \\
\text { hospitals } \\
\text { (number) }\end{array}$ & $\begin{array}{l}\text { General } \\
\text { hospitals } \\
\text { (number) }\end{array}$ & $\begin{array}{l}\text { Non- } \\
\text { academic } \\
\text { teaching } \\
\text { hospitals } \\
\text { (number) }\end{array}$ & $\begin{array}{l}\text { Total } \\
\text { percentage } \\
\text { (n=35) }\end{array}$ \\
\hline $\begin{array}{l}\text { Efficiency } \\
\text { N=35 }\end{array}$ & + & 1 & 4 & 12 & $49 \%$ \\
\cline { 2 - 6 } & - & 3 & 5 & 6 & $40 \%$ \\
\cline { 2 - 6 } & $\begin{array}{l}\text { Not } \\
\text { evaluated }\end{array}$ & 1 & 1 & 2 & $11 \%$ \\
\hline \multirow{2}{*}{$\begin{array}{l}\text { Throughput } \\
\text { times } \\
\text { N=35 }\end{array}$} & + & 0 & 4 & 10 & $40 \%$ \\
\cline { 2 - 6 } & - & 4 & 5 & 6 & $43 \%$ \\
\hline $\begin{array}{l}\text { Financial } \\
\text { results } \\
\text { N=35 }\end{array}$ & + & 1 & 1 & 4 & $17 \%$ \\
\cline { 2 - 6 } & - & 1 & 6 & 5 & $31 \%$ \\
\cline { 2 - 6 } & $\begin{array}{l}\text { Not } \\
\text { evaluated }\end{array}$ & 2 & 2 & 5 & $26 \%$ \\
\hline
\end{tabular}

$+\quad=$ the goals regarding this performance aspect were achieved or exceeded

- $\quad=$ the goals regarding this performance aspect were not achieved

Table 8 shows the results per aspect of goal accomplishment per approach. The number of hospitals per approach ranges between one and 18. Due to the small number of respondents per approach, we cannot conclude that one approach is more successful than the others. Overall, about $50 \%$ of hospitals reported that they had accomplished their goals. For the most frequently prioritized approach clinical pathways in 18 hospitals - eight hospitals reported having accomplished their goals with regard to efficiency, seven those with regard to throughput times, and seven with regard to financial results. Lean management $(n=7)$ was the approach that was least often accomplished, the failures outperformed the successes on all performance aspects. 
Table 8 Results per performance aspect per prioritized approach (in numbers, $n=35$ )

\begin{tabular}{|c|c|c|c|c|c|c|c|c|c|c|}
\hline \multirow{3}{*}{$\begin{array}{l}\text { Approaches } \\
\text { for patient } \\
\text { logistics }\end{array}$} & \multirow[t]{3}{*}{$\mathbf{N}$} & \multicolumn{9}{|c|}{ Performance aspects } \\
\hline & & \multicolumn{3}{|c|}{ Efficiency } & \multicolumn{3}{|c|}{ Throughput times } & \multicolumn{3}{|c|}{ Financial results } \\
\hline & & + & - & $N E$ & + & - & $N E$ & + & - & $N E$ \\
\hline $\mathrm{CP}$ & 18 & 8 & 8 & 2 & 7 & 8 & 3 & 7 & 6 & 5 \\
\hline LM & 7 & 3 & 4 & 0 & 3 & 4 & 0 & 2 & 4 & 1 \\
\hline LSS & 6 & 3 & 3 & 0 & 3 & 2 & 1 & 3 & 1 & 2 \\
\hline BPR & 4 & 3 & 1 & 0 & 3 & 1 & 0 & 1 & 1 & 2 \\
\hline TQM & 3 & 1 & 1 & 1 & 1 & 1 & 1 & 2 & 0 & 1 \\
\hline BM & 2 & 1 & 1 & 0 & 1 & 1 & 0 & 0 & 1 & 1 \\
\hline TOC & 2 & 1 & 1 & 0 & 0 & 0 & 1 & 1 & 0 & 1 \\
\hline $\mathrm{Cl}$ & 2 & 1 & 1 & 0 & 1 & 1 & 0 & 1 & 0 & 1 \\
\hline OR & 1 & 1 & 0 & 0 & 1 & 0 & 0 & 0 & 0 & 1 \\
\hline FF & 1 & 0 & 1 & 0 & 0 & 1 & 0 & 0 & 0 & 1 \\
\hline SS & 1 & 1 & 0 & 0 & 1 & 0 & 0 & 1 & 0 & 0 \\
\hline
\end{tabular}

Between 32 and 36 hospitals provided information on their evaluation methods (see Table 9). Eighty-six percent of the hospitals performed quantitative evaluation, and $92 \%$ qualitative evaluation. Eighty-nine percent of the hospitals that performed an evaluation performed a baseline measurement, 59\% measured the results during the implementation period, and $53 \%$ performed a post-intervention measurement. Forty-six percent repeated their periodic samples and 50\% continuously measured their performance indicators. Only 14 hospitals published their results externally, four did this in a scientific journal.

Table 9 Evaluation characteristics

\begin{tabular}{|l|c|c|}
\hline Evaluation characteristics & N & Application of characteristics \\
\hline $\begin{array}{l}\text { Quantitative evaluation } \\
\text { Qualitative evaluation }\end{array}$ & 36 & $\begin{array}{l}86 \% \\
92 \%\end{array}$ \\
\hline Baseline measurement & 35 & $94 \%$ \\
\hline $\begin{array}{l}\text { Measured the results during the } \\
\text { implementation }\end{array}$ & 35 & $59 \%$ \\
\hline Post measurement & 34 & $53 \%$ \\
\hline Periodic samples & 32 & $46 \%$ \\
\hline Measured continuously & 34 & $50 \%$ \\
\hline $\begin{array}{l}\text { Publication: } \\
\text { External }\end{array}$ & 35 & $41 \%$ \\
Scientific publication & & $12 \%$ \\
\hline
\end{tabular}




\section{Discussion}

This research presents 1.) the results of a self-reported survey of the approaches and tools used in patient logistics in Dutch hospitals, 2.) the results reported for them, and 3.) the methods used to evaluate them. The overall response rate was $48 \%$, our sample containing $75 \%$ of the academic hospitals, $48 \%$ of the nonacademic teaching hospitals, and $46 \%$ of the general hospitals. The response rate is representative (53).

As $98 \%$ of the hospitals used different approaches and $26 \%$ prioritized multiple methods, most appeared not to have selected a single improvement approach. One possible reason for this is that hospitals allow various kinds of bottom-up initiatives, either because many staff groups are only familiar with specific approaches and tools, or because there is not enough convincing evidence on the effectiveness of particular approaches. Another reason may be that hospitals feel coercive, mimetic or normative pressures (54) that compel them to apply multiple approaches because proponents of these approaches claim that performance will be improved. Both explanations should be investigated in future research.

The tools most frequently used are flow charts, standardized of care pathways, waste elimination, distinction between flow charts and value, and line balancing. This may be because they do not seem to require much specific training or previous knowledge, are applicable to a wide range of settings, and belong to various improvement approaches (including CP, LM, LSS, SS and BPR). Dennis and Rodgers have shown that if an innovation - such as a tool for patient logistics - is perceived as simple, it is adopted more easily than a complex innovation $(55,56)$. This would explain the limited use of tools requiring specific operations management expertise, such as DEA analysis and the critical path method. The limited use of comparative processes - whereby inputs and outcomes could be prepared and best practices be identified - might be explained by a reluctance to collaborate with other hospitals. Similarly, the limited use of $5 \mathrm{~S}$ might be caused by the fact that it can more easily be applied to materials than to administrative processes.

Roughly, $50 \%$ of the 35 hospitals reported that they had accomplished their goals with regard to efficiency, throughput times and financial results. The explanation for this low success rate may be that hospitals do not set achievable targets and need to increase their focus on performance measurement and benchmarking. Alternatively, they may not apply the approaches properly. The reported goal 
accomplishment rate seems in contrasts with the claims made in most case studies, which suggest that considerable improvements are possible with these approaches. For references to cases see literature reviews $(9-13,16,57)$. There might thus be a publication bias towards success stories. The success rate also seems in contrast with that of Yasin et al. (17), who rated the effectiveness of approaches in US hospitals at between $68.2 \%$ and $100 \%$. Further research should explain why goals are not achieved and whether or not there are any differences between countries.

General hospitals reported a higher degree of goal accomplishment than the academic hospitals and the non-academic teaching hospitals. One explanation is that because general hospitals are smaller and less complex, it is less difficult to create an environment that supports healthcare quality improvement $(22 ; 25)$. Another reason lies in the positive association between experience with improvement approaches and the results achieved $(43,58,59)$. As Dutch general hospitals have been exposed to a competitive environment for longer, they may have been working longer or more intensively on their patient logistics. We did not include the hospital's experiences with the approaches or the extent to which they had been implemented. The sample size was too small to draw conclusions on the experience and our results were affected by the hospitals' experience with other approaches to improving patient logistics (see (59)). Both reasons for the difference between the hospital types should be examined further.

With regard to the evaluation methods, $44 \%$ of the hospitals used a post intervention measurement. Other research suggested even lower evaluation rates: $19 \%$ in a literature review on lean management and six sigma (12). As only four hospitals had published their findings scientifically, the improvement inputs covered in this study have so far produced only limited scientific evidence. This confirms our supposition that the literature does not provide a complete picture of improvement efforts and their outcomes. Although this literature bias would be overcome by the publication of more results, this might be difficult to achieve in practice, as publication might eventually reduce a hospital's competitive advantage.

Due to the low number of cases, which did not allow conclusions, we could find no leads for a relationship between specific patient logistic approaches and goal accomplishment (see Table 8). These results might also be explained by the inappropriate use of approaches or by ineffective approaches. Another possibility lies in contingency factors, which, as Sousa and Voss suggest (60), can affect the outcomes of operations management interventions. Although such factors mean that there is no universal best practice for all organizations, those affecting the 
outcomes of interventions in healthcare have been hardly studied (61). We therefore argue that, to determine which approach works best in a specific setting, further research should examine the effectiveness of the approaches and the contingency factors that apply to them.

\section{Research limitations}

While we believe that our sample is representative, it may have been subjected to respondent bias. Two hospitals that did not respond indicated that they were focusing on the introduction of an electronic patient file system and a safety management system. The non-responding hospitals may thus have reported lower use of approaches and tools.

Like Yasin et al. (17), we approached one respondent per hospital, and used selfreports. This may have led to single-source measurement bias. We feel that our selection of respondents may have led to good information as we identified the person who was responsible for the implementation of the business approach and had the most information regarding the survey. By using measurement instruments to determine the use of a specific approach or tool and its effect on a hospital's performance, future research should either increase the number of respondents per hospital or reduce the dependency on respondents' perceptions. Currently, however, very few instruments have been validated to measure the use of approaches and tools available in hospitals. There are few performance indicators, and even fewer that show the direct relationship between improvement efforts and performance. The information needed to develop such instruments can be generated by in-depth case studies that combine literal and theoretical replication (62).

\section{Conclusions}

Overall, only $50 \%$ of the hospitals indicated that these approaches had enabled them to accomplish their goals with regard to patient logistics, and that no single approach to improving patient logistics was superior to the others. Was this because management had not made specific choices, or had allowed bottom-up strategies? Or was it due to other factors? To generate the necessary understanding of which approach works best under specific circumstances, hospitals should participate in research on the selection and application of approaches, and on contingency factors and goal-setting procedures. They should also exchange positive and negative experiences on approaches, and consider 
Chapter 2

using more rigorous evaluation methods. Until better information becomes available, hospitals selecting an approach or combination of approaches will be left to rely mainly on their own experience and judgment. 


\section{Reference List}

1. Anderson GF, Frogner BK, Reinhardt UE: Health spending in OECD countries in 2004: an update. Health Affairs 2007, 26:1481.

2. Custers T, Arah OA, Klazinga NS: Is there a business case for quality in The Netherlands? A critical analysis of the recent reforms of the health care system. Health Policy 2007, 82:226-239.

3. Sanazaro PJ: Quality Assessment and Quality Assurance in Medical Care. Annual Review of Public Health 1980, 1:37-68.

4. Laffel G, Blumenthal D: The case for using industrial quality management science in health care organizations. The Textbook of Total Quality in Healthcare 1993, 262:2869-2873.

5. Committee on Quality of Health Care in America: Crossing the Quality Chasm: A New Health System for the 21st Century. Washington DC: Institute of Medicine; 2001.

6. Shortell SM, O'Brien JL, Carman JM, Foster RW, Hughes EF, Boerstler H, O'Connor EJ: Assessing the impact of continuous quality improvement / total quality management: concept versus implementation. Health Services Research 1995, $30: 377$.

7. Alexander JA, Weiner BJ, Shortell SM, Baker LC, Becker MP: The role of organizational infrastructure in implementation of hospitals' quality improvement. Hospital Topics 2006, 84:11-21.

8. Slack N, Chambers S, Johnston R: Operations Management. Financial Times/Prentice Hall; 2007.

9. Mosel D, Gift B: Collaborative benchmarking in health care. Joint Commission Journal on Quality Improvement 1994, 20:239.

10. de Koning $\mathrm{H}$, Verver JPS, van den Heuvel J, Bisgaard S, Does R: Lean six sigma in healthcare. Journal for Healthcare Quality 2006, 28:4.

11. Brailsford SC, Harper PR, Patel B, Pitt M: An analysis of the academic literature on simulation and modelling in health care. Journal of Simulation 2009, 3:130-140.

12. Langabeer JR, DelliFraine JL, Heineke J, Abbass I: Implementation of Lean and Six Sigma quality initiatives in hospitals: A goal theoretic perspective. Operations Management Research 2009, 2:13-27.

13. Van Lent WAM, de Beer R, van Harten W: International benchmarking of specialty hospitals. A series of case studies on comprehensive cancer centres. BMC Health Services Research 2010, 10:253.

14. Naveh E, Stern Z: How quality improvement programs can affect general hospital performance. International Journal of Health Care Quality Assurance 2005, 18:249270.

15. Van Lent WAM, Vanberkel PT, van Harten WH. A review on the relation between simulation and improvement. Submitted to BMC Medical Informatics and Decision Making 2011.

16. Elkhuizen SG, Limburg M, Bakker PJM, Klazinga NS: Evidence-based reengineering: re-engineering the evidence: A systematic review of the literature on business process redesign (BPR) in hospital care. International Journal of Health Care Quality Assurance 2006, 19:477-499.

17. Yasin MM, Zimmerer LW, Miller P, Zimmerer TW: An empirical investigation of the effectiveness of contemporary managerial philosophies in a hospital operational setting. International Journal of Health Care Quality Assurance 2002, 15:268-276.

18. Sluijs EM, Wagner C: Progress in the implementation of Quality Management in Dutch health care: 1995-2000. International Journal for Quality in Health Care 2003, 15:223. 
19. Alexander JA, Weiner BJ, Griffith J: Quality improvement and hospital financial performance. Journal of Organizational Behavior 2006, 27:1003-1029.

20. Õvretveit J: Total quality management in European healthcare. International Journal of Health Care Quality Assurance 2000, 13:74-80.

21. John S Oakland: Total Quality Management. London: Butterworth-Heinemann Ltd; 1989.

22. Hammer M, Champy J: Business process re-engineering. London: Nicholas Brealey 1993.

23. Research Into Global Healthcare Tools (RIGHT): Modelling and Simulation Techniques for Healthcare Decision Making: A Selection framework. Cambridge, UK: Engineering Design Centre, University of Cambridge; 2008.

24. Van Oostrum JM: Applying mathematical Models to Surgical Planning. PhD Thesis. Erasmus Research Institute of Management - ERIM PhD Series in Research in Management; 2009.

25. Morse PM, Kimball GE: Methods of Operations Research. New York: Dover Publications; 2003.

26. Mazzocato $\mathrm{P}$, Savage $\mathrm{C}$, Brommels $\mathrm{M}$, Aronsson $\mathrm{H}$, Thor J: Lean thinking in healthcare: a realist review of the literature. Quality and Safety in Health Care 2010.

27. Benders J, Santbergen S: 'Lean' in Nederlandse ziekenhuizen: Een overzicht van eerste ervaringen. M\&O, Tijdschrift voor Management en Organisatie 2007, 61:36-47.

28. Shah R, Ward PT: Defining and developing measures of lean production. Journal of Operations Management 2007, 25:785-805.

29. van den Heuvel J, Does RJMM, Bogers A, Berg M: Implementing six sigma in the Netherlands. Joint Commission Journal on Quality and Patient Safety 2006, 32:393399.

30. Frings GW, Grant L: Who moved my sigma? Effective implementation of the Six Sigma methodology to hospitals. Quality and Reliability Engineering International 2005, 21:311-328.

31. Heuvel JVD, Does RJMM, Koning HD: Lean Six Sigma in a hospital. International Journal of Six Sigma and Competitive Advantage 2006, 2:377-388.

32. George ML: Lean six sigma for service: How to use lean speed and six sigma quality to improve services and transactions. McGraw-Hill Professional; 2003.

33. Breen AM, Burton-Houle T, Aron DC: Applying the theory of constraints in health care: part 1-the philosophy. Quality Management in Healthcare 2002, 10:40.

34. Womack DE, Flowers S: Improving system performance: a case study in the application of the theory of constraints. Journal of healthcare management/American College of Healthcare Executives 44:397.

35. Borghuis TL, Bos WJW, Geers AB, Steenhoff AMT, Muis G, de Wit M, Andrea G: Vertragingen te lijf. Medisch Contact 2007.

36. Paree MJM, Borghuis-Lub TL: Klinische paden en TOC: samen beter. Medisch Contact 2010.

37. Goldratt Eliyahu M: Theory of Constraints. North-River Press, Croton-on-Hudson, NY 1990.

38. Campbell H, Hotchkiss R, Bradshaw N, Porteous M: Integrated care pathways. British Medical Journal 1998, 316:133.

39. Sermeus W, Vanhaecht K, Vleugels A: The Belgian-Dutch clinical pathway network. Journal of Integrated Care Pathways 2001, 5:10-14.

40. Vanhaecht K, Bollmann M, Bower K, Gallagher C, Gardini A, Guezo J, Jansen U, Massoud R, Moody K, Sermeus W: Prevalence and use of clinical pathways in 23 countries-an international survey by the European Pathway Association. Journal of Integrated Care Pathways 2006, 10:28.

41. Camp RC: Benchmarking: The Search for Industry Best Practices that Lead to Superior Performance. Milwaukee,(USA) 1989. 
42. Borghans I, Heijink R, Kool T, Lagoe RJ, Westert GP: Benchmarking and reducing length of stay in Dutch hospitals. BMC Health Services Research 2008, 8:220.

43. Duckers M, Makai P, Vos L, Groenewegen P, Wagner C: Longitudinal analysis on the development of hospital quality management systems in the Netherlands. International Journal for Quality in Health Care 2009, 21:330.

44. Schouten LMT, Hulscher MEJL, Everdingen JJE, Huijsman R, Grol RPTM: Evidence for the impact of quality improvement collaboratives: systematic review. British Medical Journal 2008, 336:1491.

45. Schouten LMT, Hulscher MEJL, Akkermans R, van Everdingen JJE, Grol RPTM, Huijsman R: Factors that influence the stroke care team's effectiveness in reducing the length of hospital stay. Stroke 2008, 39:2515.

46. Õvretveit J, Bate P, Cleary P, Cretin S, Gustafson D, McInnes K, McLeod H, Molfenter T, Plsek P, Robert G: Quality collaboratives: lessons from research. Quality and Safety in Health Care 2002, 11:345.

47. Herzlinger R: What Works: Health Care Focused Factories. Market-Driven Health Care 1997.

48. Herzlinger R: Retooling healthcare. 'Focused factory' model can help build a patientfriendly, service-driven system. Modern healthcare 1997, 27:96.

49. Bredenhoff $E$, van Lent WAM, van Harten WH: Exploring types of focused factories in hospital care: a multiple case study. BMC Health Services Research 2010, 10:154.

50. Pieters A, van Oirschot C, Akkermans $\mathrm{H}$ : No cure for all evils: Dutch obstetric care and limits to the applicability of the focused factory concept in health care.

International Journal of Operations \& Production Management 2010, 30:1112-1139.

51. Skinner W: The focused factory. Harvard Business Review 1974.

52. Dutch Hospital Data. Kengetallen 2009.

[http://www.dutchhospitaldata.nl/Publicaties/Kengetallen.php] Last accessed: 11-82011.

53. Frohlich MT: Techniques for improving response rates in OM survey research. Journal of Operations Management 2002, 20:53-62.

54. Powell WW, DiMaggio PJ, University of Chicago: The new institutionalism in organizational analysis. University of Chicago Press Chicago, IL; 1991.

55. Denis JL, Hqbert Y, Langley A, Lozeau D, Trottier LH: Explaining diffusion patterns for complex health care innovations. Health care management review 2002, 27:60.

56. Rogers EM: Diffusion of innovations. Free Pr; 1995.

57. Vest JR, Gamm LD: A critical review of the research literature on Six Sigma, Lean and StuderGroup's Hardwiring Excellence in the United States: the need to demonstrate and communicate the effectiveness of transformation strategies in healthcare. Implementation Science 2009, 4:35.

58. Deming WE: Out of the Crisis. The MIT Press; 2000.

59. Olson JR, Belohlav JA, Cook LS, Hays JM: Examining quality improvement programs: the case of Minnesota hospitals. Health Services Research 2008, 43:17871806.

60. Sousa R, Voss CA: Contingency research in operations management practices. Journal of Operations Management 2008, 26:697-713.

61. Alexander JA, Hearld LR: The Science of Quality Improvement Implementation. Medical Care 2010, 48:000.

62. Voss C: Case Research in Operations Management. In Researching Operations Management. Edited by Edited by Karlsson C. Taylor \& Francis; 2009:162-195. 


\title{
3 Exploring Types of Focused Factories in Hospital Care: A Multiple Case Study
}

\author{
E. Bredenhoff \\ W.A.M van Lent \\ W.H. van Harten
}

Published in BMC Health Services Research 2010, 10(1):154 


\section{Abstract}

\section{Background}

Focusing on specific treatments or diseases is proposed as a way to increase the efficiency of hospital care. The definition of 'focus' or 'focused factory', however, lacks clarity. Examples in health care literature relate to very different organizations. Our aim was to explore the application of the focused factory concept in hospital care, including an indication of its performance, resulting in a conceptual framework that can be helpful in further identifying different types of focused factories. Thus contributing to the understanding of the diversity of examples found in the literature.

\section{Methods}

We conducted a cross-case comparison of four multiple-case studies into hospital care. To cover a broad array of focus, different specialty fields were selected. Each study investigated the organizational context, the degree of focus, and the operational performance. Focus was measured using an instrument translated from industry. Data were collected using both qualitative and quantitative methods and included site visits. A descriptive analysis was performed at the case study and cross-case studies level.

\section{Results}

The operational performance per specialty field varied considerably, even when cases showed comparable degrees of focus. Cross-case comparison showed three focus domains. The product domain considered specialty based focused factories that treated patients for a single-specialty, but did not pursue a specific strategy nor adapted work designs or layouts. The process domain considered delivery based focused factories that treated multiple groups of patients and often pursued strategies to improve efficiency and timeliness and adapted work designs and physical layouts to minimize delays. The product-process domain considered procedure based focused factories that treated a single well-defined group of patients offering one type of treatment. The strategic focusing decisions and the design of the care delivery system appeared especially important for delivery and procedure based focused factories.

\section{Conclusions}

Focus in hospital care relates to limitations on the patient group treated and the range of services offered. Based on these two dimensions, we identified three types of focused factories: specialty based, delivery based, and procedure based. Focus could lead to better operational performance, but only when clear strategic focusing decisions are made. 


\section{Background}

Hospital care is under pressure to increase quality and decrease cost (1). As a result, hospitals look into the opportunities offered by concepts from business. One of these concepts is the so-called focused factory concept. Implementing 'focused factories', aimed at specific treatments or diseases, is proposed as a way to increase the efficiency of hospital care $(2,3)$.

The focused factory was introduced in manufacturing as: "a plant established to focus the entire manufacturing system on a limited, concise, manageable set of products, technologies, volumes, and markets precisely defined by the company's strategy, its technology, and its economics" $(4,5)$. Focusing aims to prevent that distinct products are produced in one and the same manufacturing system, as this will lead to trade-offs that hinder the fulfilment of product requirements and deteriorate the competitiveness of the organization (4-8). In services, focus requires organizations to segment their markets and develop focused delivery systems for each segment $(9,10)$. The objective of this segmentation is to identify relatively homogeneous groups of customers. Often, this reveals smaller, more predictable, manageable patterns in demand (9).

Both in manufacturing and services, different types of focus are identified. The literature describes focus on products (product lines or markets), processes (internal capabilities), and competitive priorities (sometimes described as 'order winners') $(6,11-13)$. We summarized the characteristics used to differentiate between different foci in Table 1. These characteristics show two focus dimensions: one relates to variety in product or customer requirements, the other to variety in the processes or technologies used in the delivery system. 
Table 1 - Characteristics in literature to differentiate between types of focus

\begin{tabular}{|c|c|}
\hline Product characteristics & Process characteristics \\
\hline $\begin{array}{l}\text { Product variety }(6,11) \text { : } \\
\text { The number and volumes of products or parts } \\
\text { produced in the manufacturing system (product } \\
\text { life cycle: evolving from low-volume one of a kind } \\
\text { products towards high volume standardized } \\
\text { products) }\end{array}$ & $\begin{array}{l}\text { Process variety }(6,11) \text { : } \\
\text { The number of technologies used in the } \\
\text { manufacturing system (process life cycle: evolving } \\
\text { from job-shop flexible systems towards continuous } \\
\text { standardized systems) }\end{array}$ \\
\hline $\begin{array}{l}\text { Customer intimacy (10): } \\
\text { The degree to which the customer interacts with } \\
\text { the service, combined with the degree to which } \\
\text { the service is customized for the consumer }\end{array}$ & $\begin{array}{l}\text { Labour intensity }(10) \text { : } \\
\text { The ratio of labour costs incurred to the value of } \\
\text { the plant and equipment }\end{array}$ \\
\hline $\begin{array}{l}\text { Customer influence }(40) \text { : } \\
\text { The degree to which the customer influences the } \\
\text { service by his presence, participation or } \\
\text { interaction with the system }\end{array}$ & $\begin{array}{l}\text { Number of routes in the delivery system (42): } \\
\text { The number of unique pathways (routes) } \\
\text { customers can take as they move through the } \\
\text { service system during delivery of the service. }\end{array}$ \\
\hline $\begin{array}{l}\text { Customization }(40,41) \text { : } \\
\text { The degree of customization (discretion) allowed } \\
\text { for in the service delivery system }\end{array}$ & \\
\hline $\begin{array}{l}\text { Uniqueness of services (42): } \\
\text { The degree of discretion, freedom, and decision } \\
\text { making power in selecting their service combined } \\
\text { with the degree of repeatability of the service }\end{array}$ & \\
\hline $\begin{array}{l}\text { Volume of customers ( } 41) \text { : } \\
\text { The number of customers processed per business } \\
\text { unit per period }\end{array}$ & \\
\hline
\end{tabular}

The literature on focus in hospital care, however, describes focus as a diffuse mix of treatment characteristics, patient characteristics, specialty characteristics, and organizational aspects (2,14-16). Examples of focused factories consider very different types of organizations, such as cancer clinics (2), trauma centres (15), specialty hospitals $(3,14,17)$, and ambulatory surgery centres $(14,16,18)$. The definition of 'focus' or 'focused factory' in hospital care lacks clarity. This is problematic in two ways.

First, the diversity of examples and diffuse mix of characteristics shows that the focused factory concept in hospital care is not well understood. Probably the closest thing to a definition of focus in hospital care is offered by Herzlinger, who describes focused factories as (multidisciplinary) organizations based on common objectives (e.g. the treatment of specific patient groups) (2). Herzlinger, in effect, calls for a change from professional-centred to patient-centred (and processcentred) organizations. This is in contrast with the traditional view of hospital organizations as professional bureaucracies, characterized by extensive division of labour and organizational units that are based on specialties $(19,20)$. However, 
creating these (multidisciplinary) organizational units might solve some of the problems associated with the traditional hospital organization, such as; coordination problems, a work-around culture, lack of team-work, and high numbers of handovers (21-23). Although Herzlinger appears to suggest that these focused organizations should be independent, Schneider et al. (17) argues there is no reason why hospitals could not create these kinds of organizational units themselves. Requirements on the organizational context, e.g. the operations strategy and design of the care delivery system, remain unclear.

Second, evaluating the efficiency of focused factories becomes difficult when there is so much diversity. Conclusions on the operational performance of focused factories are mixed. Several case studies on specialty hospitals and centres for ambulatory surgery report improved efficiencies, higher patient satisfaction, comparable or decreased mortality rates and less adverse outcomes on the hospital level $(16,18,24,25)$. Other studies found higher re-admission rates for more complex patients $(26,27)$, or reported incidents of specialty hospitals calling in emergency care from a general hospital $(28,29)$. A recent cost comparison of physician-owned specialty hospitals and full-service providers in three US states showed that orthopaedic and surgical specialty hospitals had significantly higher levels of cost inefficiency (30). In the econometric literature, a large number of hospital efficiency studies are described (see (31) for an overview). Most of these studies show inefficiencies, but offer little theoretical explanation for the efficiency differences.

A recent study into the efficiency of hospitals and their departments in the Netherlands (32), suggests these efficiency differences result from the way hospitals are organized. To understand the diversity in examples of focused factories in hospital care, further studies are required. Similar to manufacturing and services, hospital care delivery systems are influenced by varieties. For example: varieties in; case mix; the experience and capacities of medical doctors, specialty groups, and other (nursing) staff; and the availability of infrastructure and medical technologies $(19,33,34)$. In response to these varieties, it seems likely that, in hospital care, different types of focused factories may exist. These might differentiate depending on the degree of customization, the variation in services needed, and possible other characteristics that relate to varieties in hospital care provision.

This paper aims to explore the application of the focused factory concept in hospital care, including indications of its performance, resulting in a conceptual framework that can be helpful in further identifying different types of focused 
factories. We performed multiple case studies in four specialty fields, investigating the degrees of focus, the organizational context, and the operational performance. We used the two dimensions of focus from business literature to group cases with similar degrees of focus. Thus, we hope to contribute to the understanding of the characteristics of the care delivery system and operations strategy for different types of focus.

\section{Methods}

\section{Study design and selection}

The study consisted of a cross-case comparison of four, separately performed, multiple-case studies in different specialty fields. Within each specialty field, we performed a comparative multiple case study with embedded units of analysis (35). This means that within each single case (e.g. a hospital) attention was given to a subunit or subunits (the actual focused factories).

The fields for the case studies were selected to correspond with- and reflect the variety of focus examples in the literature $(2,3,14,17)$. In order to cover a broad array of focus in hospital care, we used the characteristics differentiating between different foci in the literature (see Table 1) as guidelines. There were obvious differences in the volumes, variety in case mix, and procedures offered between the studied fields of: medical oncology, orthopaedics and total knee implants, cataract care, and low-complex elective surgery.

Using the characteristics and identified fields, we sampled conveniently, primarily selecting hospitals in the Netherlands, but included international good practice cases on medical oncology and cataract care due to the limited number of cases in the Netherlands. We aimed for at least two hospitals and three units of analysis per specialty field. An overview of the cases and units of analysis included is presented in Table 2. 
Table 2 - Overview of the included cases and units of analysis, per specialty field

\begin{tabular}{|c|c|c|c|c|c|}
\hline \multicolumn{6}{|c|}{ Medical Oncology } \\
\hline Case & Unit & Region & Treatment places & & \\
\hline 1 & 1 & EU & 30 & & \\
\hline 2 & 2 & EU & 13 & & \\
\hline \multirow[t]{4}{*}{3} & 3 & US & 24 & & \\
\hline & 4 & US & 29 & & \\
\hline & 5 & US & 48 & & \\
\hline & 6 & US & 7 & & \\
\hline \multicolumn{6}{|c|}{ Orthopaedics and Total Knee Implants } \\
\hline Case & Unit & Region & Inpatient beds & & \\
\hline \multirow[t]{2}{*}{4} & 7 & $\mathrm{NL}$ & 42 & & \\
\hline & 9 & $\mathrm{NL}$ & 6 & & \\
\hline \multirow[t]{2}{*}{5} & 8 & $\mathrm{NL}$ & 78 & & \\
\hline & 10 & $\mathrm{NL}$ & & & \\
\hline \multicolumn{6}{|c|}{ Cataract Care } \\
\hline Case & Unit & Region & $\begin{array}{l}\text { No. of annual } \\
\text { cataract surgeries }\end{array}$ & & \\
\hline 6 & 11 & $\mathrm{NL}$ & 2630 & & \\
\hline 7 & 12 & UK & 6309 & & \\
\hline 8 & 13 & US & 7366 & & \\
\hline \multicolumn{6}{|c|}{ Low-complex Elective surgery } \\
\hline Case & Unit & Region & Operating rooms & Day care beds & Inpatient beds \\
\hline 9 & 14 & $\mathrm{NL}$ & 2 & 18 & - \\
\hline 10 & 15 & $\mathrm{NL}$ & 4 & 24 & 32 \\
\hline 11 & 16 & $\mathrm{NL}$ & 4 & 26 & 16 \\
\hline \multirow[t]{2}{*}{12} & 17 & $\mathrm{NL}$ & 2 & & 37 \\
\hline & 18 & $\mathrm{NL}$ & 2 & 10 & - \\
\hline
\end{tabular}

\section{Measures}

We investigated the organizational context by looking at the operations strategy (related to focusing), including the implications for the design of the care delivery system. This design, the organizational structure, is believed to influence organizational outcomes (36-38). We studied the use of standardized procedures, the use of dedicated (physical) layouts (38), the applied planning routines, and the team composition (37). The degree of focus was investigated using a measurement instrument translated from industry. In the literature, only two attempts to measure degrees of focus were found.

Mukherjee et al. (7) used a quantitative approach, calculating focus scores for one plant, based on volume and variety of products and parts. Pesch and Schroeder (39) used a mixed approach, calculating degree of focus scores for multiple plants, 
based on a questionnaire investigating variety in products, volumes and competitive priorities. Since the approach of Pesch and Schroeder (39) had been tested in multiple organizations, we chose to adapt their measurement instrument to the specialty fields investigated. Using the customization, the uniqueness of services, and the number of identifiable processes in the delivery system (see table 1), we adapted the instrument to measure two axes of focus. One axis measured the product focus, investigating the volume and variety in patients treated. The other axis measured the process focus, investigating the volume and variety in specialties involved and services offered. The measurement instrument is described in Appendix B.

The operational performance was investigated per specialty field, by looking at process indicators; such as utilization, lead times, and the costs of the resources used. The indicators chosen varied per specialty field, depending on the availability of data.

\section{Data collection}

Data were collected using both qualitative and quantitative methods. Quantitative data were retrieved from annual reports and, when necessary, provided by the organization. Qualitative data were collected through interviews and observations during site visits. Each study was performed by the authors, or as a master thesis project closely supervised by the authors. Case study protocols per specialty field were used.

\section{Analysis}

First, we discussed the similarities and differences between the individual (sub) units' organizational context, degrees of focus, and operational performance per specialty field. We analysed whether the organizational context and degrees of focus could explain differences in operational performance.

Next, we grouped the (sub) units of all four multiple case studies into a framework, based on the degrees of product and process focus. In this cross-case comparison we discussed similarities (and differences) in the organizational context between units in the same group. Replication logic (35) was used to define types of focused factories in hospital care. 


\section{Results}

Medical oncology: chemotherapy day units in the EU and US

We studied the chemotherapy day units (CDU) of three comprehensive cancer centres in the EU and US. An earlier pilot study, comparing complete cancer centres, lead us to conclude this lower level of analysis was required to explain differences. In total, 6 CDUs were studied.

The results (see Table 3) show that all centres applied dedicated layouts and standardized procedures for treatments. Planning routines, however, differed, and were based on: the total daily workload, the availability of a bed and nurse, and the arrival time and treatment duration. Only one case had an explicit strategic objective to maximize the utilization of beds and nurses, which was influenced by limited floor capacity and budget constraints.

Although all studied cases scored similar degrees of focus, the operational performance differed considerably. Both the number of patient visits per bed and the number of visits per employee showed differences up to $56 \%$. Although we were unable to correct in detail for differences in opening hours and nurse staffing between cases, we are confident considerable differences will remain when corrected. These were unlikely to be explained by the minor differences in focus. Planning procedures and staff scheduling rather seemed to explain the variation in operational performance. Higher scores of focus did not correspond with higher performance. The fit between the strategic choices on focus on patient or product categories and the design of the service delivery system appears to cause different operational performance. 
Table 3: Medical Oncology

\begin{tabular}{|c|c|c|c|c|c|c|}
\hline Unit & 1 & 2 & 3 & 4 & 5 & 6 \\
\hline \multicolumn{7}{|l|}{ Context } \\
\hline $\begin{array}{l}\text { Focusing } \\
\text { decisions/ } \\
\text { operations } \\
\text { strategy }\end{array}$ & $\begin{array}{l}\text { Focus on } \\
\text { patient } \\
\text { centeredness } \\
\text { and access/ } \\
\text { waiting times }\end{array}$ & $\begin{array}{l}\text { Maximizing } \\
\text { utilization / } \\
\text { access times }\end{array}$ & \multicolumn{4}{|c|}{$\begin{array}{l}\text { Focus on patients' safety and prevention of claims/ } \\
\text { long opening hours to allow patients to come after } \\
\text { work/ short access times. }\end{array}$} \\
\hline $\begin{array}{l}\text { Standardized } \\
\text { procedures }\end{array}$ & Yes & Yes & Yes & Yes & Yes & Yes \\
\hline $\begin{array}{l}\text { Dedicated lay- } \\
\text { out }\end{array}$ & $\begin{array}{l}\text { Yes, only } \\
\text { suitable for } \\
\text { medication } \\
\text { related } \\
\text { treatments }\end{array}$ & $\begin{array}{l}\text { Yes, only } \\
\text { suitable for } \\
\text { medication } \\
\text { related } \\
\text { treatments }\end{array}$ & $\begin{array}{l}\text { Yes, only } \\
\text { suitable } \\
\text { for } \\
\text { medication } \\
\text { related } \\
\text { treatments }\end{array}$ & $\begin{array}{l}\text { Yes, } \\
\text { special air } \\
\text { ventilation } \\
\text { etc for } \\
\text { bone } \\
\text { marrow } \\
\text { patients }\end{array}$ & $\begin{array}{l}\text { Yes, only } \\
\text { suitable } \\
\text { for } \\
\text { medication } \\
\text { related } \\
\text { treatments }\end{array}$ & $\begin{array}{l}\text { Yes, only } \\
\text { suitable } \\
\text { for } \\
\text { medication } \\
\text { related } \\
\text { treatments }\end{array}$ \\
\hline \multicolumn{7}{|l|}{ Planning routine: } \\
\hline $\begin{array}{l}1 \text { Occupancy } \\
\text { times of beds }\end{array}$ & $\begin{array}{l}\text { No, } \\
\text { calculated } \\
\text { workload it } \\
\text { based on this } \\
\text { information }\end{array}$ & Yes & \multicolumn{4}{|l|}{ Yes } \\
\hline $\begin{array}{l}2 \text { Insight into } \\
\text { available } \\
\text { beds at a } \\
\text { certain } \\
\text { moment }\end{array}$ & No & Yes & \multicolumn{4}{|l|}{ No } \\
\hline 3 Workload & $\begin{array}{l}\text { Yes, total } \\
\text { work-load of } \\
\text { the day is } \\
\text { calculated, } \\
\text { not workload } \\
\text { at a specific } \\
\text { time }\end{array}$ & $\begin{array}{l}\text { Manually } \\
\text { checked by } \\
\text { head nurse. }\end{array}$ & \multicolumn{4}{|c|}{ Done manually } \\
\hline $\begin{array}{l}4 \text { Planning is } \\
\text { visualized }\end{array}$ & No & Yes & \multicolumn{4}{|l|}{ Yes } \\
\hline $\begin{array}{l}5 \text { Relative } \\
\text { importance } \\
\text { of } \\
\text { experience } \\
\text { for the } \\
\text { planning }\end{array}$ & High & Moderate/low & \multicolumn{4}{|l|}{ High } \\
\hline $\begin{array}{l}\text { Team } \\
\text { composition }\end{array}$ & Stable & $\begin{array}{l}\text { Rotational } \\
\text { shift with } \\
\text { other } \\
\text { department(s) }\end{array}$ & \multicolumn{4}{|l|}{ Stable } \\
\hline
\end{tabular}


Table 3 Second part

\begin{tabular}{|l|l|l|l|l|l|l|}
\hline $\begin{array}{l}\text { Degrees of } \\
\text { focus }\end{array}$ & $\mathbf{1}$ & $\mathbf{2}$ & $\mathbf{3}$ & $\mathbf{4}$ & $\mathbf{5}$ & $\mathbf{6}$ \\
\hline Product focus & $85 \%$ & $85 \%$ & $78 \%$ & $85 \%$ & $85 \%$ & $100 \%$ \\
\hline Process focus & $78 \%$ & $78 \%$ & $83 \%$ & $83 \%$ & $83 \%$ & $83 \%$ \\
\hline Operational performance & 100 & 77 & & & \\
\hline $\begin{array}{l}\text { Indexed } \\
\text { average } \\
\text { number of } \\
\text { patients treated } \\
\text { per bed per } \\
\text { month (not } \\
\text { corrected for } \\
\text { differences in } \\
\text { opening hours) }\end{array}$ & 44 & & & & & \\
\hline $\begin{array}{l}\text { Indexed } \\
\text { average } \\
\text { number of } \\
\text { patient visits } \\
\text { per month per } \\
\text { total CDU staff }\end{array}$ & 58 & 100 & 44 & & & \\
\hline
\end{tabular}

Indexed $=$ the best performing CDU received a score of 100, the other CDU received a relative score compared to the best performing CDU. Table partly based on (43)

Orthopaedics care and total knee implants: comparing an orthopaedics centre and a general hospital in the Netherlands

We studied the orthopaedics departments and (joint care-) total knee implants groups of a general hospital $(\mathrm{GH})$ and an orthopaedics centre $(\mathrm{OC})$ in the Netherlands. The results (see Table 4) show that only the general hospital pursued efficiency improvements as a strategic objective, and developed a joint-care program (unit 8) directed at total hip and total knee implants. Work designs and the layout were adapted, for instance to create a 'living room' that enabled group wise treatment and rehabilitation. Planning routines differed per medical doctor and, remarkably, joint-care patients were not always operated sequentially. The orthopaedics centre performed all activities on one location. It had not developed any special programs as a strategic choice, and left initiatives in this regard to its medical doctors. Planning routines used fixed times for surgeries. Various procedures however, were operated upon in a random sequence, suggesting that minimizing changeover times was not an explicit objective. Both cases showed frequent changes in team composition.

The degrees of focus indicate we encountered two types of focused factories. One focused on the treatment of orthopaedics patients in general, and one on the 
treatment of patients for knee implants. Although the degrees of focus for knee implants groups were higher, some efficiency parameters scored lower (GH: utilization of wards, OC: length of stay) and the comparison of overhead costs favoured the general hospital. Only the knee implant patients treated in the jointcare program of the general hospital showed shorter lengths of stay. The differences in the average duration of orthopaedics surgery and the length of stay for orthopaedics patients are probably caused by the lower complexity of the case mix of the general hospital. The higher volume of knee surgeries in the orthopaedics centre probably explains why their average duration of knee surgery is shorter. The limited number of cases does not allow firm conclusions. We could thus not establish a unidirectional relation between focus and efficiency. 
Table 4: Orthopaedics care and total knee implants

\begin{tabular}{|c|c|c|c|c|}
\hline Unit & 7 & 8 & 9 & 10 \\
\hline \multicolumn{5}{|c|}{ Organizational context } \\
\hline $\begin{array}{l}\text { Focusing decisions/ } \\
\text { operations strategy }\end{array}$ & $\begin{array}{l}\text { No clear } \\
\text { strategy }\end{array}$ & $\begin{array}{l}\text { Pursuing } \\
\text { efficiency for } \\
\text { total knee } \\
\text { implants }\end{array}$ & No clear strategy & $\begin{array}{l}\text { No clear strategy for } \\
\text { total knee implants }\end{array}$ \\
\hline $\begin{array}{l}\text { Standardized } \\
\text { procedures }\end{array}$ & No & Yes & No & No \\
\hline Dedicated lay-out & $\begin{array}{l}\text { Layout was not } \\
\text { dedicated } \\
\text { Diagnostics, } \\
\text { preoperative } \\
\text { screening and } \\
\text { surgery took } \\
\text { place on } \\
\text { different } \\
\text { locations }\end{array}$ & $\begin{array}{l}\text { Layout adapted } \\
\text { to create 'living } \\
\text { room' that } \\
\text { enabled group } \\
\text { wise treatment } \\
\text { and rehabilitation } \\
\text { of knee implants } \\
\text { patients } \\
\text { Diagnostics, } \\
\text { preoperative } \\
\text { screening and } \\
\text { surgery took } \\
\text { place on different } \\
\text { locations }\end{array}$ & $\begin{array}{l}\text { Layout was not } \\
\text { (really) dedicated } \\
\text { Diagnostics, } \\
\text { preoperative } \\
\text { screening and } \\
\text { surgery took } \\
\text { place on one } \\
\text { location }\end{array}$ & $\begin{array}{l}\text { Layout was not } \\
\text { (really) dedicated } \\
\text { Diagnostics, } \\
\text { preoperative } \\
\text { screening and } \\
\text { surgery took place } \\
\text { on one location }\end{array}$ \\
\hline Planning routine & $\begin{array}{l}\text { Different } \\
\text { planning } \\
\text { routines per } \\
\text { MD }\end{array}$ & $\begin{array}{l}\text { Different routines } \\
\text { per MD. Joint- } \\
\text { care patients not } \\
\text { always operated } \\
\text { sequentially }\end{array}$ & $\begin{array}{l}\text { Standardized } \\
\text { planning } \\
\text { routines, using } \\
\text { fixed surgical } \\
\text { times } \\
\text { Sequence of } \\
\text { surgeries was } \\
\text { 'random' ignoring } \\
\text { negative } \\
\text { changeover } \\
\text { effects }\end{array}$ & $\begin{array}{l}\text { Standardized } \\
\text { planning routines, } \\
\text { using fixed surgical } \\
\text { times } \\
\text { Sequence of } \\
\text { surgeries was } \\
\text { 'random' ignoring } \\
\text { negative } \\
\text { changeover effects }\end{array}$ \\
\hline Team composition & $\begin{array}{l}\text { Frequent } \\
\text { changes in } \\
\text { team } \\
\text { composition }\end{array}$ & $\begin{array}{l}\text { Frequent } \\
\text { changes in team } \\
\text { composition }\end{array}$ & $\begin{array}{l}\text { Frequent } \\
\text { changes in team } \\
\text { composition }\end{array}$ & $\begin{array}{l}\text { Frequent changes in } \\
\text { team composition }\end{array}$ \\
\hline \multicolumn{5}{|l|}{ Degrees of focus } \\
\hline Product focus & $47 \%$ & $75 \%$ & $47 \%$ & $56 \%$ \\
\hline Process focus & $56 \%$ & $75 \%$ & $56 \%$ & $56 \%$ \\
\hline \multicolumn{5}{|c|}{ Operational performance } \\
\hline $\begin{array}{l}\text { Average duration of } \\
\text { surgery (min) }\end{array}$ & 48 & 110 & 90 & 90 \\
\hline $\begin{array}{l}\text { Preparation time for } \\
\text { knee surgery (min) }\end{array}$ & & 30 & & 40 \\
\hline $\begin{array}{l}\text { Average Length of } \\
\text { stay }\end{array}$ & 5,6 & 5,0 & 5,9 & 6,9 \\
\hline Utilization of ward & $78 \%$ & & $88 \%$ & \\
\hline $\begin{array}{l}\text { Overhead cost per } \\
\text { discharged patient } \\
(€)\end{array}$ & 107 & & 290 & \\
\hline
\end{tabular}


Cataract care: cataract clinics at eye hospitals in the Netherlands, United Kingdom and United States

We studied the cataract care of three eye hospitals, located in the Netherlands (case study 11), the United Kingdom (case study 12), and United States (case study 13). The results (see Table 5) show that two cases aimed at efficient patient flows and short waiting times. Both cases created a dedicated cataract clinic to realize efficient care delivery and adapted their work designs to offer diagnostics and preoperative assessments on the same day. These cases showed extensive division of labour allocating specific tasks to nursing staff, while in the other case medical doctors performed most tasks. This last case seemed especially geared towards preventing liability and, as a consequence, performed redundant preoperative assessments and reviews.

Although all cases had similar degrees of focus, the highest efficiency seemed to be found in the UK (12), followed by NL (11) and lastly the US (13). As is supported by the results on the number of visits per treatment episode and the use of day surgery operating rooms over more expensive general operating rooms. The operational performance seemed most influenced by the different operational strategies pursued, aiming for: efficiency (11), timeliness (12), and medical liability (13). These strategies reflected the characteristics of the national reimbursements systems. 
Table 5: Cataract care

\begin{tabular}{|c|c|c|c|}
\hline Unit & 11 & 12 & 13 \\
\hline \multicolumn{4}{|c|}{ Organizational context } \\
\hline $\begin{array}{l}\text { Focusing } \\
\text { decisions/ } \\
\text { operations } \\
\text { strategy }\end{array}$ & $\begin{array}{l}\text { Strategy pursuing } \\
\text { efficiency }\end{array}$ & $\begin{array}{l}\text { Strategy to reduce the } \\
\text { no. of visits in order to } \\
\text { realize lead time } \leq 18 \\
\text { weeks }\end{array}$ & $\begin{array}{l}\text { Strategy pursuing open } \\
\text { access, prevent medical } \\
\text { liability }\end{array}$ \\
\hline $\begin{array}{l}\text { Standardized } \\
\text { procedures }\end{array}$ & Yes & Yes & Yes \\
\hline Dedicated lay-out & $\begin{array}{l}\text { Cataract clinic with } \\
\text { dedicated day-surgery } \\
\text { operating rooms }\end{array}$ & $\begin{array}{l}\text { Cataract clinic with } \\
\text { dedicated day- surgery } \\
\text { operating rooms }\end{array}$ & $\begin{array}{l}\text { Clinic applied general } \\
\text { operating rooms }\end{array}$ \\
\hline Planning routine & $\begin{array}{l}\text { One stop diagnostics } \\
\text { and scheduling of } \\
\text { surgery } \\
\text { Preoperative } \\
\text { assessments according } \\
\text { to open access model }\end{array}$ & $\begin{array}{l}\text { One stop diagnosis, } \\
\text { preoperative } \\
\text { assessment and } \\
\text { scheduling of surgery }\end{array}$ & $\begin{array}{l}\text { One stop diagnosis, } \\
\text { preoperative assessment } \\
\text { and scheduling of surgery } \\
\text { for clinic patients } \\
\text { Most diagnostics ( } 91 \% \text { of } \\
\text { the patients) take place } \\
\text { outside the hospital at the } \\
\text { practice of affiliated } \\
\text { ophthalmologists }\end{array}$ \\
\hline $\begin{array}{l}\text { Team } \\
\text { composition }\end{array}$ & $\begin{array}{l}\text { Extensive division of } \\
\text { labour allocating tasks } \\
\text { to nurses }\end{array}$ & $\begin{array}{l}\text { Extensive division of } \\
\text { labour allocating tasks } \\
\text { to nurses }\end{array}$ & MDs perform most tasks \\
\hline \multicolumn{4}{|l|}{ Degrees of focus } \\
\hline Product focus & $94 \%$ & $94 \%$ & $94 \%$ \\
\hline Process focus & $84 \%$ & $84 \%$ & $84 \%$ \\
\hline \multicolumn{4}{|c|}{ Operational performance } \\
\hline Visits/ patient & 3.2 & 3.0 & 3.6 \\
\hline Lead time (days) & 91.0 & 109.2 & 15.0 \\
\hline $\begin{array}{l}\text { - Access time to } \\
\text { outpatient clinic }\end{array}$ & 25.0 & 31.5 & 0.0 \\
\hline $\begin{array}{l}\text { - Waiting time for } \\
\text { surgery }\end{array}$ & 66.0 & 77.7 & 15.0 \\
\hline
\end{tabular}

The organizational outcomes for unit 13 exclude diagnostics (as these take place outside the hospital). If these outside diagnostics were taken into account, the degree of focus score on process focus could deteriorate to $78 \%$ or $72 \%$ 
Low-complex elective surgery: hospital-owned centres for low-complex elective surgery in the Netherlands

We studied five hospital-owned centres for low-complex elective surgery in four teaching hospitals in the Netherlands. We investigated the perceived advantages of their care delivery systems. The results (see Table 6) show that most hospitals applied strategies aimed at improving efficiency and timeliness of care. This resulted in the (re)development of smaller hospitals as centres for elective surgery offering low-complex surgery in day care, short stay, or both. All cases performed one-stop shop preoperative assessments, and only admitted patients with low-risk physical conditions. Physical layouts were adapted to reduce transportation times and delays. Planning routines differed; sometimes a separate planning department made the schedule, sometimes the medical specialty itself. In most cases, staff worked in both the elective surgery centre and the general operating room.

The degrees of product focus were similar for all cases, while two had higher scores on process focus, probably related to reduced variety, as they only performed elective surgery in day care. All centres for elective surgery treated a less complex case mix (compared to the general hospital) and performed surgical procedures with shorter average duration and lower variation in duration. The Herfindahl-Hirschmann Index $(\mathrm{HHI})$, calculated based on the surgical procedure codes and their volumes, showed reductions in variety by two to four times compared to the hospital, depending on the specialty. In one case (16) a medical doctor even reported a shorter average duration for one type of surgical procedure, compared to the same procedure performed on the general OR (thought to be caused by the experience of staff). Data were, however, insufficient to compare the exact utilization of the operating rooms, as each case used different definitions to collect data. Although obtaining comparable data proved difficult, observations showed that strategic decisions on the introduction of focus actually led to more efficient processes (cases 14, 16 and 18). We observed short turnover times on the OR and wards. Furthermore, all studied centres used less expensive OR resources compared to a general hospital, as only a limited set of surgical procedures was performed. 


\begin{tabular}{|c|c|c|c|c|c|}
\hline$\stackrel{\infty}{\leftarrow}$ & 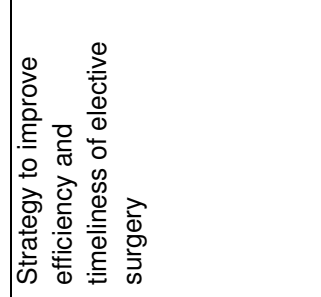 & 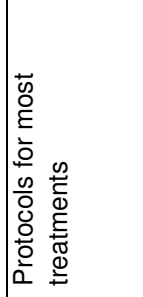 & 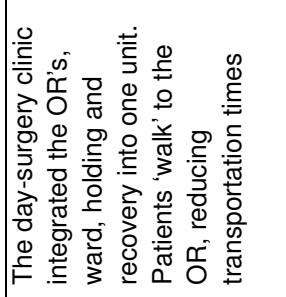 & 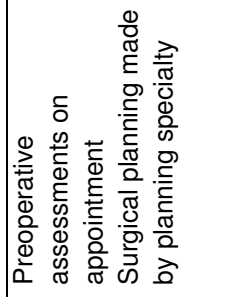 & 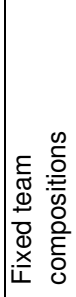 \\
\hline 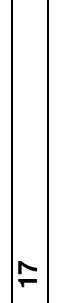 & 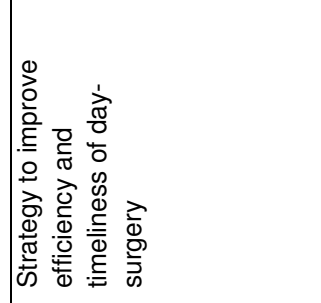 & 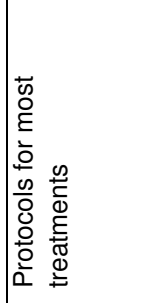 & 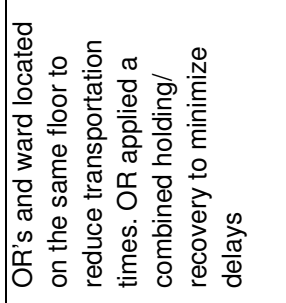 & 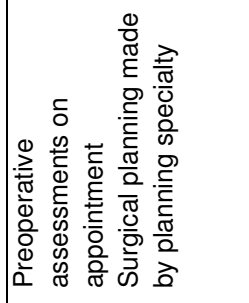 & 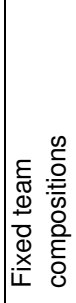 \\
\hline 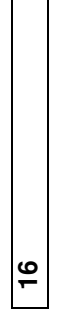 & 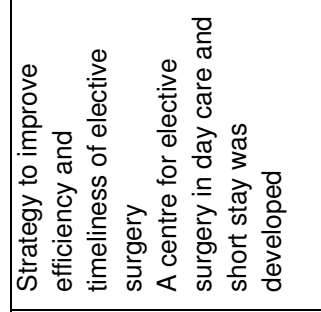 & 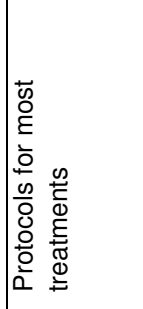 & 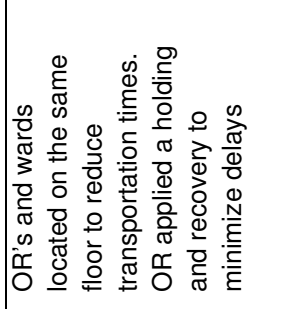 & 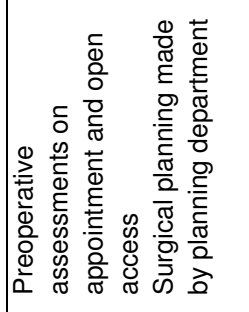 & 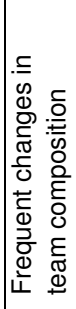 \\
\hline$\stackrel{2}{\leftarrow}$ & 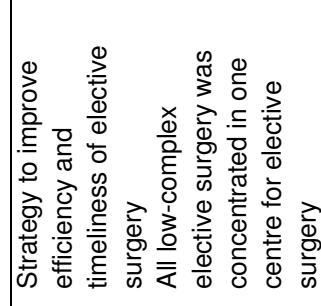 & 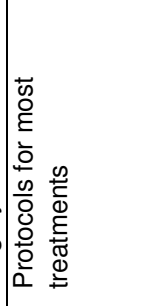 & 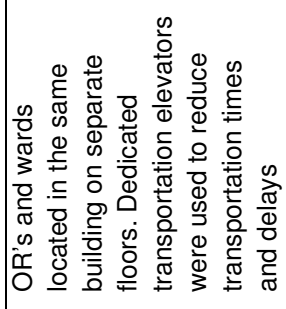 & 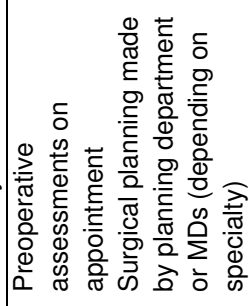 & 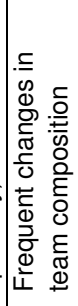 \\
\hline 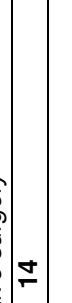 & 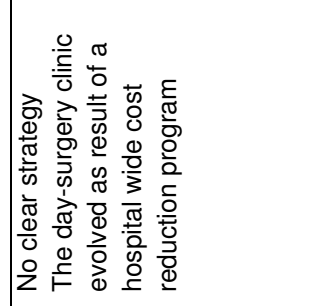 & 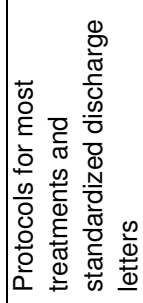 & 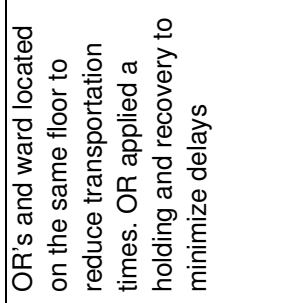 & 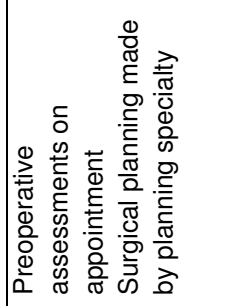 & 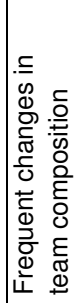 \\
\hline$=\frac{\pi}{\frac{\pi}{2}}$ & 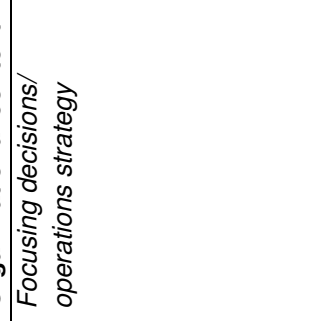 & 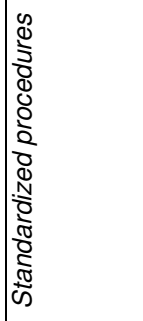 & 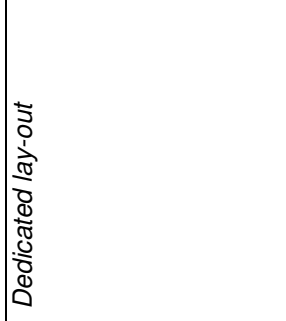 & 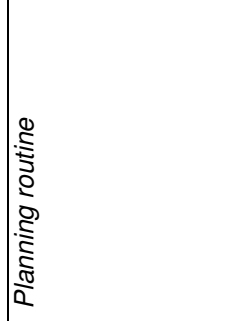 & 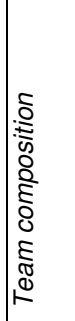 \\
\hline
\end{tabular}




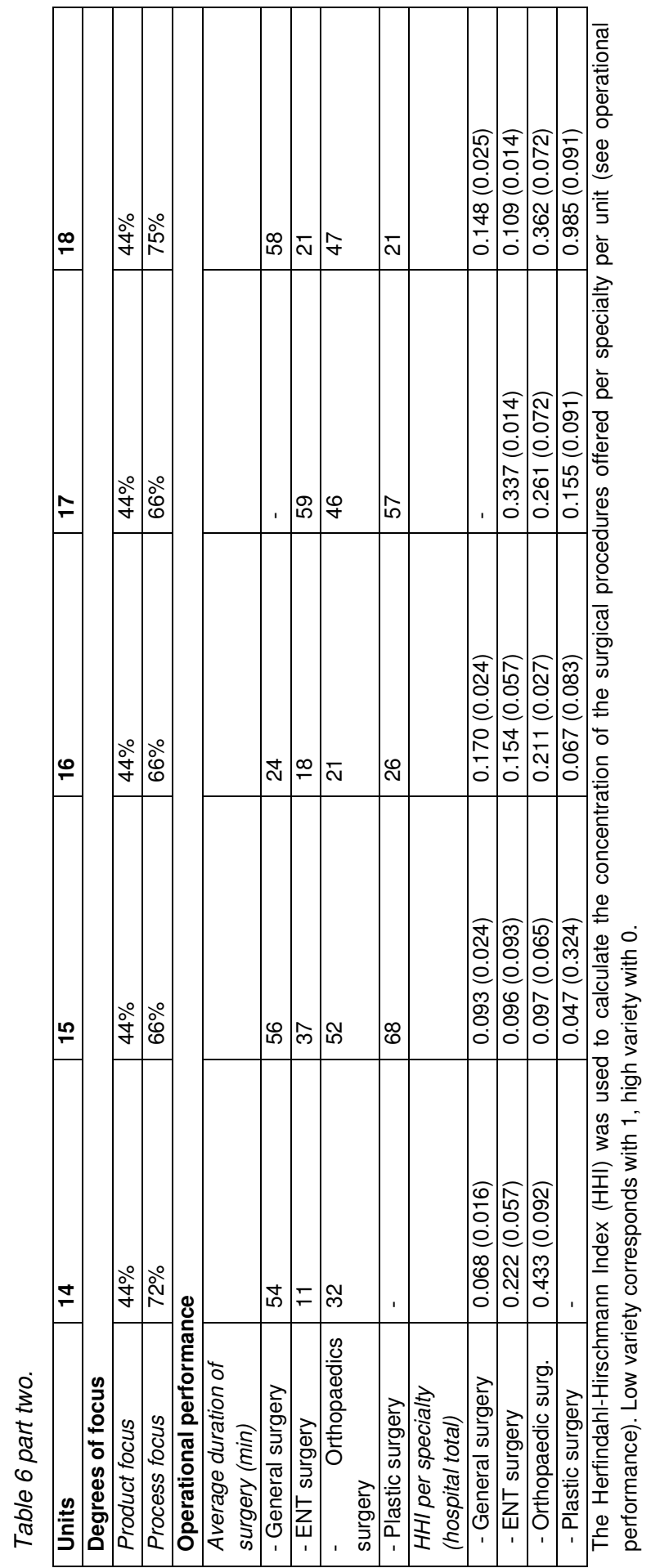


Cross-case analysis: towards a framework of focused factories

The results of the four specialty fields did not show a clear relationship between the degrees of focus and the organizational context. Operational performance seemed to depend on focus, strategic choices, and the related organizational context. Units that combined a high degree of focus with clear strategic objectives aimed at efficiency or timeliness, often showed higher degrees of efficiency or timeliness. When focus scores were similar, variations in efficiency seemed to be related to differences in operating procedures or operations strategy.

Combining high degrees of focus with a well-defined operations strategy and work designs, thus, appeared more important in realizing higher efficiencies than the degree of focus alone. It is of importance, to gain insights in the organizational characteristics of different types of focused factories.

We positioned the 18 (sub)units of the four specialty fields into a focus matrix, based on their degrees of focus on product and process (see Figure 1). Units in the field of orthopaedics care and knee implants showed high degrees of focus on products, with the units for knee implants also showing higher degrees of focus on processes. Units in the field of elective surgery showed high degrees of focus on the process axis, but lower degrees of focus on products. The units in the fields of medical oncology and cataract care showed high degrees of focus on both products and process axes. 
Figure 1 Position of the units in the focus matrix.

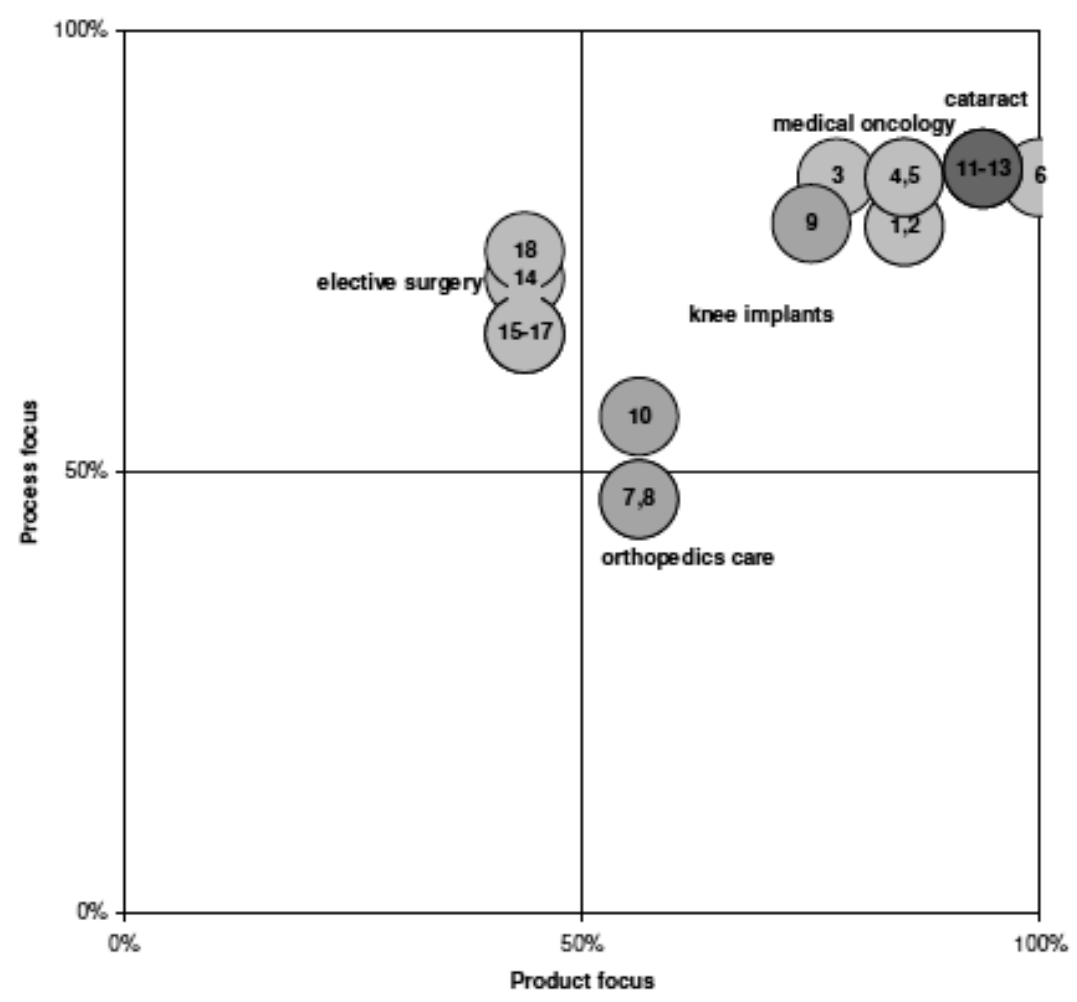

Based on the degrees of focus on product and process, the positions of the units are depicted in the focus matrix. Four specialty fields were studied. Medical oncology (yellow) considered two EU units (1, 2) and four US cases $(4-6)$. Orthopaedics care and knee implants considered the orthopaedic departments $(7,9)$ and knee implants $(8,10)$ of a general hospital and orthopaedics centre in the Netherlands. Cataract care (green) considered one NL (11), one UK (12), and one US (13) case. Elective surgery (blue) considered five centres for low-complex elective surgery in the Netherlands (14 18).

This focus matrix can be used as a framework for identifying different types of focused factories. We propose three domains of focus, related to high scores on the separate axis: the product domain, the process domain, and the productprocess domain. For each domain we compared the similarities (dissimilarities) in the organizational context of all units in the same domain (see Table 7 on the next page). 
Table 7: Cross case comparison, per focus domain of the focus matrix

\begin{tabular}{|c|c|c|c|}
\hline Focus Domain & Product domain & Process domain & Product-Process domain \\
\hline \multicolumn{4}{|c|}{ Degrees of focus } \\
\hline Product focus & $50-100$ & $0-50$ & $50-100$ \\
\hline Process focus & $0-50$ & $50-100$ & $50-100$ \\
\hline Units & 7,9 & $14,15,16,17,18$ & $1,2,3,4,5,6,8,10,11,12,13$ \\
\hline \multicolumn{4}{|c|}{ Organizational context } \\
\hline $\begin{array}{l}\text { Operations } \\
\text { strategy } \\
\text { (focusing } \\
\text { decisions) }\end{array}$ & $\begin{array}{l}\text { No clear operations } \\
\text { strategy }\end{array}$ & $\begin{array}{l}\text { Strategy aimed at high } \\
\text { efficiency and short lead } \\
\text { times }\end{array}$ & $\begin{array}{l}\text { Strategy aimed at efficiency } \\
\text { and/ or timeliness }\end{array}$ \\
\hline $\begin{array}{l}\text { Standardized } \\
\text { procedures }\end{array}$ & No & Yes & Yes \\
\hline $\begin{array}{l}\text { Dedicated lay- } \\
\text { out }\end{array}$ & $\begin{array}{l}\text { Activities grouped in } \\
\text { one location }\end{array}$ & $\begin{array}{l}\text { Layouts adapted to } \\
\text { minimize distances and } \\
\text { delays }\end{array}$ & $\begin{array}{l}\text { Layouts adapted to enable } \\
\text { more efficient ways of } \\
\text { treating patients (e.g. group } \\
\text { rehabilitation). } \\
\text { Distances are minimized }\end{array}$ \\
\hline $\begin{array}{l}\text { Planning } \\
\text { routines }\end{array}$ & $\begin{array}{l}\text { Planning routines } \\
\text { differed per MD }\end{array}$ & $\begin{array}{l}\text { Most units showed one stop } \\
\text { shop arrangements for } \\
\text { diagnostics and } \\
\text { preoperative assessments } \\
\text { Planning routines were both } \\
\text { centralized and } \\
\text { decentralized }\end{array}$ & More or less standardized \\
\hline $\begin{array}{l}\text { Team } \\
\text { composition }\end{array}$ & $\begin{array}{l}\text { Frequent changes in } \\
\text { team composition }\end{array}$ & $\begin{array}{l}\text { Most units showed frequent } \\
\text { changes in team } \\
\text { composition. Two units } \\
\text { showed stable team } \\
\text { compositions }\end{array}$ & $\begin{array}{l}\text { Frequent changes in team } \\
\text { composition }\end{array}$ \\
\hline
\end{tabular}

The product domain: specialty based focused factories

Both orthopaedic departments are found in the product domain. These organizations implemented a high degree of focus by limiting the types of patients treated, related to their specialty. Neither pursued a specific operations strategy. Work designs and physical layouts of both cases were not adapted and served more or less a general purpose. As these organizations treat a single-specialty, they can be defined as specialty based focused factories.

The process domain: delivery based focused factories

All centres for low-complex elective surgery are found in the process domain. These organizations aimed at efficient delivery of specific types of treatments: low complex, low-risk elective surgical procedures offered by multiple specialties. The 
operations strategies aimed for high efficiencies and short lead times. Processes were standardized and the physical layouts adapted to minimize distances. The care delivery systems were characterized by standardization and predictability. Two highly focused cases worked with stable team-compositions. As these organizations treat patients based on delivery characteristics, they can be defined as delivery based focused factories.

\section{The product-process domain: procedure based focused factories}

The chemotherapy day units, centres for cataract care, and the knee implants (joincare) units are found in the product-process domain. These organizations treated a single, specific, group of patients and offered one single (type of) treatment or a single surgical procedure. The majority of the cases pursued strategies aimed at efficiency or timeliness, and consequentially adapted work designs and the physical layouts. Work processes were standardized, describing well-defined tasks. Physical layouts enabled more efficient ways of treating patients (such as group rehabilitation) or minimized physical distances. Planning routines differed, but were more or less standardized. Surprisingly, most organizations changed teamcompositions frequently. As these organizations treat a single group of patients for a single (type of) treatment, they can be defined as procedure based focused factories.

\section{Discussion}

Although the majority of units we studied were procedure based focused factories, we believe that the proposed distinction between different types of focus leads to a better understanding of the relations between focus, operational choices, and the operational performance of an organization. The fit between strategic focusing decisions and the design of the care delivery system appears especially important for delivery and procedure based focused factories.

\section{Strengths and limitations of this study, suggestions for further research}

To our knowledge, our analysis, including the development of a measurement instrument, was the first attempt to measure the degree of hospital focus in a structured way. Our approach makes it possible to study and compare types and degrees of focus in different specialty fields. 
The focus measurement instrument has some drawbacks. Differences between the fields and national healthcare systems make it necessary to adapt the measurement instrument to each specialty field, for instance through defining the ICD code limits. Thus, the validity and consistency of the instrument needs further study, especially as we could only include 18 cases. Looking at the difference in focus scores, further studies into the scale and cut-off points that distinguish between different domains of focused factories are needed.

The structured case analysis, provided insights in the relations between the degrees of focus, the design of care delivery systems, and the operational performance. We concluded that the applied operations strategy and resulting adaptations to the care delivery system within focused factories explain the differences in performance. This fit between strategic focusing decisions and care delivery design, the operations strategy, appears vital. Although the degree of focus seemed less important in predicting higher efficiencies or timeliness, a higher degree of focus indicates reduced variety. This variety reduction might offer organizations the opportunity to develop a well-focused operations strategy. Further studies into the role of the operations strategy in focused factories are required. Developing a measure of the degree of fit that can be added to the scoring system seems worthwhile.

The proposed framework provides insights in the main characteristics of three types of focused factories. It offers a way for identifying similar types of focused factories, based on product and process foci. We cannot exclude the possibility that not all types of focused factories in hospital care are covered. For instance, diagnostic departments, which might require different focus choices and operational choices, were not included in our research. Further studies in other fields are therefore required to validate the framework.

A recent study of Schneider et al. (17), covering 70 cases, describes factors that are associated with the economic success of specialty hospitals, such as clinical efficiency and procedural economies of scale. They conclude that there is yet no conclusive material supporting either the advantages or disadvantages of this type of hospital and suggest that the same type of benefits might be attainable for units within larger hospitals. Schneider et al. (17) underline the need for a theory or conceptual framework to identify areas of specialization that would lead to benefits for consumers and payers. This aligns very well with our plea for further research into types and benefits of focus factories in hospital care. 


\section{Conclusions}

Our study shows that focus in hospital care relates to limitations on the patient group treated and the services or treatments offered. Four multiple case studies in the fields of medical oncology, orthopaedics, cataract care, and elective surgery showed different scores of focus on product and process. Process focus appeared more often to be related to strategic choices considering the organizational structure and the design of the care delivery system. Product focus appeared to be related to limiting the patient groups treated, having only implicit consequences for the organizational structure. Based on the differences in these degrees of focus, we distinguish three main types of focused factories: specialty based, delivery based and procedure based focused factories.

The results suggest that focus can lead to higher productivity and utilization, but only when clear strategic focusing decisions are made. The applied strategic choices and their consequences for the design of the care delivery system seem more important in explaining differences in operational performance than focus scores as such. This might be one of the reasons why studies into the effects of focused factories, including the econometric literature, show such mixed results.

\section{Competing interests}

No conflicting interests can be indicated. $\mathrm{WvH}$ is member of the executive board of one of the involved chemotherapy day units studied in the field of medical oncology.

\section{Authors' contributions}

EB co-supervised three case studies, performed one case study, (re)wrote the first draft of the paper, and revised the text. WvL performed one of the case studies and contributed to the text. WvH supervised three case-studies and contributed to- and revised the text. All authors read and approved the final manuscript.

\section{Acknowledgements}

Each study was performed by the authors, or as a Master thesis project closely supervised by the authors. We would like to thank L.J. Admiraal and L.M. Kop for their contributions to this research. 


\section{References}

1. Kohn LT, Corrigan JM, Donaldson MS: To Err Is Human. Washington, D.C.: National Academy Press; 2000.

2. Herzlinger RE: Market Drive Healthcare, Who wins, who loses in the transformation of Americas largest service industry. Reading: Addisson-Wesley; 1997.

3. Meyer H: Focused Factories. Hospital \& Health Networks 1998, 72(7):24-30.

4. Skinner W: The Focused Factory. Harvard Business Review 1974, 52(3):113-121.

5. Skinner W: Manufacturing: the formidable competitive weapon. New York: Wiley; 1985.

6. Hayes $\mathrm{RH}$, Pisano GP, Upton D, Wheelwright SC: Operations, Strategy, and Technology - Pursuing the Competitive Edge. John Wiley \& Sons; 2005.

7. Mukherjee A, Mitchell W, Talbot FB: The impact of new manufacturing requirements on production line activity and quality of a focused factory. Journal of Operations Management 2000, 18:139-168.

8. Ruwe DM, Skinner W: Reviving a Rust Belt factory. Harvard Business Review 1987, 65(3):70-77.

9. Davidow WH, Uttal B: Service Companies: Focus or Falter. Harvard Business Review 1989, 67:75-85. (July/August)

10. Schmenner RW: How Can Service Businesses Survive and Prosper? Sloan Management Review 1986, 27(3):21-32.

11. Hayes $\mathrm{RH}$, Wheelwright SC: Restoring our Competitive Edge, Competing Through Manufacturing. John Wiley \& Sons; 1984.

12. Hill TJ, Duke-Woolley RMG: Progression or regression in facilities focus. Strategic Management Journal 1983, 4(1):109-121.

13. Hill T: Manufacturing Strategy Text and Cases. Boston: Irwin; 1989.

14. Casalino LP, Devers KJ, Brester LR: Focused Factories? Physician-Owned Specialty Facilities. Health Affairs 2003, 22(6):56-67.

15. Hyer NL, Wemmerlöv U, Morris JAJ: Performance analysis of a focused hospital unit: The case of an integrated trauma center. Journal of Operations Management 2009, 27(3):185-266.

16. McLaughlin CP, Yang S, van Dierdonck R: Professional Service Organizations and Focus. Management Science 1995, 41(7):1185-1193.

17. Schneider JE, Miller TR, Ohsfeldt RL, Morrisey MA, Zelner BA, Li P: The Economics of Specialty Hospitals. Medical Care Research and Review 2008, 65(5):531-553.

18. Yang S, McLaughlin CP, Vaughan RW, Aluise JJ: Factory Focus in Hospital owned Ambulatory Surgery. International Journal of Service Industry Management 1992, $3(4): 63-75$.

19. Georgopoulos BS, Mann FC: The Community General Hospital. New York: Macmillan; 1962.

20. Mintzberg H: Towards Healthier Hospitals. Health Care Management Review 1997, 22(1):9-18.

21. Glouberman S, Mintzberg H: Managing the Care of Health and the Cure of Disease Part 1: Differentiation. Health Care Management Review 2001, 26(1):56-69.

22. Glouberman $\mathrm{S}$, Mintzberg $\mathrm{H}$ : Managing the Care of Health and the Cure of Disease Part II: Integration. Health Care Management Review 2001, 26(1):70-84.

23. Spear J: Fixing Health Care from the inside, Today. Harvard Business Review 2005, 83(9):78-91.

24. Cram P, Vaughan-Sarrazin MS, Wolf B, Katz JN, Rosenthal GE: A comparison of total hip and knee replacements in specialty and general hospitals. The Journal of Bone and Joint Surgery 2007, 89:1675.

25. Cram P, Rosenthal GE, Vaughan-Sarrazin MS: Cardiac revascularization in specialty and general hospitals. New England Journal of Medicine 2005, 352(14):1454-1462. 
26. Leavitt MO: Study of Physician-owned Specialty Hospitals Required in Section 507(c)(2) of the Medicare Prescription Drug, Improvement, and Modernization Act of 2003. Edited by: Services CfMaM. Baltimore: US Department of Health and Human Service; 2005.

27. Greenwald L, Cromwell J, Adamache W, Bernard S, Drozd E, Root E: Specialty versus community general hospitals: referrals, quality, and community benefits. Health Affairs 2006, 25(1):106-118.

28. Abelson R: Some hospitals call 911 to save their patients. New York Times: New York; 2007.

29. Zigmond J: CMS probe sought. Death sparks specialty hospital queries. Modern Healthcare 2006, 36(8):7.

30. Carey K, Burgess JF, Young GJ: Specialty and Full-Service Hospitals: A Comparative Cost Analysis. Health Services Research 2008, 43(5):1869-1887.

31. Hollingsworth B: Non-Parametric and Parametric Applications Measuring Efficiency in Health Care. Health Care Management Science 2003, 6(4):203-218.

32. Ludwig M, van Merode F, Groot W: Principal agent relationships and the efficiency of hospitals. European Journal of Health Economics 2009.

33. Flood AB, Scott WR: Hospital Structure and Performance. Baltimore: The John Hopkins University Press; 1987.

34. Perrow C: Hospitals: Technology, Structure, and Goals. In Handbook of organizations Edited by: March J. Chicago: Rand McNally; 1965.

35. Yin RK: Case Study Research: design and methods. Thousands Oaks California: Sage Publications; 2002.

36. Donabedian A: Evaluating the Quality of Medical Care. The Millbank Quarterly 1966, 44(3):166-203.

37. Campbell SM, Roland MO, Buetow SA: Defining quality of care. Social Science \& Medicine 2000, 51(11):1611-1625.

38. Waring JJ: Towards an integrated organisational framework of hospital performance. Research paper series - Aston Business School Research Institute 2000.

39. Pesch MJ, Schroeder RG: Measuring Factory Focus: An Emperical Study. Production and Operations Management 1996, 5(3):234-254.

40. Kellog DL, Nie W: A framework for strategic service management. Journal of Operations Management 1995, 13:323-337.

41. Silvestro R: Positioning services along the volume-variety diagonal: The contingencies of service design, control and improvement. International Journal of Operations \& Production Management 1999, 19(4):399-420.

42. Collier DA, Meyer SM: A service positioning matrix. International Journal of Operations \& Production Management 1998, 18(12):1223-1244.

43. Van Lent WAM, Goedbloed N, Van Harten WH: Improving the efficiency of a chemotherapy day unit: Applying a business approach to oncology. European Journal of Cancer 2009, 45:800-806. 


\title{
4 International Benchmarking of Specialty Hospitals. A Series of Case Studies on Comprehensive Cancer Centres
}

\author{
W.A.M. van Lent \\ R.D. de Beer \\ W.H. van Harten
}

Published in BMC Health Services Research 2010, 10(1), 253 


\section{Abstract}

\section{Background}

Benchmarking is one of the methods used in business that is applied to hospitals to improve the management of their operations. International comparison between hospitals can explain performance differences. As there is a trend towards specialization of hospitals, this study examines the benchmarking process and the success factors of benchmarking in international specialized cancer centres.

\section{Methods}

Three independent international benchmarking studies on operations management in cancer centres were conducted. The first study included three comprehensive cancer centres (CCC), three chemotherapy day units (CDU) were involved in the second study and four radiotherapy departments were included in the final study. Per multiple case study a research protocol was used to structure the benchmarking process. After reviewing the multiple case studies, the resulting description was used to study the research objectives.

Results

We adapted and evaluated existing benchmarking processes through formalizing stakeholder involvement and verifying the comparability of the partners. We also devised a framework to structure the indicators to produce a coherent indicator set and better improvement suggestions. Evaluating the feasibility of benchmarking as a tool to improve hospital processes lead to mixed results. Case study 1 resulted in general recommendations for the organizations involved. In case study 2, the combination of benchmarking and lean management led in one CDU to a $24 \%$ increase in bed utilization and a $12 \%$ increase in productivity. Three radiotherapy departments of case study 3, were considering implementing the recommendations.

Additionally, success factors, such as a well-defined and small project scope, partner selection based on clear criteria, stakeholder involvement, simple and wellstructured indicators, analysis of both the process and its results and, adapt the identified better working methods to the own setting, were found.

\section{Conclusions}

The improved benchmarking process and the success factors can produce relevant input to improve the operations management of specialty hospitals. 


\section{Background}

Society is struggling with the challenge of cost containment in health care; costs are expected to grow considerably, mainly due to population ageing and the introduction of new technologies. Additionally, the workforce required to deliver the health care services is showing a relative decline. This has created growing interest in the performance of health services and the practices leading to excellent performance.

Research on operations management (OM) studies the production and delivery of products and services (1). In order to improve their efficiency, hospitals are introducing OM practices, like benchmarking. Benchmarking is defined as "the search for- and implementation of best practices" (2), it originated in the manufacturing industry and is now widely applied in healthcare. Mosel and Gift provide the following definition for healthcare: "... benchmarking is the continual and collaborative discipline of measuring and comparing the results of key work processes with those of the best performers. It is learning how to adapt these best practices to achieve breakthrough process improvements and build healthier communities" (3).

The literature presents numerous benchmarking processes $(4,5)$. Spendolini $(5)$ compared 24 benchmarking processes and found four common characteristics in all of them, see Figure 1. Most benchmarking processes originated in manufacturing industries; therefore it is uncertain whether they are suitable for application to hospitals. Hospital services may be described as professional bureaucracies with characteristics like multiple stakeholders and possibly conflicting professional and business objectives. Van Hoorn et al. (6) described a benchmarking process for healthcare, which is illustrated in Figure 1. This process (6) stressed the importance of creating project support and emphasized the need to assess the comparability of the organizations and the involvement of stakeholders in the development of indicators.

Health services research (HSR) applied benchmarking mainly to identify best practices for national health systems and treatments. The WHO World Health Report (7) concluded that although health status between countries was comparable, healthcare costs differed considerably. Nevertheless, the "knowledge on the determinants of the health system performance, as distinct from understanding health status, remains very limited." (7) This conclusion underlines the possibility in understanding international practices as an instrument to improve 
healthcare performance. International benchmarking helps to explain for instance efficiency differences in hospitals and it supports hospitals to improve their processes.

Although international benchmarking on operations management may improve hospital processes, research on this subject is limited. It seems that so far most attention is given to the comparison of healthcare systems on a national level and to the development of indicators. The importance of indicator development is highlighted by Groene et al. (8) who found 11 national indicator development projects in a systematic review.

This focus on indicators has also been adopted by healthcare agencies, like the National Health Service (NHS) in the UK, the Joint Commission on Accreditation of Healthcare Organizations (JCAHO) in the USA, and for-profit service providers. Under the term benchmarking, these organizations use indicators to publish hospital performance rankings, assuming that they foster competition and lead to the dissemination of best practices (9). However, most rankings do not provide thorough insight into the organizational practices that led to the measured performance although this insight is required to improve healthcare processes, as they are often based on readily available administrative data sets (9).

We conclude that benchmarking as a tool to improve operations management in hospitals is not well described and possibly not well developed.

\section{Specialty hospitals and benchmarking}

In order to become more efficient, healthcare is also showing a trend towards specialization of hospitals (or their units). Schneider et al. (10) described specialty hospitals as hospitals "that treat patients with specific medical conditions or those in need of specific medical or surgical procedures." The number of specialty hospitals is increasing (10-12). Porter, Herzlinger and Christensen (13-15) suggested that specialization improves the performance, because it results in a better organization of processes, improved patient satisfaction, more cost-effective treatments and better outcomes. Most research involving specialty hospitals concentrated on the differences with general hospitals (10) whereas identifying optimal practices, especially regarding operations management, was seldom the topic of research.

Because specialty hospitals represent a trend and the opinions about the added value are divided, more insight into the benchmarking process in specialty 
hospitals could be useful to study differences in organization and performance and the identification of optimal work procedures.

Benchmarking of operations management in specialty hospitals has not been frequently examined. By the end of 2009, we could find only 23 papers in PubMed about operations management in specialty hospitals, 6 of them concerning cancer centres. About half of the 23 papers turned out to be a mismatch with the research topic. Most of the relevant papers appeared to be non-scientific, mentioned just a few outcomes, and emphasized the experiences of the project members. Only four publications reported on a competitive benchmark for specialty hospitals, but none described benchmarking in an international setting, nor did they focus on the benchmarking process or the success factors.

\section{Research questions}

We conclude that international benchmarking as part of an approach to improve performance in specialty hospitals, has not been the subject of thorough research. Therefore, we address the following research questions:

1. What is the most suitable process for benchmarking operations management in international comprehensive cancer centres or departments (benchmarking process) to improve hospitals?

2. What are the success factors for international benchmarking in comprehensive cancer centres (success factors)?

\section{Methods}

\section{Study design}

International benchmarking with the objective to identify OM improvements in specialty hospitals is examined on the basis of three independent multiple case studies in comprehensive cancer centres. We used multiple case studies, because they are suitable for exploratory investigations and allow in-depth research. Each multiple case study consisted of international comprehensive cancer centres (CCC) or departments within a CCC, as these may be representative for specialty hospitals operating in an internationally competitive environment. A comprehensive cancer centre means a (partly) tertiary hospital specializing in the treatment of oncology patients, which is also involved in education and translational research. 
Each multiple case study concerned a different hospital level: total hospital level, unit level and department level. Multiple case study 1 was limited to the comparison of operations management within CCCs. Three CCC's were included. In study 2, a small project scope was defined to enable to go through the complete benchmarking process, including the translation of more optimal working procedures and the evaluation of the implemented changes. Three chemotherapy day units (CDUs) were the cases for this study. In study 3, the scope was widened to a department, but the study was limited to the delivery of recommendations to the involved organizations. This study especially evaluated the involvement of internal stakeholders and the indicator development process. Radiotherapy departments were the cases of this study.

\section{Case selection}

The purpose of the case studies was an international comparison with well-known, similar organizations to identify better working methods in operations management in specialty hospitals. The selected cases had to match the research objectives (16). Since scarcely any objective data on best practices for OM in (specialty) hospitals were available, it was impossible to select cases based on performance. Therefore, convenient sampling was the most obvious way to obtain meaningful results.

Together with the stakeholders of the initiating centre, the researchers developed inclusion criteria to verify to organizational comparability. Table 1 summarizes the three multiple case studies and their inclusion criteria. Patient characteristics were not verified in advance, since the mission and strategy of the comprehensive cancer centres suggested a similar case mix. Besides, better working methods could also be identified when patient characteristics differ.

Management approached potential participants and whenever participants fulfilled the criteria and agreed to participate, they were included. The organizations involved are presented anonymously in the text. 
Table 1 Overview of the case studies

\begin{tabular}{|l|l|l|}
\hline Multiple case study 1 & Multiple case study 2 & Multiple case study 3 \\
\hline $\begin{array}{l}\text { Operations management in } \\
\text { Comprehensive Cancer Centres } \\
\text { (CCC) }\end{array}$ & $\begin{array}{l}\text { Operations management in } \\
\text { Chemotherapy day units (CDU) }\end{array}$ & $\begin{array}{l}\text { Operations management in } \\
\text { Radiotherapy departments (RT) }\end{array}$ \\
\hline Total organization & Unit level & Department level \\
\hline Comprehensive cancer centres & $\begin{array}{l}\text { Part of comprehensive cancer } \\
\text { centres }\end{array}$ & $\begin{array}{l}\text { Part of comprehensive cancer } \\
\text { centres }\end{array}$ \\
\hline & $\begin{array}{l}\text { Only medication related } \\
\text { treatments }\end{array}$ & $\begin{array}{l}\text { Size: minimum of three linear } \\
\text { accelerators }\end{array}$ \\
\hline & $\begin{array}{l}1 \text { with perceived high efficiency, } \\
1 \text { with > 50 beds }\end{array}$ & Strategy \\
\hline & & Patient case mix \\
\hline 3 European partners & $3 ; 2$ from Europe, 1 USA & 4 European partners \\
\hline
\end{tabular}

Case study research protocol

To increase the reliability and validity of the case studies, the researchers developed a separate research protocol for each case study (17). The protocols described the selection criteria for the hospitals involved, the benchmarking process, and the indicators. As case research protocols need to be tested (16), we piloted the research protocol in the initiating hospital. A distinction between HSR benchmarking and the approach taken in this paper was that our process focused on gaining insight into the organizational aspects, thus creating learning opportunities to improve performance. This research did not emphasize the development of extensively validated indicators or procedures to validate the comparability of organizations (for example on case mix).

In multiple case study 1 the benchmarking process was based on Spendolini's benchmarking process (5) (see Table 2 and Figure 1). Since this is a general model that has been based on benchmarking experiences in manufacturing industries, we scrutinized it, and when necessary adapted it to ensure a comprehensive and appropriate benchmarking approach. Table 2 describes the benchmarking process used in each case. The benchmarking process used in each multiple case study differs on details as the lessons learned were integrated in the next multiple case study. 
Table 2 Benchmarking process employed per multiple case study

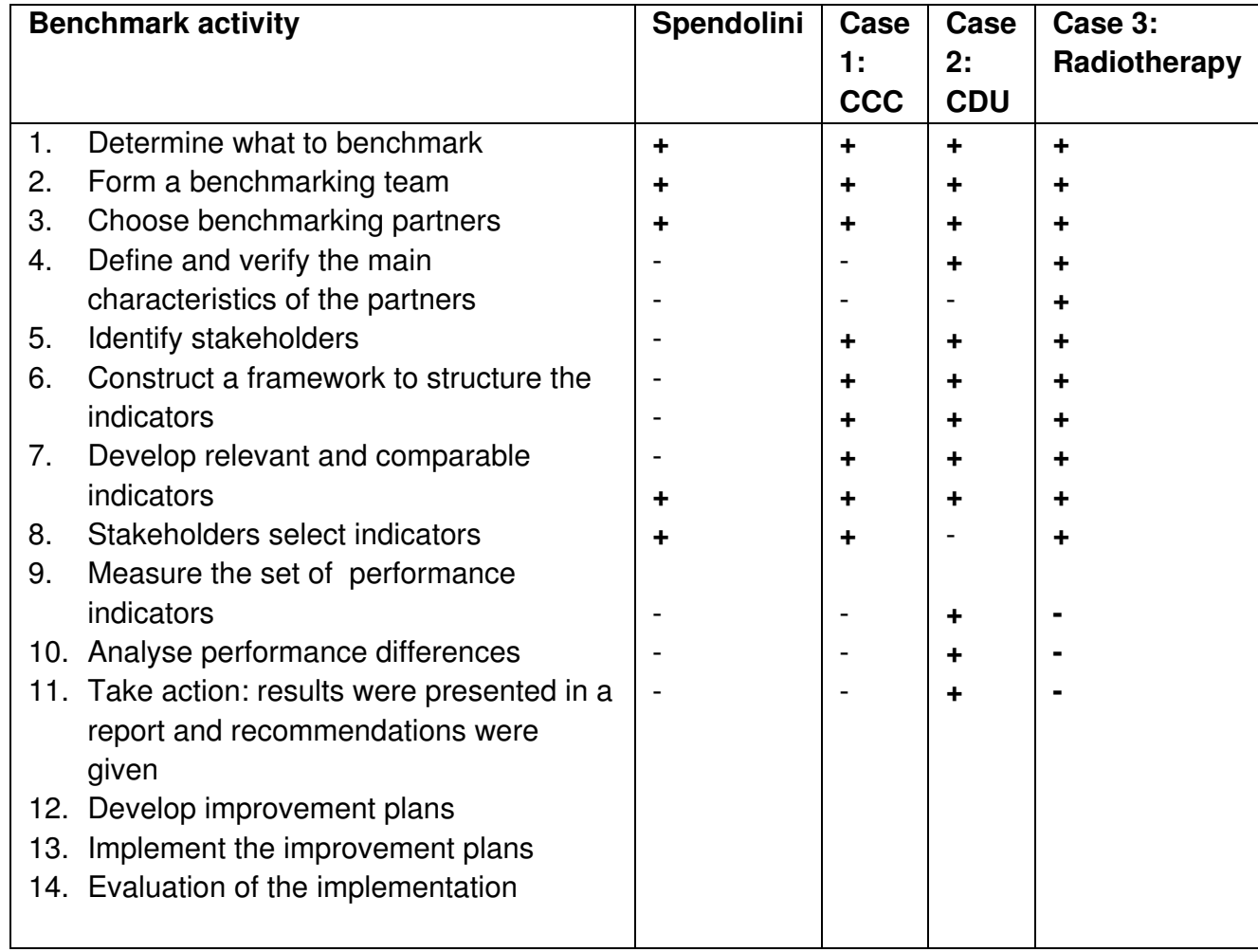

$+=$ used in benchmarking case study

- = not used in benchmarking case study

In multiple case study 1, we expanded Spendolini's benchmarking process (5) to include a framework that structured the indicators (Table 2, step 6), ensured comparability and covered all relevant aspects. We selected the EFQM (European Foundation for Quality Management) model because it considered strategic aspects, the processes and the outcomes. Another reason is that the EFQM model and its USA variant, the Malcolm Baldridge Quality Award (MBQA), are used in many hospitals (18). Additionally, the step involving 'Collect and Analyse benchmarking information' was broken up into four phases: i) develop relevant and comparable indicators, step 7; ii) stakeholders select indicators, step 8; iii) measure the indicators, step 9; and iv) analyse performance differences, step 10. Finally, we separated the 'take action' into two phases: develop improvement plans (step 12) and implement improvement plans (step 13).

Table 2 shows the benchmarking process used in multiple case study 2. Compared to study 1 , we added step 4 . In this step we verified the comparability of the 
partners using the patient case mix (based on the ICD-9 coding system and treatment urgency) and the services delivered by the CDU.

In multiple case study 3 , we additionally used input from a benchmarking process for healthcare developed by Van Hoorn et al. (20), since this became available after study 2. This study emphasized the indicator development process, the involvement of internal stakeholders and the comparability of the results. Compared to case study 2, step 5 - identification of stakeholders - was added. In a stakeholder analysis (19-21) we identified cancer centre management, radiotherapy department management, radiation oncologists and clinical physicists as stakeholders. In collaboration with the stakeholders, the benchmarking team earmarked 'commitment' and 'shared ownership' for improvement suggestions.

At the start of each benchmark, literature was searched for relevant indicators. Stakeholders of the initiating organization provided feedback, resulting in a reduced list of indicators. Although some only described a situation or condition, most indicators consisted of a numerator and a denominator. For example, the number of patients treated per linear accelerator per opening hour.

\section{Data collection methods}

Industrial engineering and management students collected the data according to the research protocols. We used both qualitative and quantitative methods to collect data for each case. Quantitative data were retrieved from annual reports and requested from the administrative departments, whereas qualitative data were mainly collected by conducting semi-structured interviews during the site visits. In the CDU case, we also used direct observations to gain a better understanding of the processes that led to the results.

To increase the validity of the data, the outcomes of the indicators were presented to the contact persons of the relevant comprehensive cancer centres. Most quantitative indicators were collected from databases and were verified with the stakeholders; this process of triangulation increased the validity of the data (22).

\section{Data analysis}

Per multiple case study, the data for each indicator were compared. In cases of exceptional outcomes, the persons who delivered the data were asked to comment on the differences. These explanations helped us to understand differences between the organizations. Besides comparing individual indicators, we took the 
total indicator set into consideration, because a good score on one indicator seemed to affect the performance on another indicator. For example, a high utilization rate is related to longer access delays.

After reviewing each multiple case study, the research team examined the feasibility, actual process and success factors of international benchmarking in comprehensive cancer centres.

\section{Results}

Below we describe the findings to the research questions. Per question, the results of the multiple case studies are presented. The indicators presented are examples of the indicators used to analyse the organizations involved.

\section{Question 1: benchmarking process}

Multiple case study 1: comprehensive cancer centres (CCC)

The methods section already described the benchmarking process, which is summarized in Table 2. The adapted benchmarking process of Spendolini (5) was workable, but adjustments might increase the generation of improvement suggestions regarding operations management. Although the CCCs were satisfied with the results, they commented that the results would not always be applied in change processes because they were uncertain that the same performance could be achieved in their setting because the processes might still not be sufficiently comparable.

The selected indicators distinguished between the total organization level, diagnostics, surgery, medication related treatments, radiotherapy and research. The results showed possibilities for improvements. For example, Table 3 shows that the percentages of staffing costs were comparable, but the percentage of nonmedical support staff ranged between 24\% (CCC2) and 14.5\% (CCC1). CCC2 could thus learn from $\mathrm{CCC} 1$ to reduce the percentage of support staff. Regarding radiotherapy, CCC2 treated 53\% more patients per linear accelerator, CCC3 could learn from $\mathrm{CCC} 2$ to improve their performance. Actually embarking on related improvement activities would however require further research. 
Table 3 Examples of indicators for the benchmarking of CCC

\begin{tabular}{|l|l|l|l|l|}
\hline Indicator & $\begin{array}{l}\text { Indicator } \\
\text { type }\end{array}$ & CCC1 & CCC2 & CCC3 \\
\hline $\begin{array}{l}\text { Percentage staff costs on total } \\
\text { costs (in \%) }\end{array}$ & $\begin{array}{l}\text { Organizational } \\
\text { level }\end{array}$ & 61 & 64 & 58 \\
\hline $\begin{array}{l}\text { Percentage of supportive staff } \\
\text { on total staff in full-time } \\
\text { equivalents }\end{array}$ & $\begin{array}{l}\text { Organizational } \\
\text { level }\end{array}$ & $15 \%$ & $24 \%$ & Not available \\
\hline $\begin{array}{l}\text { Number of hospital beds } \\
\text { (admission longer than } 24 \\
\text { hours) }\end{array}$ & $\begin{array}{l}\text { Department } \\
\text { level }\end{array}$ & 174 & 327 & $\begin{array}{l}56, \text { only beds for } \\
\text { radiotherapy and } \\
\text { internal medicine }\end{array}$ \\
\hline $\begin{array}{l}\text { Number of surgeries } \\
\text { performed per OR }\end{array}$ & $\begin{array}{l}\text { Department } \\
\text { level }\end{array}$ & 558 & 741 & Not identifiable \\
\hline $\begin{array}{l}\text { Number of patients treated per } \\
\text { linear accelerator }\end{array}$ & $\begin{array}{l}\text { Department } \\
\text { level }\end{array}$ & $490^{*}$ & 480 & 313 \\
\hline $\begin{array}{l}\text { Number of patient visits per } \\
\text { CT scanner }\end{array}$ & $\begin{array}{l}\text { Department } \\
\text { level }\end{array}$ & 7648 & 9047 & $\begin{array}{l}\text { Only for a specific } \\
\text { treatment for one } \\
\text { location available }\end{array}$ \\
\hline $\begin{array}{l}\text { Percentage of staff costs on } \\
\text { total costs of radiology } \\
\text { department }\end{array}$ & $\begin{array}{l}\text { Department } \\
\text { level }\end{array}$ & 44 & 65 & Not available \\
\hline
\end{tabular}

${ }^{*}=$ number of treatment series, not patients. 1 patient can receive multiple series.

Multiple case study 2: chemotherapy day units (CDU)

Since the CDUs found verification of their comparability useful, e.g. in respect of patient case mix treated and the services delivered, we included this as a new step in the benchmarking process (see Table 2, step 4). A self-made instrument was developed to test the comparability of the involved organizations. The case mix was examined with the ICD-9 coding system, the fraction of urgent patients and the duration of the treatments. The delivered services were examined based on the main techniques used for treatments. Table 4 shows that the patient case mix and services offered were similar.

In Table 4 the estimated number of patient visits for 2005 shows that all CDUs were growing rapidly. CDU 3 clearly outperformed the others on the number of patients treated per bed and the number of patients treated per nurse or staff member, and provided possibly more optimal working methods for the planning procedure, reduction of non-value adding activities and nursing staff utilization. 
Table 4 Examples of indicators for the benchmarking of CDU

\begin{tabular}{|l|l|l|l|}
\hline Items compared & CDU 1 & CDU 2 & CDU 3 \\
\hline Patient case mix & 23 out of 30 & $21-27$ out of 30 & 23 out of 30 \\
\hline Services offered & 28 out of 36 & 30 out of 36 & 28 out of 36 \\
\hline Total patient visits 2004 & 11.152 & 80.000 & 12.371 \\
\hline $\begin{array}{l}\text { Estimated total patient visits 2005 in } \\
\text { November }\end{array}$ & 12.000 & 107.000 & 12.500 \\
\hline $\begin{array}{l}\text { Indexed average number of patients treated } \\
\text { per bed per month (not corrected for } \\
\text { differences in opening hours) }\end{array}$ & 44 & 77 & 100 \\
\hline $\begin{array}{l}\text { Indexed average number of patient visits per } \\
\text { month per total CDU staff }\end{array}$ & 58 & 44 & 100 \\
\hline $\begin{array}{l}\text { Indexed average number of patient visits per } \\
\text { nurse per month }\end{array}$ & 62 & 53 & 100 \\
\hline
\end{tabular}

The benchmark resulted in recommendations for improving patient planning and work procedures concerning resources (bed, nurses and medication) needed for a medical procedure. A multidisciplinary team implemented the recommendations by translating the lessons learned from CDU3 to CDU1. During this translation process, CDU1 also used lean management principles to obtain even better results. For more details about this improvement project, see Van Lent et al. (23). This resulted in a $24 \%$ growth in the number of patient visits, a $12 \%$ to $14 \%$ increase in staff productivity and an $80 \%$ reduction of overtime while the average expected treatment duration remained stable.

\section{Multiple case study 3: radiotherapy departments (RT)}

We further adapted the benchmarking process based on the work of Van Hoorn et al. (20), on verifying the comparability of hospitals and developing indicators that achieve consensus among stakeholders. This suggested the researchers to examine the role of the stakeholders and the development of indicators more thoroughly. Just as in study 2, the tumour types of the patients (ICD-codes) were used to verify the comparability of the involved radiotherapy departments (Table 2, step 4). Since these data were not available for the departments we checked the comparability of the ICD-codes on a national level, assuming that the patients of radiotherapy centres reflected the national data on the use of international treatment protocols. The comparability was acceptable.

Compared to study 2, step 5 - identification of stakeholders with a stakeholder analysis (19-21) - was added. The improved benchmarking process (see Table 2) resulted in better acceptance of the indicators, although it proved difficult to obtain all the requested data. 
The stakeholder analysis supported the development of the indicators. Just as in the other studies an initial list of indicators was based on relevant literature. The stakeholders identified in step 5 provided feedback on the relevancy, measurability and comparability of the selected indicators. As a result indicators were removed, adapted and added. New in this case study was an evaluation of the used indicators after the benchmark.

Table 5 presents examples of the benchmarked outcomes. For patient satisfaction and risk analysis, we measured whether the departments systematically applied the Plan-Do-Check-Act cycle to achieve improvements. None of the organizations performed all phases of the cycle; even the most optimal procedure did not keep track of the changes.

Table 5 Examples of indicators for the benchmarking of radiotherapy departments

\begin{tabular}{|l|l|l|l|l|}
\hline Examples of indicators & RT1 & RT2 & RT3 & RT4 \\
\hline Patient satisfaction, stage in PDCA cycle & Check-Act & Plan-Do & Do-Check & Plan- Do \\
\hline Risk analysis, stage in PDCA cycle & Do- Check & Do-Check & Plan-Do & Plan-Do \\
\hline $\begin{array}{l}\text { Average impact points per publication and total } \\
\text { publications }\end{array}$ & $\begin{array}{l}5.6 \text { out of } \\
297\end{array}$ & $\begin{array}{l}2.3 \text { out of } \\
55\end{array}$ & $\begin{array}{l}2.4 \text { out of } \\
33\end{array}$ & $\begin{array}{l}\text { Not } \\
\text { available }\end{array}$ \\
\hline Percentage of patients in clinical trials & $4.4 \%$ & $0.7 \%$ & $10.7 \%$ & $3.5 \%$ \\
\hline $\begin{array}{l}\text { Percentage of treatment planning with: } \\
\text { Simulator }\end{array}$ & 0 & 0 & 5 & 40 \\
$\begin{array}{l}\text { CT } \\
\text { MRI }\end{array}$ & 91 & 98 & 1 & 56 \\
PET & 8 & 2 & 74 & 0 \\
\hline $\begin{array}{l}\text { Patients treated per linear accelerator per } \\
\text { standard opening hour }\end{array}$ & 4.5 & 4.6 & 5.4 & 3 \\
\hline $\begin{array}{l}\text { Number of hours of downtime for planned } \\
\text { maintenance per linear accelerator }\end{array}$ & 156 & 173 & 47,5 & 84 \\
\hline
\end{tabular}

Our analysis revealed that radiotherapy centre 1 (RT1) seemed to have the most optimal working method for risk analysis, access times, patient satisfaction and scientific publications. RT3 and RT4 achieved better results regarding the linear accelerator utilization. Although the organizations involved accepted the results and recognized the improvement opportunities, they wanted more details before implementation because they did not have sufficient insight into the underlying organizational processes and the coherence between the indicators. A change in respect of one indicator (like a reduction of linear accelerator downtime) might affect the performance regarding another one (linear accelerator utilization). 
RT1 started to work on their patient satisfaction and risk analysis score and a switch to measuring access time per tumour type instead of general access times is being considered. Furthermore, RT1 studied opportunities to reduce planned downtime during regular working hours. RT2 examined its inclusion rate for clinical trials and the information included in management reports. This should support them in making their status as a high-quality radiotherapy centre transparent. RT4 has been working on a system to register misses (part of the risk analysis) and it used the indicator outcomes to measure how many investments in staff and equipment are needed to remain a high-quality radiotherapy centre.

\section{Question 2: success factors for international benchmarking}

Multiple case study 1: CCC

International benchmarking of a CCC on operations management is complex. Due to different reimbursement and accounting systems, the use of financial indicators was especially complex. Moreover, differences between external environments (mainly caused by government regulations) and the organizational choices resulted in difficulties with data availability.

Furthermore, policy affected the data directly and the organizational structure often determined the procedures for data collection and aggregation. The administrative organization of CCC3 was not yet capable of providing data for all activities as an identifiable unit on that level of organization because it shared resources with a general hospital. This problem was exacerbated because the CCC was in the middle of a merger and the data registration systems were not yet completely integrated. As the oncology surgeries could not be identified separately, it was impossible to verify the exact numbers. This case study used simple indicators, like patient-staff ratios or patient-resource ratios that could easily be collected.

An identifiable unit or department such as radiotherapy, radiology or a chemotherapy day unit seemed more suitable for benchmarking as this simplifies data collection. Radiology departments could be compared if referring policies are comparable. Specialized surgical departments seemed difficult to benchmark, due to problems with data availability, indicator definitions and the organizational embedding of the operating theatre.

\section{Multiple case study 2: CDU}

The small project scope together with the use of interviews and observations resulted in improved insight into the organizational principles that delivered the 
results. The benchmark made the partners aware that other organizations with similar problems were able to achieve better outcomes. This resulted in useful recommendations that have been implemented in CDU1. The management of CDU1 reported that the verification of the comparability had resulted in increased confidence in the identified improvement opportunities.

\section{Multiple case study 3: RT}

The results revealed that organization-specific characteristics influenced the outcomes because some departments, like radiotherapy, are quite dependent on technology (for example, most clinical trials require linear accelerators with special functions, like a cone beam). Thus, indicators measuring the percentage of patients included in clinical trials did not only reflect the organizational quality of the process, but rather the availability to scarce resources. This highlighted the importance of careful partner selection.

Comparable to multiple case study two, it is impossible to define a single most optimal working method for a department without considering its operational priorities. This should be taken into account whenever the team identifies a learning opportunity.

All indicators were measured over a one-year period. A discussion with the benchmarking partners revealed that some indicators were subject to large year-toyear variations. Examples are the average impact points per publication and the number of patients included in a clinical trial. Thus, measuring indicators over a one year period as done in this case study, does not always give a good impression of the performance.

\section{Discussion}

Based on our results we present the following answers to the research questions.

1. What is the most suitable process for benchmarking operations management in international comprehensive cancer centres or departments (benchmarking process) to improve hospitals?

Figure 1 (see page 97) shows the recommended benchmarking process based on this study and compares it with the benchmarking processes of 
Spendolini (5) and Van Hoorn et al. (6). Compared to case study 3 (see Table 2) we have added two steps, translation of the improvement opportunities to the individual situation and the evaluation of the benchmarking project. The project team has to establish consensus on the content of each step.

The results on the feasibility of benchmarking as a tool to improved hospital processes are mixed. The multiple case study 1 provided insight into the benchmarking process and gave indications for improvement opportunities. For study 2 we presented evidence of improvements. Although implementation was conducted together with lean management (see (23)), the benchmark enabled discussion about the working procedures and prevented a reinventing of the wheel because it gave direction to the improvements. Study 3 resulted in recommendations that are being considered for implementation. Altogether our conclusion confirms the work of De Korne et al. (24) who concluded after an international benchmarking initiative of eye hospitals that it is possible but "not so easy to compare performance in an international setting, especially if the goal is to quantify performance gaps or to identify best practices."

2. What are critical success factors for international benchmarking in comprehensive cancer centres?

Table 6 summarizes the success factors and relates them to the steps described in the proposed benchmarking process in Figure 1. 
Table 6 Success factors for the proposed benchmarking process

\begin{tabular}{|l|l|}
\hline $\begin{array}{l}\text { Success factors for international benchmarking on operations } \\
\text { management }\end{array}$ & Step in Figure 1 \\
\hline $\begin{array}{l}\text { Internal stakeholders should be convinced that others might have } \\
\text { developed solutions for problems that can be translated to their own } \\
\text { setting. }\end{array}$ & Step 1 \\
\hline Management must reserve sufficient resources for the total benchmark & Step 1 \\
\hline Limit the scope to a well-defined problem & Step 1 \\
\hline $\begin{array}{l}\text { Define criteria to verify the comparability of the benchmarking partners } \\
\text { based on the subject and the process. }\end{array}$ & Step 4 \\
\hline Construct a format that enables a structured comparison. & Step 6 \\
\hline Use both quantitative and qualitative data for measurement & Step 7 \\
\hline $\begin{array}{l}\text { Involve stakeholders to obtain consensus about the indicators, to } \\
\text { provide information on data availability and reliability, and to assist in } \\
\text { data collection. }\end{array}$ & Step 5,6,7,8,9 \\
\hline $\begin{array}{l}\text { Keep indicators simple so that enough time can be spent on the analysis } \\
\text { of the underlying processes. }\end{array}$ & Step 7,8,9,10 \\
\hline $\begin{array}{l}\text { For those indicators showing a large annual variation in outcomes, } \\
\text { measurement over a number of years should be considered. }\end{array}$ & Step 7,9,10 \\
\hline $\begin{array}{l}\text { Adapt the identified better working methods, so that they comply with } \\
\text { other practices in the organization. }\end{array}$ & Step 11 \\
\hline
\end{tabular}

a. Before embarking on benchmarking to improve hospital (unit) performance, three additional conditions should be met. First, the internal stakeholders need to be convinced that others have developed solutions for problems that can be translated to their own setting (as in the CDU case), otherwise they might frustrate the project, by either questioning the validity of the outcomes or withholding implementation. Second, management must reserve sufficient resources (time and money) to execute the total process, including the development of improvement plans. Third, a manageablesized project scope is required for a thorough analysis of the selected process and its results. The scope should be limited to a well-defined problem, for example capacity utilization. This can be found in an identifiable department or unit, but it can also be a small process that involves several departments.

b. The initiating organization should define criteria to verify the comparability of the benchmarking partners based on the subject and the process. Cases two and three showed the usefulness of the criteria for creating support for the benchmark and preventing comparability difficulties that were related to organization-specific characteristics. De Korne et al. (24) concluded that a comparison with peers provided an incentive to professionals to change current practices. 
Often information on hospitals is collected on a national level. Thus, specialty hospitals with few competitors in their own country will more frequently encounter a lack of data on comparable organizations. In these cases, possible partners should be contacted and screened on the inclusion criteria.

c. Stakeholder involvement is crucial for obtaining consensus about the indicators, providing information on data availability and reliability, and assisting in data collection.

d. Both quantitative and qualitative data should be used to determine the performance and construct a format that enables a structured comparison, such as the EFQM model.

e. Do not spend too much time on the reliability of the indicators, keep them simple so that enough time can be spent on the analysis of the underlying processes because this leads to improvement suggestions $(4,24)$. Qualitative indicators, observations and interviews should be used for this purpose. This is especially important in an international benchmark with a score for differences in and between organizations. A comparison of financial data has to be undertaken with care, especially in an international benchmark with different price levels and national reimbursement systems per country. Comparative purchasing power enables cost comparison (25); however this is time consuming, whereas non-financial indicators sometimes achieve a good comparison within a shorter time frame.

f. For those indicators showing a large annual variation in outcomes, measurement over a number of years should be considered.

g. Adapt the identified better working methods, so that they comply with other practices in the organization.

To our knowledge, this is the first attempt that examined international benchmarking on operations management in (speciality) hospitals. The approach we followed makes it possible to improve the structure of international benchmarking processes. This process in combination with the provided success factors may increase the chance that benchmarking results in improved operations management performance in specialty hospitals like comprehensive cancer centres.

A limitation is that our benchmarking process was only tested in three multiple case studies involving three to four cases. Involving larger series could be useful to further improve the validity of the benchmarking process. Furthermore, our multiple case studies were limited to cancer centres, but we presume that the 
benchmarking process is valid for other multidisciplinary specialty hospitals. Single specialty hospitals might be easier to compare. Further research is required to confirm this. As the benchmarking process seems more time consuming in an international setting as system differences add to the complexity, we suggest that the described process is useful for benchmarking in a national or regional setting provided the objective is to identify relevant operations aspects into sufficient depth.

To our knowledge, there is no accepted guideline or norm describing a complete indicator set for comparing the operations management performance in hospitals or hospital departments. Per multiple case study we defined an initial list of indicators, based on relevant literature and stakeholder feedback. Stakeholders provided feedback on the relevancy, measurability and comparability. As a result indicators were removed, adapted and sometimes added. A limitation of this approach is that more emphasis could be laid on the methodological quality of the indicators. However, combining the benchmarking process with a thorough and detailed process of indicator development could further improve the benchmarking, but will prove to be complex and demanding. In this way generic indicator sets on operations management could become available.

The developed indicator sets enabled the assessment of the operations management of specialty hospitals and generated suggestions for improvement. Collecting and interpreting data, however, has to be done carefully and must be based on the total indicator set, as there is not (yet) one single best method to organize processes. For example, a good performance by one indicator (utilization rate) is often associated with a negative effect on another indicator (long access times).

A limitation of the sampling method is that it remains uncertain whether the best practices within the sector have actually been included. Because information on best practices was not available, we used personal management contacts to select presumed good working methods. As data availability and comparability seems more frequently a problem in an international context, we recommend the use of international benchmarking only if comparable organizations are not available within the same country.

Although Mosel and Gift (3) stated that benchmarking is a continuous process, the cases were only benchmarked once. Recurrent measuring seems only useful if different outcomes can be expected within short time frames, and the partners are ready for a long-term commitment. 


\section{Conclusions}

This study generated more insight into the process of international benchmarking as a tool to improve operations management in specialty hospitals. All multiple case studies provided areas for improvement and multiple case study 2 presented the results of a successful improvement project based on international benchmarking. The provided method and the success factors can be used in international benchmarking projects on operations management in speciality hospitals. 
Figure 1 Comparison of benchmarking process

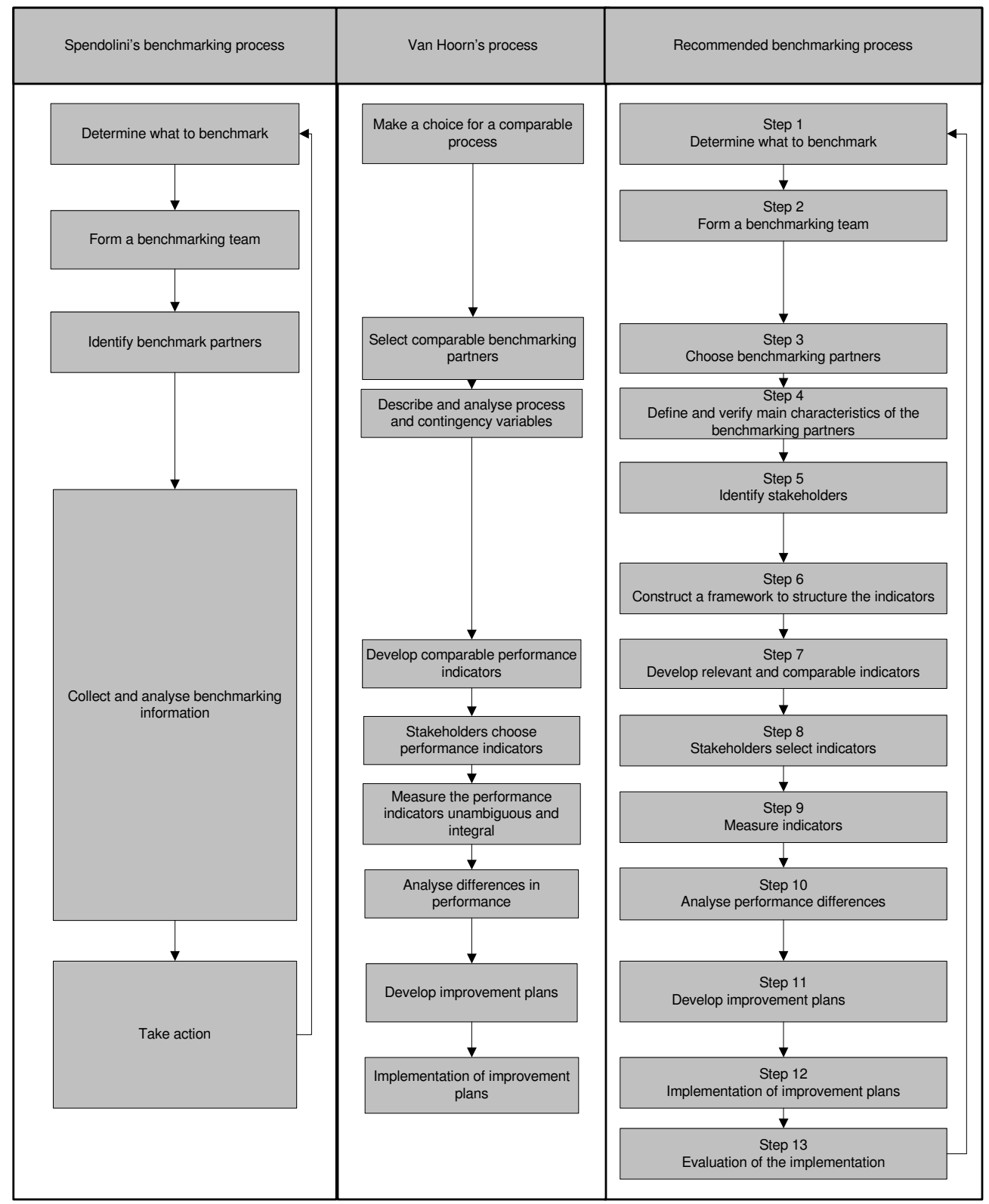




\section{Competing interests}

Wim $\mathrm{H}$ van Harten is a member of the executive board of the Netherlands Cancer Institute - Antoni van Leeuwenhoek Hospital. Wineke AM van Lent is also employed by this organization as a PhD-student and advisor on patient logistics.

\section{Authors' contributions}

WVL developed the research design and carried out case studies 1 and 2. She also drafted the manuscript. RdB improved the research design for case study 3 and conducted this case study. Furthermore, she contributed to revision of the manuscript. $\mathrm{WvH}$ was involved in the research design of all case studies, supervised them and contributed to the intellectual content of the manuscript. All authors read and approved the final manuscript.

\section{Acknowledgements}

We acknowledge all participating staff and the management of the participating cancer centres. We would like to acknowledge M. Verheij for his support on the radiotherapy benchmark. The authors acknowledge the helpful suggestions from the reviewers. 


\section{Reference List}

1. Slack N, Chambers S, Johnston R: Operations Management. Harlow: Prentice Hall; 2001.

2. Camp RC: Business Process Benchmarking: Finding and Implementing Best Practices. Wisconsin: Milwaukee; 1995.

3. Mosel D, Gift B: Collaborative benchmarking in health care. Joint Commission Journal for Quality Improvement 1994, 20: 239.

4. Camp RC: A Bible for Benchmarking, by Xerox. Financial Executive 1993, 9: 23.

5. Spendolini Michael J: The Benchmarking Book. New York: Amacom ;1992.

6. Van Hoorn A, Van Houdenhoven M, Wullink G: Een nieuw stappenplan voor benchmarking. Management Executive 2006, 1-15.

7. World Health Organization: The World Health Report 2000. Health Systems: Improving Performance. Geneva; 2000.

8. Groene O, Skau JKH, Frolich A: An international review of projects on hospital performance assessment. International Journal for Quality in Health Care 2008, 20: 162.

9. Powell AE, Davies HTO, Thomson RG: Using routine comparative data to assess the quality of health care: understanding and avoiding common pitfalls. Quality and Safety in Health Care 2003, 12: 122.

10. Schneider JE, Miller TR, Ohsfeldt RL, Morrisey MA, Zelner BA, Li P: The Economics of Specialty Hospitals. Medical Care Research and Review 2008, 65(5): 531.

11. United States Government Accountability Office [GAO]: Specialty Hospitals: Geographic Location, Services Provided, and Financial Performance., GAO-04-167. Washington, DC: GAO; 2003. [http://www.gao.gov/new.items/d04167.pdf] last accessed 16/Sept./2009.

12. United States Government Accountability Office [GAO]: Specialty Hospitals: Information on Potential Facilities., GAO-05-647R. Washington, DC: GAO; 2005. [http://www.gao.gov/new.items/d05647r.pdf] last accessed: 16/Sept./2009.

13. Porter ME, Teisberg EO: Redefining health care: creating value-based competition on results. Boston, Massachusetts: Harvard Business School Press; 2006.

14. Christensen CM, Grossman JH, Hwang J: The Innovator's Prescription. A Disruptive Solution for Health Care. United States of America: McGraw-Hill; 2009.

15. Herzlinger RE: Market-Driven Health Care: Who Wins, Who Loses in the Transformation of America's Largest Service Industry. Perseus Books Group; 1999.

16. Karlsson C: Researching Operations Management. Routledge; 2009.

17. Yin R: Case study research: Design and methods. Sage Pubns; 2008.

18. Minkman M, Ahaus K, Huijsman R: Performance improvement based on integrated quality management models: what evidence do we have? A systematic literature review. International Journal for Quality in Health Care 2007, 19(2): 90.

19. Mitchell RK, Agle BR, Wood DJ: Toward a Theory of Stakeholder Identification and Salience: Defining the Principle of Who and What Really Counts. Academy of Management Review 1997, 22: 853-886.

20. Brugha R, Varvasovszky Z: Stakeholder analysis: a review. Health Policy and Planning 2000, 15: 239-246.

21. Carignani V: Management of change in health care organisations and human resource role: Socio-economics in radiology. European Journal of Radiology 2000, 33: 8-13.

22. McCutcheon DM, Meredith JR: Conducting case study research in operations management. Journal of Operations Management 1993, 11: 239-256.

23. Van Lent WAM, Goedbloed N, Van Harten WH: Improving the efficiency of a chemotherapy day unit: Applying a business approach to oncology. European Journal of Cancer 2009, 45(5): 800-806. 
24. de Korne DF, Sol KJCA, van Wijngaarden JDH, van Vliet EJ, Custers T, Cubbon M et al.: Evaluation of an international benchmarking initiative in nine eye hospitals. Health Care Management Review 2010, 35(1): 23-35.

25. Van Harten, WH, Van Luenen, HG, and Van Bokhorst, L: Benchmarking Biology Research Organisations Using a New, Dedicated Tool. Molecular Oncology 2010, 4 (1): 12-18. 


\title{
5 Improving the Efficiency of a Chemotherapy Day Unit: Applying a Business Approach to Oncology
}

\author{
W.A.M. van Lent \\ N. Goedbloed \\ W.H. van Harten
}

Published in European Journal of Cancer 2009, 45(5): 800-806 


\section{Abstract}

Aim

To improve the efficiency of a hospital based chemotherapy day unit (CDU).

\section{Methods}

The CDU was benchmarked with two other CDUs to identify their attainable performance levels for efficiency, and causes for differences. Furthermore, an indepth analysis using a business approach, called lean thinking, was performed. An integrated set of interventions was implemented, among them a new planning system. The results were evaluated using pre- and post-measurements.

\section{Results}

We observed $24 \%$ growth of treatments and bed utilization, a $12 \%$ increase of staff member productivity and an $81 \%$ reduction of overtime.

\section{Conclusions}

The used method improved process design and led to increased efficiency and a more timely delivery of care. Thus, the business approaches, which were adapted for healthcare, were successfully applied. The method may serve as an example for other oncology settings with problems concerning waiting times, patient flow or lack of beds. 


\section{Introduction}

With an estimated 2.9 million new cases and 1.7 million deaths each year in the European Union, cancer presents an important health problem (1). These volumes make it understandable that the costs related to cancer care are substantial. In the Netherlands these are estimated to be $4.1 \%$ of total healthcare expenditure (2) and in the United States of America (USA) almost 5\% (3). In the near future, costs of cancer care are expected to increase at a faster rate than overall medical expenditures. As the population ages, the absolute number of cancer patients will grow relatively fast and the introduction of new cancer treatments will contribute considerably to total expenditure (3). In combination with workforce availability problems, these trends increase the pressure on efficiency.

Traditionally, healthcare quality focused mainly on treatment issues and the patient-physician relationship (4) and so did improvement techniques (5). A broader definition of quality, including efficiency and timeliness, has currently been accepted (6). As a consequence, the acceptance for related improvement techniques is growing. In this paper, we will show how business approaches can support efficiency improvements in a hospital-based chemotherapy day unit (CDU 1). Due to an increasing demand, the unit was facing difficulties with access time, waiting times and work pressure. The objective was to enable at least $20 \%$ patient growth without adding proportionally more staff while sustaining current quality and patient satisfaction levels.

\section{Applying business approaches to improve efficiency in oncologic care}

Because healthcare is labour-intensive, productivity is regarded as an important efficiency element. Working harder is unlikely to gain much effect; people have to work more effectively to obtain increased productivity (7). Changing the organisation of processes may help to realise this as "every system is perfectly designed to achieve the results it achieves" (8). During the last decade hospitals have sought the support of business approaches to improve their efficiency. Examples are:

- Business process re-engineering (BPR) - this argues that radical change is the best way to improve. However, only an estimated 30 to $50 \%$ of all BPR projects achieve the intended results (9) and as a consequence organisations are looking for more comprehensive approaches.

- Benchmarking (10) - this is used to identify best practices which can be used as input for improvements. This is done by comparing organisations, sometimes in other sectors.

- Total quality management - this focuses on the development of a culture and system for continuous quality improvements. The aim is avoiding 
mistakes. These approaches do not describe in detail how processes should be organised and do not use process change as a means of achieving efficiency improvements.

Pollitt (11) provides an overview of the successes of BPR and benchmarking in hospitals and concludes that although both approaches sound promising, the results of the few studies - often based on single case studies - are not very convincing.

Another approach that focuses on process organization and appears more promising is lean thinking, also known as lean production. It originated at Toyota and provides "a way to specify value, line up value-creating actions in the best sequence, conduct those activities without interruption whenever someone requests them, and perform them more and more effectively" (12). It focuses on value for the customer (in healthcare the patient), the value stream (each activity must add value for the patient), flow (service delivery without stoppages or backflows), pull (deliver it when it is needed) and perfection (12). Lean thinking is described as a philosophy to organise processes. It consists of many tools; those that we used are discussed in the methods section. Examples of lean thinking provided by national healthcare quality agencies, such as $\mathrm{IHI}$, the NHS (13), and the Lean Management Institute (14), all show promising results but most publications tend to have a descriptive character, lack pre- and post-measurements and do not use controlled studies.

Thus, although most business approaches claim to improve efficiency, the scientific evidence in (oncology) healthcare supporting this claim is limited. The complexity of cancer care and the continuous changes caused by scientific progress make oncology a difficult area to study improvement projects. Other reasons for the apparent lack of reported success from business approaches could be related to methodological issues caused by the implementation of multiple interventions and changing contingency factors (15).

\section{Methods and results per project phase}

We applied lean thinking because it focuses on the organization of processes and the results seem promising. Many lean principles correspond with oncology and healthcare in general, where patients need to receive the right treatment at the right time in the most effective way. In order to obtain more insight into attainable performance levels we also decided to use benchmarking. Like many healthcare improvement projects, this project is structured according to the Plan-Do-Check- 
Act cycle (16). This iterative method has much in common with clinical practice where "therapies are initiated under close observation and adjustments are made as data and experience accumulate" (17). The project lasted from 2005 until 2008, but we did not work full-time on it. Table 1 provides the time required per phase. We discuss the application of lean management tools and benchmarking per phase.

Table 1 Time span of the various Plan-Do-Check-Act phases

\begin{tabular}{|l|l|}
\hline Phase & Period \\
\hline Plan & $\begin{array}{l}\text { Mar 2005 - Nov 2005. Arranging the benchmarking resulted in time } \\
\text { delays }\end{array}$ \\
\hline Do & $\begin{array}{l}\text { Jan 06 - Oct 2006. Minor adaptations have been made after this } \\
\text { period. }\end{array}$ \\
\hline Check & March 2008 \\
\hline Act & March - April 2008 \\
\hline
\end{tabular}

\section{Plan-phase}

During the Plan-phase the process was analysed. The pre measurements delivered data about efficiency, patient satisfaction and staff satisfaction. We used the following techniques:

1. An in-depth process analysis of CDU1 consisting of lean thinking techniques:

a. Direct observation of the entire process, including pharmacy and phlebotomy. Few publications have included the interrelatedness between departments (18).

b. Mapping the process, with a technique called value stream mapping (12). We also identified patient groups based on the track they completed before reporting at the CDU.

c. Identification of gaps between staff members' perceptions and the results from previous steps. Root-cause analysis techniques (12) revealed causes of the perceived bed shortage and high work pressure.

d. Collecting data. Measurements were needed for: time spent in the waiting room, time needed to order medication, medication preparation time, and the waiting time on a bed before medication is administered. We also had to minimise the administrative burden needed to execute the measurements. Therefore, we collected 1 week data and evaluated the results with the staff.

e. Doing a Rapid-Plant-Assessment (19) which was translated to Dutch and modified for use in hospitals. The assessment contains 
a framework to determine whether the department is lean and includes a questionnaire about the application of best practices.

f. Visualisation of the improvement potential when reducing the weak points. Although not a lean technique in a strict sense this was important for the rest of the project. We used data of two busy days, according to the department head, to discuss the current capacity use and the best capacity use.

2. Benchmarking with two other CDUs in the USA and Europe. Literature reviews, desk research and interviews were used to identify performance indicators. Interviews and site visits were used to retrieve the data needed for comparison.

The main findings of the analysis are:

1. In a CDU the pharmacy prepares most medication when there is certainty about the actual administration. The continuation of the treatment often depends on the phlebotomy results. The observations and value stream map showed the different tracks patients complete before reporting at the CDU. Figure 1 shows a simplistic visualization of those tracks. We identified the patient groups' volume during a one month sample. Depending on their treatment phase, patients switch between groups. Each group affects the process in a different way and therefore optimisation per group is required. For example, patients with previous appointments are more likely to arrive later than those without.

2. Root-cause analysis techniques revealed that the reported bed shortage and high work pressure were caused by unequally distributed daily demand with peaks around 11.00 AM and 1.30 PM. In turn, this peak was caused by the planning system because scheduling did not match with the nurses and beds available at a specific time.

3. The analysis showed different forms of waste. An example of wasted nursing time is the time spent on patients waiting on a bed for their medication. Stagnation was found in the medication order process. Pharmacy measurements revealed that on average $23 \mathrm{~min}$ are needed to prepare medication $(n=92)$ while CDU measurements showed that medication was delivered 53 min after the scheduled appointment time $(n=126)$. The measurements have been confirmed by the CDU and pharmacy. They concluded that medication was often ordered after the original appointment time. Causes were unavailable lab results and the work pressure of the single nurse practitioner responsible for the orders.

4. The Rapid-Plan-Assessment appointed information transparency and materials management as improvement areas. A reorganised inventory 
would ease inventory control while transparency contributes to an improvement culture.

5. The visualisation of possible improvements showed a planning system considering nurse and bed capacity, enabling the treatment of the same amount of patients with $30 \%$ less beds in an ideal situation. The project team confirmed plausibility of the results.

Figure1: Relation of $C D U$ and other departments

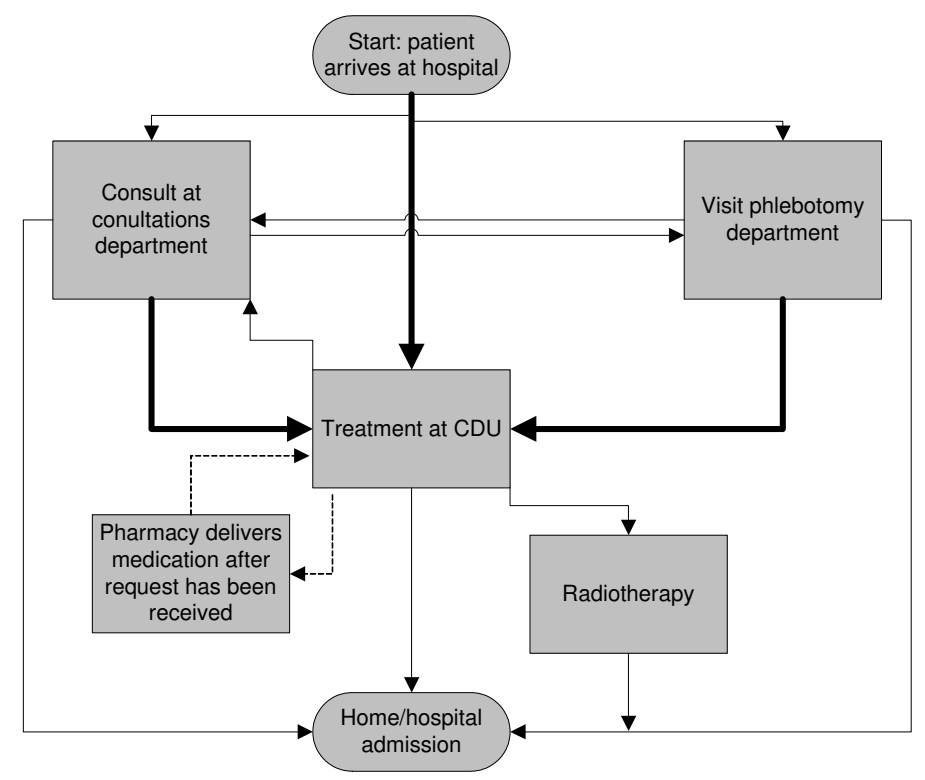

Table 2 summarises the main performance indicators of the benchmarking. CDU 2 was by far the largest involved organisation. CDU 3 clearly outperforms the others on efficiency; we tried to understand how this was done. CDU 3 provided possible best practices for the planning system, reduction of non-value added activities and use of nurses. Table 3 provides a list of data collected for this study. 
Table 2 Main performance indicators benchmarking

\begin{tabular}{|l|l|l|l|}
\hline Performance indicators & CDU 1 & CDU 2 & CDU 3 \\
\hline Total patient visits 2004 & 11.152 & 80.000 & 12.371 \\
\hline $\begin{array}{l}\text { Estimated total patient visits 2005 in } \\
\text { November }\end{array}$ & 12.000 & 107.000 & 12.500 \\
\hline $\begin{array}{l}\text { Indexed average number of patients treated } \\
\text { per bed per month (not corrected for } \\
\text { differences in opening hours) }\end{array}$ & 44 & 77 & 100 \\
\hline $\begin{array}{l}\text { Indexed average number of patient visits per } \\
\text { month per total CDU staff }\end{array}$ & 58 & 44 & 100 \\
\hline $\begin{array}{l}\text { Indexed average number of patient visits per } \\
\text { nurse per month }\end{array}$ & 62 & 53 & 100 \\
\hline
\end{tabular}

Indexed $=$ the best performing CDU received a score of 100 , the other CDU received a relative score compared to the best performing CDU.

\section{Do-phase}

In the Do-phase a multidisciplinary project team examined which recommendations seemed suitable for implementation. The team included among others: a medical oncologist, nurse, nurse practitioner, secretary and programmers. The following activities were conducted:

1. Waste reduction. Based on the value stream map, waste - activities without added value for the patient - was identified. Waste was eliminated whenever possible.

2. Developing the new planning method that delivers optimal value for patients and staff.

3. Techniques to align the capacity of related departments with the CDUs patient flow:

a. We tried to level peak demand by reserving certain times for specific patient groups, a technique called heijunka (12).

b. We either tried to eliminate causes of variation or adapted the system to enable absorption of variation.

4. Measures to make the changes last.

During this phase a set of interventions were implemented, examples of the most important interventions are:

1. Waste reduction:

a. Nurses welcome patients when available instead of being called in the middle of an activity.

b. A single code for a set of lab tests is used instead of ticking each test separately. 
c. Patients requiring no staff attention no longer wait on a bed but in the waiting room, which has been converted into a lounge like environment.

d. Medication orders for non-phlebotomy dependent treatments for the next day are signed around 14.00 PM to enable preparation in the afternoon.

e. The pharmacy prepares all biphosphonate medication and about $75 \%$ of the trastuzumab needed for that day in advance instead of preparing per single patient. This reduces pharmacy time for almost $20 \%$ of the patients.

f. Oral medication is handed out by nurse practitioners at the consultations department instead of the CDU where medication delivery often involved a $1 \mathrm{~h}$ waiting time.

g. Nurses do the paperwork in the patient's presence while discussing the patient's situation.

2. The development of a new planning system:

a. Planning is based on expected treatment duration.

b. Planning is based on the availability of a bed and nurse. Each nurse has three beds.

c. The CDU attempts to assign patients to their primary nurse.

d. Inserting a venous cannula is the most labour-intensive part of the treatment, thus this is avoided during the lunch break of the two shifts. However, the goal is to occupy all beds before lunch because this increases bed utilisation while dealing with the limited staffing levels.

3. Aligning the planning method with the capacity of related departments to improve patient flow:

a. The pharmacy's early morning demand was high because it had to prepare medication for the wards and the CDU. Treatments that are administered independent of phlebotomy results are scheduled before $10.00 \mathrm{AM}$ or after 3.00 PM. The medication is prepared in advance, during quiet hours of the pharmacy. This corresponds with the recommendations of a simulation study in a CDU (18).

b. Service level agreements with other departments determined the compulsory time between appointments to reduce chances on delayed patients. Phlebotomy for patients with long treatments now takes place the day before the treatment. In this way the treatment can start in time.

4. Measures to maintain the effects of the interventions:

a. Development of standard working procedures for patient planning, emergencies and cancellations. 
b. Logistic information was added to the patient leaflet so patients knew what to expect (20). This was done in the form of boxes that were ticked by the nurses. Examples are: time needed for blood analysis, compulsory time between consultations department and CDU appointments.

Initially, staff members reacted sceptically to the proposed changes, which required a cultural change, but management succeeded in gaining the essential project support. The project support did reduce, however, after nine months had expired and no changes had been noticed, but this time was needed to develop an ITsystem that supported the new planning method.

\section{Check-phase}

In this phase the results were evaluated with a post-measurement. Table 4 shows a $24 \%$ growth in the number of patient visits, a $12-14 \%$ increase in staff productivity, and an $81 \%$ reduction of overtime while the average expected treatment duration remained stable.

Part of the objectives was to increase efficiency without harming the other quality aspects. The number of complaints was already low before the interventions and we have found indications that this decreased slightly. Medical oncologists participated in the project to safeguard quality and ensure that internal medical guidelines had not been changed due to this project. Patient satisfaction remained stable. Part of the questionnaire is the perceived waiting time; this received only a $52 \%$ satisfaction score. However, additional measurements showed that patients wait on average almost $10 \mathrm{~min}$ between the scheduled appointment time and actual treatment start $(n=144)$. This suggests a discrepancy between the perceived and realised waiting time. Almost $45 \%$ of the patients report at the CDU $30 \mathrm{~min}$ before their appointment; this is the starting signal for preparation of the medication. Comparison of waiting times with 2005 is difficult because patients used to wait on a bed while they now wait in the waiting room. The questionnaire also showed that some interventions, like the scheduling of non-phlebotomy dependent treatments on specific times, had not enhanced satisfaction. However, this was implemented to enable more patients to be treated in a timely manner.

Staff satisfaction was evaluated by workplace absenteeism, overtime and observations. We found a $36 \%$ decrease in workplace absenteeism and an $81 \%$ reduction in overtime. Finally, observations revealed a decrease in perceived work pressure and a more relaxed working environment. 
Table 3 Data collected

\begin{tabular}{|c|c|c|}
\hline Indicator & & \\
\hline $\begin{array}{l}\text { Walk-in appointment system } \\
\text { or planning system at } \\
\text { phlebotomy department? }\end{array}$ & $\begin{array}{l}\text { Phlebotomy department information } \\
\text { system }\end{array}$ & Benchmark \\
\hline $\begin{array}{l}\text { Analysing waiting time } \\
\text { phlebotomy department }\end{array}$ & $\begin{array}{l}\text { Phlebotomy department information } \\
\text { system }\end{array}$ & Benchmark \\
\hline $\begin{array}{l}\text { Time needed to determine } \\
\text { phlebotomy results }\end{array}$ & $\begin{array}{l}\text { Phlebotomy department information } \\
\text { system }\end{array}$ & Benchmark \\
\hline $\begin{array}{l}\text { General description of CDU } \\
\text { planning system }\end{array}$ & $\begin{array}{l}\text { System includes: } \\
\text { 1. Occupancy time of beds? } \\
\text { 2. Available beds at a certain } \\
\text { moment? } \\
\text { 3. Available nurses at a } \\
\text { certain moment? } \\
\text { 4. Workload? } \\
\text { 5. Planning is visualized? } \\
\text { 6. Knowledge about CDU } \\
\text { needed for planning? }\end{array}$ & Benchmark \\
\hline Number of patient visits & & Benchmark \\
\hline Number of beds/chairs & & Benchmark \\
\hline CDU Opening hours & & Benchmark \\
\hline $\begin{array}{l}\text { Number of staff employed at } \\
\text { CDU (in full time } \\
\text { equivalents) }\end{array}$ & $\begin{array}{l}\text { Relative importance of experience } \\
\text { for the planning }\end{array}$ & Benchmark \\
\hline Number of nurses & Head CDU & Benchmark \\
\hline Number of other CDU staff & Head CDU & Benchmark \\
\hline Time needed per treatment & $\begin{array}{l}\text { Hospital information system / } \\
\text { treatment protocols }\end{array}$ & In-depth analysis \\
\hline Patient arrival time & Sample: measured by secretary & In-depth analysis \\
\hline Planned appointment time & Hospital information system & In-depth analysis \\
\hline Patient on bed/chair & Sample: measured by nurses & In-depth analysis \\
\hline Prescription to pharmacy & $\begin{array}{l}\text { Sample: measured by nurse } \\
\text { practitioner }\end{array}$ & In-depth analysis \\
\hline Medication ready & Sample: measured by pharmacy & In-depth analysis \\
\hline Medication administered & Sample: measured by nurses & In-depth analysis \\
\hline Bed utilization per hour & Sample: measured by project leader & In-depth analysis \\
\hline Patient groups & $\begin{array}{l}\text { Sample: combination of HIS and } \\
\text { treatment information }\end{array}$ & In-depth analysis \\
\hline Workplace absenteeism & HRM system & In-depth analysis \\
\hline Overtime & $\begin{array}{l}\text { HRM system / CDU head (claims for } \\
\text { expenses) }\end{array}$ & In-depth analysis \\
\hline $\begin{array}{l}\text { Patient satisfaction } \\
\text { questionnaire }\end{array}$ & $\begin{array}{l}\text { Sample. standard hospital } \\
\text { questionnaire }\end{array}$ & In-depth analysis \\
\hline
\end{tabular}


Table 4: Before-and-after measurement CDU

\begin{tabular}{|c|c|c|c|}
\hline Indicator & 2005 & 2007 & Difference in \% \\
\hline Number of beds & 30 & 30 & $0 \%$ \\
\hline $\begin{array}{l}\text { Total number of patient } \\
\text { visits }\end{array}$ & 12634 & 15662 & $+24 \%$ \\
\hline Average $\mathrm{nr}$ of visits per bed & 421 & 522 & $+24 \%$ \\
\hline $\begin{array}{l}\text { Average number of } \\
\text { employees }\end{array}$ & 19.65 & 21.75 & $+11 \%$ \\
\hline Average number of nurses & 11.2 & 12.21 & $+9 \%$ \\
\hline $\begin{array}{l}\text { Average } \mathrm{nr} \text { of visits per } \\
\text { employee* }^{*}\end{array}$ & 643 & 720 & $+12 \%$ \\
\hline $\begin{array}{l}\text { Average } \mathrm{nr} \text { of visits per } \\
\text { nurse* }^{*}\end{array}$ & 1128 & 1283 & $+14 \%$ \\
\hline $\begin{array}{l}\text { Average treatment time per } \\
\text { visit in hours }\end{array}$ & 2.2 & 2.2 & No change \\
\hline $\begin{array}{l}\text { Workplace absenteeism } \\
\text { excluding maternity leave }\end{array}$ & $9.2 \%$ & $5.9 \%$ & $3 \%$ \\
\hline Overtime in hours & 581 & 113 & $-81 \%$ \\
\hline $\begin{array}{l}\text { Patient satisfaction }(1-10) \\
\text { 2005: } n=109 \\
2007: n=146\end{array}$ & 8.1 & 8.2 & $1 \%$ \\
\hline
\end{tabular}

${ }^{*}$ = based on the average number of full time employees (FTE)

Act-phase: results

In this phase, the project team discussed the results, with the objective of identifying disadvantages of the interventions that had to be changed to ensure a more effective use in daily practice. Two types were identified: implemented interventions with disappointing results and possibilities for further improvements. We will give examples of each group.

Not all implemented interventions lead to the desired results. Although the patient leaflet was renewed, patients still arrived too late because the leaflet proved too complex. This is currently being adapted. Furthermore, only a part of the team does the paperwork in the patient's presence while discussing the patient's situation. Management decided to implement this in 2009 together with a project to improve the quality of the administration.

Although the results are successful, further efficiency improvements seem possible. Firstly because capacity is not completely used, a further $10 \%$ growth seems possible but there was no more demand. Secondly, the introduction of the new hospital information system required 0.66 FTE staff which could not be directly used for the CDU. Besides that, the implementation of several interventions has 
been postponed. The optimisation of the administrative procedure to order chemotherapy was postponed due to its' complexity and interference with patient safety. Also, transparency and materials management were postponed because they were not essential to enable the desired patient growth.

\section{Discussion}

This project resulted in considerable efficiency improvements in CDU 1: $24 \%$ growth of treatments and bed utilisation, $12-14 \%$ increase of staff productivity and $81 \%$ overtime reduction. The objectives have been reached and additional patient growth seems possible.

A disadvantage of this research type is that socio-dynamic processes might change during the project and affect the results (15). However, we have not found indications that the results are influenced by other contingency factors, thus it is most likely that the interventions have caused the results. Another disadvantage is the dilemma caused by using staff members to execute measurements for the analysis. Although this increases staff involvement, the disadvantage is the administrative burden that comes with it. To minimize this we chose small sample sizes, whereas from a research perspective larger sample sizes $(n>1000)$ might have been better. However, the outcomes have been accepted by the staff and thus it is unlikely that this would have led to different findings.

The combination of benchmarking and lean thinking was experienced as logical and seemed to enhance the results. Therefore, best practices from the benchmarking were used in discussions about the planning system. Furthermore, the PDCA-cycle offered a good project structure.

In the Do-phase it was decided not to implement all proposed changes due to their perceived negative effects towards other quality aspects or staff satisfaction. One example is doing the medication check before administering medication (not to be confused with the check on medication prescription) with two nurses instead of one because this might harm patient safety. For patient satisfaction we did not reduce the duration of patient education and the system of assigning patients to a primary nurse. For staff satisfaction we left opening hours and staffing levels at the end of the day unchanged.

Further research in comparable settings is needed to prove the method's success. The current performance levels and decisions made concerning the different quality aspects determine the success rate. The use of a control group would be 
ideal but almost impossible due to organisation specific characteristics and sociodynamic processes.

Based on our experience we recommend considering the following items when applying business approaches to (oncology) healthcare:

1. Ensure that increasing added value for the patient is the main project objective. Ultimately, this guarantees commitment of all stakeholders.

2. Objectify choices concerning the trade-off between efficiency and the other quality aspects as defined by the loM (6).

3. Avoid using business jargon since it reduces project support by alienating medical professionals (13). However, 'translated' lean principles seem to appeal to most professionals.

4. Optimise process flow as this diminishes suboptimal cooperation of departments.

5. Choose a sample size that is workable. For short process improvement projects, limited sample sizes are preferred.

6. Benchmarking should not only be used for comparison of performance, but especially to gain insight into underlying organisational principles.

7. Include someone with expertise on process improvement techniques from outside the organisation (department) in the project. The required expertise seems related to the organisations development stage and capability (21).

8. Make sure that there is noticeable change within a short period of time after the project's start (11).

All organisations delivering (oncology) care should strive for operational excellence. However, efforts to provide compassionate high quality care should also be taken into consideration. This contributes to the quality of care, as more patients receive their treatment in time while accessibility increases as more patients are treated with the same resources.

\section{Conflict of interest statement}

None declared.

\section{Acknowledgements}

We would like to thank E. Bredenhoff, A. Dernison, E. van Kessel, R. Roodbergen, $M$. Kerst and $G$. Sonke for their contribution to this paper. 


\section{References}

1. Boyle P, Ferlay J: Cancer incidence and mortality in Europe, 2004. Annals of Oncology 2005;16:481-8.

2. RIVM. Costs of diseases version 1.0. 2006 [http://www.kostenvanziekten.nl] Last accessed: 24-1-2008. [report in Dutch].

3. National Cancer Institute, NIH, DHHS, Bethesda, MD. Cancer trends progress report 2007 Update. 2007. [http://progressreport.cancer.gov] Last accessed: 24-1-2008.

4. Sanazaro PJ: Quality assessment and quality assurance in medical care. Annual Reviews in Public Health 1980, 1:37-68

5. Laffel G, Blumenthal D: The case for using industrial quality management science in health care organizations. Journal of the American Medical Association 1989, 262:2869-73.

6. Committee on Quality of Health Care in America, Institute of Medicine. Crossing the quality chasm: A new health system for the 21st century. Washington, DC: National Academy Press; 2001.

7. Drucker PF: The new productivity challenge. Harvard Business Review 1991 (November-December):69-79.

8. Berwick DM: A primer on leading the improvement of systems. British Medical Journal 1996, 312:619-22.

9. Hammer M, Champy J. Re-engineering the corporation - a manifesto for business revolution. London: Nicholas Brearly; 1995. p. 2000.

10. Mosel D, Gift B. Collaborative benchmarking in health care. Joint Commission Journal for Quality Improvement 1994, 20(5):239-49.

11. Pollitt C: Business approaches to quality improvement: why they are so hard for the NHS to swallow. Quality in Health Care 1996, 5:104-10.

12. Womack JP, Jones DT: Lean thinking; banish waste and create wealth in your corporation. London: Simon and Schuster; 2003.

13. Locock L: Healthcare redesign: meanings, origins and application. Quality and Safety in Health Care 2003, 12:53-7.

14. Lean Enterprise Institute [http://www.lean.org/Community/Registered/SuccessStories.cfm] Last accessed 26-32008.

15. Van Harten WH, Casparie TF, Fisscher OM: Methodological considerations on the assessment of the implementation of quality management systems. Health Policy 2000 , 54:187-200.

16. Deming WE. Out of crisis. Cambridge, MA: Cambridge University Press; 1986.

17. Berwick DM: Developing and testing changes in delivery of care. Annals of Internal Medicine 1998, 128(8):651-6.

18. Matta ME, Patterson SS: Evaluating multiple performance measures across several dimensions at a multi-facility outpatient center. Health Care Management Science 2007, 10:173-94.

19. Goodson RE. Read a plant-fast. Harvard Business Review 2002, 5:105-21.

20. Von Plessen $\mathrm{C}$, Aslaksen A: Improving the quality of palliative care for ambulatory patients with lung cancer. British Medical Journal 2005, 330:1309-13.

21. Fraser I, Encinosa W, Glied S: Improving efficiency and value in health care: Introduction. Health Services Research 2008, 43(5p2):1781-6. 


\title{
6 A Review on the Relation between Simulation and Improvement
}

\author{
W.A.M. van Lent \\ P.T. Vanberkel \\ W.H. van Harten
}

Submitted to BMC Medical Informatics and Decision Making 


\section{Abstract}

\section{Background}

Simulation applications on operations management in hospitals are frequently published and claim to support decision making on operations management subjects. However, the reported implementation rates of recommendations are low and the actual impact of the changes recommended by the modeller has hardly been examined. This paper examines: 1) the execution rate of simulation study recommendations, 2) the research methods used to evaluate implementation of recommendations, 3) factors contributing to implementation, and 4) the differences regarding implementation between literature and practice.

\section{Methods}

A literature review in PubMed and Business Source Elite on stochastic simulation applications on operations management in individual hospitals published between 1997 and 2008. From those reporting implementation, cross references were added. In total, 89 papers were included. A scoring list was used for data extraction. Two reviewers evaluated each paper separately; in case of discrepancies, they jointly determined the scores. The findings were validated with a survey to the original authors.

\section{Results}

Altogether 16 hospitals executed the recommendations (at least partially). Implementation results were hardly reported upon; 1 study described a before-andafter design, 2 a partial before-and-after design. Factors that help implementation were grouped according to 1) technical quality, of which data availability, validation/verification with historic data/expert opinion, and the development of the conceptual model were mentioned most frequently 2) process quality, with client involvement and 3) outcome quality with, presentation of results. The survey response rate of traceable authors was $61 \%, 18$ authors implemented the results at least partially. Among these responses, evaluation methods were relatively better with 3 time series designs and 2 before-and-after designs.

\section{Conclusions}

Although underreported in literature, implementation of recommendations seems limited; this review provides recommendations on project design, implementation conditions and evaluation methods to increase implementation. 


\section{Background}

The median spending on healthcare in the Organisation for Economic Co-operation and Development (OECD) countries is $8.8 \%$ of GDP, with the spending $15 \%$ (1). These countries are struggling to contain costs, forcing hospitals to rethink strategies on efficiency and the organization of processes. Due to the complexity and variability of many processes, managers find it difficult to estimate whether a redesign will result in significant improvements. To overcome this, hospitals need techniques that support them in making well-informed decisions about the trade-off between costs and quality (2). Simulation provides various techniques that help hospitals face these challenges $(3 ; 4)$.

The perceived advantages of simulation models and the growing number of applications (5) suggest this is a suitable approach for the healthcare sector. After reviewing 163 papers on operations research (OR) in healthcare Brailsford et al. (6) concluded that simulation is the second most popular OR technique after statistical analysis. These results are comparable with other sectors $(7 ; 8)$.

\section{The implementation of simulation recommendations}

In the past 30 years, at least seven reviews on simulation in healthcare appeared $(5 ; 6 ; 9-13)$, leading to the conclusion that simulation is widely used and can be regarded as a mature tool (14). Four papers researched the prevalence of implementing recommendations derived from OR models in healthcare $(6 ; 9 ; 13 ; 15)$.

After reviewing more than 200 papers on simulation, Wilson (13) found only 16 studies reporting the execution of recommendations and only 11 of these papers described operational problems in healthcare. Lagergren (15) found that almost two-third the papers on OR models in healthcare discussed general OR aspects or did not report on execution. In a review of 182 papers about simulation modelling in population health and health care delivery, Fone et al. (9) concluded that evidence of implementation is scarce. More recently Brailsford et al. (6) presented an extensive literature review of different types of modelling efforts in healthcare. They examined implementation on a three level scale: suggested (theoretically proposed by authors), conceptualized, implemented (actually used in practice). Only $5.3 \%$ of the 342 papers reported to have been used in practice.

Although these reviews provided insight into the prevalence of implementing simulation recommendations, it remains unclear if the results are valid in the 
present context. Wilson's study (13) although comprehensive, was completed in 1981 , which leads to the question whether the conclusions are still valid, given the advances in simulation software and techniques. The review of Lagergren was not focused solely on simulation and was by the author's own account 'incomplete' (15). Fone et al. (9) reviewed simulations on population health and healthcare delivery instead of operations management in individual hospitals. Although the work of Brailsford et al. (6) appeared comprehensive, the results were not limited to simulation and did not examine the realized impact of the changes recommended by the simulation study.

We conclude that the reported implementation rates are low, and that none of the mentioned reviews examined the realized impact of the changes recommended by the modeller. This suggests that although simulation is widely reported upon in healthcare, it is not clear whether actual implementation is carried out by management.

\section{Realizing improvements with simulation models}

To achieve improvements with simulation studies, one needs both a competent change management strategy and a simulation model and results deemed acceptable by the stakeholders. This paper focuses on simulation models. For references on change management, sufficient papers are available (16-19).

We identified two frameworks on the development of simulation models in healthcare (20-21). Both emphasized that in healthcare the problem definition phase consumes more time due to conflicting stakeholder objectives and an unclear problem understanding. Additionally, more involvement of staffs is required because decision makers are often unfamiliar with simulation techniques and therefore treat it with suspicion.

Understanding the relation between simulation models and improvements requires insight into the conditions that increase the implementation rate of recommendations. To our knowledge, four papers (22-25) have strived to identify these conditions. However, the focus and results were not specific to the healthcare sector. Robinson and Pidd interviewed 10 simulation modellers and 10 organizations to determine factors considered as important (24). This led to SIMQUAL (25), a survey that compared the expected quality with the perceived quality. McHaney and Cronan used a contingency model of simulation success as input for a survey among 126 projects to examine the relation between simulation project characteristics and their success in 126 projects (23). 
Research objectives

Several research gaps exist on the relation between simulation applications in healthcare and the execution of the recommendations. Therefore, we report on the following research objectives:

1. To determine the frequency that simulation recommendations are executed to improve operations management in individual hospitals.

2. To determine what factors contribute to the implementation of simulation study recommendations.

3. To determine the research methods used to evaluate implemented simulation recommendations.

4. To examine the difference between literature and reality with regard to the implementation of simulation recommendations.

The answers to these questions can support the transformation from simulated scenarios to improved hospital processes.

\section{Methods}

A literature review on simulation applications in individual hospitals provided answers to all research objectives. Relevant literature was checked on: 1) the reported implementation of recommendations, 2) the evidence that the changes resulted in improvements and, 3) comments of the researchers on factors contributing to the implementation of the study recommendations. In addition to the literature review, an email survey was sent to the traceable contact persons of the included papers.

\section{Search strategy and inclusion criteria}

We searched the PubMed and Business Source Elite (BSE) databases for relevant scientific healthcare and business literature. We used medical subject headings for the search strategy in PubMed, while for BSE we searched the abstracts for specific key words.

Two reviewers read all the abstracts and separately used the criteria of Table 1 to select papers for inclusion. We only included stochastic simulation applications that discussed operations management in individual hospitals and were published between 1997 and 2008. In case of disagreement, the full paper was retrieved and together a decision was made. Additionally, papers reporting (partial) 
implementation of the simulated recommendations were investigated further, with all cross references.

Table 1 Inclusion and exclusion criteria for abstracts

\begin{tabular}{|c|c|}
\hline Inclusion criteria & Exclusion criteria \\
\hline $\begin{array}{l}\text { - The paper discusses an application } \\
\text { of simulation } \\
\text { The discussed simulation model is } \\
\text { stochastic. The current state does } \\
\text { not determine the next state. } \\
\text { - Goal of the simulation is to improve } \\
\text { patient flow / process design or } \\
\text { efficiency and resource capacity } \\
\text { planning of primary processes } \\
\text { (=processes related to patient care) } \\
\text { The simulation is concerned with } \\
\text { processes within hospitals }\end{array}$ & $\begin{array}{ll}\text { - } & \text { Other models than simulation } \\
\text { - } & \text { Deterministic simulation models } \\
\text { - } & \text { Applications outside the hospital } \\
\text { - } & \text { Simulations concerning processes in } \\
\text { hospital systems in which multiple hospitals } \\
\text { collaborate } \\
\text { - Simulation models that support medical } \\
\text { decision making (related to guidelines), or } \\
\text { preventing errors related to the treatment } \\
\text { - No surveys and reviews } \\
\text { - } \quad \text { Papers published before } 1997 \\
\text { - Papers written in other languages than } \\
\quad \text { English }\end{array}$ \\
\hline
\end{tabular}

\section{Data extraction}

Using literature, a scoring list with multiple-choice answers was developed to analyse all papers. In a pilot, consisting of 10 papers, the form was adapted to it's final form. The scoring list consisted of six sections. Section I asked for the simulated departments, the affiliation of the authors and the number of settings in which the model was used.

The implementation phases (Section II) determined the extent of the implementation. This is evaluated by considering the process from simulation to improvements (see Figure 1, which is based on a 'four stage model of success' (24).

Figure 1 Phases from simulation to improvement

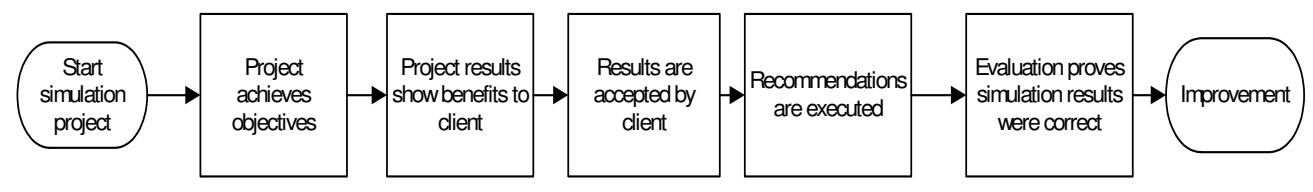


Section III assessed the evidence that simulation leads to improvements (in case of implemented results) with the work of Eccles et al. (26). It also examined whether implementation proved the results of the simulation to be correct.

Section IV, V and VI, concerned quality factors of the simulation study as stated by the author. We considered three quality aspects: technical quality, the process in which the model is developed, and outcome quality (27). The latter concerns the usefulness of the simulation; did it support the decision making process? The factors related to each quality aspect were based on Robinson and Pidd (24).

Two reviewers evaluated each paper separately and in case of discrepancies, they jointly determined the scores; in case of disagreement the third author was involved.

\section{Survey}

We were able to contact 67 of the 89 authors by email, the missing authors could not be traced. The survey consisted of four multiple choice questions that are comparable to the data extraction form. The survey asked the authors 1) whether the hospital accepted the recommendations of the simulation study 2) whether the recommendations were implemented, 3 ) whether the impact of the implementation was evaluated 4) whether the simulation study proved the recommendations to be correct.

\section{Results}

The search strategy resulted in 161 abstracts in PubMed and 125 in BSE, in total 277 different abstracts. The reviewers selected 113 abstracts for inclusion. We obtained the full text of all, except two papers. Only 68 met all inclusion criteria. The cross reference check on those partially implemented simulation recommendations, resulted in 21 additional papers. In total, 89 papers were included. Figure 2 visualizes the paper selection process. 
Figure 2 Overview selected papers for literature review

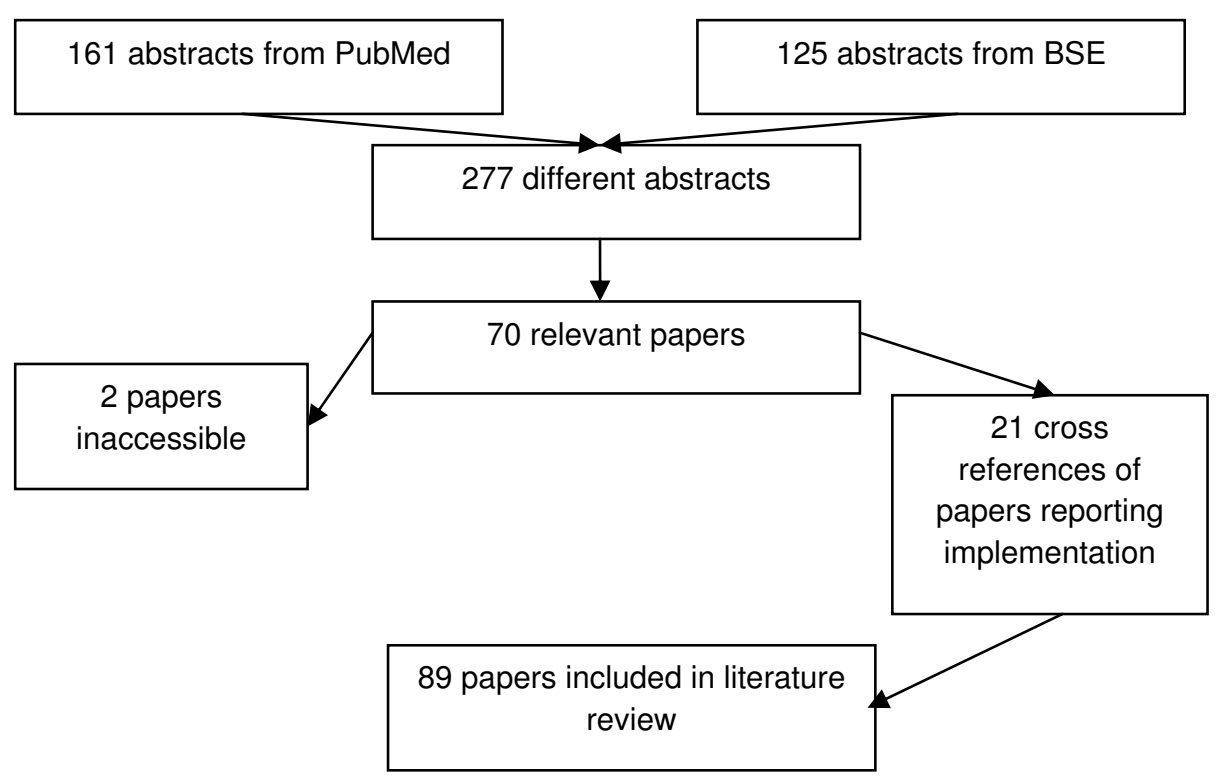

Section I: Project scope and background

Altogether, 68 papers simulated a single department, 21 multiple departments. Of all multi-department simulations, 12 included the nursing wards, 11 the operating theatre, 7 the emergency department, 7 diagnostic facilities, 3 the intensive care and 1 the pharmacy. The most frequently examined single departments are the emergency \& accidents department (18 papers), the operations theatre (15 papers) and the consultations department (13 papers). Additionally, 9 papers reported the use of their model in more than one setting.

\section{Section II: Implementation phases}

Table 2 shows that the simulation models of 73 papers presented (partial) direct benefits to the hospital and 26 stated that the hospital (partially) accepted their results. Only 10 papers reported the execution of recommendations, while 6 reported partial execution (totalling to $18 \%$ ) and 3 mentioned the intention to do this. 
Table 2 Results Section II: Implementation phases

\begin{tabular}{|l|l|l|l|l|l|}
\hline Implementation phases & Yes & Partially & $\begin{array}{l}\text { Intention is } \\
\text { mentioned }\end{array}$ & No & Not stated \\
\hline $\begin{array}{l}\text { Did the study achieve the clients } \\
\text { objectives }\end{array}$ & 89 & 0 & N/A & 0 & 0 \\
\hline $\begin{array}{l}\text { Show the study results direct } \\
\text { benefits to the client? }\end{array}$ & 71 & 2 & N/A & 11 & 5 \\
\hline $\begin{array}{l}\text { The study results are accepted } \\
\text { by the client }\end{array}$ & 21 & 5 & N/A & 0 & 63 \\
\hline The study results are executed & 10 & 6 & 3 & 1 & 69 \\
\hline
\end{tabular}

$\mathrm{N} / \mathrm{A}=$ not available

Section III: Assessing the evidence that simulation leads to improvements

Only 3 papers reported data on the effects of the implementation. One of these papers had a before-and-after design (for definition see (26)) and 2 papers described a few results after the implementation. The post implementation measurements showed that the model of 1 paper was correct, whereas the other 2 papers were correct on most of the evaluated aspects.

\section{Section IV: Technical quality factors of a simulation study}

Table 3 shows data availability is the most frequently mentioned factor that contributes to implementation of recommendations (57 times). The validation and verification of the simulation model through historic data was also identified as important (37 times). The same is true for validation and verification through expert opinion (30 times). Furthermore, the quality of the conceptual model was mentioned in 31 papers. The others' category mentioned the choice for modelling software and user friendliness 5 times, and modeller skills, 4 times. 
Table 3 Results Section IV and V: Factors related to the technical quality and process quality of a simulation study

\begin{tabular}{|l|l|}
\hline Section IV: Technical quality factors & Times cited \\
\hline Data availability & 57 \\
\hline Validation and verification through historic data & 37 \\
\hline Quality of the conceptual model & 31 \\
\hline Validation and verification through expert opinion & 30 \\
\hline Keep the model as simple as possible & 25 \\
\hline Quality of data & 21 \\
\hline Quality of data analysis & 21 \\
\hline Others & 23 \\
\hline Model includes all relevant aspects & 18 \\
\hline Sensitivity analysis & 18 \\
\hline Section V; process quality factors & Times cited \\
\hline Total commitment and support from user / client involvement & 21 \\
\hline Appropriate use of animation in the model & 19 \\
\hline Others & 16 \\
\hline Communication between those involved & 13 \\
\hline Well defined objectives and project scope & 12 \\
\hline Complete the project within time & 11 \\
\hline Realistic expectations between client and modeller & 5 \\
\hline Do not exceed the available budget & 2 \\
\hline
\end{tabular}

Section V: Factors related to the process quality of a simulation study

Table 3 also presents the process quality factors. Client involvement was the most frequently mentioned factor (21 times), followed by appropriate use of animation (19 times). In the others' category, 5 papers reported the importance of allowing sufficient time for the hospital to experiment with the model.

Section VI: Factors related to the outcome quality of a simulation study related to implementation as stated by the authors.

Most often (15 times), the presentation of the results was mentioned. Negative factors were: the simulated recommendations show improvements on one aspect but deterioration on others (10 times), changing circumstances during the project (5 times) and doubts on the cost benefit ratio (3 papers). In the others' category, 4 papers stated that, although relevant for implementation, a simulation model cannot include cultural or behavioural aspects.

\section{Survey}


After a reminder, we received responses for 41 papers; 29 returned the survey; for 12 papers the authors responded that they did not have the intention to improve a specific hospital process, the data only served to illustrate the potential of the model. The research thus limited itself to a method to calculate an optimal solution and in some cases involved a sensitivity analysis.

Table 4 shows that 21 of the 41 papers confirmed the (partial) acceptance of the recommendations. On 18 out of 41 papers $(44 \%)$ the survey reported at least partial implementation of the results. Additionally, the authors of 7 papers reported that the implemented changes were evaluated: 3 time series designs (all from the same researcher), 1 controlled before-and-after design, 1 before-and-after design and 2 partial before-and-after designs. Altogether, the survey showed that in 9 papers the implementation proved the model to be correct, 5 other models were partially correct.

Table 4 Results of the electronic survey of the authors

\begin{tabular}{|l|l|l|l|l|l|l|l|}
\hline Question & Yes & Partially & No & Unknown & Missing & $\begin{array}{l}\text { Not } \\
\text { relevant for } \\
\text { study }\end{array}$ & Total \\
\hline $\begin{array}{l}\text { The study results } \\
\text { are accepted by the } \\
\text { hospital }\end{array}$ & 11 & 10 & 1 & 4 & 3 & 12 & 41 \\
\hline $\begin{array}{l}\text { The study results } \\
\text { are executed }\end{array}$ & 7 & 11 & 5 & 6 & 0 & 12 & 41 \\
\hline $\begin{array}{l}\text { Implementation } \\
\text { proved the study to } \\
\text { be correct? }\end{array}$ & 9 & 5 & 1 & 3 & 11 & 12 & 41 \\
\hline
\end{tabular}

\section{Discussion}

The literature review and the survey showed respectively an $18 \%$ and $44 \%$ implementation rate, suggesting that actual implementation occurred more often than reported in literature. In addition, the quality of the research methods in those few cases the results were evaluated was higher in reality (17\%) than was reported in the literature $(3 \%)$. Likewise, the survey showed that more models proved to be correct in reality than in the literature. However, the survey reported that 14 models proved to be at least partially correct, while only 7 projects were evaluated with a before-and-after design. This makes the reliability of this response doubtful. It seems that some authors reported their model to be correct based on (subjective) reactions of the hospital. 
An explanation for the differences between literature and reality is that the majority of papers focused on the technical simulation aspects and not the contribution to hospital improvements. This might be related to the authors' affiliations; the majority of the papers (66 out of 89 ) included at least one member of mathematical, operations research, industrial engineering or economics research groups. These researchers may tend to publish mainly the technical modelling aspects. Consequently, most conditions for success were related to the technical quality of the model. Fone et al. (9) provided another explanation; due to the time pressure to publish "it is likely that many modelling studies are published before validation is complete and before implementation has been carried out (and assessed)." In addition, scientific publications on improvements achieved with simulation may be hampered because of the difficulty to draft a 'ceteris paribus' design, to find control sites and of many unpredictable interfering variables.

Most factors contributing to actual implementation concerned the technical quality of the simulation. Data availability was the most frequently mentioned factor ( 57 times). At least $43 \%$ of the involved hospitals had to generate new data to gain sufficient insight into their problem, this fraction could even be higher as $27 \%$ of the papers did not report on data collection. Data availability is important because the reliability of a simulation model is affected by the quality of the data used to calculate input distributions. Validation and verification of the models are essential to check the quality of the model (see Table 3).

The process management factors are related to managing the expectations of the hospital and the modeller (see Table 3). This finding is consistent with Robinson and Pidd (24). The use of animation was mentioned 19 times as a means to simplify communication between modeller and hospital. Animation, however, should be used carefully as it distracts staffs from the model details (28). It seems that closely involving medical professionals during the model development, drafting of the scenarios and the analysis of the results increases the acceptance and creates commitment for change.

Our finding that only 9 of the 89 papers reported the use of their model in more than one setting is in line with Proudlove et al. (29). An explanation is the emphasis placed on working closely with the client, meaning the best model for one hospital may be inappropriate for other hospitals (30). Often researchers make detailed models to increase the statistical descriptive power, but this hinders the demonstration of general principles (29). Fletcher and Worthington (31) plead for more generic models after identifying differences between specific and general 
models in healthcare. In emergency care, initiatives are undertaken to develop generic models (32).

\section{Research limitations}

There may be a selection bias in the paper selection process as papers were found in medical, health services and operations management and -research domains. We feel, however, that the included 89 papers are a good reflection of the available literature in this field.

Although non-scientific literature contains many examples of simulation models in healthcare (6), we did not include these since non peer-reviewed articles are not held to the same rigorous quality standards. Additionally, it is difficult to systematically identify these publications (6).

Another limitation is the possible bias in respondents of the survey. We were only able to contact authors from 67 of the 89 papers. Furthermore, of the contacted authors related to the 67 papers, only 41 responded. It is more likely that staffs still present were involved in implementation.

\section{Future research}

The relative advantage that an innovation (here simulation) has over other methods affects the uptake (33). This paper found that implementation can take place in up to $44 \%$, however actual evidence that simulation leads to improved hospital performance is limited. To increase the uptake of simulation, researchers should provide high quality evidence of improvements. To get these results published, scientific journals need to ask their authors to state whether the findings were accepted and implemented, and whether there is any evidence of an impact. Furthermore, examining popular literature on this subject remains an item for further research (6).

It would be interesting to study whether the technical, process and outcome quality of implemented recommendations are higher than those of studies that were not implemented. Because of the encountered differences between literature and reality, a survey seems the most appropriate method to study this.

This research was limited to simulation studies on operations management in hospitals. It would be interesting to extent the scope to other techniques to enable 
researchers to select the most appropriate OR techniques for specific settings. The overview of OR techniques and their advantages and disadvantages recently published by the RIGHT project is an important contribution (4) because it also discusses when to apply a specific technique and the required resources. In addition, generalization of the methods and results needs further attention. It is relevant to identify a pool of generic approaches and to design a decision schedule for its use, involving the contingent factors relevant for the decision to embark on a specific simulation approach.

\section{Conclusions}

This study showed that implementing recommendations of stochastic simulation applications on operations management in hospitals does not occur frequently; literature reports an $18 \%$ implementation rate and a survey among these researchers a 44\% implementation rate. Formal evaluations were hardly reported upon in literature; 1 study described a before-and-after design, 2 a partial beforeand-after design. To ensure a wider uptake of simulation models in hospitals more evidence of improvements, based on rigorous evaluation methods, seems necessary. Modellers and their clients - in this case relevant users within hospitals such as physicians, nurses and managers- should pay more attention to the success factors that affect the technical quality of the model, the process in which the model is developed and the usefulness of the simulation (outcome quality). Success factors regarding the technical quality are data availability, validation and verification with historic data, validation and verification through (internal) expert opinion, and the development of the conceptual model to be used in the simulation. Client involvement is most important for quality of the development process. Presenting the results in an understandable and attractive way has a large impact on the usefulness of the model as it affects acceptance and actual implementation. 


\section{References}

1. Anderson GF, Frogner BK, Reinhardt UE: Health spending in OECD countries in 2004: an update. Health Affairs 2007, 26:1481.

2. Lowery JC: Getting started in simulation in healthcare. Proceedings of the 30th conference on Winter simulation 1998, 31-6.

3. Brandeau ML, Sainfort F, Pierskalla WP. Operations research and health care. $A$ Handbook of methods and applications. International Series in Operations Research \& Management Science 70; 2004.

4. Research Into Global Healthcare Tools (RIGHT). Modelling and Simulation Techniques for Healthcare Decision Making: A Selection framework. Cambridge, UK: Engineering Design Centre, University of Cambridge; 2008.

5. Jun JB, Jacobson SH, Swisher JR: Application of discrete-event simulation in health care clinics: A survey. Journal of the Operational Research Society 1999, 109-23.

6. Brailsford SC, Harper PR, Patel B, Pitt M: An analysis of the academic literature on simulation and modelling in health care. Journal of Simulation 2009, 3(3):130-40.

7. Amoako-Gyampah K, Meredith JR: The operations management research agenda: An update. Journal of Operations Management 1989, 8:250-62.

8. Pannirselvam GP, Ferguson LA, Ash RC, Siferd SP. Operations management research: an update for the 1990s. Journal of Operations Management 1999, 18(1):95112.

9. Fone D, Hollinghurst S, Temple M, Round A, Lester N, Weightman A, et al: Systematic review of the use and value of computer simulation modelling in population health and health care delivery. Journal of Public Health, 2003;25(4):325-35.

10. Klein R, Dittus R, Roberts S, Wilson J: Simulation Modeling and Healthcare Decision Making. Medical Decision Making 1993, 13(4):347.

11. Smith-Daniels V, Schweikhart S, Smith-Daniels D: Capacity Management in Health Care Services: Review and Future Research Directions. Decision Sciences 1988, 19(4):889-919.

12. Vanberkel PT, Boucherie RJ, Hans EW, Hurink JL, Litvak NI: A Survey of Health Care Models that Encompass Multiple Departments. International Journal of Health Management and Information 2010, 1(1):37-69

13. Wilson JCT: Implementation of Computer Simulation Projects in Health Care. Journal of the Operational Research Society 1981, 32(9):825-32.

14. VanBerkel $\mathrm{P}$, Blake $\mathrm{J}$ : A comprehensive simulation for wait time reduction and capacity planning applied in general surgery. Health Care Management Science 2007, 10:37385.

15. Lagergren $\mathrm{M}$ : What is the role and contribution of models to management and research in the health services? A view from Europe. European Journal of Operational Research 1998, 105:257-66.

16. Carter L, Ulrich D, Goldsmith M. Best practices in leadership development and organization change: how the best companies ensure meaningful change and sustainable leadership. Pfeiffer; 2005.

17. Christensen CM. The innovator's dilemma: when new technologies cause great firms to fail. Harvard Business School Press; 1997.

18. Kotter JP. Leading change. Harvard Business School Press; 1996.

19. Rogers EM. Diffusion of innovations. Free Press; 1995.

20. Eldabi T, Irani Z, Paul RJ: A proposed approach for modelling health-care systems for understanding. Journal of Management in Medicine 2002, 16(2/3):170-87. 
21. Harper PR, Pitt MA: On the challenges of healthcare modelling and a proposed project life cycle for successful implementation. Journal of the Operational Research Society 2004, 55(6):657-61.

22. McHaney R, Cronan TP: Toward an empirical understanding of computer simulation implementation success. Information \& Management 2000;37(3):135-51.

23. McHaney R, White D, Heilman GE: Simulation project success and failure: Survey findings. Simulation \& Gaming 2002;33(1):49.

24. Robinson S, Pidd M: Provider and customer expectations of successful simulation projects. Journal of the Operational Research Society 1998, 49(3):200-9.

25. Robinson S: Measuring Service Quality in the Process of Delivering a Simulation Study: The Customer's Perspective. International Transactions in Operational Research 1998, 5(5):357-74.

26. Eccles M, Grimshaw J, Campbell M, Ramsay C: Research designs for studies evaluating the effectiveness of change and improvement strategies. Quality and Safety in Health Care 2003, 12(1):47.

27. Robinson S: General concepts of quality for discrete-event simulation. European Journal for Operational Research 2002;138(1):103-17.

28. Lehaney B, Clarke SA, Paul RJ : A case of an intervention in an outpatients department. Journal of the Operational Research Society 1999, 877-91.

29. Proudlove NC, Black S, Fletcher A: OR and the challenge to improve the NHS: modelling for insight and improvement in in-patient flows. Journal of the Operational Research Society 2007, 58:145-58.

30. Brailsford SC: Tutorial: Advances and challenges in healthcare simulation modeling. Winter Simulation Conference 2007, 1436-48.

31. Fletcher A, Worthington D: What is a generic hospital model? A comparison of generic and specific hospital models of emergency patient flows. Health Care Management Science 2009, 1-18.

32. Dumas A, Gunal MM, Pidd M: Moving from specific to generic: generic modelling in health care. Proceedings of the 2007 INFORMS Simulation Society Research Workshop 2007.

33. Greenhalgh T, Robert G, MacFarlane F, Bate P, Kyriakidou O: Diffusion of innovations in service organizations: systematic review and recommendations. Milbank Quarterly 2004, 82(4):581. 


\title{
7 Reducing the Throughput Time of the Diagnostic Track involving CT Scanning with Computer Simulation
}

\author{
W.A.M. van Lent \\ J.W. Deetman \\ H.J. Teertstra \\ S.H. Muller \\ E.W. Hans \\ W.H. van Harten
}

Submitted 


\section{Abstract}

Objective: To examine the use of computer simulation to reduce the time between the $\mathrm{CT}$ request and the consult in which the $\mathrm{CT}$ report is discussed (diagnostic track) while restricting idle time and overtime.

Methods: After a pre intervention analysis in our case study hospital, by computer simulation three possible interventions were evaluated on access time, overtime and idle time of the CT. Effects were prospectively evaluated on these same aspects in a post intervention analysis.

Results: The pre intervention analysis showed an average CT access time of 9.8 operating days and an average diagnostic track of 14.5 operating days. Based on the expected outcomes of the simulation, management changed the capacity for the different patient groups in such a way that a diagnostic track of ten operating days, with a CT access time of seven operating days was facilitated.

After the intervention, the average diagnostic track duration was 12.6 operating days with an average CT access time of 7.3 days. The fraction of patients with a total throughput time of maximum ten operating days increased from 29 percent to 44 percent while the utilization remained equal with 82 percent, the idle time increased by 11 percent and the overtime was reduced by 82 percent.

Conclusions: The fraction of patients that completed the diagnostic track within ten days improved with 52 percent. Computer simulation proved useful for studying the effects of proposed interventions in radiology management. Besides the tangible effects, the model increased the awareness that optimizing capacity allocation can reduce access times. 


\section{Introduction}

The volume of sophisticated technology and high-cost diagnostic imaging, such as CT and MRI, has increased substantially over the past decades. At the same time, hospitals are forced to contain their costs and consequently do not extend their capacity at the same rate. Without measurements to treat more patients with the same resources, this results in prolonged access times. Increasing the productivity is a preferable option to maintain costs, but this may be conflicting with achieving acceptable access times.

Expanding capacity, improving operating procedures, and improving capacity allocation procedures in combination with scheduling procedures can all aid in reducing $\mathrm{CT}$ access time. Expanding capacity will reduce access time, but this solution is rather expensive (1). Although improved operating procedures can reduce access time by better utilizing CT capacity, it is questionable whether this creates sufficient capacity for departments confronted with access time problems for specific patient groups. In these situations, changing the capacity allocated to each patient group can be a solution.

Due to the stochastic and uncertain nature of the process, it is usually difficult to predict the effects of a changed capacity allocation on access time and utilization. Operations research (OR) uses mathematical techniques to support decision making processes by quantifying the consequences of improvement suggestions and designing optimized interventions (2). Simulation, queuing and linear programming are examples of OR techniques. Numerous simulations in healthcare have already reported on the possible consequences of interventions that may improve resource capacity planning in uncertain and variable hospital processes $(3,4)$.

This study examines OR can be used to reduce the throughput time of the diagnostic track involving CT scanning by changing the capacity allocated to each patient group while maintaining an acceptable CT utilization. The diagnostic track starts with the outpatient consultation where the CT request is written, followed by the CT procedure(s) and ends with the consultation in which the CT report is discussed. From the patient perspective and that from the referring physician, the throughput time of the diagnostic track is more important than the CT access time. 


\section{Materials and methods}

\section{Research setting}

The Netherlands Cancer Institute - Antoni van Leeuwenhoek Hospital (NKI-AVL) is a comprehensive cancer centre, located in The Netherlands. At the time of this study the radiology department used one CT scanner for diagnostic purposes. The available capacity is divided in slots of 10 minutes. An elective diagnostic CT request consumes one slot, while requests requiring multiple $C T$ procedures may consume multiple slots. Per day, the department defined the following CT slots for diagnostic purposes:

1. 40 slots are reserved for urgent, short-term and long-term requests with a planning horizon between one day and one year. Of these slots, per day one to two slots are reserved for CT requests requiring drainage or biopsy.

2. 10 slots are reserved for emergency requests and requests that could not be treated in their preferred slot.

Staff involved in CT-scanning claimed that long-term requests (appointments scheduled more than 20 operating days ahead) filled most of the available slots and thereby blocked capacity for other requests. This resulted in prolonged access times for other requests. This last group consisted of urgent requests that need a CT within five operating days and short-term requests that need an appointment within 20 operating days. The urgent and short-term requests make up 58 percent of the total. We focused on improving the capacity allocated to each type of request. The throughput time reduction focuses on urgent and short-term requests.

\section{Study design}

A pre and post intervention design was used to study the effects of the interventions on throughput time of the diagnostic track and the overtime and idle time of the CT. With a simulation model, the effects of the proposed interventions to change the capacity allocated to each type of request were examined. Simulation was selected as preferred OR technique as it seemed suitable to solve this problem, it usually has a client friendly interface and because it is commonly applied in healthcare $(3 ; 5)$.

The throughput time of the diagnostic track is composed of three events (see A, B, $C$ in Figure 1). We measured these events for short-term and urgent requests. 
Figure 1 Throughput time indicators

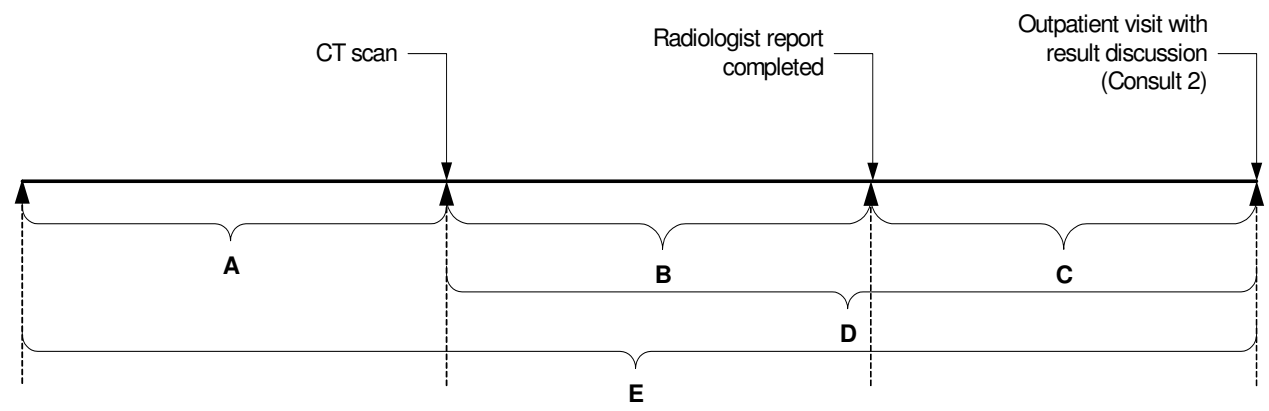

$A=$ access time to the CT scanner: working days between first outpatient appointment and the CT-scan

$\mathrm{B}=$ throughput time of the radiologist report: working days between examination and completion of radiologist's report

$\mathrm{C}=$ Throughput time between radiologist report and second consult

$\mathrm{D}=$ Access time from CT scan to second consult

$E=$ total throughput time: working days between first and second outpatient consult

To gain insight into the CT utilization we collected all performed diagnostic CT requests for outpatients, the total slots used to scan these requests, and the utilization rate. The latter was calculated as the total slots used to scan these requests divided by the capacity minus closures.

\section{Step 1: Pre intervention analysis}

This analysis is based on diagnostic CTs performed between 8 October 2007 up to and including March 2008. Data were retrieved from the radiology information system (RIS). Figure 2 describes the data collection process. First, we collected the following RIS information on all 3261 performed non-emergency diagnostic CTscans: date and time of the request, date and time of the CT, date and time of completion of the radiologist report, referring specialty, planned number of slots for the request, and urgency. For all urgent and short-term requests $(n=2022)$, we sought the corresponding consultations from the referring specialty in the Hospital Information System (HIS). Seventy-four percent of the scans were matched as requests were handed over to another specialty or consults were not registered. After matching, we excluded outliers according to the criteria in Figure 2. We were able to include $812(40 \%)$ requests with complete data in the pre intervention analysis of the diagnostic track. We calculated the throughput time in operating days. The same dataset from the RIS was used to analyse the CT utilization. 
Figure 2 Selection criteria for requests to calculate throughput time of the diagnostic track

All diagnostic $\mathrm{CT}$ requests

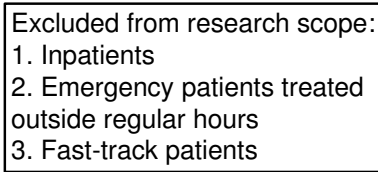

Excluded long-term patients (more than 20 operating days between first consult and CT)
Exclude incomplete data matches:

1. First consult is missing

2. Second consult is missing

3. Different specialty consults CT
Outliers excluded

1. More than 2 operating days

between outpatient consult and day on which CT was scheduled

2. More than 15 operating days

between CT scan and report completion

3. More than 20 working days between report and second consult

Patients included in analysis of the throughput time of the diagnostic track involving CT scanning 
Step 2: model development

\section{Simulation objectives}

The model, developed in Excel, calculated the CT utilization based on the parameters: access time for specific requests and a given number of total slots and a given number of slots per type of request. The model also allows the user to combine or separate capacity for urgent and short-term requests.

The throughput time from CT to second outpatient consult was not modelled. As $94 \%$ of the reports are completed within two working day (period B in Figure 1), three operating days between CT and second consult becomes a feasible target as the second consult can take place the day following report completion.

\section{Model input}

We included the capacity for inpatients, urgent outpatients and short-term outpatients as variables in the model as these groups caused most concerns, and their CT appointment and had to be scheduled within one month. Daily demand per group was determined by distributions of the requested number of slots per group. We used one year of data and Crystall Ball to determine the distributions. The generated random data were separately inserted in the model. The model assumes a stable number of available slots for each day of the week and for al weeks.

For the long-term requests we assumed a stable demand. The realized slots, noshows and cancelled scans, resulted in an average of 13 slots per day. As radiology received more than 13 long-term requests in $35 \%$ of the weeks during a year.

Before running the model, the user defines the maximum access times for the emergency requests, the urgent requests and the short-term requests. The total number of slots available is also defined, with a maximum of 55 per day. The available slots for a specific group can also be defined.

\section{Algorithm}

Before the start of each day, the model draws the daily demand per group in slots from the input file. The model schedules each demand for a slot in the first available slot for that group and takes into consideration whether a minimal CT access time of one day exists due to the need for the patient to drink contrast fluids 12 hours before the actual scan. If there are no slots available to plan the request within the user-defined maximum access time, the request is performed in overtime. When the urgent and short-term requests have the same CT access 
time, the model considers them as pooled and adjoins their capacity and demand. Figure 3 presents the planning algorithm.

\section{Model output}

For each combination of desired CT access time and slots per request group, the model calculates the expected mean, standard deviation, and confidence interval $(95 \%)$ for the idle time, overtime and hours necessary for CT scanning (regular hours and overtime).

\section{Model validation}

To create support for changes, we asked stakeholders to validate the model $(4 ; 6)$. Radiology management confirmed the face validity; the input distributions resembled demand per request group, the model and its outcomes was deemed logical. The model also was validated with historical data from the pre intervention analysis. We compared the outcomes of the model when run with real data from the pre intervention analysis and the estimated input distributions. The real data required fewer slots than the model ( 37.9 slots per day; model: 40.1 slots per day). The difference originates from a deviation between the data and input distributions. We accepted this increase of $6.0 \%$, as the department expected a similar growth in two years. 
Figure 3 planning algorithm

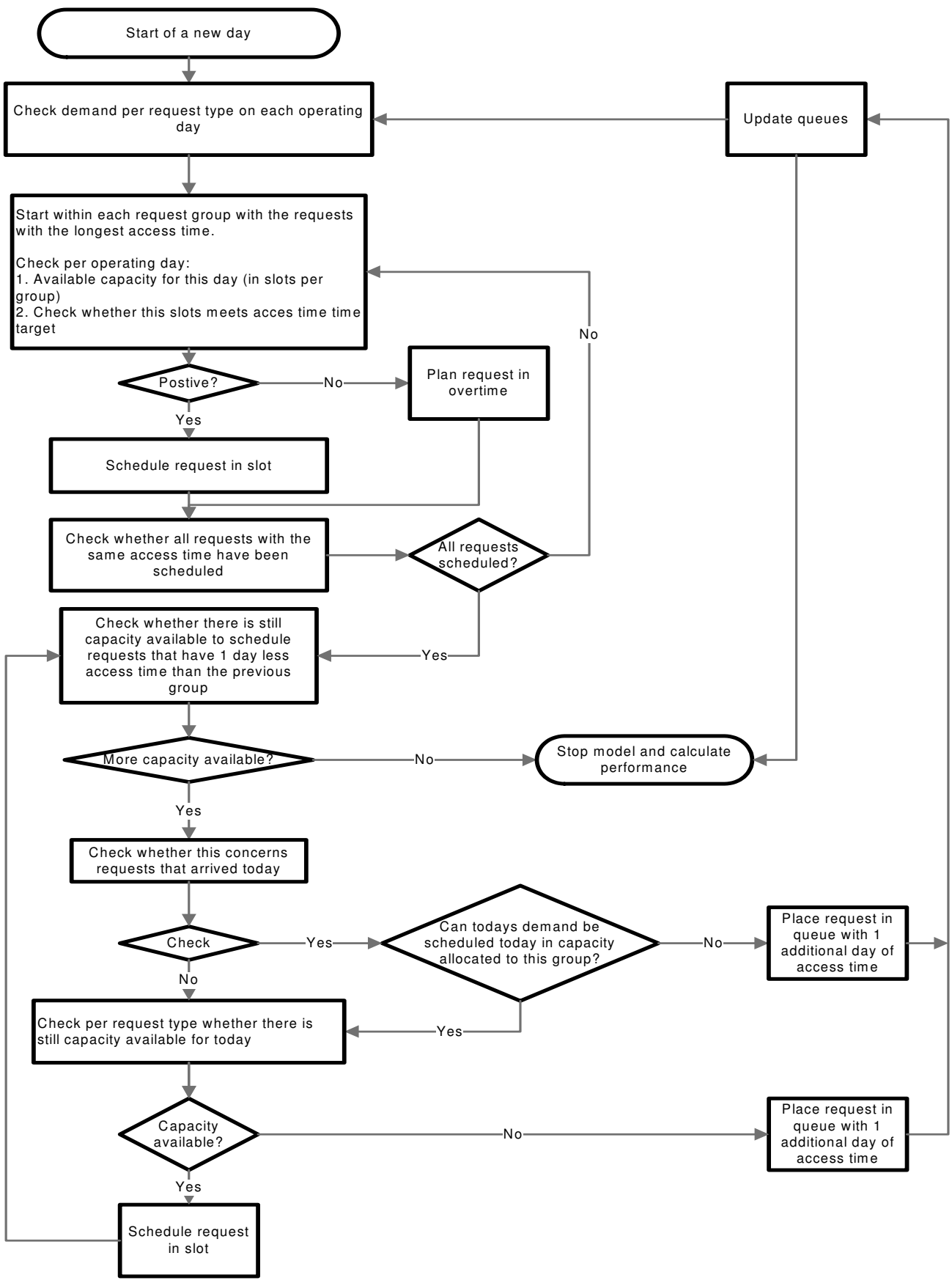




\section{Interventions}

Radiology management defined the maximum CT access time for three possible interventions. Intervention 1 allocates slots to all groups and imposes a maximum throughput time of one week for urgent requests and two weeks for short-term requests. Intervention 2 combines the urgent and short-term slots with an access time of one week. Intervention 3 has a throughput time for all requests of less than seven operating days. Table 1 summarizes the proposed interventions.

\section{Step 3: Selection of an intervention}

Radiology management used the computer simulation to select an intervention. The theoretical best intervention was defined as the shortest throughput time of the diagnostic track combined with an acceptable idle time and overtime of the CT. Radiology management verified these criteria against practical considerations such as practical feasibility and ability to handle unexpected breakdowns of equipment. Practical feasibility also included the possible increase in demand that can be expected when access times are reduced (7).

\section{Step 4: Evaluation of the intervention}

First, the pre and post intervention results were compared, followed by a comparison of the modelled outcomes and the post intervention results. Both evaluations considered the throughput time of the diagnostic track and the CT utilization as described in the pre intervention section.

For the evaluation, we collected one year of data (2009) in the same way as described in the pre intervention analysis. To determine the throughput time, we used a representative sample of requests; from all 4223 short-term and urgent CT requests that were eligible to our sample, we randomly selected 1681 (40\%) requests. Finally, we included 945 (22\%) useful diagnostic tracks in the post intervention measurement. 


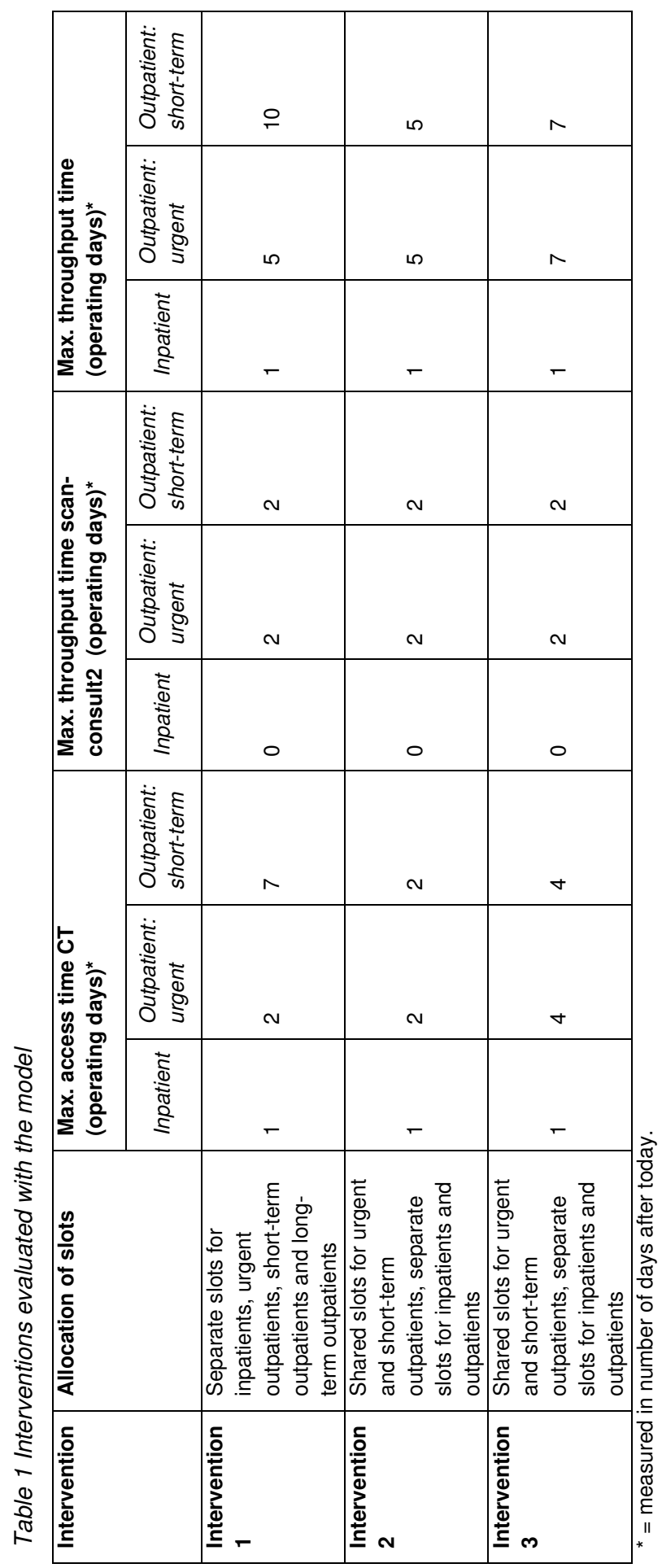




\section{Results}

Pre intervention analysis

Table 2 shows that the average throughput time for urgent and short-term requests was 14.5 operating days; altogether $29 \%$ of these requests completed the diagnostic track within two weeks. The main delay for the urgent requests was the access time of the second outpatient consult, 4.9 days on a total throughput time of 7.0 days, while on average the radiologist report was completed within 1.0 operating days after the scan. For short-term requests, the CT access time delays the total throughput time of the diagnostic tracks the most (12.3 operating days out of 16.9 operating days).

Table 2 Pre and post intervention analysis on throughput time of the diagnostic track

\begin{tabular}{|c|c|c|c|c|c|c|}
\hline \multicolumn{2}{|c|}{ Throughput time indicators } & \multicolumn{3}{|c|}{ Old situation } & \multirow{2}{*}{$\begin{array}{l}\text { New } \\
\text { situation } \\
\text { Total }\end{array}$} & \multirow{2}{*}{$\begin{array}{l}\text { Improvement } \\
(\%)\end{array}$} \\
\hline & & Urgent & $\begin{array}{l}\text { Short- } \\
\text { term }\end{array}$ & Total & & \\
\hline \multicolumn{2}{|l|}{ Requests included } & 199 & 613 & 812 & 941 & \\
\hline \multirow[t]{2}{*}{ CT access time $(\mathrm{A})$} & $\begin{array}{l}\text { Average (working } \\
\text { days) }\end{array}$ & 2.1 & 12.3 & 9.8 & 7.3 & $-25 \%$ \\
\hline & $\begin{array}{l}\text { \% treated with } \max 7 \\
\text { operating days }\end{array}$ & 100 & 13 & 34 & 58 & $+71 \%$ \\
\hline \multirow[t]{2}{*}{$\begin{array}{l}\text { Report completion } \\
\text { time (B) }\end{array}$} & $\begin{array}{l}\text { Average (working } \\
\text { days) }\end{array}$ & 1.0 & 1.1 & 1.0 & 1.0 & $0 \%$ \\
\hline & $\begin{array}{l}\% \text { treated with max } 2 \\
\text { operating days }\end{array}$ & 90 & 96 & 94 & 93 & $-1 \%$ \\
\hline \multirow[t]{2}{*}{$\begin{array}{l}\text { Access time second } \\
\text { outpatient consult (D) }\end{array}$} & $\begin{array}{l}\text { Average (working } \\
\text { days) }\end{array}$ & 4.9 & 4.6 & 4.7 & 4.4 & $-6 \%$ \\
\hline & $\begin{array}{l}\% \text { treated with } \max 3 \\
\text { operating days }\end{array}$ & 45 & 39 & 40 & 51 & $+28 \%$ \\
\hline \multirow[t]{2}{*}{$\begin{array}{l}\text { Total throughput time } \\
(E=A+D)\end{array}$} & $\begin{array}{l}\text { Average (working } \\
\text { days) }\end{array}$ & 7.0 & 16.9 & 14.5 & 12.6 & $-13 \%$ \\
\hline & $\begin{array}{l}\% \text { treated with max } \\
10 \text { operating days }\end{array}$ & 85 & 11 & 29 & 44 & $+52 \%$ \\
\hline
\end{tabular}

During the pre intervention, 3261 CT requests for diagnostic purposes were performed and they consumed 4148 slots. When correcting the number of available slots for closures due to maintenance, this resulted in a utilization rate of $82 \%$ and an overtime of 44 minutes per operating day (see Table 3 ). 
Table 3 Pre and post intervention analysis of the organizational performance of the CT

\begin{tabular}{|l|l|l|l|}
\hline Indicator & $\begin{array}{l}\text { Pre } \\
\text { intervention } \\
\text { results }\end{array}$ & $\begin{array}{l}\text { Post } \\
\text { intervention } \\
\text { results }\end{array}$ & Difference \\
\hline $\begin{array}{l}\text { Included number of requests in samples on organizational } \\
\text { performance (excluding inpatients, emergencies and } \\
\text { interventions) }\end{array}$ & $\begin{array}{l}3261 \quad \text { year: } \\
6522)\end{array}$ & 7442 & $+14 \%$ \\
\hline $\begin{array}{l}\text { Total number of slots on organizational performance } \\
\text { (excluding inpatients, emergencies and interventions) }\end{array}$ & $\begin{array}{l}4148 \\
\text { (year: 8296) }\end{array}$ & 8380 & $+1 \%$ \\
\hline Utilization rate * & $82 \%{ }^{* *}$ & $82 \%{ }^{* * *}$ & $0 \%$ \\
\hline Idle time & 73 & 81 & $11 \%$ \\
\hline Overtime & 44 & 8 & $-82 \%$ \\
\hline
\end{tabular}

* = hours used to perform CT requests for outpatients for diagnostic purposes / capacity used for diagnostic outpatient corrected for holidays and maintenance

${ }^{* *}=$ Of the 50 slots available during opening hours, 40 are available for diagnostic requests for outpatients

${ }^{* * *}=$ Of the 56 slots available during opening hours, 44 are available for diagnostic requests (24 longterm, 17 for urgent en short-term, 3 for special procedures).

\section{Modelled interventions}

Table 4 compares the interventions on idle time and overtime per operating day and throughput time of the diagnostic track. Table 4 shows that intervention 1 (two days access time for urgent requests, seven days for short-term patients) and intervention 2 (shared slots for urgent and short-term requests, two days CT access time) lead to a similar idle time, overtime time, and CT operating hours. Intervention 2 provides the best overall results; it reduces the throughput time of the short-term requests by $50 \%$, while the operating time, idle time and overtime perform slightly worse than intervention 1. Intervention 3 (CT access time of one week, shared slots for urgent and short-term requests) has the lowest overtime of the modelled interventions and the worst throughput time. 


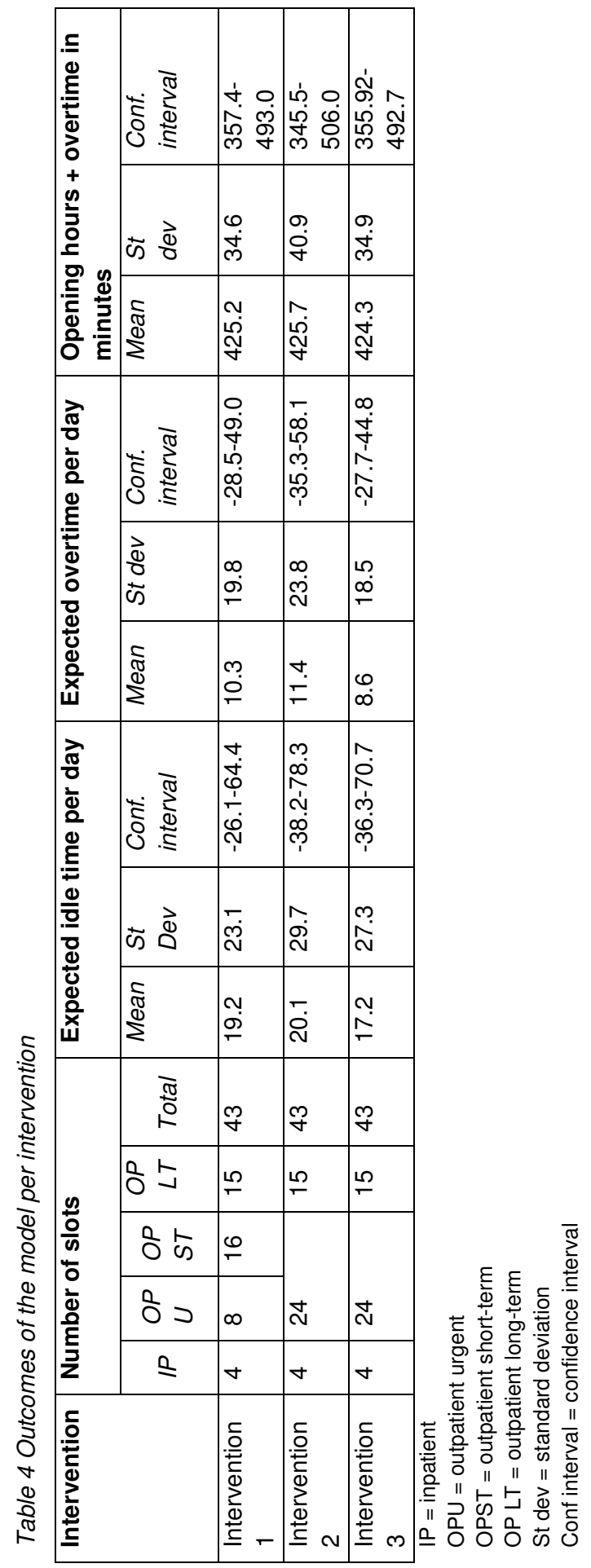


The intervention

Radiology management rejected intervention 2 (shared slots for urgent and shortterm requests, CT access time of two operating days) because with the proposed throughput times the department would be unable to anticipate on unexpected equipment breakdowns. In addition, management expected an increased demand as a result of reduced access times (7). Instead a variant to intervention 3 (CT access time of one week, shared slots for urgent and short-term requests) was selected. The modification is an additional planning rule: urgent requests require a CT access time of at most five operating days, while short-term requests are allowed CT scan within seven operating days. Thus, the capacity allocation is based on the model (tactical planning) while the proposed planning rule is implemented on the operational level.

To implement intervention 3, the new slot allocation had to be inserted into the planning system (RIS). In total, 15 long-term slots could be scheduled a year ahead, while slots for urgent and short-term requests became available seven days ahead. This would lead to a problem for slots that have to be scheduled with between eight and twenty operating days as the model regarded these as shortterm while they can only be scheduled in long-term demand slots in the RIS. Most clinical trial patients belong to this patient group (about $5 \%$ of all CT requests). Radiology management used a trial-and-error process to convert sufficient shortterm slots to long-term slots. Finally, they decided to allocate 24 long-term slots, 17 slots for short-term and urgent requests, three inpatient slots and three slots for biopsy procedures. The remaining six slots were used to level out peak demand and for breaks of the staffs. The department also changed operating procedures to enable completing a radiologist report within two operating days after the scan. Radiology informed the consultations department to plan a maximum of ten operating days between both consults, and a maximum of three operating days between scan and consult.

\section{Evaluation of the intervention}

Table 3 compares the pre intervention analysis with the post intervention analysis. The CT access time $(\mathrm{A})$ decreased from 9.8 to 7.3 days. The completion time of the radiologist report $(B)$ remained stable (1.0 versus 1.0 days) while the access time to the second consult $(C)$ hardly changed (4.7 versus 4.4 days). The average total throughput time decreased from 14.5 to 12.6. The fraction of requests with a total throughput time within ten operating days increased from 29 to $44 \%$. The fraction of requests with a CT access time within seven operating days of the first consultation increased from $34 \%$ to $58 \%$. The fraction of requests with an access time to the second consult of less than four operating days increased from $40 \%$ to $51 \%$. 
During the post intervention period 7442 CT requests were handled with 8380 slots. The utilization rate was $86 \%$. This means that the requests increased by $14 \%$ while the number of used slots increased $1 \%$. Due to changed capacity allocation, the utilization rate of the CT remained stable $(82 \%)$, while the idle time increased by $11 \%$ and the overtime reduced by $82 \%$.

We also compared the modelled results of intervention 3 with the post intervention analysis as this intervention is most comparable to reality. In the model, all requests were scanned within five operating days, had a maximum report completion time of two operating days and a maximum diagnostic track of ten operating days. In reality, $58 \%$ of the requests met the CT access time target, $51 \%$ the access time from CT to the second consult and $44 \%$ the total throughput time target.

\section{Discussion}

With a pre and a post-intervention measurement, this study showed how a computer simulation supported radiology management in their decision making process on capacity allocation for different groups on the CT scanner. Our study was rather unique as few researchers have included capacity allocation to request groups in operations research models for radiology (8-12). Of these publications, only Vasanawala et al. (8) compared the expected outcomes with the realized results. Additionally, most models regard the radiology facility as an autonomous unit that can be optimized (9-11). Our study showed that the acceptability of the recommendations in practice is affected by socio-dynamic factors, this can lead to a rejection of the intervention that was found the best according to the model. For example, when management preferred intervention 3 over intervention 2. The evaluation shows a reduced throughput time of the diagnostic track from 14.5 to 12.6 days. In the new situation, $44 \%$ of diagnostic tracks were finished within ten operating days versus $29 \%$ in the original situation. Hence, although the total throughput time has reduced, the desired levels have not been met for the majority of the eligible requests.

\section{Differences between modelled outcomes and reality}

The simulation model assumes a stable CT capacity, while in reality capacity was reduced by $12 \%$ due to maintenance, technical malfunctions and illness of staff. Thus, the model had $12 \%$ more capacity than in reality. This explains why the throughput time target was not achieved. Future research could modify the model to include capacity outages. 
The modelled outcomes already included a growth of $6 \%$ in slots, reality showed a $1 \%$ growth in slots (and a 14\% growth in requests and since 2007 a $9 \%$ growth per year in billable CT procedures). Thus, more patients are scanned in less time. As the number of slots did not grow as fast as expected, the department was able to compensate some capacity loss.

The model also assumes that maximum throughput times are always met, even if this leads to overtime. However, in reality only $51 \%$ of the second outpatient consults were planned within their target of three days. This may be caused by the lack of capacity in the consultation department or because their schedulers do not stick to the new scheduling rule.

The model does not include no-shows, which do happen in reality. When other patients cannot use these slots, capacity remains unused. The no show percentage was $1.3 \%$ in 2009 but it is impossible to determine whether the slots have been filled with other patients. Finally, a small patient group may prefer a CT scan after more than seven operating days, for example to combine the CT scan with other hospital visits.

\section{Additional benefits for radiology}

In the old situation many non-emergency CT scans had to be performed outside the slots reserved for this group. To control the workload, these scans could only be scheduled after consulting a technician or radiologist. As a result of our study, consulting a technician or radiologist to plan a request reduced considerably. The capacity was also more equally used throughout the week as the overtime reduced considerable (82\%). Another advantage of this study was that it created more awareness that good capacity allocation and planning procedures have a positive effect on access times. It also provided insights that a limited number of different types of slots in combination with sufficient slots makes planning less complex.

This study showed that combining slots for urgent and short-term requests reduces the throughput time significantly while hardly affecting the CT utilization. The department learned that pooling slots could lead to benefits. This is in line with VanBerkel et al. (13) who argue that separating patient groups usually leads to increased access times unless the service time in the unpooled department is decreased. It seems that in this study, splitting demand in urgent and short-term requests results in a highly variable demand that is more difficult to manage. 


\section{Further improvements for the case study hospital}

First, better forecasting of expected demand per type of request would support radiology management to manage access times and the efficient use of the CT. Second, management should try to provide more patients a CT access time within seven operating days. This requires a better balance between capacity and demand. This implies adaptations to the current capacity allocation caused by changes in demand and improving operating procedures, and maybe even adding more resources to the system. Third, using the online dictating system for all reports reduces the report completion time with one day and therewith the total throughput time of the diagnostic track. Fourth, the consultations department should enable more patients a consult within three days after the scan.

\section{Research limitations}

During the matching process of the RIS and HIS data, we matched about $50 \%$ of the records. Matching requests and consults with the same specialty may have been too strict. However, radiology management explained that there were no indications that the requests that were excluded by this criterion have different CT access times.

In the new situation, we could not control for changes in ratio between urgent and short-term request due to software changes in the RIS. We found neither indications that the hospital case mix had changed nor suggestions for a changed case mix in the radiology department or urgent requests that are not scheduled within time.

The model used the same demand distribution for each day of the week, which is likely to be not the case in reality. The department is able to spread out demand as most requests have a CT access time target of multiple operating days. In case of shorter target times, the department becomes more vulnerable to fluctuations in demand. Future research should consider this.

We used computer simulation because it was suitable to answer the research questions, it is popular in healthcare (5) and it can be extended to include other process aspects of the CT and radiology department as well. However, other techniques such as queuing models could be considered. This model would be somewhat similar to the model of VanBerkel et al. (14), who discuss the effects of pooling and unpooling in a chemotherapy day unit. Further research could check 
whether a queuing model would have led to the same conclusions and the efforts needed to build this model.

\section{Conclusion}

To our knowledge, this is the first study reporting on an operations research based intervention in radiology that includes the diagnostic track and that presents both the model and the results of the pre and post intervention analysis. We conclude that the use of a model to determine the capacity required per request subgroup supports the decision making process of radiology management on reducing throughput times while making efficient use of the CT: in this case $52 \%$ more patients completed the diagnostic track within ten days.

The model can be adapted to other settings examining capacity allocation for different patient groups covering all service functions of a clinical pathway such as other radiology modalities, and even other departments that are confronted with a mix of urgent and non-urgent requests. Applications of the model can also be considered for cross organizational use. 


\section{Reference List}

1. Boland GW: Diagnostic imaging centres for hospitals: a different business proposition for outpatient radiology. Journal of the American College of Radiology 2007, 4(9):581.

2. Buhaug $\mathrm{H}$ : Long waiting lists in hospitals Operational research needs to be used more often and may provide answers. British Medical Journal 2002, 324(7332):252-253.

3. Jun JB, Jacobson SH, Swisher JR: Application of discrete-event simulation in health care clinics: A survey. Journal of the Operational Research Society 1999, 109-23.

4. Van Lent WAM, Vanberkel PT, Van Harten WH: A review on the relation between simulation and improvement. Submitted to BMC Medical Informatics and Decision Making 2011.

5. Brailsford SC, Harper PR, Patel B, Pitt M: An analysis of the academic literature on simulation and modelling in health care. Journal of Simulation 2009, 3(3):130-40.

6. Law A, Kelton W. Simulation Modeling and Analysis. New York: McGraw-Hill; 2000.

7. Elkhuizen SG, Van Sambeek JRC, Hans EW, Krabbendam KJJ, Bakker PJM: Applying the variety reduction principle to management of ancillary services. Health care management review 2007, 32(1):37.

8. Vasanawala SS, Desser TS: Accommodation of Requests for Emergency US and CT: Applications of Queueing Theory to Scheduling of Urgent Studies Radiology 2005, 235(1):244.

9. Green LV, Savin S, Wang B: Managing patient service in a diagnostic medical facility. Operations Research 2006, 54(1):11-25.

10. Kolisch R, Sickinger S: Providing radiology health care services to stochastic demand of different customer classes. OR Spectrum 2008, 30(2):375-95.

11. Sickinger S, Kolisch R: The performance of a generalized Bailey-Welch rule for outpatient appointment scheduling under inpatient and emergency demand. Health Care Management Science 2009, 12(4):408-19.

12. Vermeulen IB, Bohte SM, Elkhuizen SG, Lameris H, Bakker PJM, Poutré HL. Adaptive resource allocation for efficient patient scheduling. Artificial Intelligence in Medicine 2009, 46(1):67-80.

13. Vanberkel PT, Boucherie RJ, Hans EW, Hurink JL, Litvak N: Efficiency evaluation for pooling resources in health care. OR Spectrum 2010, 25;1-20.

14. Vanberkel PT, Boucherie RJ, Hans EW, Hurink JL, Litvak N, van Lent WAM, et al: Reallocating resources to focused factories: a case study in chemotherapy. In: 34th Meeting of the European Group on Operations Research Applied to Health Services, ORAHS. 2008, Toronto, Canada. 


\section{Discussion}




\section{Introduction (chapter 1)}

The overall objective of this dissertation was the translation of business approaches to improve the resource capacity planning in care processes in hospitals. In this final chapter, the main findings are summarized and discussed, followed by methodological considerations. Subsequently, implications for further research as well as implications for hospitals are described.

\section{Main findings}

\section{Chapter 2 Exploring business approaches in Dutch hospitals}

Chapter 2 presented the results of a survey on the reported business approaches, tools and performance on resource capacity planning (also called patient logistics) in Dutch hospitals.

Hospitals reported to apply a combination of approaches and tools; a choice for a specific approach seemed lacking. The most frequently used tools, such as flow charts, standardization of care pathways, elimination of waste, distinction between flow charts and value, and line balancing did not seem to require much specific training or pre-knowledge. These tools seem also applicable to a wide range of settings and they seem to belong to different improvement approaches. Innovations, such as tools for patient logistics, that can be perceived as simple, seem to be more easily adopted than complex innovations $(1,2)$. The most frequently used tools seem to be more related to operational levels of the framework for hospital planning and control.

Of the 35 hospitals, about $50 \%$ reported to have accomplished their goals on efficiency, throughput times and financial results. This seems in contrast with Yasin et al. (3), who rated the effectiveness of approaches in US hospitals at between $68.2 \%$ for business process re-engineering and $100 \%$ for continuous improvement. The reported results were in eighty-six percent of the hospitals obtained after a quantitative evaluation, and by $92 \%$ with a qualitative evaluation. Fifty-three percent of the hospitals performed an evaluation after the intervention.

General hospitals reported a higher degree of accomplishment of their goals more frequently than the academic hospitals and the non-academic teaching hospitals. An explanation is that because general hospitals are smaller and less complex, it is 
less difficult to create an environment that supports quality improvement $(1,4)$. Another reason lies in the positive association between length of experience and the intensity of the experience with improvement approaches and the results achieved (5-7). As general hospitals have been exposed to a competitive environment for longer, they may have been working longer or more intensively on their patient logistics. Research into the selection and application of approaches, their contingency factors and goal setting procedures is required to understand what approach or combination of approaches works under specific circumstances.

\section{Chapter 3 Exploring types of focused factories in hospital care}

In chapter 3, we explored the application of the focused factory concept in hospital care with multiple case studies in which we examined the degrees of focus, the organizational context, and the operational performance.

Four multiple case studies were performed in the fields of medical oncology, orthopaedics, cataract care, and elective surgery as this reflected the variety of focus examples in the literature. The cases showed that although organizations have a comparable degree of focus, the performance might differ. This seemed affected by the alignment between the operations strategy and the resulting adaptations to the care delivery system. This is in agreement with Ketokivi and Jokinen (8) who suggested that superior performance might be the result of the design of the production processes after they found superior performance in focused and unfocused manufacturing plants.

Cross-case comparison resulted in a framework to classify focused factories: focus on the patient group treated (specialty-based), focus on the range of services offered (delivery-based) and a combination of the two other options (procedurebased). Specialty-based organizations did not seem to pursue a specific operations strategy nor adapted work designs or layouts. On the other hand, pursued deliverybased organizations often strategies to improve efficiency and lead times, they also adapted work designs and physical layouts to minimize delays. The majority of the procedure-based organizations, pursued strategies aimed at efficiency or timeliness and consequentially adapted work designs and the physical layouts. These organizations also standardized their processes and they used well-defined tasks. Physical layouts in these organizations were adapted to facilitate the treatment. Planning routines differed, but they were rather standardized. Surprisingly, most organizations in the product and process domain changed team compositions frequently. 
To measure focus an instrument based on the work Pesch and Schroeder (9) was developed. Together with the cross-case comparisons, this instrument resulted in a framework that provides insights in the main characteristics of three types of focused factories, based on product and process foci. Regarding the framework for hospital planning and control (see Figure 1 in chapter $1(10)$ ), the conclusions in chapter 2 also showed that changing the strategic level of resource capacity planning alone does not guarantee improvements, the tactical and operational level require change as well.

In 2011, McDermott and Stock (11) published another operational measure of focus in healthcare. They emphasized the patient case mix as they compared the relative size of a specific patient group with that of competing hospitals. They applied this instrument to 264.000 cardiology patients in New York and concluded that increased focus is associated with improved cost performance. This relation between focus as emphasis and improved cost performance is also in line with Schneider et al. (12) who described factors that are positively associated with the economic performance of specialty hospitals. They suggested that the same type of benefits in specialty hospitals might be attainable for units within larger hospitals.

\section{Chapter 4 International benchmarking of specialty hospitals}

Chapter 4 dealt with 1) the feasibility, 2) the process and 3) the success factors of international (comprehensive) benchmarking in specialty hospitals and specialized cancer centres. The selected research setting consisted of comprehensive cancer centres, as representative of a type of specialty hospital operating in an internationally competitive environment.

Regarding the feasibility, we conclude that comprehensive international benchmarking of specialty hospitals, such as cancer centres can produce relevant input for improvement activities regarding resource capacity planning. This was shown especially in the benchmarks on the chemotherapy day units and the radiotherapy departments. However, as registration requirements differ per country, international comparisons are often more complex than national ones; a recent international benchmarking exercise in eye hospitals confirmed this (13). The presented benchmarking process was useful in an international setting. Therefore seems the described process also useful for application in a national or regional setting.

For the second aim of this study, verifying and improving the benchmarking process, we provided a benchmarking process based on adjustments on existing benchmarking processes from Spendolini (14) and Van Hoorn et al. (15). Main 
adjustments were formalizing stakeholder involvement and verifying comparability of the partners. We also devised a framework to structure the indicators to come up with better improvement suggestions.

Finally, the research team distilled success factors for benchmarking and related them to the steps described in the proposed benchmarking process. Examples of success factors are: a well-defined and small project scope, partner selection based on clear criteria, stakeholder involvement, simple and well-structured indicators, analysis of both the process and its results, adapt the identified better working methods to the own setting and collecting and interpreting data based on an indicator set instead of an individual indicator. This latter is important as there is not (yet) a universal best practice to organize processes and the indicators within a set affect each other. For example, a good performance of one indicator (high utilization rate) can be often associated with a negative effect on another indicator (long access times).

The development of clear, reliable, comparable and discriminative indicators for benchmarking on resource capacity planning was a challenge. Appendix $\mathrm{C}$ describes the development process of an indicator set for case study 3 (radiotherapy) and the evaluation of this set in a benchmark. The indicator development process supports hospitals to develop indicators that can be used for international benchmarking.

Chapter 5 Improving the chemotherapy day unit using benchmarking and lean management

This case study examined how a combination of benchmarking and lean management can enable considerable patient growth in a chemotherapy day unit (CDU) without adding proportionally staff, while sustaining current quality and patient satisfaction levels. The study was structured according to the Plan-DoCheck-Act cycle (PDCA-cycle) (5). The chemotherapy day unit (CDU) was benchmarked with two CDUs to identify their attainable performance levels for efficiency, and causes for differences. One of the CDUs clearly outperformed the others on efficiency. This CDU provided possible best practices for the planning system and the reduction of non-value added activities.

In the Plan-phase, an in-depth analysis on efficiency, patient satisfaction and staff satisfaction in one of the CDU using lean management techniques, was performed. The following techniques were applied: direct observation of the entire process, including pharmacy, value stream mapping (16), identifying patient groups, 
identification of gaps between staff members' perceptions and performance. Rootcause analysis techniques (16) revealed causes of the perceived bed shortage and high work pressure. Furthermore, we performed an adapted Rapid-PlantAssessment (17) to determine whether the department was lean and used best practices. Finally, the improvement potential when reducing the weak points was visualized.

The in-depth analysis focused on the operational performance and the patient scheduling system. In terms of the framework for hospital planning and control ((10), see also Figure 1 in chapter 1), this study mainly focused on the operational offline level. On the strategic level, the degree of focus of the involved CDU was compared (as described in chapter 3 ) as we assumed that organizations with a similar focus could achieve similar results.

In the Do-phase, a multidisciplinary project team implemented an integrated set of interventions. The team reduced waste, based on the value stream map, developed a new planning method that delivers better value for patients and staff and tried to level peak demand by reserving certain times for specific patient groups, a technique called heijunka (16) and it tried to eliminate causes of variation or adapted the system to enable absorption of variation.

In the Check-phase, the results were evaluated. We observed $24 \%$ growth of treatments and bed utilization, a $12 \%$ increase of staff member productivity and an $81 \%$ reduction of overtime, while the average expected treatment remained stable. In the Act-phase, the project team discussed the results, with the objective of identifying further improvements.

The combination of benchmarking and lean thinking was successful in improving the efficiency of the CDU. The interventions contributed to the delivery of more timely care. Best practices from the benchmarking were used in discussions to develop a planning system that supports lean practices. Furthermore, the PDCAcycle offered a good project structure. Although the interventions are context specific, the method may serve as an example for other (oncology) settings with problems concerning resource capacity planning such as waiting times, patient flow or lack of beds. 
To our knowledge, this was one of the first peer-reviewed published studies on lean management in oncology based on a before-and-after design. Reviews on lean management published after 2009 confirm this (18-21).

\section{Chapter 6 A review on the relation between simulation and improvement}

In chapter 6, we examined 1) the execution rate of simulation study recommendations, 2) the research methods used to evaluate implementation of recommendations, 3) factors contributing to implementation, and 4) the differences regarding implementation between literature and reality. Question 1, 2 and 3 were answered with a literature review. With a survey, among authors identified in our literature review, question 4 was examined.

Altogether, 89 simulation applications on resource capacity planning in individual hospitals were included in the review. We found proof of 16 hospitals executing the recommendations (at least partially). Evaluation of the changes is seldom reported upon; only one study described a before-and-after design, two a partial before-andafter design.

The survey response rate was $61 \%$. Combining the review and the survey leads to 18 hospitals that implemented the results at least partially. The evaluation method encountered was more rigorous with three time series designs and two before-andafter designs. Although simulation publications provide promising recommendations to improve resource capacity planning in hospitals, this study showed that the evidence for results realized in practice is still limited. Our implementation rate is in line with conclusions of other reviewers in the same field (22-28).

Factors that support implementation were grouped according to 1) technical quality, 2) process quality and 3) outcome quality. Within the technical quality group, respondents mentioned data availability, validation/verification with historic data/expert opinion, and the development of the conceptual model most frequently. Client involvement is the most frequently mentioned process quality factor while presentation of results is most mentioned regarding outcome quality. These factors may support hospitals to increase the implementation rate of simulated recommendations and may support the provision of firmer evidence.

Our success factors are in agreement with Forsberg et al. (28) who identified cooperation, careful planning of simulation and modelling projects, stakeholder or 
customer involvement, and using graphics or visualizing facilitates communication as success factors.

The differences between literature and reality may be caused by the affiliation of authors to research groups that focus on model development and therefore tend to emphasize technical aspects. Sixty-six out of 89 papers included at least one member of such research group. Fone et al. (26) argue that due to the time pressure to publish, simulation studies are published before implementation has been carried out. In addition, publication may be hampered by the difficulty to draft a 'ceteris paribus' design.

\section{Chapter 7 Reducing the diagnostic track of CT scanning with computer simulation}

In chapter 7, a before-and-after analysis showed how computer simulation supported radiology management in their decision making process to reduce the throughput time of the diagnostic track involving CT scanning by changing the capacity allocated to each patient group while maintaining an acceptable CT utilization. The study showed that socio-dynamic factors sometimes lead to a rejection (or as partly accepting) of the best possible intervention according to the model.

Management decided to change the allocated capacity to enable a diagnostic track of ten operating days with a CT access time of seven operating days. After the intervention, the average throughput time of the diagnostic track (first consult - CT - second consult) was reduced from 14.5 to 12.6 days. The fraction of patients with a total throughput time of maximum ten days increased by 52 percent from 29 to 44 percent. At the same time, the utilization remained equal with 82 percent, the idle time increased by 11 percent and the overtime reduced by 82 percent.

To our knowledge, this is one of the first studies reporting on the model and the results of an intervention in radiology that includes the diagnostic track and not just the access time to a radiology modality. Using computer simulation to analyse the effects of capacity allocated to a specific patient group and desired CT access times on CT utilization supported the decision making process for radiology management. Besides the tangible effects, the model increased the awareness that optimizing capacity allocation can reduce access times. The model can be adapted to other, similar settings, when the input data are adjusted to the new research setting. 


\section{Methodological considerations}

This section summarizes the methodological considerations of this dissertation per case and/or research method; research designs in organizational improvement cannot always follow optimal clinical research methods as extensively described by Övretveit et al. (29).

\section{Considerations}

In chapters 2, 3, 4, 5, and 7, we applied business approaches. As the taxonomy of business approaches in healthcare is rather unexplored and validated instruments to operationalize the approaches are in a premature stage, it is difficult to state in an objective way whether a hospital (department) applies a specific approach. Future research should develop this taxonomy and measurement instruments.

With the exception of the survey on patient logistics (chapter 2) and the literature review and survey on simulation (chapter 6), this dissertation consists of case studies (see chapter 3, 4, 5 and 7). All case studies used a before-and-after design. A disadvantage of this research type is that various aspects such as sociodynamic processes might change during the project and affect the results (30). Consistently, we checked whether management of the department experienced other changes that may have affected the results and whether they perceived changes in quality, patient satisfaction or staff satisfaction. In chapter 5 we used data to confirm this. We did not find indications for these changes, thus it is most likely that the results are valid.

In chapter 7, we used mathematical modelling. This model was based on assumptions such as no capacity reductions due to maintenance and all patients show up, as it was a simplification of reality. The assumptions explained most of the differences between the modelled and realized outcomes. Models that include more accurate assumptions lead to better projections although their development is more time consuming. A long duration between start and finish of the model may also increase the chance on changes in the modelled setting (see chapter 6). To improve the models, more data on the assumptions is needed. Chapter 6 showed that data availability is an important success factor to implement recommendations of a simulation. At least $43 \%$ of case study hospitals had to generate new data. Chapter 7 showed that these data are often hard to obtain. 


\section{Generalizability}

The study population of the survey of chapter 2 consisted of Dutch hospitals. A relevant question is whether the results of the survey remain valid for other countries. Financial stimuli seem to motivate hospitals to change their processes, therefore the results seem most generalizable to countries with comparable financial systems. The results seemed, however, in contrast with the paper of Yasin et al. (3) who found that the effectiveness of approaches in US hospitals was rated between $68.2 \%$ (business process re-engineering) and 100\% (continuous improvement). The difference with our study may be caused by differences between the countries or the reporting method. Yasin et al. (3) asked the respondents to rate the approaches from very ineffective to very effective whereas our survey checked whether the objectives were achieved. Both explanations require further research. The survey itself does not contain country specific information and is valid for use in other countries.

Chapter 3, 4, 5, and 7 used case studies. Conclusions based upon case studies can be generalized if the following conditions are satisfied: transparency about methods and context (31), combination of quantitative and qualitative methods (32). By using a combination of quantitative data and qualitative data to verify the results and, we tried to use data triangulation wherever possible to check for indications that other (uncontrolled) factors affected the results. In each paper, we described the context. We also explained that the presented interventions in chapter 3, 4, 5 and 7 are more or less context specific. Most cases were limited to cancer centres. Cancer care is represented in nearly all hospitals, the costs related to cancer care are substantial $(33,34)$ and the costs are expected to increase at a faster rate than overall medical expenditures (34). We expect the used research methods to be applicable to other settings as well, because cancer care seems representative for many hospital processes due to its urgency, complexity and uncertainty. Thus, the methods used to improve processes seem general applicable, while the scope of the resulting changes is context specific.

The simulation model described in chapter 7 can be adapted to other settings examining capacity allocation for different patient groups when the input data are adjusted. Possible new settings include other CT-scan facilities, but also other radiology facilities and possibly even other departments. The model can also be applied to an extramural setting in which the GP can be considered as referring department. 


\section{Implications for research and practice}

The findings and methodological considerations have implications for further research and hospital practice. The recommendations for further research focus on actions needed to determine which approach is most successful in a specific setting. The implications for hospitals elaborate on the experiences based on this dissertation to select specific business approaches.

\section{Further research}

Develop a taxonomy and validated instruments to verify whether a specific approach is applied

In chapter 2, no indications for a relation between specific business approaches and goal accomplishment were found. Inappropriate use of methods and ineffective methods may explain these results. When research projects into the implementation and effects of certain business approaches are to be executed on a more developed methodological level, we are in need of a taxonomy of approaches and validated instruments that can be used to verify whether a hospital (or department) applies a specific approach.

A start was made for focused factories with the instrument developed in chapter 3 to measure the degree of focus. Differences between the fields and national healthcare systems make it necessary to adapt the instrument to each specialty field, for instance through defining the ICD code limits. Also McDermott et al. (11) developed an instrument to measure focus, they measured focus as the relative proportion of the total hospital.

In 2010, Van Vliet et al. (35) used lean literature to operationalize lean characteristics in order to examine the degree to which lean characteristics (operational focus, physical layout, dedicated resources, cross training, pull planning and eliminated waste) were incorporated in the cataract pathway to efficiency. They suggest that operational focus has stronger effect on efficiency than other lean characteristics.

Pluimers et al. (36) explored the differences and similarities between lean and lean six sigma tools in a literature review and developed and used a theoretical framework of lean and lean six sigma criteria to verify the tools encountered in applications reported in the literature. They identified 38 papers and suggest that a combination of tools does not seem to match with a structured format, and a strict 
demarcation between lean and lean six sigma could not be identified yet. Further development of these definitions and types of frameworks may result in instruments to measure whether a hospital applies a specific approach.

\section{Use more rigorous evaluation methods}

Chapter 2, 3, 4, 5, 6, and 7 presented evidence that focused factories, lean management, benchmarking and mathematical models can be translated to hospitals to improve resource capacity planning. Future research, however, should include more rigorous evaluation methods to minimize the effect of a combination of changes occurring simultaneously and other uncontrolled activities in the research setting $(29,37)$ as firmer evidence increases the generalizability of the findings.

First, evaluations of interventions using a time series design are needed as this allows studying the sustainability of improvements (38). Second, from a methodological perspective, the use of a control group would be ideal but this is often impossible due to organization specific characteristics and the willingness of hospitals to participate in this type of research type. Starting with single control organization would be a first valuable step. Third, future descriptive research should preferably use larger series of hospitals that include organizations with similar characteristics and organizations with different characteristics. This allows both literal and theoretical replication (39). Finally, stronger evidence for the success of these approaches, -including the effects on other quality aspects as defined by the loM (49) such as safety and patient centeredness-, might increase the uptake of specific approaches. Recently, Pluimers et al. (40) reviewed the literature for evidence of operations management based applications on patientrelated (clinical) outcomes. They identified 18 papers of which nine studies reported quantitative outcomes and six reported significance. The limited number of papers, suggest that this is an unexplored area and that further research is recommended.

\section{Examine the effectiveness of the approaches and their contingency factors}

Sousa and Voss (41) suggested contingency factors affect the outcomes of operations management intervention and therefore there is probably no universal best practice for all organizations. This might explain why we did not find indications for a relation between specific patient logistic approaches and goal accomplishment. In chapter 3 on focused factories, we showed that it is likely that these contingency factors affect the relation between focus and performance. Zinn 
and Mor (42) argue that effective organizations design their structures to support their service delivery process and to have a good fit with their customer environment. From a contingency perspective, the match between organizational structure - which is strongly affected by focus- and a specific setting affects the ability of an organization to achieve its objectives (43). However, factors affecting the outcomes of interventions that aim to improve performance have not been examined frequently in healthcare (44). Therefore, more research on the effectiveness of the approaches and their contingency factors is needed to figure out which approach works best in a specific setting.

\section{Extend the research scope towards multidepartment processes}

Another suggestion for further research is to examine the use of the specific approaches in multidepartment processes or specific hospital functions. In our approach on lean management in chapter 4, a start was made with this by checking the alignment with other related departments. In chapter 7 on the radiology department, we considered the diagnostic track of a CT instead of access time to the CT. In this way, improvements are not aimed at a single department or a specific function but at an entire process. This multidepartment approach can prevent sub optimization of a department.

\section{Implications for hospitals}

Since the interventions to improve resource capacity planning (see chapter $3,4,5$ and 7) are more or less context specific, hospitals can use the improvement processes that these approaches provide but they need to draft their interventions accordingly. For (international) benchmarking, they may use the process presented in chapter 3. They can also use the lean management elements of the in-depthanalysis presented in chapter 4 and the PDCA-cycle. The success factors that help hospitals to increase the implementation rate of simulation recommendations (see chapter 6) can be used when hospitals decide using simulation. When the input data for the model presented in chapter 7 are adapted, the model may be used in other settings that examine capacity allocation for different patient groups. We consecutively describe considerations regarding the use of the business approaches and leadership issues.

\section{Considerations regarding the use of the business approaches}

The cross-case comparison in chapter 3 suggested that focus factories might lead to higher productivity and utilization, especially when the service delivery system is adapted to accommodate to the focus strategy. As separating departments into focused units is expensive and often almost irreversible, the decision for focus 
cannot be made lightly. Vanberkel et al. (45) examined this problem mathematically and concluded that focus under most circumstances leads to an increased access time in the unfocused department unless the service time in the unfocused department is decreased without adding additional resources. The main characteristics to consider in this decision are utilization of the original clinic, proportional size of the patient groups, resource division and variability in appointment length. Thus, hospitals considering focus should consider these characteristics before deciding to focus. In this light, the work of McDermott et al. (11) becomes more relevant as they concluded that focus as emphasis also results in better performance.

Hospitals considering benchmarking to improve resource capacity planning (see chapter 4) should realize that the initiating organization is dependent of its benchmarking partners in identifying improvement opportunities. This includes both the willingness of other organizations to participate and the ability to identify partners with better working procedures. Top hospitals in the field of resource capacity allocation are often unknown, although rankings of high-performing hospitals in a specific field tend to include more of these aspects. However, rankings are not sufficient to spread best practices across hospitals (46) as insight into the underlying processes is needed (47).

Chapter 5 provided recommendations for hospitals who are considering the use of lean management principles. An advantage of lean management is its focus on the creation of value for the customer which is usually the patient in hospital settings. This contributes to commitment of all stakeholders. Aligning all stakeholders is important, Klopper et al. (48) showed a positive relation between cooperation between managements and physicians, and hospitals performance. The effect of value creation is even larger because it is not limited to operations management as it includes safety as well. For hospitals, this means that trade-off between efficiency and other quality aspects as defined by the loM (49) are addressed as well. When business jargon is avoided, hospital staffs such as physicians and nurses may be more willing to stand open for lean management (50). It is likely that most lean management elements can be taught to hospital staff members as all staffs at Toyota also participate in lean improvements (51). Training staffs in lean management, enables staffs to change their own processes. This staff involvement fits well with hospitals as they are characterized as professional bureaucracies with highly educated staffs that need more autonomy to function well (52). Broad principles that can be taught to many staffs in different process are an advantage of lean management. However, this has the disadvantage that it remains rather vague what exactly constitutes lean management (53). 
Chapter 7 presented the development of a simulation model that supported decision makers within valuable information on the allocation of capacity on the CT scan. The process was so complex that the consequences of the proposed intervention on access time and CT utilization could not be overseen. In these situations, simulations seem most valuable. Hospitals should however consider that simulations do not represent reality perfectly as models are based on assumptions (see chapter 7). In chapter 6 we presented success factors that support the implementation of simulated recommendations. The most frequently mentioned success factors considered technical aspects such as data availability, validation/verification with historic data/expert opinion and development of the conceptual model. This pleads for modellers that have had sufficient training and experience. Most hospitals however, employ few people with these competitions. This means that the modeller is usually an external person (academic or consultant) or a staff advisor in the hospital. Chapter 6 also showed that a good collaboration between modeller and client is necessary to develop a model that will be used for decision making. This collaboration has to include the project planning, the development of the conceptual model, the assumptions and the presentation of the results.

\section{Leadership issues}

During our case studies, a type of action research was followed as the researcher was actively involved in the research project (54). We had the impression that this increased the effectiveness of the change process as it brought new capabilities to the hospital (55). The approach guaranteed a scientific base to this work. This provided authority to convince physicians of the benefits of business approaches more easily. This suggests that hospital leaders should have sufficient knowledge on the business approaches to take over the role that was fulfilled by the researcher or they should appoint someone with that knowledge in their department.

As it is yet unknown which improvement approach works best in a specific setting, hospital leaders should be open for exchanges of experiences with peers and new scientific evidence. Hospitals should also stand open for a contingency approach in that there is no universal best practice to organize resource capacity planning in hospitals (41). For example, experience with improvement approaches has a positive effect on the results achieved (5-7). Standing open for these considerations can be helpful in choosing the appropriate (combinations of) approaches on the strategic, tactical and operational level. In view of the reflection on the use of the business approaches, lean management and operations research seem most promising. 


\section{Reference List}

1. Denis JL, Hébert $Y$, Langley A, Lozeau D, Trottier LH: Explaining diffusion patterns for complex health care innovations. Health care management review 2002, 27:60.

2. Rogers EM: Diffusion of innovations. Free Press; 1995.

3. Yasin MM, Zimmerer LW, Miller P, Zimmerer TW: An empirical investigation of the effectiveness of contemporary managerial philosophies in a hospital operational setting. International Journal of Health Care Quality Assurance 2002, 15:268-276.

4. Carman JM, Shortell SM, Foster RW, Hughes EFX, Boerstler H, O'Brien JL, O'Connor EJ: Keys for successful implementation of total quality management in hospitals. Health care management review 1996, 21:48.

5. Deming WE: Out of the Crisis. The MIT Press; 2000.

6. Duckers M, Makai P, Vos L, Groenewegen P, Wagner C: Longitudinal analysis on the development of hospital quality management systems in the Netherlands. International Journal for Quality in Health Care 2009, 21:330.

7. Olson JR, Belohlav JA, Cook LS, Hays JM: Examining quality improvement programs: the case of Minnesota hospitals. Health Services Research 2008, 43:17871806.

8. Ketokivi M, Jokinen M: Strategy, uncertainty and the focused factory in international process manufacturing. Journal of Operations Management 2006, 24:250-270.

9. Pesch MJ, Schroeder RG: Measuring factory focus: an empirical study. Production and Operations Management 1996, 5:234-254.

10. Hans EW, Van Houdenhoven M, Hulshof PJH: A framework for health care planning and control. In: Handbook of Health Care Systems Scheduling. Hall, Randolp (Ed.) Springer International Series in Operations Research \& Management Science, 2011, 168: chapter 12.

11. McDermott CM, Stock GN: Focus as emphasis: Conceptual and performance implications for hospitals. Journal of Operations Management 2011.

12. Schneider JE, Miller TR, Ohsfeldt RL, Morrisey MA, Zelner BA: The economics of specialty hospitals. Medical Care Research and Review 2008, 65:531.

13. de Korne DF, Sol KJCA, van Wijngaarden JDH, van Vliet EJ, Custers T, Cubbon M, Spileers W, Ygge J, Ang CL, Klazinga NS: Evaluation of an international benchmarking initiative in nine eye hospitals. Health care management review 2010, 35:23.

14. Spendolini Michael J: The Benchmarking Book. New York: Amacom 1992.

15. Van Hoorn A, Van Houdenhoven M, Wullink G: Een nieuw stappenplan voor benchmarking. Management Executive 2006,1-15.

16. Womack JP, Jones DT: Lean thinking: banish waste and create wealth in your corporation. Simon and Schuster; 2003.

17. Goodson RE: Read a Plant-Fast. Harvard Business Review 2002, 80:105-113.

18. Mazzocato $P$, Savage $C$, Brommels $M$, Aronsson $H$, Thor J: Lean thinking in healthcare: a realist review of the literature. Quality and Safety in Health Care 2010.

19. Vest JR, Gamm LD: A critical review of the research literature on Six Sigma, Lean and StuderGroup's Hardwiring Excellence in the United States: the need to demonstrate and communicate the effectiveness of transformation strategies in healthcare. Implementation Science 2009, 4:35.

20. Poksinska B: The Current State of Lean Implementation in Health Care: Literature Review. Quality Management in Healthcare 2010, 19:319.

21. DelliFraine JL, Langabeer JR, Nembhard IM: Assessing the evidence of Six Sigma and Lean in the health care industry. Quality Management in Healthcare 2010, 19:211. 
22. Brailsford SC, Harper PR, Patel B, Pitt M: An analysis of the academic literature on simulation and modelling in health care. Journal of Simulation 2009, 3:130-140.

23. Wilson JCT: Implementation of Computer Simulation Projects in Health Care. Journal of the Operational Research Society 1981, 32:825-832.

24. Lagergren $\mathrm{M}$ : What is the role and contribution of models to management and research in the health services? A view from Europe. European Journal of Operational Research 1998, 105:257-266.

25. Fone D, Hollinghurst S, Temple M, Round A, Lester N, Weightman A, Roberts K, Coyle E, Bevan G, Palmer S: Systematic review of the use and value of computer simulation modelling in population health and health care delivery. Journal of Public Health Medicine 2003, 25:325-335.

26. Gunal MM, Pidd M: Discrete event simulation for performance modelling in health care: a review of the literature. Journal of Simulation 2010, 4:42-51.

27. Brailsford S: Overcoming the barriers to implementation of operations research simulation models in healthcare. Clinical and investigative medicine Medecine clinique et experimentale 2005, 28:312.

28. Forsberg HH, Aronsson $\mathrm{H}$, Keller $\mathrm{C}$, Lindblad S: Managing Health Care Decisions and Improvement Through Simulation Modeling. Quality Management in Healthcare 2011, 20:15.

29. Õvretveit J, Gustafson D: Evaluation of quality improvement programmes. Quality and Safety in Health Care 2002, 11:270.

30. Van Harten WH, Casparie TF, Fisscher OAM: Methodological considerations on the assessment of the implementation of quality management systems. Health Policy 2000, 54:187-200.

31. Plochg T: Handboek gezondheidszorgonderzoek. Bohn Stafleu van Loghum; 2007.

32. Bergen A, While A: A case for case studies: exploring the use of case study design in community nursing research. Journal of Advanced Nursing 2000, 31:926-934.

33. RIVM. Costs of diseases version 1.1 [http://www.kostenvanziekten.nl] [In Dutch: Kosten van Ziekten 2005] Last accessed 7-7-2011.

34. National Cancer Institute. Cancer trends progress report. 2006. [http://progressreport.cancer.gov] Last accessed: 7-7-2011.

35. Van Vliet EJ, Bredenhoff E, Sermeus W, Kop LM, Sol JCA, van Harten WH: Exploring the relation between process design and efficiency in high-volume cataract pathways from a lean thinking perspective. International Journal for Quality in Health Care 2011, 23:83.

36. Pluimers DJ, van Vliet EJ, Van Harten WH. Comparing lean with lean six sigma interventions in healthcare; do reported studies reflect the theory? Submitted to International Journal for Quality in Health Care 2011.

37. Õvretveit J, Gustafson D: Using research to inform quality programmes. BMJ 2003, 326:759.

38. Eccles M, Grimshaw J, Campbell M, Ramsay C: Research designs for studies evaluating the effectiveness of change and improvement strategies. Quality and Safety in Health Care 2003, 12:47.

39. Voss C: Case Research in Operations Management. In Researching Operations Management. Edited by Edited by Karlsson C. Taylor \& Francis; 2009:162-195.

40. Pluimers DJ, Van Harten WH. Relationships between healthcare-applied operations management techniques and patient-related (clinical) outcomes. Submitted to International Journal for Quality in Health Care 2011.

41. Sousa R, Voss CA: Contingency research in operations management practices. Journal of Operations Management 2008, 26:697-713.

42. Zinn JS, Mor V: Organizational structure and the delivery of primary care to older Americans. Health Services Research 1998, 33:354. 
43. Tummers GER, van Merode GG, Landeweerd JA: Organizational characteristics as predictors of nurses psychological work reactions. Organization Studies 2006, 27:559.

44. Alexander JA, Hearld LR: The Science of Quality Improvement Implementation. Medical Care 2010, 48:000.

45. Vanberkel PT, Boucherie RJ, Hans EW, Hurink JL, Litvak N: Efficiency evaluation for pooling resources in health care. OR Spectrum 2010 (online first), 1-20.

46. Powell AE, Davies HTO, Thomson RG: Using routine comparative data to assess the quality of health care: understanding and avoiding common pitfalls. Quality and Safety in Health Care 2003, 12:122.

47. Camp RC: Benchmarking: The Search for Industry Best Practices that Lead to Superior Performance. Milwaukee,(USA) 1989.

48. Klopper-Kes HAHJ.: Mind the gap. Assessing cooperation between physicians and managers and its association with hospital performance. PhD Thesis. 2011.

49. Committee on Quality of Health Care in America: Crossing the Quality Chasm: A New Health System for the 21st Century. Washington DC: Institute of Medicine; 2001.

50. Locock L: Healthcare redesign: meaning, origins and application. British Medical Journal 2003, 12:53.

51. Liker JK: The Toyota way: 14 management principles from the world's greatest manufacturer. McGraw-Hill Professional; 2004.

52. Mintzberg H: Mintzberg on management. Free Press New York; 1989.

53. Shah R, Ward PT: Defining and developing measures of lean production. Journal of Operations Management 2007, 25:785-805.

54. Coughlan P, Coghlan D: Action research for operations management. International Journal of Operations \& Production Management 2002, 22:220-240.

55. Fraser I, Encinosa W, Glied S: Improving Efficiency and Value in Health Care: Introduction. Health Services Research 2008, 43:1781-1786. 
9 Summary 


\section{Chapter 1: Introduction}

To deliver high quality care against acceptable costs, hospitals have to increase the utilization of their resources while delivering timely and patient centred care. Resource capacity planning addresses the capacity used to deliver the services. The aim of this dissertation was to contribute to the knowledge on the translation of approaches from business and services to improve the resource capacity planning on the tactical and operational level in hospital care. The research questions and main findings are described per chapter.

\section{Chapter 2: Patient logistic approaches in Dutch hospitals}

The research question of chapter 2 was: what approaches and tools on patient logistics use Dutch hospitals, what is their effect on performance and how are they evaluated? In 94 hospitals, we surveyed such approaches and the tools used to support them, and analysed the results the hospitals claimed to have achieved.

Forty-eight percent of all hospitals participated. Ninety-eight percent of the respondents used multiple approaches, $39 \%$ of them using five approaches or even more. Care pathways were the approach preferred by $43 \%$, followed by business-process re-engineering and lean six sigma (both 13\%). Flowcharts were the commonest tool, and were used on a regular basis by $94 \%$ hospitals. Less than $10 \%$ of the hospitals used DEA analysis and critical path analysis on a regular basis. Approximately $50 \%$ of hospitals that evaluated the effects of approaches on efficiency, throughput times and financial results reported that they had accomplished their goals. Goal accomplishment in general hospitals ranged from $63 \%$ to $67 \%$, in academic teaching hospitals from $0 \%$ to $50 \%$, and in teaching hospitals from $25 \%$ to $44 \%$.

Hospitals used a combination of approaches and tools. Management did not seem to select a specific approach. No approach seemed to outperform the others on efficiency, throughput times and financial results. To understand which approach works best under specific circumstances, research should be conducted into the selection and application of approaches, their contingency factors, and goal-setting procedures. 


\section{Chapter 3: Exploring types of focused factories in hospital care}

Focusing on specific treatments or diseases is proposed as a way to increase the efficiency of hospital care. Examples of focused factories consider very different types of organizations such as cancer clinics, trauma centres, specialty hospitals and ambulatory surgery centres. As the definition of 'focus' in hospital care seemed to lack clarity, we explored in chapter 3 the application of the focused factory concept in four multiple case studies, by examining the degree of focus, the organizational context, and the operational performance.

Four multiple case studies in different medical fields were selected to reflect the variety of focus examples reported in the literature. The degree of focus was investigated with an instrument from industry that was adapted for this study. Data were collected using both qualitative and quantitative methods and included site visits. A descriptive analysis was performed at the case study and cross-case studies level.

Focus in hospital care relates to limitations on the patient group treated and the range of services offered. Cross-case comparison resulted in a framework with three focus domains: specialty-based domain, delivery-based domain and a combination of the two other options. The product domain considered specialty based focused factories that treated patients for a single-specialty, but did not pursue a specific strategy nor adapted work designs or layouts. The process domain considered delivery based focused factories that treated multiple groups of patients and often pursued strategies to improve efficiency and timeliness and adapted work designs and physical layouts to minimize delays. The productprocess domain treated a single well-defined group of patients offering one type of treatment.

Furthermore, the cross-case analysis concluded that although organizations have a comparable degree of focus, the performance might differ. This seems to be affected by the alignment between the operations strategy and the resulting adaptations to the care delivery system.

The conclusions also showed that changing the strategic level of resource capacity planning alone does not guarantee an improved operational performance, the tactical and operational level require change as well. The proposed framework provides insights in the main characteristics of three domains of focused factories and offers a way for identifying similar types of focused factories, based on product and process foci. 


\section{Chapter 4: International benchmarking in specialty hospitals}

Benchmarking is one of the approaches used in business that are applied to hospitals to increase the management of their operations. As there is a trend towards specialization and international exchange, Chapter 4 dealt with the feasibility, the process and the success factors of international (comprehensive) benchmarking in specialty hospitals and specialized cancer centres. This was examined in three international benchmarking studies in three comprehensive cancer centres (CCC), three chemotherapy day units (CDU) and four radiotherapy departments.

Case study 1 concentrated on the process for benchmarking operations management within CCCs. It resulted in general recommendations for the involved organizations and the benchmarking process. In the other cases, the benchmarking process was further refined, and success factors were examined. In case 2, we applied benchmarking to the CDU; together with lean management this led in one unit to an increased bed utilization and productivity of $24 \%$ and $12 \%$ respectively. In case 3 , we focused on the indicator development process. Two radiotherapy departments are currently working on improvement of linear accelerator downtime and on the clinical trial inclusion process.

Comprehensive benchmarking of specialty hospitals, such as cancer centres, can produce relevant input for improvement activities. We adapted existing benchmarking processes, by formalizing stakeholder involvement and verifying comparability of the partners. We also devised a framework to structure the indicators to come up with better improvement suggestions. Finally, the research team distilled success factors such as a well-defined and small project scope, partner selection based on clear criteria, stakeholder involvement, simple and wellstructured indicators, analysis of both the process and its results, adapting the identified better working methods to the own setting and collecting and interpreting data based on an indicator set instead of an individual indicator.

Related to benchmarking is indicator development, Appendix $C$ describes this process for radiotherapy departments. .

\section{Chapter 5: Improving the chemotherapy day unit using benchmarking and lean management}

This case study examined how a combination of benchmarking and lean management can enable considerable patient growth in a chemotherapy day unit 
(CDU) without adding proportionally staff, while sustaining current quality and patient satisfaction levels. Like many healthcare improvement projects, this project is structured according to the Plan-Do-Check-Act-cycle. The chemotherapy day unit (CDU) was benchmarked with two CDUs to identify attainable performance levels for efficiency, and causes for differences. Furthermore, an in-depth analysis on efficiency, patient satisfaction and staff satisfaction in one of the CDU using lean management techniques, was performed in the Plan-phase. In the Do-phase, a multidisciplinary project team implemented an integrated set of interventions such as a new planning system. In the Check-phase, the results were evaluated.

We observed $24 \%$ growth of treatments and bed utilization, a $12 \%$ increase of staff member productivity and an $81 \%$ reduction of overtime, while the average expected treatment remained stable. In the Act-phase, the project team discussed the results and identified further improvements.

The used method increased the efficiency of the CDU and resulted in a more timely delivery of care. Thus, the business approaches, which were adapted for healthcare, were successfully applied. The method may serve as an example for other healthcare settings with problems concerning waiting times, patient flow or lack of beds.

\section{Chapter 6: The relation between simulation and implementation of recommendations}

Simulation applications on operations management in hospitals claim to support decision making. Chapter 6 examined: 1 ) the execution rate of simulation study recommendations, 2) the research methods used to evaluate implementation of recommendations, 3) factors contributing to implementation, and 4) the differences regarding implementation between literature and reality.

Question 1, 2 and 3 were answered by a literature review on stochastic simulation applications in individual hospitals. From those papers reporting implementation, cross-references were added. In total, 89 papers were included. A scoring list was used for data extraction. Two reviewers evaluated each paper separately; in case of discrepancies, they jointly determined the scores. Question 4 was examined with a survey to the original authors.

The review found that 16 hospitals executed the recommendations (at least partially). Implemented results were seldom evaluated; one study reported a 
before-and-after design, two a partial before-and-after design. Factors that help implementation were grouped according to 1) technical quality, of which data availability, validation/verification with historic data/expert opinion, and the development of the conceptual model were mentioned most frequently 2) process quality, with client involvement and 3) outcome quality, with presentation of results. The survey response rate of traceable authors was $61 \%, 18$ authors implemented the results at least partially. Among these responses, evaluation methods were relatively better with three time series designs and two before-and-after designs.

Although underreported in literature, implementation of recommendations seems limited; this review provides recommendations on implementation conditions and evaluation methods to increase implementation.

\section{Chapter 7: Reducing the diagnostic track of CT scanning with computer simulation}

Chapter 7 examined the use of computer simulation to reduce the time between the CT request and the consult in which the CT report is discussed (diagnostic track) while maintaining an acceptable idle time and overtime of the CT. After a pre intervention analysis in the Netherlands Cancer Institute - Antoni van Leeuwenhoek Hospital (NKI-AVL), four possible interventions were evaluated by computer simulation on access time, overtime and idle time of the CT. After implementation of one intervention, the effects of the intervention were evaluated with a before-and-after design.

Based on the expected outcomes of the model, management decided to change the allocated capacity to enable a diagnostic track of ten operating days, with a CT access time of seven operating days. After the intervention, the average throughput time of the diagnostic track was reduced from 14.5 to 12.6 days. The fraction of patients with a total throughput time of maximum ten days increased from 29 to 44 percent. At the same time, the utilization remained equal with 82 percent, the idle time was increased by 11 percent and the overtime was reduced by 82 percent.

Using computer simulation to analyse the effects of capacity allocated to specific patient groups and desired CT access times, on CT utilization supported the decision making process for radiology management. Besides the tangible effects, the model increased the awareness that optimizing capacity allocation can reduce access times. 


\section{Discussion}

This dissertation showed that benchmarking, lean management and operations research can be successful approaches to improve resource capacity planning in hospitals. With the exception of the survey and the literature review, this dissertation consisted of case studies. In each paper, we attempted to be as specific as possible about the context, the methods and the data collection methods. Therefore, the examined business approaches seem general applicable, while the specific interventions are context specific. Although most case studies were situated in the field of cancer care, we expect the approaches to be applicable to other settings as well, as cancer care seems representative for many other hospital processes due to its urgency, complexity and uncertainty.

Chapter 4, 5 and 7 used a before-and-after design. Although various aspects such as socio-dynamic processes might change during the project and affect the results, we did not found indications this happened. Thus, it is most likely that the interventions have led to the results.

\section{Implications for further research}

Chapter 2, 3, 4, 5, 6, and 7 presented evidence that focused factories, lean management, benchmarking and simulation can be translated to hospitals to improve resource capacity planning. Future research should include more rigorous evaluation methods to present firmer evidence for improvements. Validated instruments that verify whether a hospital (or department) applies a specific approach will support this research. Future research should also consider the effectiveness of the approaches and their contingency factors to figure out which approach works best in a specific setting.

New directions for future research include examining the use of specific approaches in multidepartment processes and examining the effect of the approaches on medical outcomes and patient centeredness.

\section{Implications for hospitals}

Hospitals will have to collaborate with researchers to collect further evidence on the approaches and to gain insight into which improvement approach works best in a specific setting. Until better information becomes available, hospitals should exchange experiences to select an approach or combination of approaches. Hospitals can use the insights gained from this research to select approaches and to guide their improvement efforts. In view of the reflection on the use of the 
Chapter 9

business approaches, lean management and operations research seem most promising. 
10 Samenvatting 


\section{Hoofdstuk 1: introductie}

Om kwalitatief hoogwaardige zorg tegen acceptabele kosten te leveren, moeten ziekenhuizen de bezettingsgraad van hun bedrijfsmiddelen vergroten en tegelijkertijd zorgen voor aanvaardbare wachttijden en processen waarin de patiënt centraal staat. Resource capacity planning houdt zich bezig met de inzet van capaciteiten die nodig zijn om producten te maken of diensten te verlenen. Het doel van dit onderzoek was kennis over benaderingen op het gebied van resource capacity planning uit de industrie en dienstensector te vertalen naar het tactisch en operationeel planningsniveau van ziekenhuizen. Per hoofdstuk worden de belangrijkste bevinden gepresenteerd.

\section{Hoofdstuk 2: patiëntenlogistiek in Nederlandse ziekenhuizen}

In dit hoofdstuk zijn de volgende vragen onderzocht: 1) welke benaderingen met betrekking tot patiëntenlogistiek passen Nederlandse ziekenhuizen toe? 2) welke instrumenten gebruiken de ziekenhuizen hierbij? 3) wat zijn de effecten van deze benaderingen op de ziekenhuisprestaties? 4) op welke wijze worden deze benaderingen en instrumenten geëvalueerd? Om deze vragen te beantwoorden werden in 94 ziekenhuizen vragenlijsten over dit onderwerp uitgezet.

Achtenveertig procent van alle Nederlandse ziekenhuizen nam deel aan het onderzoek. Achtennegentig procent van de respondenten paste meerdere benaderingen toe, $39 \%$ zelfs vijf of meer benaderingen. Zorgpaden werden het meest intensief gebruikt (43\%), gevolgd door business process re-engineering en six sigma (beide 13\%). Op het gebied van de instrumenten werden processchema's met een regelmatig gebruik van $94 \%$ het meest frequent toegepast. Minder dan 10\% gebruikte regelmatig de DEA analyse en de 'kritieke pad methode'. Ongeveer de helft van de ziekenhuizen die de effecten van de benaderingen op efficiency, doorlooptijden en financiële resultaten evalueerden, rapporteerden dat de doelen bereikt waren. In algemene ziekenhuizen behaalde 63 tot $67 \%$ de gestelde doelen, in academische ziekenhuizen tussen de 0 en $50 \%$ en in topklinische ziekenhuizen tussen de 25 en $44 \%$.

Samenvattend, ziekenhuizen passen een combinatie van benaderingen en instrumenten toe en hier lijkt weinig sturing op te bestaan. Van de onderzochte benaderingen steekt geen enkele benadering qua gerapporteerd resultaat echt boven de anderen uit. Meer onderzoek naar de selectie en toepassing van de benaderingen, de bijbehorende contingentiefactoren en doelen die ziekenhuizen stellen, is nodig om te begrijpen welke benadering onder welke omstandigheden het beste werkt. 


\section{Hoofdstuk 3: Focused factories}

Specialisatie op specifieke behandelingen (diensten) of ziekten (ziektebeelden) wordt voorgesteld als één van de manieren om de efficiency van ziekenhuizen te verbeteren. Deze vorm van specialisatie wordt ook wel focus genoemd. De definitie van 'focus' in ziekenhuizen lijkt onduidelijk doordat in de literatuur zeer diverse voorbeelden worden beschreven zoals kankerklinieken, traumacentra, gespecialiseerde ziekenhuizen en ambulante chirurgiecentra. In hoofdstuk 3 is de toepassing van het concept focused factory onderzocht door in een aantal cases de mate van focus, de organisatiecontext en de operationele prestaties te analyseren.

Hiervoor werden vier meervoudige case studies geselecteerd op basis van de diversiteit van gerapporteerde focused factories in de literatuur. De mate van focus werd geanalyseerd met een instrument dat ontwikkeld is voor de industrie, maar dat voor deze studie werd aangepast voor toepassing in ziekenhuizen. Gegevens over indicatoren werden verzameld door een combinatie van kwantitatieve en kwalitatieve indicatoren. Bezoeken aan de ziekenhuizen en dataverzameling ter plaatse waren hier onderdeel van. Een beschrijvende analyse vond plaats per case studie en tussen de cases onderling.

Vergelijkingen tussen de case studies resulteerden in een raamwerk met drie domeinen van focus: focus op product, focus op proces en een combinatie van de twee voorgaande opties. Bij focus op product wordt een specifieke patiëntengroep behandeld (vaak één specialisme en één ziektebeeld). Meestal ontbreekt een expliciete operations strategie en worden de fysieke inrichting en de werkprocessen niet aangepast op de focus. Focus op proces bestaat uit specialisatie in bepaalde procedures of verrichtingen. Hierbij worden vaak meerdere patiëntengroepen behandeld en zijn strategieën aanwezig om de efficiency en doorlooptijden van het proces te verbeteren. Ook zijn de werkprocessen en de fysieke inrichting vaak afgestemd op het beperken van vertragingen. Bij een combinatie van focus op proces en product wordt een specifieke patiëntengroep met een beperkt aantal behandelingen behandeld.

De analyse tussen de meervoudige case studies toont daarnaast aan dat hoewel organisaties een vergelijkbare mate van focus hebben, de prestaties kunnen verschillen. Dit lijkt te worden veroorzaakt door de afstemming tussen de operations strategie en de daar uit volgende aanpassingen aan het proces.

De conclusies laten zien dat wijzigingen op het strategische niveau van resource capacity planning alleen geen garantie zijn voor verbeterde operationele prestaties. 
Hiervoor zijn ook wijzigingen op het tactische en operationele niveau nodig. Het voorgestelde raamwerk geeft inzicht in de voornaamste kenmerken van de drie domeinen van focus. Dit creëert mogelijkheden om vergelijkbare typen focused factories te identificeren op basis van product en proces focus.

\section{Hoofdstuk 4: Internationale benchmarking in gespecialiseerde ziekenhuizen}

Benchmarking is ontstaan in de industrie en wordt toegepast in ziekenhuizen. Omdat ziekenhuizen steeds meer gaan specialiseren en informatie steeds vaker internationaal uitgewisseld wordt, bespreekt dit hoofdstuk internationale benchmarking van gespecialiseerde ziekenhuizen. De toepasbaarheid van benchmarking voor het verbeteren van operations management in ziekenhuizen, het benchmarkingproces en de succesfactoren van internationale benchmarking werden onderzocht. De onderzoeksmethode bestond uit drie benchmarks die werden uitgevoerd in drie kankercentra, drie dagbehandelingen voor de verstrekking van chemotherapie en vier radiotherapieafdelingen.

Case studie 1 richtte zich op het proces voor het benchmarken van operations management binnen kankercentra. Dit resulteerde in algemene aanbevelingen voor de betrokken organisaties en het benchmarkingproces. In de andere case studies werd het benchmarkingproces verder aangescherpt en werden succesfactoren geïdentificeerd. In de tweede case studie, werd benchmarking toegepast op de dagbehandeling voor de verstrekking van chemotherapie. Na de benchmark paste één afdeling ook lean management technieken toe (zie hoofdstuk 5), deze combinatie leidde tot een verbeterde bedbezetting en productiviteit van respectievelijk $24 \%$ en $12 \%$. Case studie 3 was vooral gericht op het proces van de ontwikkeling van de indicatoren voor benchmarking. Twee radiotherapieafdelingen zijn na de benchmark aan de slag gegaan met de aanbevelingen. Deze bestonden onder andere uit het reduceren van de tijd dat de lineaire versnellers niet gebruikt werden in verband met onderhoud en het verbeteren van deelname aan klinische studies.

Hoofdstuk 4 toont aan dat het gevolgde benchmarkingproces relevante input kan genereren voor verbeteringsactiviteiten. Wij hebben bestaande benchmarkingprocessen aangepast door de betrokkenheid van belanghebbenden te formaliseren en de vergelijkbaarheid van de betrokken organisaties te verifiëren. We hebben ook een raamwerk toegevoegd om de indicatoren te structureren waardoor betere aanbevelingen gegenereerd kunnen worden. Tenslotte heeft het onderzoeksteam succesfactoren voor benchmarking gedefinieerd. Voorbeelden hiervan zijn een goed afgebakende project scope, selectie van partners gebaseerd 
op heldere criteria, betrokkenheid van belanghebbenden, simpele en goed gestructureerde indicatoren, analyse van proces en resultaten, aanpassen van geïdentificeerde best practices naar de eigen situatie en het interpreteren van gegevens op basis van een set van indicatoren in plaats van een individuele indicator.

Het ontwikkelen van indicatoren is belangrijk bij benchmarking. Appendix $\mathrm{C}$ beschrijft dit proces.

\section{Hoofdstuk 5: Het verbeteren van de dagbehandeling voor chemotherapie met behulp van benchmarking en lean management}

Deze case studie onderzocht hoe een combinatie van benchmarking en lean management ingezet kon worden om een aanzienlijke patiëntengroei op een dagbehandeling voor de verstrekking van chemotherapie te realiseren, zonder proportioneel meer medewerkers in te zetten en tegelijkertijd goede kwaliteitsniveaus en patiënttevredenheid te behouden. Dit project werd gestructureerd volgende de plan-do-check-act cyclus. De dagbehandeling werd gebenchmarked met twee andere afdelingen om haalbare prestatieniveaus voor efficiency te identificeren en om oorzaken voor verschillen te achterhalen. Daarnaast werd in de plan-fase op één van de afdelingen een diepgaande analyse op gebied van efficiency, patiënttevredenheid en medewerkertevredenheid met behulp van lean management uitgevoerd. In de do-fase werd een integrale set van aanbevelingen, waaronder een nieuw planningssysteem, door een multidisciplinaire projectgroep geïmplementeerd. In de check-fase werden de resultaten geëvalueerd door middel van voor- en nametingen.

In totaal is een patiëntengroei en een verbeterde bedbezetting van $24 \%$ gerealiseerd, een $12 \%$ groei in productiviteit van medewerkers en een $81 \%$ daling van overwerk. Dit resultaat is gerealiseerd met een gelijkblijvende verwachte behandelduur. In de act-fase bediscussieerde de projectgroep de resultaten en werden verdere verbeteringen geïnitieerd.

In deze studie werden benaderingen uit het bedrijfsleven, na aanpassing voor de zorg, succesvol toegepast. Dit heeft geleid tot een efficiëntere dagbehandeling die in staat is meer patiënten tijdig te helpen. De gebruikte methode kan als voorbeeld dienen voor andere vergelijkbare situaties waar problemen met wachttijden, doorstroom van patiënten, of een tekort aan bedden zich voordoen. 


\section{Hoofdstuk 6: De relatie tussen simulatie en implementatie van de aanbevelingen}

Toepassingen van simulaties op het gebied van operations management in ziekenhuizen claimen het besluitvormingsproces te ondersteunen. In hoofdstuk 6 werd onderzocht: 1) hoe vaak aanbevelingen van simulatiestudies daadwerkelijk in de praktijk ingevoerd worden, 2) de onderzoeksmethoden die gebruikt worden om de aanbevelingen te evalueren, 3) factoren die bijdragen aan implementatie, en 4) de verschillen in implementatie tussen literatuur en praktijk. De onderzoeksvragen werden beantwoord door middel van een literatuuronderzoek naar stochastische toepassingen van simulatiemodellen. Van de artikelen die implementatie rapporteerden werden de referenties ook geanalyseerd.

In totaal zijn 89 artikelen geïncludeerd. Een scoringslijst werd gebruikt voor dataextractie. Twee onderzoekers evalueerden ieder artikel afzonderlijk. In geval van discrepanties, besloten zij samen over de juiste scores. De implementatie in de praktijk werd onderzocht met vragenlijsten die verstuurd werden naar de auteurs van de publicaties.

Het literatuuronderzoek vond 16 artikelen waarin minstens gedeeltelijke implementatie van de aanbevelingen werd benoemd. Geïmplementeerde resultaten werden zelden geëvalueerd: één studie gebruikte een voor- en nameting, twee een gedeeltelijke voor- en nameting. Factoren die implementatie ondersteunen werden gegroepeerd naar: 1) technische kwaliteit, waarvan beschikbaarheid van data, validatie/verificatie met behulp van historische data/ expert opinie, en de ontwikkeling van een conceptueel model het vaakst werden genoemd 2) proces kwaliteit, met betrokkenheid van de cliënt als meest genoemde factor en 3) kwaliteit van de uitkomsten met presentatie van de resultaten als meest genoemde factor. De responsgraad op de traceerbare onderzoekers was $61 \%, 18$ auteurs implementeerden de resultaten tenminste gedeeltelijk. De gerapporteerde evaluatiemethoden waren relatief beter met drie multimoment metingen en twee voor- en nametingen.

Implementatie van gesimuleerde aanbevelingen lijkt beperkt, zelfs ondanks het verschil tussen literatuur en werkelijkheid. Deze literatuurstudie geeft succesfactoren die bijdragen aan implementatie en geeft daarnaast aanbevelingen om evaluaties van ingevoerde aanbevelingen te publiceren. 


\section{Hoofdstuk 7: Verkorten het diagnostisch traject van de CT scanner met behulp van simulatie}

In hoofdstuk 7 werd computersimulatie gebruikt om alternatieven te onderzoeken die de tijd tussen de aanvraag van een CT en de afspraak waarin de resultaten van de CT met de patiënt worden besproken kunnen verkorten (diagnostisch traject). Tegelijkertijd moesten de ongebruikte tijd van de CT en het overwerk acceptabel blijven. Na een nulmeting in het Nederlands Kanker Instituut - Antoni van Leeuwenhoek Ziekenhuis (NKI-AVL) werden vier interventies geëvalueerd met een computersimulatie op toegangstijd, overwerk en ongebruikte CT tijd.

Naar aanleiding van de simulatie besloot het management de capaciteit zodanig toe te wijzen dat een diagnostisch traject van tien dagen ontstond met een toegangstijd tot de CT van maximaal zeven werkdagen. Na de interventie daalde de gemiddelde doorlooptijd van het diagnostische traject van 14.5 tot 12.6 dagen. Het percentage patiënten met een totale doorlooptijd van tien werkdagen steeg met 52 procent, van 29 naar 44 procent. Tegelijkertijd bleef de bezettingsgraad stabiel (82 procent), de ongebruikte CT tijd steeg met 11 procent en het overwerk daalde met 82 procent. De interventie leek dus tot aanzienlijke verbetering te leiden.

Wij concluderen dat het gebruik van simulatie om de benodigde capaciteit per patiëntengroep te bepalen, management helpt besluiten te nemen over acceptabele toegangstijden in combinatie met een efficiënt gebruik van de CT. Naast de meetbare effecten, vergroot de simulatie het inzicht bij de afdeling dat een andere verdeling van de capaciteiten wachttijden kan verkorten.

\section{Hoofdstuk 8: Discussie}

Dit onderzoek toont aan dat focused factories, benchmarking, lean management en simulatie succesvol vertaald kunnen worden voor gebruik in ziekenhuizen om daar de resource capacity planning te verbeteren. Met uitzondering van de vragenlijsten (hoofdstuk 2) en het literatuuronderzoek (hoofdstuk 6) is dit proefschrift gebaseerd op case studies. In ieder onderzoek is geprobeerd zo specifiek mogelijk de context, de onderzoeksmethode en de dataverzameling te beschrijven. Daardoor lijkt de gevolgde aanpak breder toepasbaar terwijl de interventies afhankelijk van de context elders toepasbaar zijn. Hoewel de meeste case studies plaatsvonden in de oncologische zorg, lijken de benaderingen ook toepasbaar in andere zorgsituaties omdat oncologische zorg representatief is voor veel zorgprocessen door de urgentie, complexiteit en onzekerheid. 
Een ander discussiepunt is het gebruik van voor- en nametingen (zie hoofdstuk 4, 5 en 7). Hoewel diverse aspecten, zoals veranderende socio-dynamische processen kunnen veranderen tijdens het project en daardoor de resultaten kunnen beïnvloeden, hebben wij geen indicaties gevonden dat andere factoren de resultaten beïnvloed hebben. Het is dus waarschijnlijk dat de interventies tot de gerapporteerde resultaten hebben geleid.

\section{Verder onderzoek}

Dit proefschrift toont aan dat benaderingen uit de industrie en dienstensector zodanig vertaald kunnen worden naar ziekenhuizen dat zij bijdragen aan het verbeteren van de resource capacity planning. Toekomstig onderzoek zou sterkere onderzoeksmethoden moeten gebruiken om het succes van de benaderingen aan te tonen. Gevalideerde instrumenten die verifiëren of een ziekenhuis (of afdeling) een bepaalde benadering toepast, zijn hiervoor noodzakelijk. Toekomstig onderzoek zou ook de effectiviteit van de benaderingen en de bijbehorende contingentiefactoren moeten onderzoeken om duidelijk te krijgen welke benadering het beste werkt in een bepaalde situatie.

Toekomstig onderzoek zou zich ook kunnen richten op het gebruik van specifieke benaderingen in afdelingsoverstijgende processen. Een andere richting is het onderzoeken van de effecten van de benaderingen op medische uitkomsten en patiënttevredenheid.

\section{Gevolgen voor ziekenhuizen}

Om inzicht te krijgen in welke benadering het beste kan worden toegepast in een specifieke situatie, is meer onderzoek nodig. Om dit te bereiken zouden ziekenhuizen met onderzoekers moeten samenwerken. Totdat betere informatie beschikbaar komt, is het aan te bevelen dat ziekenhuizen wegen zoeken om hun ervaringen uit te wisselen teneinde de meest passende (combinatie van) benaderingen te selecteren. Ziekenhuizen kunnen de inzichten gebruiken om de onderzochte benaderingen toe te passen voor het verbeteren van hun resource capacity planning. Terugblikkend op dit proefschrift lijken lean management en operations research vooralsnog veelbelovende benaderingen. 
11 Dankwoord 
Bij het schrijven van dit proefschrift heb ik veel geleerd over mijn vakgebied en over mezelf. Tien jaar geleden had ik niet gedacht dat ik een promotieonderzoek zou afronden. Tijdens mijn studie aan de Universiteit Twente begon ik in te zien dat onderzoek op het gebied van Operations Management in de zorg zeer interessant is en dat het bijdraagt aan de uitdagingen waar de gezondheidszorg voor staat.

Allereerst wil ik mijn promotor, Prof. Wim van Harten, bedanken. Tijdens het begeleiden van mijn afstudeertraject heeft Wim mijn interesse voor onderzoek aangewakkerd. Ook maakte ik tijdens dit onderzoek voor het eerst kennis met Lean Management. Eefje, bedankt voor deze introductie. Na een jaar werken in het Nederlands Kanker Instituut - Antoni van Leeuwenhoek Ziekenhuis (NKI-AVL) kwam mijn promotor met een mooi voorstel om onderzoek en werken in de praktijk te combineren. Hierna ben ik dan ook enthousiast begonnen aan mijn onderzoek. Wim, bedankt dat je mijn promotor wilde zijn, me steeds weer wist te motiveren om de resultaten nog beter op te schrijven en dat je ondanks de volle agenda altijd tijd vrij kon maken voor mijn onderzoek. Jorrita en Marianne, bedankt voor jullie steun en het maken, verplaatsen en soms opnieuw verplaatsen van alle afspraken.

Ik wil mijn coauteurs in het bijzonder bedanken voor de bijdrage die zij hebben geleverd aan het onderzoek: Marloes Sanders, Joost Deetman, Relinde de Beer, Jelle Teertstra, Saar Muller, Eelco Bredenhof, Peter VanBerkel and Baukelien van Triest. Peter, bedankt voor je aanwezigheid in het NKI-AVL. Onze gesprekken en jouw enorme schrijftempo hebben mij gemotiveerd bij het schrijven van dit proefschrift.

Ook wil ik de leden van mijn beoordelingscommissie - Prof. M.J. ljzerman, Prof. A.P.W.P. van Montfort, Prof. J.J. van de Klundert, Prof. O.A.M. Fisscher, Prof. J. Wijngaard, Prof. H.J.J.M. Berden en Dr. Ir. E.W. Hans - bedanken voor het mede mogelijk maken van dit proefschrift. Ik ben vereerd dat jullie zitting genomen hebben in mijn commissie.

Dit proefschrift was er niet geweest zonder mijn collega's in het NKI-AVL. Bedankt voor jullie bijdrage aan de projecten die beschreven zijn in dit onderzoek en jullie bereidheid om deze data openbaar te maken. In het bijzonder wil ik Nicolette Goedbloed, Arthur Dernison, Rita Roodbergen en Theo van Ooij bedanken voor hun input en de discussies die we gehad hebben over verschillen tussen ziekenhuizen en bedrijven. Valesca, dat jij net twee maanden eerder ging promoveren dan ik heeft me gestimuleerd in de afronding. 
Bijzondere dank gaat ook uit naar mijn collega's van de afdeling PSOE in het NKIAVL en de HTSR vakgroep van de Universiteit Twente. De (methodologische) discussies over jullie onderzoek heb ik als zeer nuttig ervaren.

Ook wil ik mijn (schoon)familie, vriendinnen en vrienden bedanken voor hun interesse in mijn onderzoek en het doorlezen van de laatste hoofdstukken van mijn proefschrift. Cindy, bedankt voor het ontwerpen van de omslag van mijn proefschrift! Gonne en Eveline, bedankt dat jullie mijn paranimfen willen zijn.

Tenslotte wil ik mijn vriend, Bart, bedanken omdat je me altijd onvoorwaardelijk steunt. Jouw beroemde woorden helpen altijd: “Jij bent de beste en je gaat een prachtig proefschrift afleveren."

Wineke 


\section{Curriculum Vitae}




\section{Curriculum Vitae}

In 2005, Wineke (A.M.) van Lent completed her master's degree in Industrial Engineering and Management from the University of Twente. Her thesis concerned the application of focused factories and benchmarking in chemotherapy day units. In 2006, she started as a project coordinator on patient logistics at the Netherlands Cancer Institute - Antoni van Leeuwenhoek Hospital (NKI-AVL). A year later, she started her PhD at NKI-AVL on the translation of approaches from businesses and services to improve the resource capacity planning on tactical and operational level in hospital care. She combined the PhD with working as a project coordinator. This dissertation is a result of an explorative research informed by actual practice at the NKI-AVL. The research proposes new theories for implementation that can greatly benefit hospital settings. In 2010, she became formally involved with the University of Twente, Health Technology Services Research Department in education on operations management in healthcare, where she also provides supervision to bachelor and master students. In the future, she aspires to continue her work in research and academia, lending her expertise at the University of Twente and at the NKI-AVL where she has been currently promoted to be a staff advisor for care and management. 


\section{List of Publications}




\section{List of Publications}

\section{This dissertation}

1. WAM van Lent, N Goedbloed, WH van Harten: Improving the efficiency of a chemotherapy day unit; applying a business approach to oncology, European Journal of Cancer 2009, 45(5); 800-806

2. E Bredenhoff, WAM van Lent, WH van Harten: Exploring types of focused factories in hospital care: a multiple case study, BMC Health Services Research 2010, 10(1);154

3. WAM van Lent, RD de Beer, WH van Harten: International benchmarking of specialty hospitals. A series of case studies on comprehensive cancer centres, BMC Health Services Research 2010, 10(1):253

\section{Submitted}

1. WAM van Lent, $P$ VanBerkel, WH van Harten: $A$ review on the relation between simulation and improvement, Submitted

2. WAM van Lent, JW Deetman, HJ Teertstra, SH Muller, WH van Harten: Reducing the throughput time of the diagnostic track involving CT scanning with computer simulation. Submitted

3. WAM van Lent, EM Sanders, WH van Harten, Exploring improvements in patient logistics in Dutch hospitals Submitted

4. WAM van Lent, RD de Beer, B van Triest, WH van Harten, Selecting indicators for international benchmarking of radiotherapy centres. Revised version submitted to Journal of Radiotherapy in Practice

\section{Other publications}

1. WAM van Lent, E Bredenhoff, W van Harten, Een focus op benchmarking, ZM Magazine, Dec. 2006

2. PT Vanberkel, RJ Boucherie, EW Hans, JL Hurink, N Litvak, WAM van Lent, WH van Harten: Reallocating resources to focused factories; a case study in chemotherapy. In: 34th Meeting of the European Group on Operations Research Applied to Health Services, ORAHS, 2008, Toronto, Canada

3. WAM van Lent, $\mathrm{H}$ Schoo, WH van Harten: Lean management in het NKI-AVL: het afslanken van processen om harder te kunnen groeien. Chapter in: 'Lean denken en doen in de zorg, acht verhalen uit de praktijk', 2009, Lemma Tilburg.

4. WH van Harten, EW Hans, WAM van Lent: Aanpak efficiency te ondoordacht, Medisch Contact 2010, 6:11

5. PT Vanberkel, RJ Boucherie, EW Hans, JL Hurink, WAM van Lent, WH van Harten, An exact approach for relating recovering surgical patient workload to the master surgical schedule, Journal of the Operational Research Society, Published online 6 October 2010

6. PT Vanberkel, RJ Boucherie, EW Hans, WAM van Lent, WH van Harten: Accounting for Inpatient Wards When Developing Master Surgical Schedules, Anesthesia and Analgesia June 2011 112:1472-1479; published ahead of print May 4, 2011. 
Appendix A: Definitions 


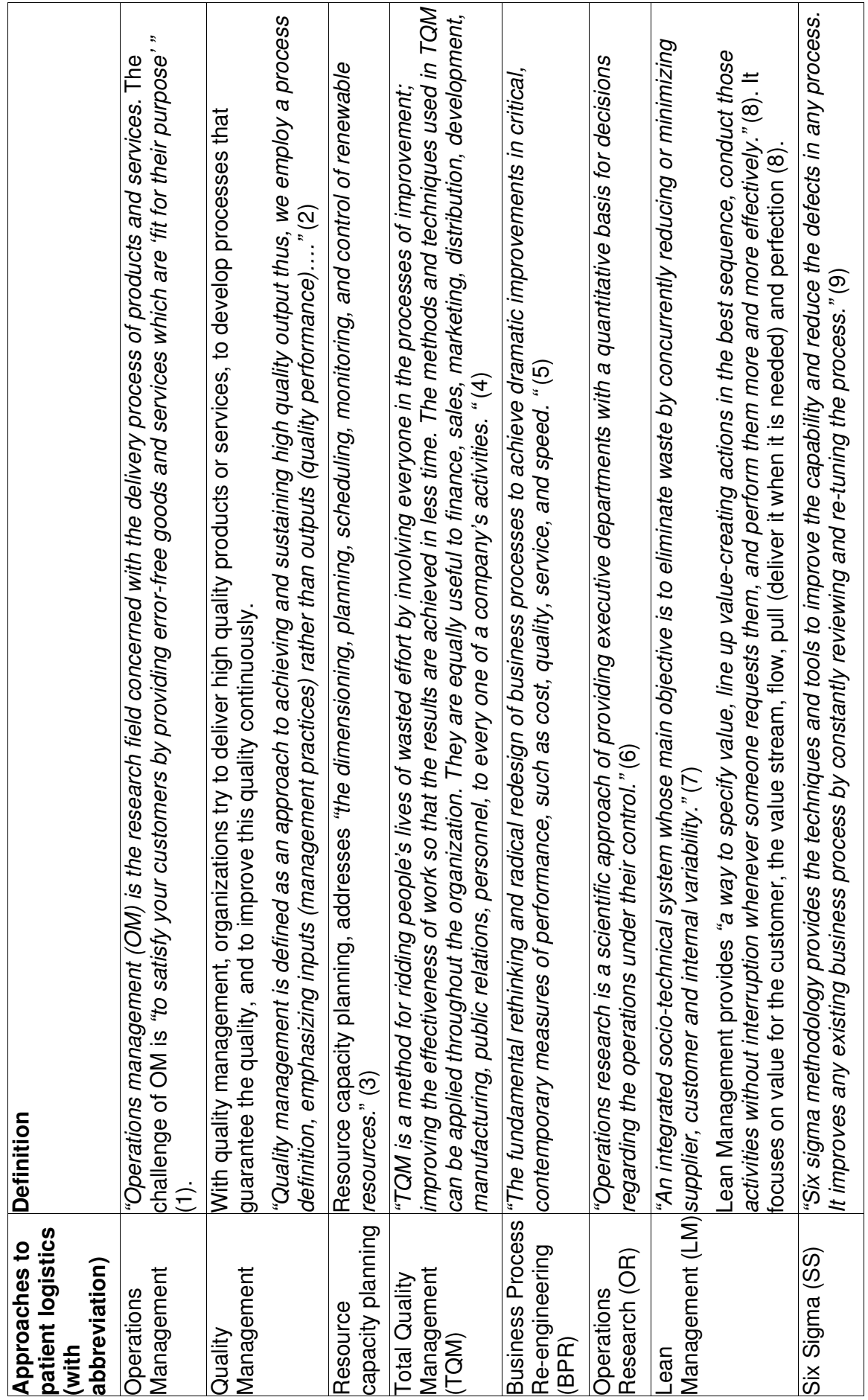




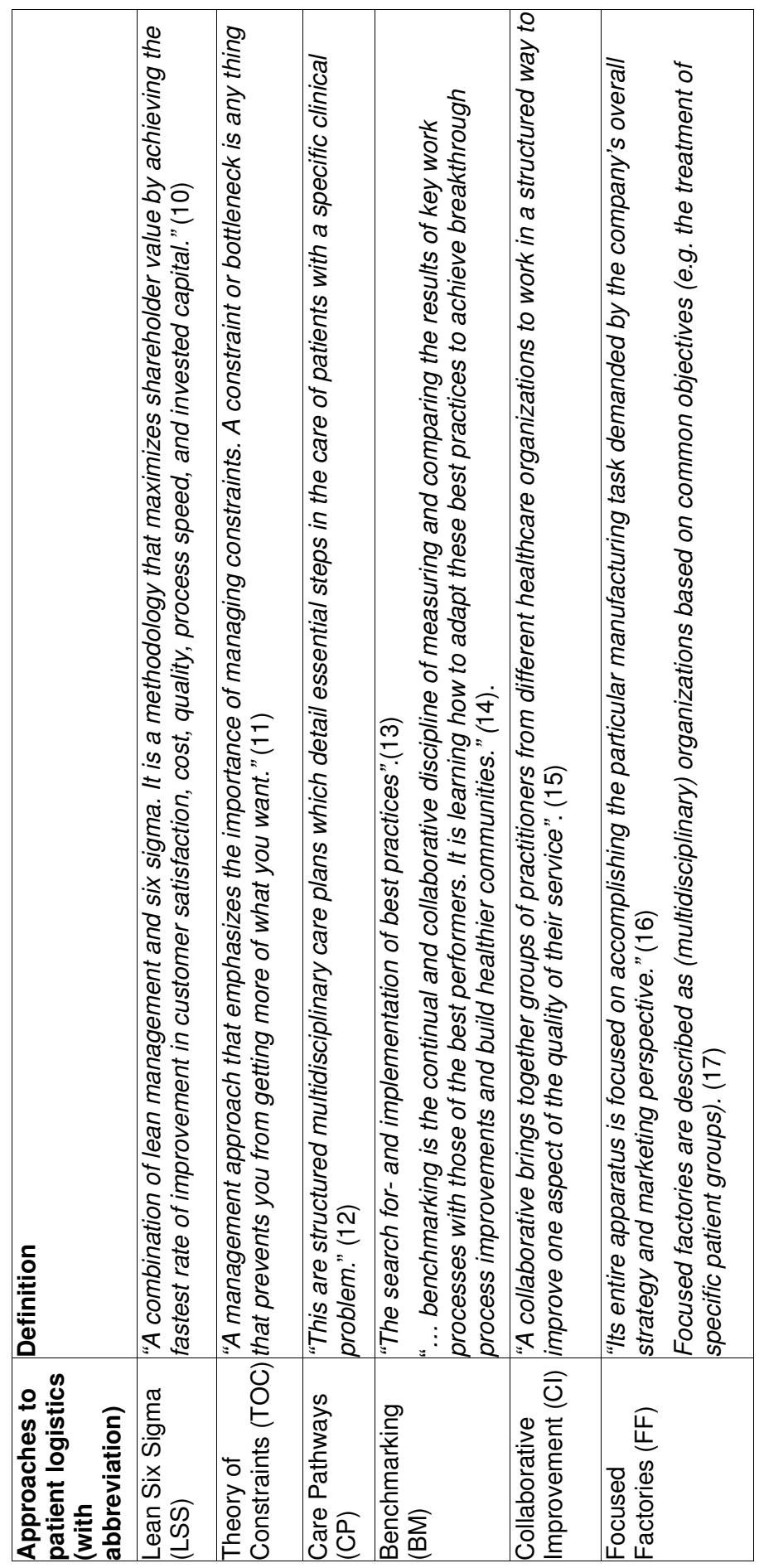




\section{Reference List}

1. Slack N, Chambers S, Johnston R: Operations Management. Financial Times/Prentice Hall; 2007.

2. Flynn BB, Schroeder RG, Sakakibara S: A framework for quality management research and an associated measurement instrument. Journal of Operations Management 1994, 11:339-366.

3. Hans EW, Van Houdenhoven M, Hulshof PJH. A framework for health care planning and control. In: Handbook of Health Care Systems Scheduling. Hall, Randolp (Ed.) Springer International Series in Operations Research \& Management Science, 2011, 168: chapter 12.

4. John S Oakland: Total Quality Management. London: Butterworth-Heinemann Ltd; 1989.

5. Hammer M, Champy J: Business process re-engineering. London: Nicholas Brealey 1993.

6. Morse PM, Kimball GE: Methods of Operations Research. New York: Dover Publications; 2003.

7. Shah R, Ward PT: Defining and developing measures of lean production. Journal of Operations Management 2007, 25:785-805.

8. Womack JP, Jones DT: Lean thinking: banish waste and create wealth in your corporation. Simon and Schuster; 2003.

9. de Koning $\mathrm{H}$, Verver JPS, van den Heuvel J, Bisgaard S, Does R: Lean six sigma in healthcare. Journal for Healthcare Quality 2006, 28:4.

10. George ML: Lean six sigma for service: How to use lean speed and six sigma quality to improve services and transactions. McGraw-Hill Professional; 2003.

11. Goldratt Eliyahu M: Theory of Constraints. North-River Press, Croton-on-Hudson, NY 1990.

12. Campbell H, Hotchkiss R, Bradshaw N, Porteous M: Integrated care pathways. British Medical Journal 1998, 316:133.

13. Camp RC: Benchmarking: The Search for Industry Best Practices that Lead to Superior Performance. Milwaukee,(USA) 1989.

14. Mosel D, Gift B: Collaborative benchmarking in health care. Joint Commission Journal for Quality Improvement 1994, 20:239.

15. Õvretveit J, Bate P, Cleary P, Cretin S, Gustafson D, McInnes K, McLeod H, Molfenter T, Plsek P, Robert G: Quality collaboratives: lessons from research. Quality and Safety in Health Care 2002, 11:345.

16. Skinner W: The focused factory. Harvard Business Review 1974.

17. Herzlinger RE: Market Drive Healthcare, Who wins, who loses in the transformation of Americas largest service industry. Addisson-Wesley; 1997 


\section{Appendix B: Measurement Instrument for Focused Factories in Hospital Care}

This appendix is published as Additional file 1 (Measurement instrument focused factories in hospital care) for the paper presented in Chapter 3.

Exploring types of focused factories in hospital care: a multiple case study Published in BMC Health Services Research 2010, 10(1):154 


\section{Measurement instrument focused factories in hospital care}

\section{Measuring the degree of focus on patients (patient variety)}

These questions gather information about the groups of patients that are treated, the volume of these groups, and the variety (between and within these groups). These questions give us information about the customer needs and particularities.

\section{Question 1}

We would like to know how many patient groups are treated in your organization. A patient group will be considered as all patients that belong to one chapter of the ICD classification (please see Table 1).

How many of the ICD classification chapters describe your patients? Please consider the period of a year. Only one answer possible.
A. one or two chapters
B. three chapters
C. more than three chapters 
Table 1: Main topics ICD classification, needed to answer question I, II and III

\begin{tabular}{|c|c|c|}
\hline Chapter & Blocks & Title \\
\hline $\mathrm{I}$ & $\begin{array}{l}\text { A00- } \\
\text { B99 }\end{array}$ & Certain infectious and parasitic diseases \\
\hline II & $\begin{array}{l}\text { C00- } \\
\text { D48 }\end{array}$ & Neoplasms \\
\hline III & $\begin{array}{l}\text { D50- } \\
\text { D89 }\end{array}$ & $\begin{array}{l}\text { Diseases of the blood and blood-forming organs and certain disorders involving } \\
\text { the immune mechanism }\end{array}$ \\
\hline IV & $\begin{array}{l}\text { E00- } \\
\text { E90 }\end{array}$ & Endocrine, nutritional and metabolic diseases \\
\hline$\overline{\mathrm{V}}$ & $\begin{array}{l}\text { F00- } \\
\text { F99 }\end{array}$ & Mental and behavioural disorders \\
\hline $\mathrm{VI}$ & $\begin{array}{l}\text { G00- } \\
\text { G99 }\end{array}$ & Diseases of the nervous system \\
\hline VII & $\begin{array}{l}\mathrm{H} 00- \\
\mathrm{H} 59\end{array}$ & Diseases of the eye and adnexa \\
\hline VIII & $\begin{array}{l}\mathrm{H} 60- \\
\mathrm{H} 95\end{array}$ & Diseases of the ear and mastoid process \\
\hline IX & $100-199$ & Diseases of the circulatory system \\
\hline $\mathrm{X}$ & $\begin{array}{l}\text { J00- } \\
\text { J99 }\end{array}$ & Diseases of the respiratory system \\
\hline$\overline{X I}$ & $\begin{array}{l}\text { K00- } \\
\text { K93 }\end{array}$ & Diseases of the digestive system \\
\hline $\mathrm{XII}$ & $\begin{array}{l}\text { L00- } \\
\text { L99 }\end{array}$ & Diseases of the skin and subcutaneous tissue \\
\hline XIII & $\begin{array}{l}\text { M00- } \\
\text { M99 }\end{array}$ & Diseases of the musculoskeletal system and connective tissue \\
\hline XIV & $\begin{array}{l}\text { N00- } \\
\text { N99 }\end{array}$ & Diseases of the genitourinary system \\
\hline$\overline{\mathrm{XV}}$ & $\begin{array}{l}\text { O00- } \\
\text { O99 }\end{array}$ & Pregnancy, childbirth and the puerperium \\
\hline $\mathrm{XVI}$ & $\begin{array}{l}\text { P00- } \\
\text { P96 }\end{array}$ & Certain conditions originating in the perinatal period \\
\hline$\overline{\mathrm{XVII}}$ & $\begin{array}{l}\text { Q00- } \\
\text { Q99 }\end{array}$ & Congenital malformations, deformations and chromosomal abnormalities \\
\hline XVIII & $\begin{array}{l}\text { R00- } \\
\text { R99 }\end{array}$ & $\begin{array}{l}\text { Symptoms, signs and abnormal clinical and laboratory findings, not elsewhere } \\
\text { classified }\end{array}$ \\
\hline$\overline{X I X}$ & $\begin{array}{l}\text { S00- } \\
\text { T98 }\end{array}$ & Injury, poisoning and certain other consequences of external causes \\
\hline$\overline{X X}$ & $\begin{array}{l}\text { V01- } \\
\text { Y98 }\end{array}$ & External causes of morbidity and mortality \\
\hline$\overline{X X I}$ & $\begin{array}{l}\text { Z00- } \\
\text { Z99 }\end{array}$ & Factors influencing health status and contact with health services \\
\hline XXII & $\begin{array}{l}\text { U00- } \\
\text { U99 }\end{array}$ & Codes for special purposes \\
\hline
\end{tabular}




\section{Question 2}

We are interested in the variation in patients (defined by ICD code) treated. Each chapter of the ICD classification consists of a number of blocks. What percentage of blocks in the chapters indicated in question 1, describes your patients? Please consider the period of a year.

If multiple chapters were indicated in question 1, describe the overall percentage. Only one answer possible.
A. $0-20 \%$
B. $20-40 \%$
C. $40-60 \%$
D. $60-80 \%$
E. $>80 \% \quad($

\section{Question 3}

We are interested in how patients are distributed between the blocks. Large differences between blocks suggest high variety in patient needs. Please indicate how you value the variety in the number of patients between blocks of a chapter.

Please indicate how the variety in numbers of patients between blocks is perceived
A. very high
B. high
C. moderate
D. low
E. very low

\section{Question 4}

The health of a patient can be described by the Classification of the American Society of Anesthesiologists (ASA). Each ASA class (Please see 
Table 2) describes a different physiological situation of a patient. Patients classified as ASA 1 have fundamentally different needs than patients classified as ASA 4. Limiting an organization to serve patients classified to only one or a few ASA classes suggests a higher degree of focus on patient groups. 
Table 2: ASA classification, needed to answer question 4

\begin{tabular}{|ll|}
\hline Class & Description \\
\hline I & The patient is normal and healthy \\
\hline II & $\begin{array}{l}\text { The patient has mild systemic disease that does not limit their activities (e.g., } \\
\text { controlled hypertension or controlled diabetes without systemic sequellae) }\end{array}$ \\
\hline III & $\begin{array}{l}\text { The patient has moderate or severe systemic disease, which does limit their } \\
\text { activities (e.g., stable angina or diabetes with systemic sequellae). }\end{array}$ \\
\hline IV & $\begin{array}{l}\text { The patient has severe systemic disease that is a constant potential threat to life } \\
\text { (e.g., severe congestive heart failure, end-stage renal failure). }\end{array}$ \\
\hline V & $\begin{array}{l}\text { The patient is morbid and is at substantial risk of death within } 24 \text { hours, with or } \\
\text { without surgery. }\end{array}$ \\
\hline
\end{tabular}

How many ASA classes describe the patients receiving the care of your organization?
A. one or two ASA classes
B. three ASA classes
C. more than three ASA classes

\section{Measuring the degree of focus on processes (service variety)}

These questions gather information about the number of involved specialties, the number of offered services, the variety in services and some patient characteristics that strongly influence the predictability of care delivery system.

\section{Question 5}

We are interested in the number of specialties that are involved in the delivery of care in your organization. Radiology and Anesthesiology must be excluded in this number.

How many specialties are involved in your organization?
A. one specialty
B. two specialties
C. more than 3 specialties 


\section{Question 6}

We are interested in the number of subspecialties within the specialties in your organization. Please indicate which option applies.

How many subspecialties are involved in your organization?
A. one subspecialty
B. two subspecialties
C. more than 3 subspecialties

\section{Question 7}

Does your organization has its own (dedicated) radiology department? Please, indicate if your organization does not use X-ray, CT or MRI imaging in serving its patient groups.

A. Yes, we have our own radiology department

B. No, but the radiology department is ours for the majority $(90 \%)$ of the day

C. No, but (part of) the radiology department is ours on specific (parts of) days

D. No, but we have a higher priority at the radiology department

E. No, the radiology department is a shared resource out of our control

F. No, we do not use X-ray, CT or MRI in serving patients (not applicable)

\section{Question 8}

The number of services your organization offers is measured by the number of treatments or diagnostics offered. We identify medical, surgical, and radiation treatments. We therefore distinguish between four types of services: 1) medical treatments, 2) surgical treatments, 3) radiation treatments, and 3) diagnostics. Consultation is seen as an integral part of care delivery, and is therefore not seen as a distinct service. 
Please indicate how many of these types of services your organization offers
A. Only one of these types of services
B. Two of these types of services
C. More than two types of services

\section{Question 9}

For each type of service offered, we are interested in the variety within this service. In the case of medical treatments, we are interested in the number of medicines used, and the number methods for administering these medicines. In the case of surgical treatments we are interested in the number of different surgical procedures performed. In the case of radiation treatments we are interested in the variety within treatment times. In the case of diagnostics we are interested in the number of diagnostic services (techniques/ technologies) used such as lab-tests, radiology, physical exam, ECG, etc.

Please indicate, for each service your organization offers, which options applies. The different options are modelled on examples in literature and expert opinion.

\section{$\underline{\text { Medical }}$}
A. few medicines, few methods
B. multiple medicines, few methods
C. moderate medicines and methods
D. Few medicines multiple methods
E. Multiple medicines and methods

$\underline{\text { Surgical }}$
A. $<50$ different procedures
B. 50-100 different procedures
C. 100-250 different procedures
D. 250-500 different procedures
E. $>500$ different procedures 
$\underline{\text { Radiation }}$
A. very high variety in treatment times
B. high variety in treatment times
C. moderate variety in treatment time
D. low variety in treatment times
E. very low variety in treatment times

(0)

Diagnostics
A. one or two diagnostics used
B. three or four diagnostics used
C. five or more diagnostics used

If multiple services were indicated, use the lowest score when establishing the degree of focus on offered services.

\section{Question 10}

The ASA classes (see Table 2), used to describe the health of patients, can seriously influence the predictability of the delivery of care. Although the ASA classification depends on patients, we also see it as an indicator for interruptions in the delivery of care. Patients in the high ASA classes require a care delivery system that is able to rapidly respond to unpredictable events. Patients in the low ASA classes mainly require routine care. The ASA classes that occur in the care delivery system therefore indicate the predictability of this system.

Please, indicate which option applies for your organization.
A. no patient has an ASA classification higher than 2
B. Less than $50 \%$ of the patients have an ASA classification equal to 3 , no patients have an ASA classification higher than 3
C. more than $50 \%$ of the patients have an ASA classification larger or equal to 3 , but no patients have an ASA classification equal or higher than 4
D. more than $25 \%$ of the patients have an ASA classification higher or equal to 4
E. more than $50 \%$ of the patients have an ASA classification higher or equal to 4




\section{Question 11}

Another process characteristic is the percentage of inpatient and outpatient admissions compared to the total number of admissions.

Please indicate which option applies for your organization
A. more than $95 \%$ of all patients is treated either inpatient or outpatient
B. less than $95 \%$ of all patients is treated outpatient, but inpatient LOS $<5$
C. less than $95 \%$ of all patients is treated either inpatient or outpatient

\section{Question 12}

Also the number of urgent cases tells us something about the services offered, and their predictability. It is possible to focus on non-urgent cases, as it is to focus on urgent cases.

Please indicate which option applies for your organization.
A. more than $95 \%$ or less than $5 \%$ of all patients are urgent cases (4)
B. other (0)

\section{Calculate the degree of focus and classify the type of focus factory}

We calculate the percentages of the maximum degree focus score that was attained. This gives us a score of $0-100$ percent on both dimensions.

\section{Focus on patients}

Sum the scores of the questions 1 to 4 . Divide this score by the maximum possible score of 16 points. Multiply the result with 100 . This leads to a degree of focus score of $0-100$.

\section{Focus on services}

Sum the scores of the questions 5 to 11 . Divide this score by the maximum possible score of 28 points. Multiply the result with 100 . This leads to a degree of focus score of $0-100$. 


\title{
Appendix C: Selecting Indicators for International Benchmarking of Radiotherapy Centres.
}

\author{
W.A.M. van Lent \\ R.D. de Beer \\ B. van Triest \\ W.H. van Harten
}

Revised version submitted to Journal of Radiotherapy in Practice 


\section{Abstract}

\section{Purpose}

Benchmarking can be used to improve hospital performance. It is however not easy to develop a concise and meaningful set of indicators on aspects related to operations management. We developed an indicator set for managers and evaluated its use in an international benchmark of radiotherapy centers. The indicator set assessed the efficiency, patient-centeredness and timeliness of the services delivered.

\section{Methods}

We identified possible indicators from literature and professionals. Stakeholders' feedback helped to produce a shortlist of indicators. For this indicator set data was obtained in a pilot that included four European radiotherapy centers. With these data the indicators were evaluated on definition clarity, data availability, reliability and discriminative value.

\section{Results}

Literature produced a gross list of 81 indicators. Based on stakeholder feedback, 33 indicators were selected and evaluated in the benchmark. Six negatively evaluated indicators were adapted, together with eight positively evaluated indicators 14 indicators seemed feasible. Examples of indicators concerned utilization, waiting times, patient satisfaction and risk analysis.

\section{Conclusions}

This study provides a pragmatic indicator development process for international benchmarks on operations management. The presented indicators showed to be feasible for use in international benchmarking of radiotherapy centers. The pilot identified attainable performance levels and provided leads for improvements. 


\section{Purpose}

Improving the performance of quality of care was and is an important item on the agenda of hospitals and radiotherapy departments. Improvement initiatives used to focus on clinical effectiveness and patient centeredness $(1,2)$. Gradually a broader definition of quality was accepted that also included societal concerns over access to healthcare, effectiveness, efficiency and safety (3).

Benchmarking, a technique that originated in operations management, is used to identify good and best practices (4). It is a stepwise process whereby best practices are identified by comparing similar processes, and are then transposed to other situations so as to achieve major process improvements (5). To increase transparency on performance, an increasing number of medical and managerial performance indicators are presented in public reports (6) or offered through consultancy firms. At first glance they seem to provide useful information, but they hardly explain how these results were achieved. Hospitals might benefit from more thorough national or international benchmarking methods that provide insight into the underlying organizational principles. As the topic seems to be covered mainly in popular management literature, there are few peer-reviewed publications on benchmarking and its use in health organizations $(7,8)$. Moreover, it is known that there can be considerable performance differences between countries (and regions) (9), so exploring international benchmarking on the operations management of hospitals or hospital departments can be relevant. Recent research on the process of international benchmarking on operations management showed that publications on this subject are scarce and that the selection of indicators is an important issue (10).

This paper shows the development of an indicator set for (international) benchmarks on operations management in hospitals. We selected and evaluated an indicator set assessing the efficiency, patient-centeredness and timeliness of radiotherapy centres in an international setting. The set we obtained was evaluated in a benchmark exercise in four European radiotherapy centres that are also actively involved in research and training. 


\section{Methods}

\section{Benchmarking process}

Many benchmarks are based on the stepwise process described by Spendolini (11). Van Hoorn et al. (12), adapted the process to compare hospitals using indicators that achieve consensus among stakeholders. The latter is important: those that receive the information, may have different perspectives on performance and quality of care (13). The indicators were primarily developed for managers; however, the researchers asked feedback from a broader range of radiotherapy stakeholders to increase support for this set. This resulted in a set that combined the perspectives of all stakeholders as performance on one aspect (for example staffs used to treat the patients) affects other aspects (research outcomes). For the benchmark pilot we further adjusted the Van Hoorn et al. benchmarking process (12) for purposes of international comparison of radiotherapy centres (Figure 1). For more details into the process of benchmarking used in this case study see (10). 
Figure 1 Benchmarking process; visual representation of the research method

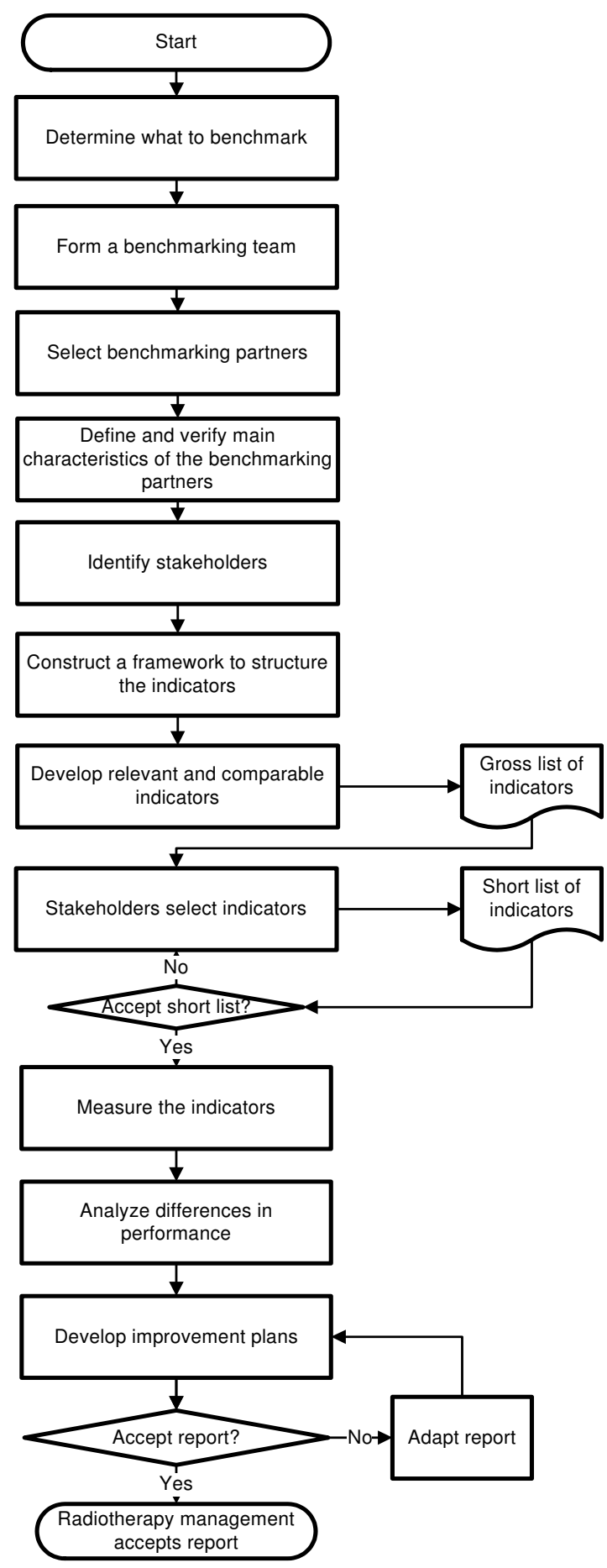




\section{Indicator-selection process}

Figure 2 summarizes the indicator selection process. To develop a gross list of indicators relevant for our research purpose, we first performed a literature study. Initially we started a search in PubMed, as this produced very few relevant hits, we decided to add free text and to search databases that contain more management publications (Google scholar and PiCarta, i.e. the end-user web interface to the Dutch Union Catalogue). The following combinations of key words were used: indicators, performance indicators, indicator development, quality, efficiency, radiotherapy, cancer, healthcare, hospital. We also checked cross-references from the most relevant publications and we checked who cited these publications. Also non scientific publications released by agencies involved in benchmarking (such as the i.e. the Dutch society for radiation oncologists (NVRO), and the Ministry of Health, Welfare and Sport) was included.

The indicators identified were added to the gross list only when the following criteria were met: 1.) they were relevant to the international benchmarking of managerial aspects of performance and quality of care in radiotherapy, 2.) the underlying characteristics could be influenced by decision-makers (13), 3.) they were suitable for comparing organizations, and 4.) they were discriminative.

For the selection process we used triangulation, whereby indicators were selected on the basis of literature and of interviews with the main stakeholders within a single radiotherapy centre. After a stakeholder analysis (14-16), one person of each stakeholder group - managers, radiotherapy department managers, radiation oncologists, and clinical physicists - provided feedback on the relevance of the indicator for the research purpose, definition clarity, data availability and discriminative value of the indicators on the gross list. Thereafter, the researcher decided to refine the definitions of some indicators, to remove irrelevant indicators, and to add new and relevant indicators. As the goal of our indicator set was to use it in an international benchmark on operations management to identify learning opportunities, a pragmatic approach seemed feasible.

The most relevant indicators were found in a paper on performance measurement in radiotherapy (17), publications of the NVRO and in not publicly accessible project descriptions on benchmarking within the Organization of European Cancer Institutes $(\mathrm{OECl})$. The indicator selection process resulted in a shortlist of 33 indicators (see Table 1), that were to be used in a pilot study. 
Figure 2 Results of the indicator selection and evaluation process

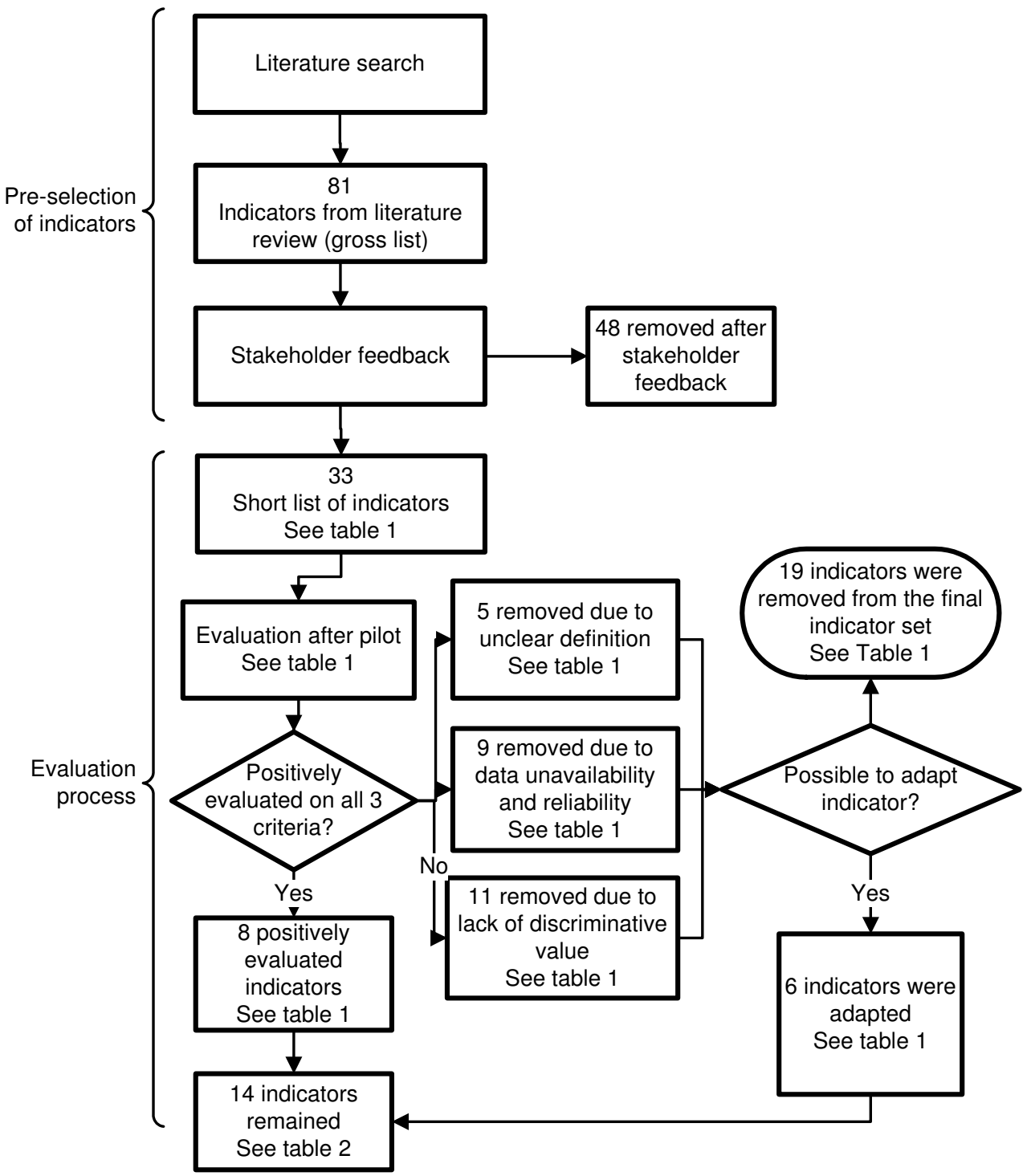

\section{Evaluation of indicators after the pilot}

After collecting the data on the 33 indicators, we rated the face validity of the indicators using the responses of the contact persons at the radiotherapy centres involved on the basis of three criteria, based on (8) and (18):

1. Definition clarity 
2. Data availability (administrative burden?) and data reliability (comparable and reliable?)

3. Discriminative value of the indicator (useful to compare this indicator?)

\section{Selection of radiotherapy departments for pilot study}

The structure, processes and outcomes of organizations involved in benchmarking should be sufficiently similar (19), we used the following inclusion criteria: 1) the radiotherapy centres should be situated within Europe, 2) each centre had to be part of a cancer centre that also delivered treatments other than radiotherapy, 3) should have a minimum of three linear accelerators, and 4) had to be involved in research and training. This last aspect seems important as the time spent on research and training cannot be spent on patient treatment; organizations without research and training activities may probably see more patients per radiation oncologist. Data envelopment analysis on 213 hospitals has proven that teaching may attribute to up to $20 \%$ of the total inefficiency score of a hospital (20).

Participants were approached through management contacts within the Organization of European Cancer Institutes (OECl). Four radiotherapy centres (in the Netherlands, Belgium, Germany and Sweden) fulfilled the criteria, and agreed to participate in the benchmarking exercise. The centres are anonymously presented in the text as RT1, RT2, RT3 and RT4.

\section{Data collection for indicator evaluation}

After the radiotherapy departments had agreed to participate, a site visit was made to each. Before these visits took place, the departments received an information letter and the complete indicator set. During the visit, one researcher collected the information needed to calculate the indicator outcomes. Most parameters were based on data from annual reports, or calculated using information from the hospital information systems. During these visits, qualitative data needed for the indicators was collected by interviews with one of the stakeholders that had been earlier identified. The semi structured interviews were also used to obtain more background information on the involved departments. Two indicators that were perceived as relevant - access time and percentage of patients treated with new technologies - were measured with a convenience sample on site.

The contact persons at the radiotherapy centres verified the data and gave written permission for its use in this paper. 


\section{Results}

We evaluated the indicator data against the set of criteria and the results of the pilot study. The latter shows how the indicators can be used to identify opportunities for improvement.

\section{Indicator evaluation}

In the benchmark pilot the 33 indicators were evaluated and Figure 2 summarizes the results. We identified 5 indicators whose definition was inadequate. Nine other indicators did not meet our reliability and data-availability criteria, and 11 more had no discriminative value (see Table 1). 
Appendix C

Table 3 Shortlist of indicators and the results of the evaluation

\begin{tabular}{|c|c|c|c|c|c|}
\hline & Indicator & $\begin{array}{l}\text { Definition } \\
\text { clear? }\end{array}$ & $\begin{array}{l}\text { Data } \\
\text { availability } \\
\text { and } \\
\text { reliability }\end{array}$ & $\begin{array}{l}\text { Discriminative } \\
\text { value }\end{array}$ & Adapted? \\
\hline \multicolumn{6}{|c|}{ Indicators that were evaluated positively } \\
\hline 1 & $\begin{array}{l}\text { Information technology use in } \\
\text { multidisciplinary meetings }\end{array}$ & $\checkmark$ & $\checkmark$ & $\checkmark$ & No \\
\hline 2 & Patient satisfaction & $\checkmark$ & $\checkmark$ & $\checkmark$ & No \\
\hline 3 & Risk analysis & $\checkmark$ & $\checkmark$ & $\checkmark$ & No \\
\hline $\begin{array}{l}4 \\
5 \\
6 \\
7\end{array}$ & $\begin{array}{l}\text { Percentage of treatment planning } \\
\text { with a curative intent using a specific } \\
\text { imaging technique } \\
\text { Simulator } \\
\text { CT } \\
\text { MRI } \\
\text { PET }\end{array}$ & $\checkmark$ & $\checkmark$ & $\checkmark$ & No \\
\hline 8 & Utilization of the linear accelerators & $\checkmark$ & $\checkmark$ & $\checkmark$ & No \\
\hline \multicolumn{6}{|c|}{ Indicators that could be adjusted after negative evaluation } \\
\hline 9 & Workload (per staff type) & - & TBD & TBD & Yes \\
\hline 10 & Access times & $\checkmark$ & - & $\checkmark$ & Yes \\
\hline 11 & $\begin{array}{l}\text { Total number of publications and } \\
\text { average impact points per publication }\end{array}$ & $\checkmark$ & $\checkmark$ & $\checkmark$ & Yes \\
\hline 12 & $\begin{array}{l}\text { Percentage of patients included in a } \\
\text { clinical trial }\end{array}$ & $\checkmark$ & $\checkmark$ & $\checkmark$ & Yes \\
\hline 13 & $\begin{array}{l}\text { Percentage of patients treated with } \\
\text { new technology, e.g. IMRT }\end{array}$ & - & $\checkmark$ & $\checkmark$ & Yes \\
\hline 14 & $\begin{array}{l}\text { Downtime for planned maintenance } \\
\text { per linear accelerator }\end{array}$ & - & $\checkmark$ & $\checkmark$ & Yes \\
\hline
\end{tabular}

$\mathrm{TBD}=$ To be determined, this information was not checked. The criteria were judged in the order provided in the table. When one criteria was not fulfilled it was impossible to check the other criteria. 


\begin{tabular}{|c|c|c|c|c|c|}
\hline & Indicator & $\begin{array}{l}\text { Definition } \\
\text { clear? }\end{array}$ & $\begin{array}{l}\text { Data } \\
\text { availability } \\
\text { and } \\
\text { reliability }\end{array}$ & $\begin{array}{l}\text { Discriminative } \\
\text { value }\end{array}$ & Adapted? \\
\hline \multicolumn{6}{|c|}{ Indicators that were removed after negative evaluation } \\
\hline 15 & Sick leave & - & TBD & TBD & No \\
\hline 16 & RT department overheads & - & TBD & TBD & No \\
\hline 17 & Staff turnover rate & $\checkmark$ & - & TBD & No \\
\hline 18 & Staff overtime & $\checkmark$ & - & TBD & No \\
\hline 19 & No shows & $\checkmark$ & - & TBD & No \\
\hline 20 & Equipment quality-control programs & $\checkmark$ & $\checkmark$ & - & No \\
\hline 21 & Cone Beams available & $\checkmark$ & $\checkmark$ & - & No \\
\hline 22 & Segments per treatment & $\checkmark$ & - & TBD & No \\
\hline 23 & Cross-hair position & $\checkmark$ & $\checkmark$ & - & No \\
\hline 24 & Field symmetry of photon beams & $\checkmark$ & $\checkmark$ & - & No \\
\hline 25 & Electron beam dosimetry & $\checkmark$ & $\checkmark$ & - & No \\
\hline 26 & Gantry-angle dependence & $\checkmark$ & $\checkmark$ & - & No \\
\hline 27 & $\begin{array}{l}\text { Instrumentation for dosimetry and } \\
\text { QC }\end{array}$ & $\checkmark$ & $\checkmark$ & - & No \\
\hline 28 & Simulator efficiency & $\checkmark$ & $\checkmark$ & - & No \\
\hline 29 & CT efficiency & $\checkmark$ & $\checkmark$ & - & No \\
\hline 30 & MRI efficiency & $\checkmark$ & - & TBD & No \\
\hline 31 & PET efficiency & $\checkmark$ & - & TBD & No \\
\hline 32 & Treatments per radiation oncologist & $\checkmark$ & - & TBD & No \\
\hline \multirow[t]{2}{*}{33} & Idle time of linear accelerators & $\checkmark$ & - & TBD & No \\
\hline & Total 33 & 5 & 9 & 9 & 6 \\
\hline
\end{tabular}

- $\quad$ = did not meet this criterion

$\checkmark \quad=$ fulfilled criterion

$\mathrm{TBD}=$ To be determined, this information was not checked. The criteria were judged in the order provided in the table. When one criteria was not fulfilled it was impossible to check the other criteria.

Thus in total 25 indicators were negatively evaluated. Based on suggestions of the stakeholders and the researchers, we were able to adapt 6 indicators in such a way that all criteria were met, the other 19 were not fit for use. Together with the 8 positively evaluated indicators, we have an indicator set of 14 indicators; their definitions are presented in Table 2. 
Table 2: Final list of indicators for benchmarking radiotherapy centres

\begin{tabular}{|c|c|c|c|}
\hline Indicator & Objective & Numerator & Denumerator \\
\hline $\begin{array}{l}\text { Workload (also } \\
\text { called patient-to- } \\
\text { staff ratio") * }\end{array}$ & $\begin{array}{l}\text { To measure staff } \\
\text { productivity over a } \\
\text { one-year period }\end{array}$ & $\begin{array}{l}\text { Number of patients treated } \\
\text { in year } X\end{array}$ & $\begin{array}{l}\text { Total number of staff } \\
\text { members in year } X \text { (in full- } \\
\text { time equivalents) } \\
\text { Preferable: staff per } \\
\text { function }\end{array}$ \\
\hline Access times * & $\begin{array}{l}\text { To measure the } \\
\text { treatment delay } \\
\text { between the day } \\
\text { patients are referred } \\
\text { to the radiotherapy } \\
\text { department and the } \\
\text { day they receive the } \\
\text { first radiation fraction. }\end{array}$ & $\begin{array}{l}\text { Sum of the access times (in } \\
\text { days) per treatment in year } \\
\text { X. Total of four points: } \\
\text { 1. } \mathrm{T} 1=\text { day of referral to } \\
\text { the radiotherapy } \\
\text { department } \\
\text { T2 = day of the initial } \\
\text { 2. prescription } \\
\text { T3 = day of the final } \\
\text { prescription/ treatment } \\
\text { plan finished } \\
\text { T4 = day the patient } \\
\text { receives the first } \\
\text { radiation fraction }\end{array}$ & $\begin{array}{l}\text { Number of patients treated } \\
\text { in year } X .\end{array}$ \\
\hline $\begin{array}{l}\text { Patient } \\
\text { satisfaction }\end{array}$ & $\begin{array}{l}\text { To measure the } \\
\text { quality aspect of } \\
\text { patient- } \\
\text { centeredness. }\end{array}$ & \multicolumn{2}{|c|}{$\begin{array}{l}\text { Determine position in PDCA cycle: } \\
\square \text { Plan: develop method to collect data } \\
\square \text { Do: Collect, analyse, and implement recommendations } \\
\square \text { Check: Did the actions result in an improvement? } \\
\square \text { Act: If necessary, change the method } \\
\text { Start the cycle over again. }\end{array}$} \\
\hline Risk analysis & $\begin{array}{l}\text { To focus on the } \\
\text { quality aspects of } \\
\text { safety and patient- } \\
\text { centeredness. }\end{array}$ & \multicolumn{2}{|c|}{$\begin{array}{l}\text { Determine position in PDCA cycle: } \\
\square \text { Plan: develop method to collect data } \\
\square \text { Do: Collect, analyse, and implement recommendations } \\
\square \text { Check: Did the actions result in an improvement? } \\
\square \text { Act: If necessary, change the method } \\
\text { Start the cycle over again. }\end{array}$} \\
\hline $\begin{array}{l}\text { Information } \\
\text { technology use } \\
\text { in } \\
\text { multidisciplinary } \\
\text { meetings (MDM) } \\
\text { * }\end{array}$ & $\begin{array}{l}\text { To measure } \\
\text { differences in the } \\
\text { organization of MDM. } \\
\text { A MDM is already } \\
\text { standard. }\end{array}$ & \multicolumn{2}{|c|}{$\begin{array}{l}\text { Use of information technology in MDM: } \\
\text { 1. Is the information for the multidisciplinary meetings } \\
\text { digitally available in } 1 \text { computer system? Yes/No } \\
\text { 2. Are the conclusions of the meeting immediately } \\
\text { digitally registered in this system? Yes/ No }\end{array}$} \\
\hline
\end{tabular}

* This indicator has been adapted. A new definition for the indicator was suggested after evaluation, but has not been tested in a case study. 


\begin{tabular}{|c|c|c|c|}
\hline \multirow[t]{2}{*}{$\begin{array}{l}\text { Total number of } \\
\text { publications and } \\
\text { average impact } \\
\text { points per } \\
\text { publication * }\end{array}$} & \multirow{2}{*}{$\begin{array}{l}\text { To measure the } \\
\text { quality of output of } \\
\text { researchers in the RT } \\
\text { research department } \\
\text { on volume and } \\
\text { quality. }\end{array}$} & $\begin{array}{l}\text { Total number of peer- } \\
\text { reviewed published by RT } \\
\text { research department over } \\
\text { three years. }\end{array}$ & $\begin{array}{l}\text { Number of years included } \\
\text { in the selected period (in } \\
\text { this paper, } 1 \text { year was } \\
\text { used). }\end{array}$ \\
\hline & & $\begin{array}{l}\text { Total impacts points of all } \\
\text { publications }\end{array}$ & $\begin{array}{l}\text { Total number of peer- } \\
\text { reviewed published by RT } \\
\text { research department over } \\
\text { three years. }\end{array}$ \\
\hline $\begin{array}{l}\text { Patients } \\
\text { included in a } \\
\text { clinical trial * }\end{array}$ & $\begin{array}{l}\text { To describe the } \\
\text { percentage of } \\
\text { patients included in a } \\
\text { trial, and thus to } \\
\text { indicate efficiency } \\
\text { losses caused by } \\
\text { research activities. }\end{array}$ & $\begin{array}{l}\text { Number of patients who } \\
\text { participated in a clinical trial } \\
\text { over the last three years. }\end{array}$ & $\begin{array}{l}\text { Number of patients treated } \\
\text { over the last three years. }\end{array}$ \\
\hline $\begin{array}{l}\text { Treatment } \\
\text { planning with a } \\
\text { specific imaging } \\
\text { technique: } \\
\text { - } \quad \text { Simulator } \\
\text { - } \quad \text { CT } \\
\text { - } \quad \text { MRI } \\
\text { - } \\
\text { Pet }\end{array}$ & $\begin{array}{l}\text { To measure the } \\
\text { percentage of } \\
\text { treatment planning } \\
\text { with a curative intent } \\
\text { using a specific } \\
\text { imaging technique. } \\
\text { This technique affects } \\
\text { the quality of the } \\
\text { treatment plan. }\end{array}$ & $\begin{array}{l}\text { Number of treatment plans } \\
\text { based with a curative intent } \\
\text { based on a specific imaging } \\
\text { technique in year } X \text {. }\end{array}$ & $\begin{array}{l}\text { Total number of treatment } \\
\text { plans with a curative intent } \\
\text { made in year } X \text {. }\end{array}$ \\
\hline $\begin{array}{l}\text { Percentage of } \\
\text { patients treated } \\
\text { with new } \\
\text { technologies }\end{array}$ & $\begin{array}{l}\text { To describe the } \\
\text { centres' use of } \\
\text { Intensity Modulated } \\
\text { Radiotherapy (IMRT), } \\
\text { Image Guided } \\
\text { Radiotherapy (IGRT) } \\
\text { and Adapted } \\
\text { Radiotherapy (ART). }\end{array}$ & $\begin{array}{l}\text { Number of patients treated } \\
\text { with IGRT. IMRT or ART }{ }^{* *} \\
\text { in year X. }\end{array}$ & $\begin{array}{l}\text { Number of patients treated } \\
\text { in year } X \text {. }\end{array}$ \\
\hline $\begin{array}{l}\text { Use of the linear } \\
\text { accelerators }\end{array}$ & $\begin{array}{l}\text { To determine the } \\
\text { overall equipment } \\
\text { efficiency of the linear } \\
\text { accelerators }\end{array}$ & $\begin{array}{l}\text { Number of patients treated } \\
\text { in year } X \text {. }\end{array}$ & $\begin{array}{l}\text { Number of linear } \\
\text { accelerators in the centre } \\
\text { in year X. }\end{array}$ \\
\hline $\begin{array}{l}\text { Planned Linear } \\
\text { accelerator } \\
\text { downtime * }\end{array}$ & $\begin{array}{l}\text { To quantify } \\
\text { unplanned } \\
\text { maintenance of the } \\
\text { linear accelerators } \\
\text { during working hours }\end{array}$ & $\begin{array}{l}\text { Number of hours of } \\
\text { unplanned } \\
\text { per linear accelerator during } \\
\text { opening hours in year } X \text {. }\end{array}$ & $\begin{array}{l}\text { Total number of opening } \\
\text { hours per linear accelerator } \\
\text { in year } X \text {. }\end{array}$ \\
\hline
\end{tabular}

${ }^{* *}$ Adjusted to what was state of the art at the time of measurement.

*** Planned maintenance consists of planned maintenance, time needed for quality control, and time reserved for research activities. All other maintenance activities are considered to be unplanned maintenance. 
Of the rejected 19 indicators sick leave, staff turnover rate and overtime (indicators15-18 in Table1) were removed because the length of the paid maternity leaves or because the tasks performed by radiation oncologists differed per country. In some countries radiation oncologists also act as medical oncologist. This made the total number of staff members incomparable. Indicator 19, no shows, was excluded because the data were unreliable. We also excluded indicators 20-27 (see Table 1) as they lacked discriminative value, or interpretation is related more to the safety of the treatments as such than to the management of a radiotherapy centre. The indicator on simulator utilization (indicator 28) was supposed to provide information on the efficiency of a radiotherapy department but proved to have no discriminative value. It seemed outdated as more advanced imaging techniques are currently being introduced, such as CT, PET and MRI. As a consequence, all departments have overcapacity on the simulator. Indicators 29-31 on the utilization of CT, MRI and PET were excluded as some of the radiotherapy departments shared their equipment with the radiology department who used it for diagnostic purposes and local registries did not provide adequate insight in the exact division. The number of treatments per radiation oncologist (indicator 32) was excluded as the activities of the radiation oncologists differed per country. The idle time of linear accelerators had to be excluded because the available production capacity excluding unexpected maintenance was not registered everywhere and uniform local definitions were lacking.

We also identified 6 indicators with an insufficient score on at least one of the evaluation criteria (indicators 9-14 in Table 1) that could be redefined:

- We included workload per staff type (Table 1, indicator 9) Comparison of the data was initially impossible because the tasks of the staff members differed per country. Therefore, in this exercise this indicator was adjusted to number of patients treated per staff member of the radiotherapy department. Nevertheless, using the original indicator definition was thought to be preferable.

- Access time (Table 1, indicator 10) was defined as the time between referral from the medical or surgical oncologist to the radiotherapy centre and the start of the first treatment. However, no department consistently measured access times according to this definition. Four points in time Table 2 - were checked manually in the patients' records in a random sample of 15 breast-cancer patients and 15 prostate-cancer patients who had been treated in 2006. The interpretation of access times is complicated as these can be affected by different factors not related to the 
radiotherapy process, such as the start and end dates of chemotherapy and hormonal therapy. As all stakeholders saw the importance of this indicator, it remained on the list.

- Research output was measured on the basis of the number of published papers. Since this is interesting only in conjunction with their quality, we added the average impact factor per publication (indicator 11).

- The percentage of patients included in a clinical trial (indicator 12) is an indicator with a high variation per year. We adapted this indicator to measure for three years instead of one.

- Percentage of patients treated with new technologies, e.g. Intensity Modulated Radiotherapy IMRT (indicator 13). Since radiotherapy is a rapidly advancing specialty that involves complex technologies, we examined the use of new technologies. Originally the indicator asked about the use of a specific technology, but the verb 'use' caused confusion. The adjusted indicator therefore examines the percentage of patients treated with IMRT, Image Guide Radiotherapy (IGRT) and Adapted Radiotherapy (ART) per tumor type.

- Downtime for unplanned maintenance per linear accelerator (indicator 14). Linear accelerator downtime was redefined and specified to downtime for planned maintenance because some organizations did not register unplanned maintenance.

Pilot study results: usability of the final benchmark indicator set

All indicators in Table 1 were tested during our pilot, only indicators 1-14 met the criteria for positive evaluation and the definitions are provided in Table 2. The outcomes as found in the pilot are presented in Table 3. 
Table 3 Examples of indicators and their outcomes (collected for 2007)

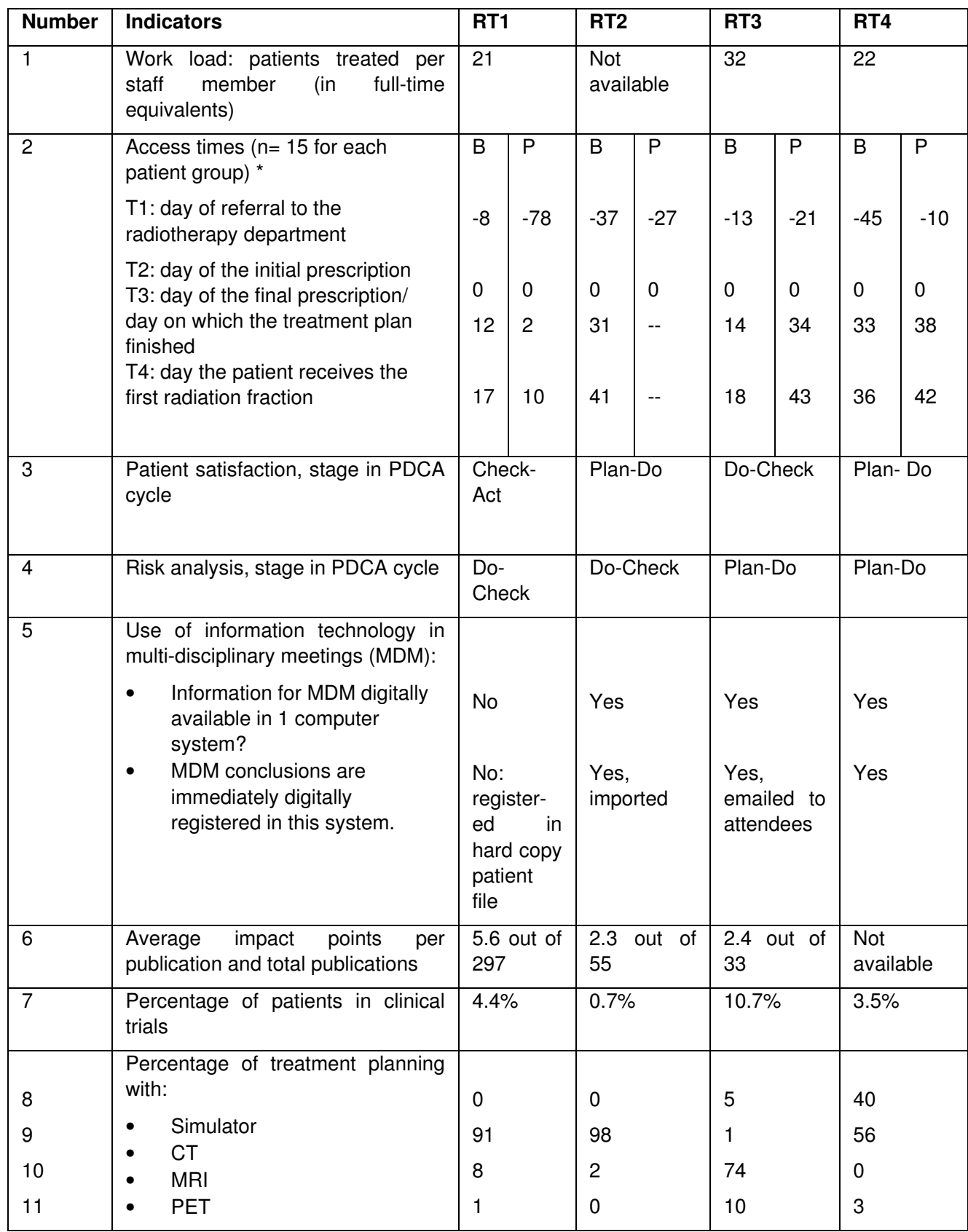

$\mathrm{B}=$ breast cancer

$\mathrm{P}=$ prostate cancer

${ }^{*}=\mathrm{T} 1$ is affected by other treatments before radiotherapy, therefore $\mathrm{T} 2$ was regarded as starting point (value 0 ). Therefore $\mathrm{T} 1$ is negative.

-- = Information was not available for publication 


\begin{tabular}{|c|c|c|c|c|c|c|c|c|c|}
\hline Number & Indicators & RT1 & & RT & & RT & & RT & \\
\hline 12 & \begin{tabular}{ll}
\multicolumn{2}{l}{ Percentage of patients treated with } \\
- $\quad$ IMRT \\
- $\quad$ IGRT \\
- $\quad$ ART
\end{tabular} & $\begin{array}{l}\text { B: } \\
31 \\
14 \\
0\end{array}$ & $\begin{array}{l}P: \\
39 \\
40 \\
17\end{array}$ & $\begin{array}{l}\text { B: } \\
0 \\
0 \\
0\end{array}$ & $\begin{array}{l}P: \\
1 \\
2 \\
1\end{array}$ & $\begin{array}{l}\mathrm{B}: \\
0 \\
0 \\
0\end{array}$ & $\begin{array}{l}P: \\
6 \\
87 \\
78\end{array}$ & $\begin{array}{l}\text { B: } \\
0 \\
0 \\
0\end{array}$ & $\begin{array}{l}P: \\
0 \\
0 \\
0\end{array}$ \\
\hline 13 & $\begin{array}{l}\text { Patients treated per linear accelerator } \\
\text { per standard working hour }\end{array}$ & \multicolumn{2}{|l|}{4.5} & \multicolumn{2}{|c|}{4.6} & \multicolumn{2}{|l|}{5.4} & \multicolumn{2}{|c|}{5.6} \\
\hline 14 & $\begin{array}{l}\text { Number of hours of downtime for } \\
\text { planned maintenance per linear } \\
\text { accelerator }\end{array}$ & \multicolumn{2}{|c|}{156} & \multicolumn{2}{|c|}{173} & \multicolumn{2}{|c|}{47,5} & \multicolumn{2}{|l|}{84} \\
\hline
\end{tabular}

$\mathrm{B}=$ breast cancer

$\mathrm{P}=$ prostate cancer

Per indicator we discuss how the results provide opportunities for improvement:

- In the patient-to-staff ratio (indicator 1 in Table 3), we included all staff that were paid from the radiotherapy budget and that were involved in the treatment of RT patients. Included staff members were: radiation oncologists, radiation oncologists under training, radiation technicians, physicists, radiotherapy management, secretaries, and researchers and other physicians working on radiotherapy treatments. The patient-to-staff ratio for RT3 is almost a third of RT1 and RT4 and may provide leads for improving the efficiency of staff input.

- Access times (indicator 2). We found large differences between the day of the actual prescription of radiotherapy (T2) and referral to the radiotherapy department (T1). These are due mainly to the differences in the preparation and treatment processes before the first radiotherapy fraction. Access times for breast cancer were short in RT1 and RT4. RT3 had the shortest prostate-cancer access time.

- The patient-satisfaction indicator (indicator 3) measured whether the radiotherapy centre systematically collected and used patient satisfaction information to improve their results. This was measured using the PDCA cycle:

- Plan: construct a method to collect patient satisfaction information

- Do: collect and analyse the data, determine improvement actions, and implement them

- Check: determine whether the changes improved patient satisfaction. 
- Act: if necessary, change the method so that it leads to improved patient satisfaction. Start the cycle over again.

None of the radiotherapy centres completed the cycle. Only RT1 and RT3 systematically provided all patients with a satisfaction questionnaire. RT3 did not analyse the results in a structured way. RT1 analysed the results and formulated improvements which were reported to all radiotherapy employees every two months, but did not complete the cycle.

- Indicator 4, the risk analysis method, was also examined with the Plan-DoCheck-Act cycle. None of the centres completed the cycle. RT3 had no registration system for misses or near-misses, while RT4 registered only misses. RT2 registered misses and near-misses, which were published in monthly reports. However, we found no evidence that these reports led to improvement actions. RT1 discussed improvements on the basis of misses and near-misses in the department meetings, but did not report on them structurally.

- Use of information technology in multidisciplinary meetings (indicator 5). Since these meetings are standard in radiotherapy, this indicator examined digital information availability, and the immediate digital registration of the conclusions. At RT2 and RT4, the electronic patient record (EPR) was displayed, and the outcomes of the meeting were immediately imported online into the EPR for everyone present to see. RT3 developed a tool for presenting and registering the outcomes, which were e-mailed to the attending physicians. At RT1, the EPR was used only to read information. This was because the outcomes were written directly in the hard-copy patient record, with the radiation oncologist later importing the conclusions into the EPR.

- RT1 published most papers and presented the highest impact factor (indicator 6). However, due to a lack of data concerning the total number of staff per function group, it remained unclear how this related to the staff numbers actually involved in research.

- Indicator 7 shows large differences in the percentage of patients included in clinical trials. Possible explanations are different recruitment procedures and the availability of specific technologies needed to stimulate participation.

- Percentage of treatment planning with a curative intent using a specific imaging technique, such as Simulator, CT, MRI and PET (indicator 8-11). Table 3 shows that RT4 is the only centre that still uses the simulator for $40 \%$ of its treatment plans. RT3 had the highest percentage of treatment planning involving PET and MRI. 
- The percentage of patients treated with new technologies (indicator 12) was examined for breast-cancer and prostate-cancer patients. RT1 treated most patients with IMRT, while RT3 was advanced in the use of IGRT and ART for prostate-cancer patients. RT2 used these technologies only for a small percentage of prostate-cancer patients as only one of its linear accelerators was equipped with a Cone Beam; plans were made to increase this to four in two years. This shows the dependency on investment policy of the functioning of these departments. RT4 did not use any of these technologies at the moment of benchmarking because new equipment was about to be installed.

- RT1 treated fewer patients per linear accelerator per standard working hour than RT 3 and RT4 (indicator 13).

- Table 3 shows that RT1 had the highest planned linear-accelerator downtime during working hours (indicator 14), while RT3 had the lowest. Together with the previous indicator, this suggests that RT1 could increase its utilization by reducing downtime by performing less planned maintenance during working hours.

\section{Discussion and conclusions}

This study reported on the development of a set of 14 reliable, available and discriminative indicators which can be used as quantitative indicators in a comprehensive international benchmark. This study provided a pragmatic and feasible indicator development process for international benchmarks on operations management. The results of the pilot showed that the data produced for each relevant indicator, can be used to identify attainable performance levels and that using them for benchmarking provide leads for improving the quality operations. The following sections subsequently describe the research implications and the practical implications of this study.

\section{Research implications}

Although we thoroughly searched the literature to select indicators for the gross list, some suitable indicators may have been missed due to the non systematic search strategy. We also might have missed relevant indicators that are based on medical guidelines regarding radiotherapy. We did not check medical guidelines, since they focus mainly on the medical aspects of the treatment. 
We also used interviews with various stakeholders related to RT department management, to reduce the possibility of missing relevant indicators. The stakeholders screened all indicators on the following criteria: relevance for this benchmark, definition clarity, data availability and discriminative value. This resulted in the rejection of 48 indicators. Involving the stakeholders also generated support and resources for data collection.

Despite our indicator selection process, defining good indicators remained difficult, especially in an international perspective. This could have been prevented by asking multiple stakeholders from different countries to grade the indicators. However, as a first step in international benchmarking on operations management, our pragmatic approach seemed feasible.

After the selection, 5 indicators still lacked a definition that covered every country's specific characteristics (see Table 1). Radiotherapy is part of a treatment chain and when pre radiation chemotherapy is given, the radiotherapy access time should reasonably start after that is finished. The radiotherapy centres found it difficult to distinguish the pre radiation delay caused by chemotherapy. Distinguishing the pre radiation delay, caused by chemotherapy, from other delays caused by the internal organization of the radiotherapy department is essential for benchmarking.

We found that the discriminative value of 11 indicators was insufficient. Radiotherapy is an evolving healthcare discipline that introduces new technologies in rapid succession. The indicators concerning the use of new technologies and the percentage of patients in clinical trials may be particularly affected by this evolution. We therefore recommend adjusting the indicator set to the latest developments.

Despite the thoroughness of the process whereby we developed this indicator set, 9 of the 33 selected indicators did not fulfill the criteria on 'availability and reliability of the data'. Due to the time constraints and the desire to keep administrative efforts low, the radiotherapy centres provided us primarily with information that was already being collected for administrative purposes. During the site visits, it became clear that specific radiotherapy information was usually collected on a department level. For some data, government regulations required a specific registration method that was incompatible with the purpose to obtain comparable data. For example, the length of the paid maternity leaves in the sick-leave statistics and differences between staff duties. As registration requirements differ per country, international comparisons are often more complex than national ones; a recent international benchmarking exercise in eye hospitals confirmed this (8). Although differences in national health systems and social legislation inevitably lead to differences in the nature and availability of data, there is no reason to doubt 
the applicability of the approach used in this study in non European countries such as the USA. As these differences often lead to different definitions and outcomes, consideration should be given to indicators that assess process characteristics and outcomes (21).

All indicators were measured over a one-year period (2006); however for indicators with a considerable likelihood of strong variation per year, measuring over a prolonged period should be considered. Examples include the impact factor or the percentage of patients included in a clinical trial. .

\section{Practical implications}

The indicator set included indicators on efficiency, patient-centeredness and timeliness. For an appropriate and thorough identification of improvement opportunities the combination of quantitative (indicators) and qualitative information (site visits) is essential. The indicators standardize the comparison between the centres and the site visits enable a better understanding of the (underlying) processes.

We used the inclusion criteria to select radiotherapy centres that were rather comparable. For a proper comparison case mix and complexity of treatments should be taken into account; the scope of our project did not allow us to expand on that.

The pilot results suggested RT1 to reduce planned downtime during regular working hours. RT2 was suggested to examine its inclusion rate for clinical trials and productivity of research activities. RT4 had been working on a system to register misses and near-misses, and used the data to determine the extent to which additional investments in manpower and equipment were needed to improve the safety and quality of treatments.

Out of the original long list of 81 indicators, 14 proved suitable for use in an international benchmark at radiotherapy centres. As the results are affected by the technologies available, obtaining information on access to technologies, investment policies, -budgets and depreciation methods is essential. Future research should provide insight into variation of indicator scores over the years and to monitor improvement results. 


\section{Acknowledgements}

We would like to thank the involved radiotherapy departments for their cooperation. Special thanks go out to the contact persons: M. Verheij; R. Ringborg; M. Baumann; D. Zips; J.B. Burrion; D. de Valeriola; P Van Houtte. We would like to thank S Siesling for supporting the writing process. 


\section{Reference List}

1. Sanazaro PJ: Quality Assessment and Quality Assurance in Medical Care. Annual Reviews in Public Health 1980, 1: 37-68.

2. Laffel G, Blumenthal D, The case for using industrial quality management science in health care organizations, The Textbook of Total Quality in Healthcare. 1993; 262: 2869-2873.

3. Committee on Quality of Health Care in America, Crossing the Quality Chasm: A New Health System for the 21st Century, Washington, D.C. Institute of Medicine 2001.

4. Camp RC: A Bible for Benchmarking, by Xerox. Financial Executive 1993, 9: 23.

5. Mosel D, Gift R G: Collaborative benchmarking in health care. Joint Commission Journal for Quality Improvement 1994, 20(5): 239-49.

6. Sheldon T: Promoting health care quality: what role performance indicators? Quality in Health Care 1998, 7: 45-50.

7. Blank JL: Innovations and productivity: an empirical investigation in Dutch hospital industry. Advances in Health Economics and Health Services Research 2008, 18: 89-109.

8. De Korne D F, Sol K J C A, van Wijngaarden J D H et al: Evaluation of an international benchmarking initiative in nine eye hospitals. Health Care Management Review 2010, 35: 23.

9. Schoen C, Davis K, How SKH, Schoenbaum SC: US health system performance: a national scorecard. Health Affairs 2006, 25: 457-475.

10. Van Lent WAM, de Beer R, van Harten W. International benchmarking of specialty hospitals. A series of case studies on comprehensive cancer centres. BMC Health Services Research. 2010, 10: 253.

11. Spendolini J. The Benchmarking Book, New York, Amacom 1992.

12. Van Hoorn A, Van Houdenhoven M, Wullink G: Een nieuw stappenplan voor benchmarking, Management Executive 2006, 1-15.

13. Campbell SM, Braspenning J, Hutchinson A, Marshall M: Research methods used in developing and applying quality indicators in primary care. Quality and Safety in Health Care 2002, 11(4): 358-364.

14. Mitchell RK, Agle BR, Wood DJ: Toward a Theory of Stakeholder Identification and Salience: Defining the Principle of Who and What Really Counts. Academy of Management Review 1997, 22: 853-886.

15. Brugha R, Varvasovszky Z: Stakeholder analysis: a review. Health Policy Planning 2000, 15: 239-246.

16. Carignani V: Management of change in health care organisations and human resource role: Socioeconomics in radiology. European Journal of Radiology 2000, 33: 8-13.

17. Cionini L, Gardani G, Gabriele P et al: Quality indicators in radiotherapy. Radiotherapy and Oncology 2007, 82: 91-200.

18. Cowper J, Samuels M: Performance benchmarking in the public sector: the United Kingdom experience. Benchmarking, Evaluation and Strategic Management in the Public Sector, Paris, OECD 1997.

19. Gudmundsson $H$, Wyatt $A$, Gordon L: Benchmarking and Sustainable Transport Policy: Learning from the BEST Network. Transport Reviews 2005, 25: 669-690.

20. Grosskopf S, Margatitis D, Valdmanis V. The effects of teaching on hospital productivity. Socio-economic Planning Sciences 2001, 35(3): 189-204

21. Camp RC, Tweet AG: Benchmarking applied to health care. Joint Commission Journal for Quality Improvement 1994, 20: 229-238. 


\title{
Stellingen behorende bij het proefschrift
}

\author{
"Improving resource capacity planning in hospitals with business approaches"
}

Wineke Agnes Marieke van Lent, december 2011

1. Ongeveer de helft van de onderzochte Nederlandse ziekenhuizen wist haar doelstellingen met behulp van de onderzochte bedrijfskundige benaderingen te realiseren. Algemene ziekenhuizen leken succesvoller dan academische en topklinische ziekenhuizen (dit proefschrift).

2. Focus op patiëntencategorie of een bepaald type service alleen leidt niet tot een patiëntvriendelijker en efficiënter zorgproces, hiervoor zijn ook aanpassingen in het proces nodig (dit proefschrift).

3. Benchmarking en lean management kunnen achtereenvolgens succesvol toegepast worden in één verbetertraject en beide benaderingen kunnen elkaar versterken (dit proefschrift).

4. Simulatiemodellen laten vaak aanzienlijke verbetermogelijkheden met betrekking tot resource capacity planning zien; over daadwerkelijke implementatie van de aanbevelingen wordt weinig gepubliceerd (dit proefschrift).

5. Patiënttevredenheid wordt meer beïnvloed door proceskenmerken zoals communicatie, informatie en betrokkenheid van de patiënt bij het nemen besluiten belangrijker dan structuuraspecten zoals wachttijden en continuïteit van zorg (Rademakers et al. BMJ Quality and Safety, online first 2011)

6. Goede samenwerking tussen artsen en managers wordt vaker geassocieerd met betere prestaties van de organisatie dan met medische prestaties (proefschrift H Klopper-Kes, hst 6)

7. Door het reduceren van variatie in de duur van zorgprocessen kan de gemiddelde afspraaktijd teruggedrongen worden en kunnen meer patiënten worden geholpen (SG Elkhuizen et al, Health Care Management Review, 2007, 32(1): 37-45)

8. Het lastige aan simulaties is de keuze voor het detailniveau van het model; teveel detail leidt tot een onnodig lange ontwikkeltijd terwijl te weinig detail leidt tot een model dat door de gebruikers niet serieus genomen wordt

9. "It is not the strongest of the species that survives, nor the most intelligent that survives. It is the one that is the most adaptable to change." Charles Darwin

10. "There is one quality which one must possess to win, and that is definiteness of purpose, the knowledge of what one wants and a burning desire to possess it." Napoleon Hill 